University of San Diego

Digital USD

2006-05-01

\title{
Gender Influences in the Graduate Classroom: An Investigation of Female and Male Student Perceptions
}

Gerald B. Blanton EdD

University of San Diego

Follow this and additional works at: https://digital.sandiego.edu/dissertations

Part of the Leadership Studies Commons

\section{Digital USD Citation}

Blanton, Gerald B. EdD, "Gender Influences in the Graduate Classroom: An Investigation of Female and Male Student Perceptions" (2006). Dissertations. 756.

https://digital.sandiego.edu/dissertations/756

This Dissertation: Open Access is brought to you for free and open access by the Theses and Dissertations at Digital USD. It has been accepted for inclusion in Dissertations by an authorized administrator of Digital USD. For more information, please contact digital@sandiego.edu. 
GERALD B. BLANTON

A dissertation submitted in partial fulfillment of the requirements for the degree of

Doctor of Education

University of San Diego

May 2006

Dissertation Committee

Johanna S. Hunsaker, Ph.D.

Robert Donmoyer, Ph.D.

Theresa Monroe, Ed.D. 
(C) Copyright by Gerald B. Blanton, 2006 All Rights Reserved 


\begin{abstract}
Defined by Mary Rowe (1977) as micro inequities, seemingly insignificant gender bias behaviors create an inequitable academic environment and marginalize groups and individuals in the American classroom. Popularized by Hall and Sandler's 1982 report on the "chilly" classroom, gender bias is subtle and differs from the more obvious behaviors associated with sexual harassment. However, gender bias research appears incomplete. Study findings contradict each other, few studies explore gender bias in the graduate classroom, and fewer yet compare the perceptions of women and men concerning gender influences in the graduate classroom.

This dissertation investigates perceptions of the influence of gender in the graduate classroom. Using telephone interviews to gather qualitative data, the study explores the similarities and differences in the perceptions of 42 graduates of the University of San Diego (USD) Doctor of Education (Ed.D.) Program. The research not only examines graduates' perceptions of gender influences, but also considers the implications of these perceptions on a leadership studies graduate education program.

The research reveals apparent similarities in female and male perceptions about graduate classroom gender influences. When grouped into broad categories, women's and men's responses appear similar. For example, a similar number of women and men believe gender inequities exist in the graduate classroom. Also, both women and men tend to recall out-of-the-ordinary events and not micro inequities, and tend to support their own gender while criticizing the opposite gender. The research also reveals differences in female and male perceptions of gender influence, particularly with respect to the adverse influence of male privilege in the graduate classroom.
\end{abstract}


The research did not identify apparent widespread gender bias in the USD Ed.D. graduate classroom. However, the research does propose three socially constructed beliefs about acceptable behavior that may perpetuate the adverse influence of gender bias in the graduate classroom. The research also observes that graduate students may not fully understand the influence of gender on their classroom environment and suggests that a leadership studies graduate education program might benefit from a class on case studies in diversity that would include gender topics. 


\section{ACKNOWLEDGMENTS}

I began my dissertation experience in the fall of 2002 when I enrolled in EDLD 610, USD's how-to-get-started-on-your-dissertation class. When I started the class, I had no dissertation topic and, at one time, the two male professors in EDLD 610 suggested that I drop the course because I was so far behind the other students. But I found my topic - gender bias (and completed EDLD 610). I have learned much and have much to learn.

I want to express my loving appreciation to my wife, Janice, who, for the past $31 / 2$ years tolerated a messy study, and many evenings and weekends with me sequestered away, reading some new stack of reference material or writing a new section of text.

I want to thank the members of my dissertation committee: First, my chairperson and advisor, Dr. Jo Hunsaker, who seemed to patiently accept the "dominant male" in my personality. Next, Dr. Terri Monroe; we clashed in our first course at USD, she as the first-time USD instructor and me as the outspoken student in my first doctoral class. However, after three classes together, I highly value her judgment and respect her insight. Finally, Dr. Bob Donmoyer, who helped me find my dissertation topic in that first EDLD 610 class (and suggested I drop the class shortly thereafter).

I want to express my sincere appreciation to the 4 members of my pilot team and the 42 interviewees-your contributions were invaluable.

I want to thank Beth Yemma of the School of Education, who mailed 183 letters and answered my frequent questions. I want to thank my sister, Lorelei, for her insightful comments on draft 17 of my dissertation.

And finally, I want to thank Pat, John, Shirley and Sankey. 


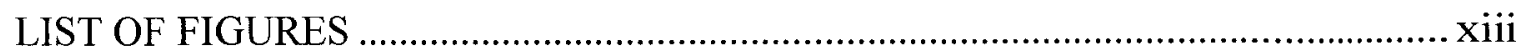

CHAPTER 1. THE PROBLEM........................................................................ 1

Statement of the Problem................................................................................... 1



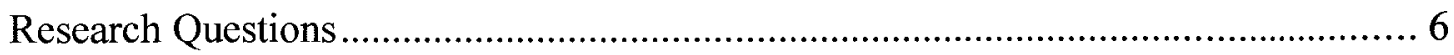

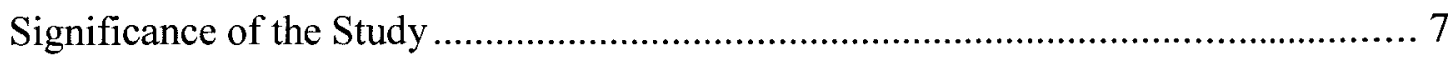

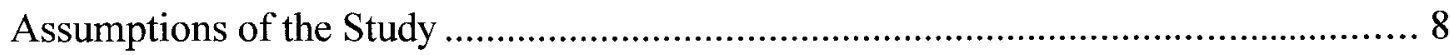

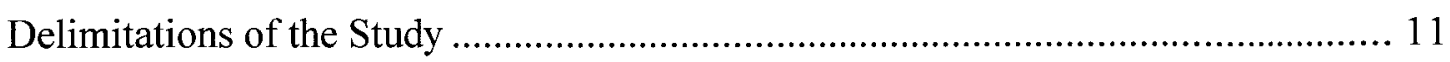

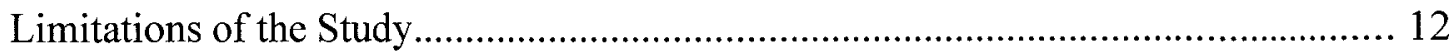

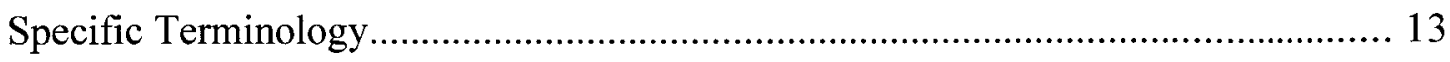

Background of the Doctoral Program in Education............................................... 14

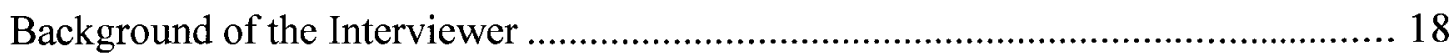

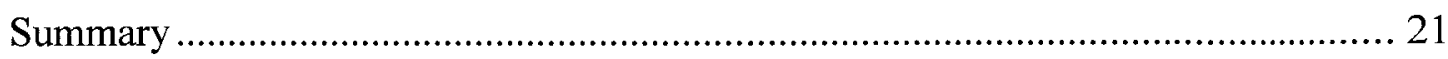

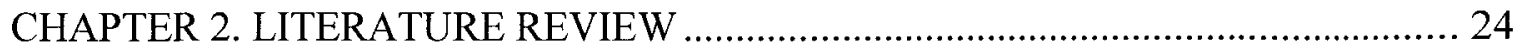

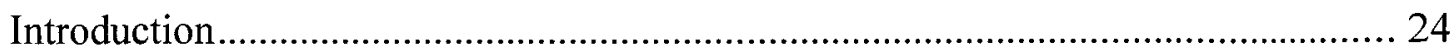

A Synthesis of Commonly Held Perceptions of Gender Bias ................................. 26

Gender Bias Research: Examples of Conflicting Assertions................................... 32

An Analysis of Gender Bias and Classroom Participation.............................. 32

An Analysis of Gender Bias and Instructors ................................................. 39

The Influences of Student Age in a Classroom Environment................................ 49

Gender Differences in the Classroom ......................................................... 53

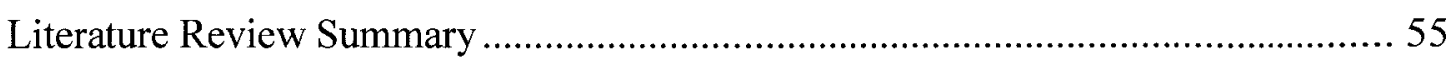

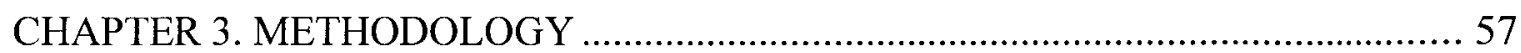

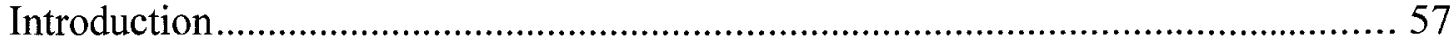

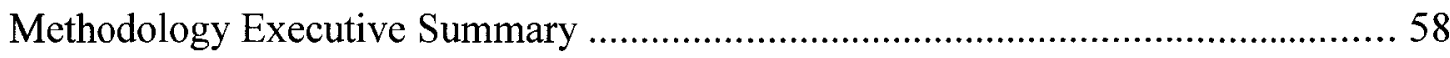

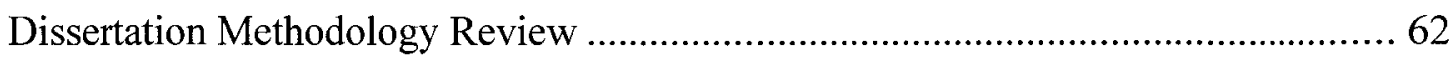

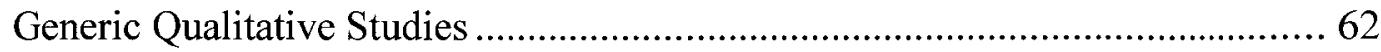

Telephone Interviews in Qualitative Research .............................................6 67

Telephone Interviews - Advantages and Disadvantages .......................... 68

The Telephone Interview in Qualitative Research .................................. 70

Telephone Interview Techniques ....................................................... 74 
Qualitative Interview Analyses............................................................................. 75

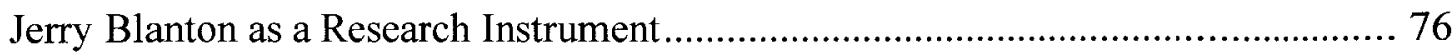

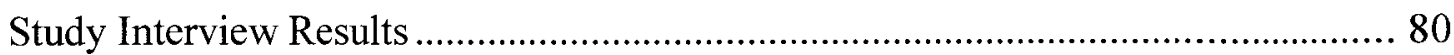

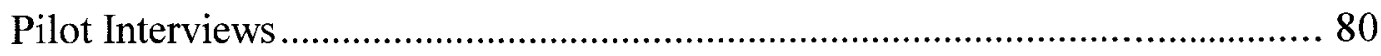

Qualitative Interview Results ................................................................ 82

Methodology Summary ........................................................................................ 83

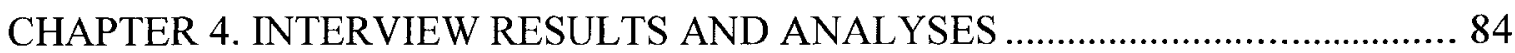

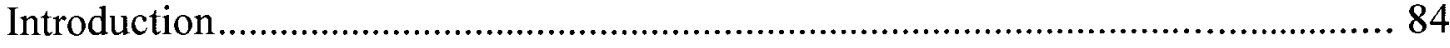

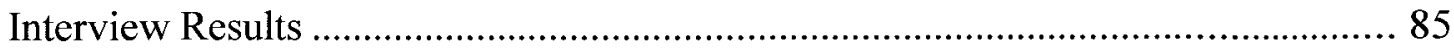

An Analysis of Demographic Questions ...................................................... 85

An Analysis of Gender Influence Questions ................................................... 89

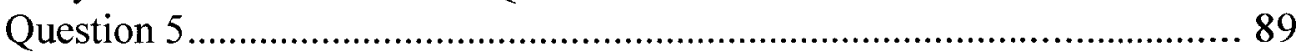

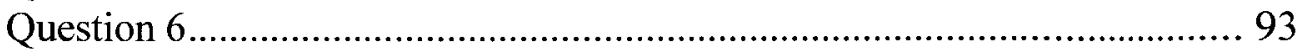

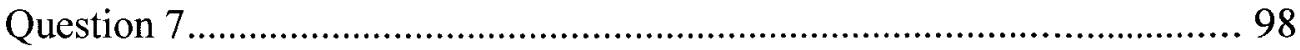

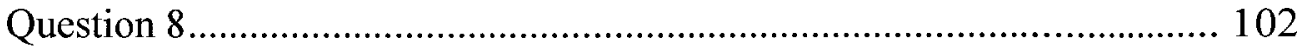

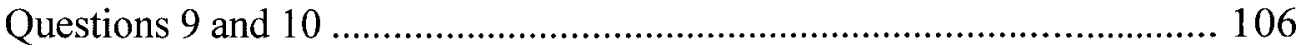

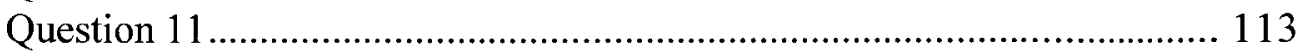

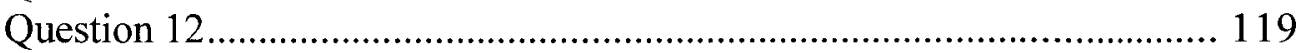

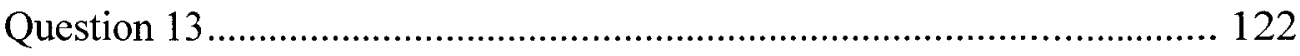

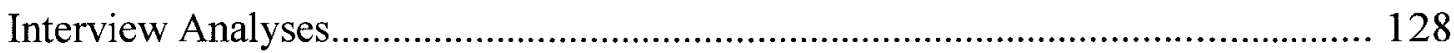

Alternative Analysis Groups..................................................................... 128

Minority Status Interviewees................................................................ 129

The Androgynous Females.................................................................... 133

The Limited Gender Opinion Group ......................................................... 136

The Second Canadian Cohort .................................................................. 137

Alternate Analysis Groups - Summary ………………………………..... 140

What Drives Interviewee Perceptions of Graduate Classroom Gender?........... 141

Dr. Buckley........................................................................................ 142

Dr. Hopper.

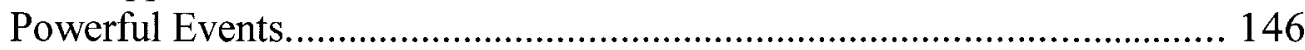

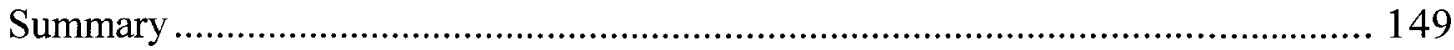

CHAPTER 5. OBSERVATIONS AND RECOMMENDATIONS................................ 152

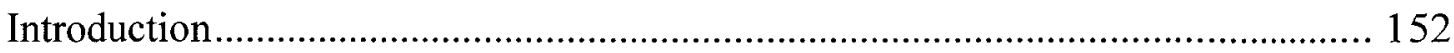

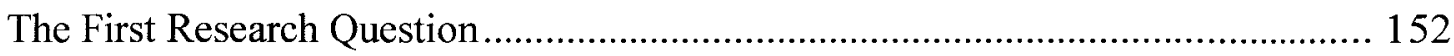

The Second Research Question ........................................................................ 158

Research Question 3: Leadership Education Programs and Gender ....................... 168

Interviewee Perceptions and a Leadership Education Program ........................ 168

Interviewee Perceptions and Efforts to Reduce Classroom Gender Bias.......... 171

Macro Gender .............................................................................. 172

The Difference Paradox........................................................................... 172 


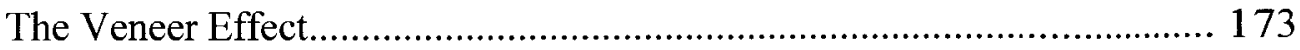

Recommendations for Further Studies.............................................................. 178

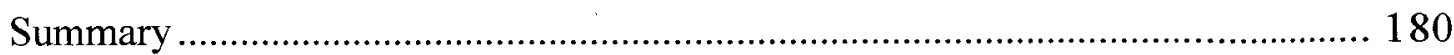

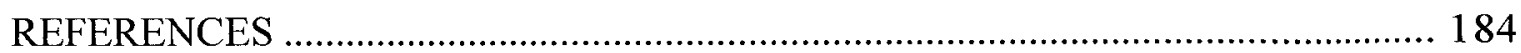

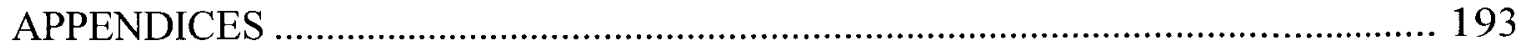



B. Qualitative Interview Questions..................................................................... 195

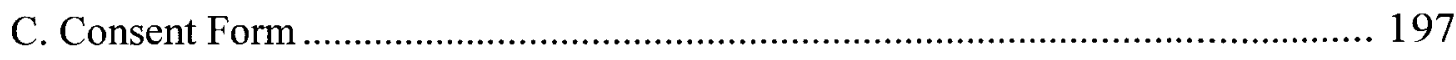

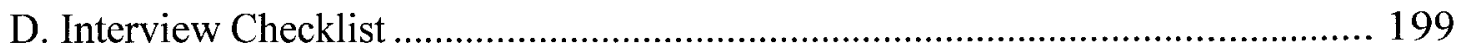

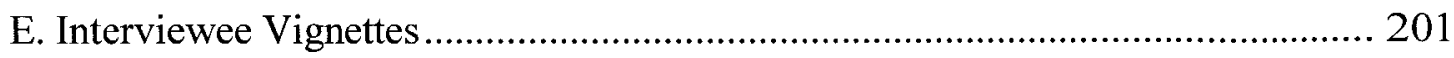

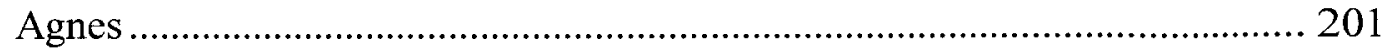

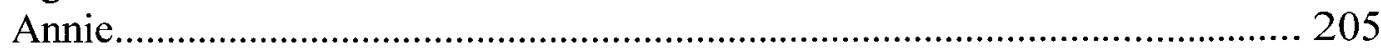

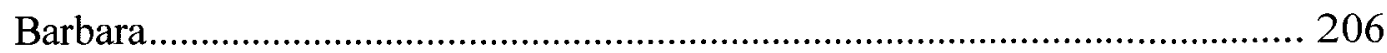

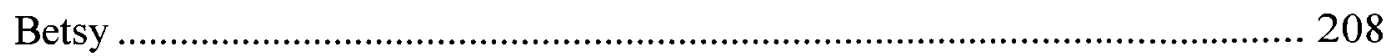

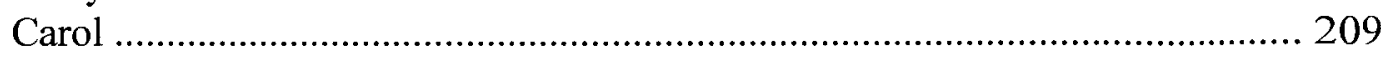



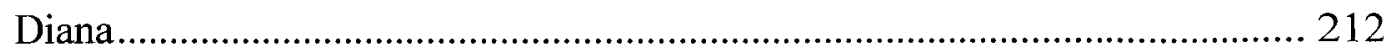

Genie

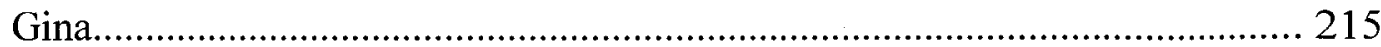

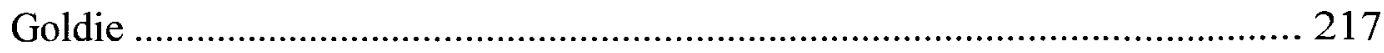

Grace

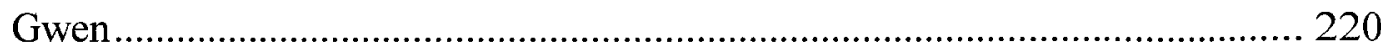



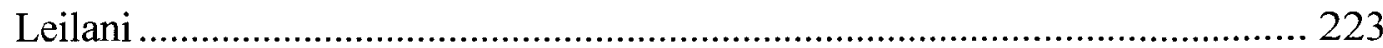

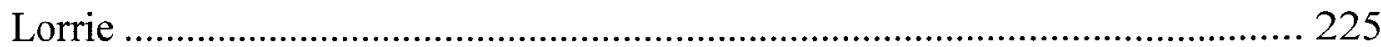

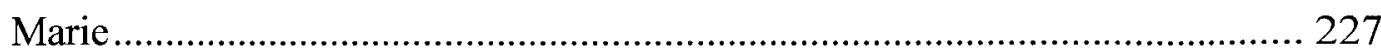

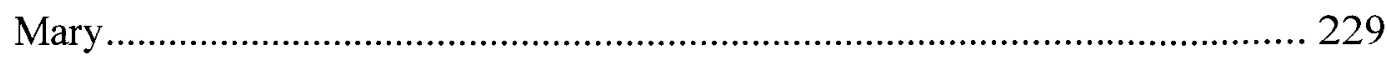

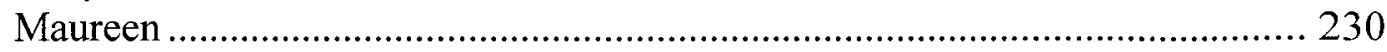

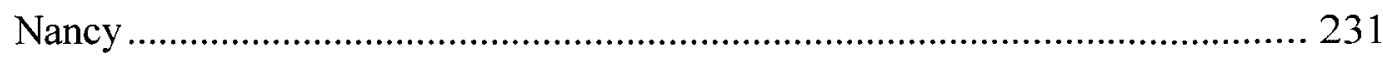

Penelope

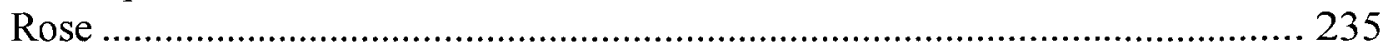

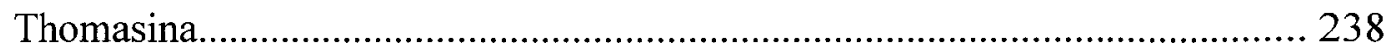

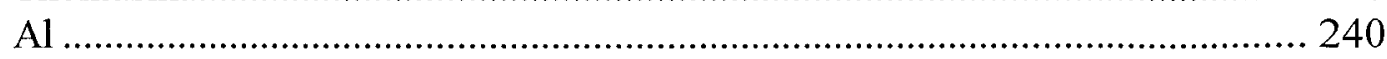

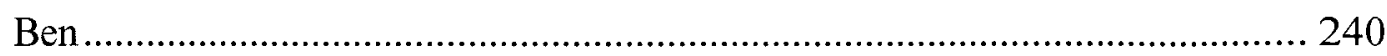

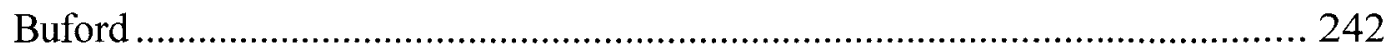

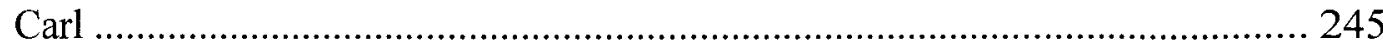

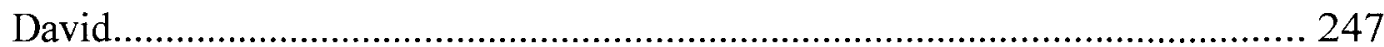




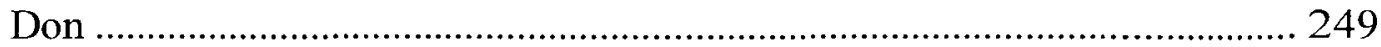

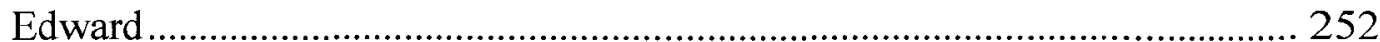

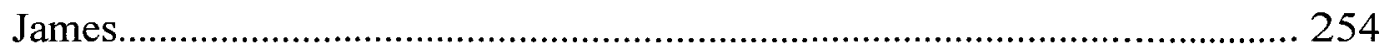



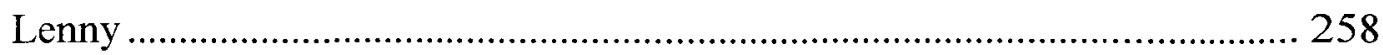

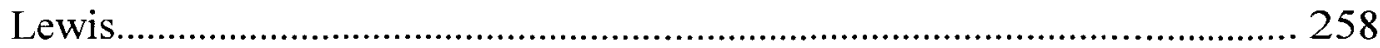

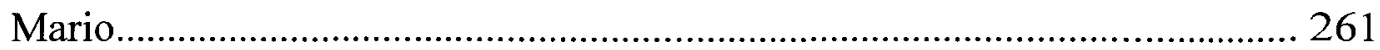

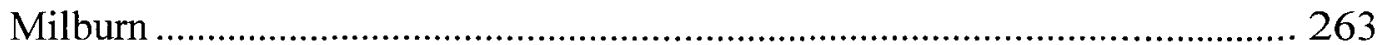

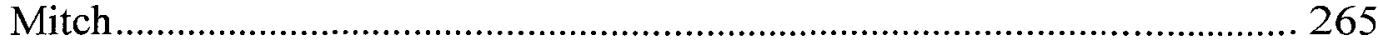

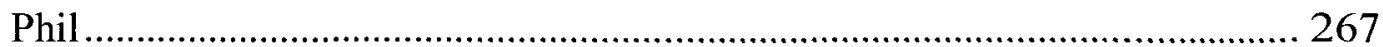

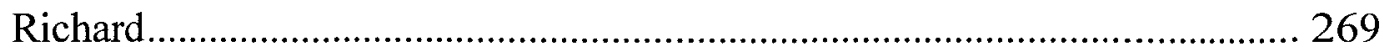

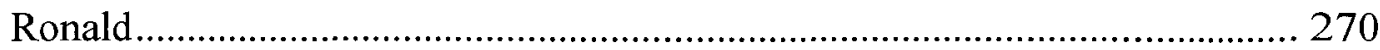

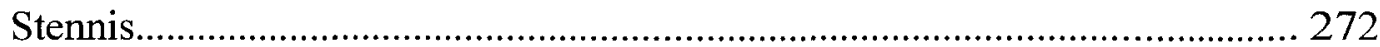

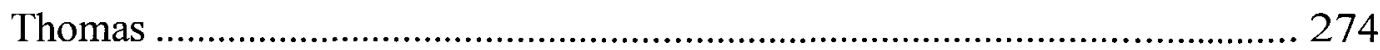

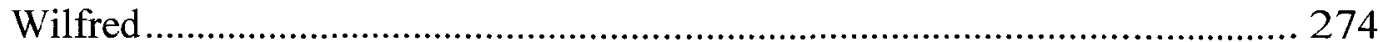

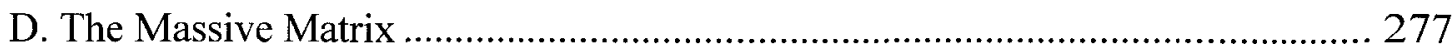




\section{LIST OF TABLES}

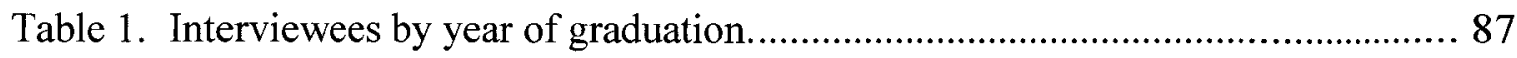

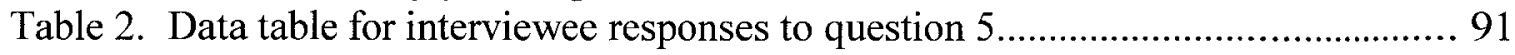

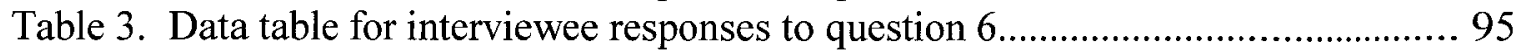

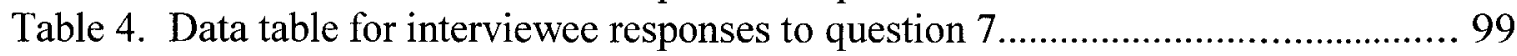

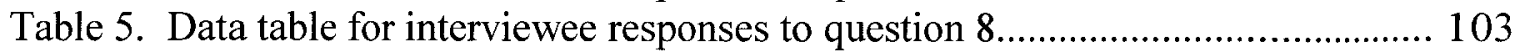

Table 6. Data table for interviewee responses to questions 9 and $10 \ldots \ldots \ldots \ldots \ldots \ldots \ldots . . . . . . . . . . . . .108$

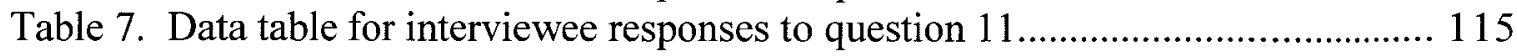

Table 8. Interviewee gender compared to analysis logic approach. ............................ 117

Table 9. Class norms compared to analysis logic approach. ................................... 118

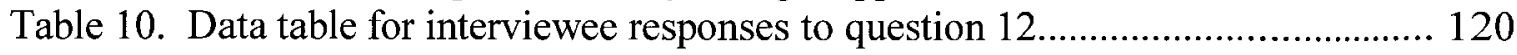

Table 11. Data table for interviewee responses to question 13................................ 124

Table 12. Selected Androgynous Female Interview Responses. ............................. 134

Table 13. Interviewee Responses about Dr. Buckley............................................... 143

Table 14. Sample responses about outspoken individuals...................................... 155

Table 15. Sample interviewee responses about gender sympathies and criticisms...... 156

Table 16. Sample female responses about male privilege. ........................................ 161

Table 17. Sample male responses about male privilege. ........................................... 164

Table 18. Data table for socially constructed beliefs about classroom gender............. 174

Table 19. The Massive Matrix — sorted by question 6....................................... 279 


\section{LIST OF FIGURES}

Figure 1. Interviewee Responses to Question 5 .................................................. 90

Figure 2. Interviewee Responses to Question 6 ...................................................... 95

Figure 3. Interviewee Responses to Question 7 ...................................................... 98

Figure 4. Interviewee Responses to Question 8 .................................................... 102

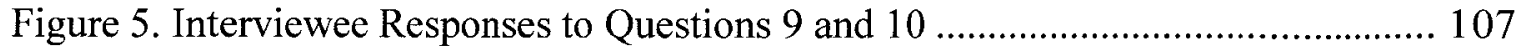

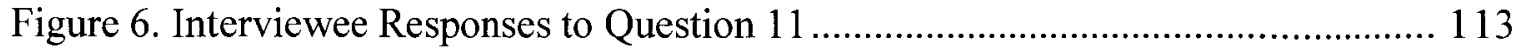

Figure 7. Interviewee Responses to Question 12 .................................................. 120

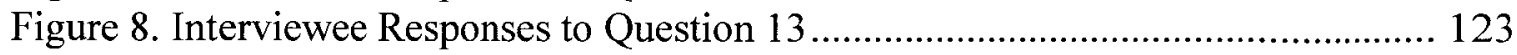

xiii 


\section{CHAPTER 1. THE PROBLEM}

\section{Statement of the Problem}

Popularized in Hall and Sandler's 1982 report, "The Classroom Climate: A Chilly One for Women?," gender bias has been recognized as a ubiquitous but subtle inequity in American colleges and universities. Gender bias is predominately viewed as male behaviors that adversely affect women. The literature provides extensive insight into gender bias behaviors; the impact of these behaviors on (undergraduate) women; potential reasons for gender bias including power, traditional stereotyping, and social conditioning; and recommended corrective actions. In addition, the literature argues that the nature of gender bias changes as women and men mature from elementary school children through adolescence, to college undergraduate and graduate students.

Given that men and women participate in gender bias behaviors, research provides limited qualitative insight to explain why men and women accept such behaviors in a classroom environment. Such insight may be difficult to obtain. Men are unlikely to acknowledge their role in gender bias. As noted by Karp and Yoels (1976), (male) students' perceptions of their actions differ from actual classroom behaviors. Men may not have adequately reflected on this issue to understand how and why they participate in gender bias, and the impact of this behavior on women. Finally, women appear to tolerate or not notice individual instances of gender bias, possibly because of "the seeming 'smallness' of each single instance" (Haslett \& Lipman, 1997, p. 38).

This dissertation compares the perceptions of male and female graduate students regarding the influence of gender in the classroom. The dissertation evaluates perceptual similarities and differences to gain an understanding of gender bias and its influence in 
the graduate classroom. Without this understanding, the fundamental basis for programs designed to minimize gender bias remain in question, and the effective implementation of such programs might be problematic. Furthermore, leadership study programs may not fully address gender issues in the classroom or in their choice of curricula. Simply stated, how can academia address gender bias without understanding the perceptions of gender as viewed by both female and male students? Once gender influences are better understood, women and men may also have the opportunity to improve their understanding of each other.

Introduction

The Civil Rights Act of 1964 outlawed discrimination based on several characteristics, including gender. Later court decisions (Meritor Savings Bank v. Vinson, 1986) determined that sexual harassment reflected a form of gender discrimination and was also a violation of the Civil Rights Act. However, legal statutes did not produce the equity in American society as the United States Congress might have hoped. Longstanding attitudes, traditions, and practices continued to subtly subjugate minority groups based on race, gender, ethnicity, age, and sexual orientation. (Many human characteristics influence the classroom - this dissertation focuses on gender.) As noted by Haslett and Lipman (1997), “As overt, visible discrimination was challenged in the 1960s and 1970s, it became replaced by subtle and covert discrimination" (p. 36).

Beginning in the early 1980 s, popular research by Sadker and Sadker (1985), Hall and Sandler (1982), and others explored subtle mechanisms that marginalized women in the American classroom. As defined by Mary Rowe (1977), gender bias produces "micro inequities" reflecting "everyday interactions in which individuals are often treated 
differently because of their gender" (Sandler, Silverberg, and Hall, 1996, p.10). Haslett and Lipman (1997) observed:

Micro inequities are particularly ubiquitous because in each instance the harm seems too small to bother with. In the aggregate, however, they constitute a serious barrier to productivity, advancement, and inclusion. Micro inequities are particularly difficult to respond to because of the face issues involved as well as the seeming "smallness" of each single instance. (p. 38)

As summarized by Fassinger (1995), research efforts produce conflicting opinions. For example, Hall and Sandler's widely referenced 1982 report provided anecdotal documentation of gender bias in academia, concluding that gender bias created a "chilly climate" for women in American colleges and universities. However, Cornelius, Gray, and Constantinople (1990); Crawford and MacLeod (1990); Drew and Work (1998); Heller, Puff, and Mills (1985); and Howard and Henney (1998) dispute the existence of a chilly climate.

While some recent literature (Kindlon \& Thompson, 1999; Sommers, 2000; Young, 2001) explores biases that have an adverse impact on boys, most gender bias research examines the marginalizing behaviors committed by men against women. However, gender bias includes more than men marginalizing women's efforts. Haslett and Lipman (1997) observed that "women may discriminate against other women through their reluctance to support other women. And women may discriminate against themselves through limiting their own aspirations or an unwillingness to take risks" (pp. 35-36). King (1998) found that women unconsciously favor academic papers based on the assumption that the paper was written by a man. 
Research on gender bias provides a rich assortment of quantitative and anecdotal investigations into the nature and impact of gender bias in academia. As examples, Karp and Yoels (1976) quantified classroom participation among undergraduate and graduate students. Hall and Sandler's chilly classroom reports (Hall \& Sandler, 1982; Sandler et al., 1996) were based primarily on anecdotal research. Jamison (1999) evaluated interviews with more than 340 undergraduate "university girls" to identify problems in adapting to the university environment. Nunn (1996) triangulated college classroom observations and student and faculty surveys to evaluate the impact of instructor behavior on student participation. Kelley and Parsons (2000) surveyed female staff, faculty, and students to research sexual harassment, including gender bias. Such research reflects the diversity of gender bias studies; however, qualitative interviews of both male and female graduate students from the same academic environment are limited. As Fassinger (1995) observed, research on classroom interactions is predominately focused on studies of children. Fassinger concluded, "Chilly classroom researchers would be well advised to turn their attention toward the dynamics of classroom peer groups [including graduate classrooms] in the future" (p. 94). In her dissertation, Hess-Almubarak (1994) observed, "The literature purports an extensive documentation of gender-based oppression in higher education" (p. 3), concluding a clear need for qualitative research of graduate women experiences. Myers and Dugan (1996) found "that gender-biased behavior remains a serious issue in graduate school classrooms" (p. 337) and called for additional research to improve the awareness of gender bias influences.

Studies by de Groot (1980); Fritschner (2000); Howard, Short, and Clark (1996); Howard and Henney (1998); and Tisdale (1993) observed that non-traditional female 
students (those 25 years old and older) participate more in classroom sessions and are more assertive. Tisdale concluded:

The fact that the women were more vocal than the males, particularly the women in their $30 \mathrm{~s}$ and $40 \mathrm{~s}$, may also be due to the fact that these were non-traditionalage students who, as graduate students, have already experienced some level of success in the higher education system. Because of their age and level of education, most of them also had some prior professional experience, which may have had some effect on their willingness to be more vocal. (pp. 221-222) Kelley and Parsons (2000) suggested that "Even within a university community different subgroups of women (e.g., undergraduates, graduate students, staff, faculty, and administrators) may experience the various types of [sexual] harassment with dissimilar frequency" (p. 550). Such research implies differing graduate classroom dynamics compared to undergraduate, primary, and secondary school classrooms, possibly with fewer incidents of some forms of gender bias. Some literature (Caplan, 1993; HessAlmubarak, 1994; Myers \& Dugan, 1996) examines women's experiences in graduate school. However, few qualitative studies compare the perceptions of women and men in a similar graduate school environment. ${ }^{1}$ Such a study could assess comparisons of both similarities and differences in student perceptions, evaluating the influence of gender (and gender bias) in the graduate classroom culture. In addition, a qualitative study of both women and men might provide insight into the basis for behaviors leading to gender

\footnotetext{
${ }^{1}$ Schroeder and Mynatt (1993) performed a qualitative and quantitative assessment of male and female graduate students with male and female major professors (advisors), concluding "there did seem to be some disadvantages to cross-gender relationships. . .however, those disadvantages seemed to be more typical of male mentor-female mentee pairs than of female mentor-male mentee pairs" (p. 14). Schroeder and Mynatt's research did not evaluate student-to-student interactions or the classroom culture.
} 
bias, possibly identifying male motivations for such behaviors (such as ignorance, prejudice, or indifference). ${ }^{2}$

\section{Research Questions}

While well documented in primary schools and the undergraduate classroom, gender bias research that compares the perspectives of both women and men appears limited, particularly in the graduate classroom. Gender bias research reflects female perceptions of marginalizing behaviors, without direct comparisons to male perceptions of similar events. Research involving both genders might serve to benefit both women and men; it could also provide men with a deeper understanding of the impact of micro inequities from the women's point of view, while informing women of male perceptions (or lack thereof) of gender issues. The general lack of comparative research on female and male perceptions concerning the influence of gender $^{3}$ in the classroom might produce basic but important questions. Thus, this dissertation investigates the following research questions:

1. How are men's and women's perceptions of the influence of gender in a graduate school classroom similar?

2. How are these perceptions different?

3. What do these perceptions reveal about a leadership education program and efforts to reduce classroom gender bias?

\footnotetext{
${ }^{2}$ Quantitative research by Parks and Roberton (1998) supports these three generalizations of potential motivations for gender bias behaviors. Parks and Roberton investigated undergraduate arguments against changes to language constructs that might reduce sexist language. In researching arguments against language changes, their findings identified frequent responses to include "change is too difficult" (e.g., indifference), "lack of knowledge/understanding" (predominately identified by women and an example of ignorance), and "sexism is acceptable" (prejudice among women and men).

${ }^{3}$ While the dissertation emphasizes gender bias in the classroom, research questions involve the "influence of gender in the classroom." If the dissertation were to directly assess gender bias, responses (particularly from men) may be guarded. Therefore, the dissertation uses the influence of gender as a proxy for gender bias.
} 
To investigate these research questions, the researcher performed a generic qualitative study (Merriam, 1999) using telephone interviews to assess the influence of gender in the University of San Diego (USD) Doctor of Education (Ed.D.) Program. The researcher interviewed 42 volunteers ( 22 women and 20 men) who graduated from this program between 1990 and 2004 to gain insight into the influence of gender in the graduate classroom.

\section{Significance of the Study}

I write this section in first person, present tense, because my personal self reflections on leadership and gender contribute, in my opinion, to the significance of this dissertation. I base this bold observation on the assumption that my past limited knowledge and inappropriate attitudes toward gender issues are representative of some segment of older American White male business executives and military leaders.

As I began my dissertation research, I could not recall a single research assignment during my doctoral classes that emphasized gender issues. Furthermore, only two of my female professors had introduced gender as part of class discussions and reading assignments - only one of these classes was required for my course of study. Had I chosen a different dissertation topic, I could have received my Ed.D. in Leadership Studies with minimal development of my knowledge and leaderships skills with respect to gender issues.

These observations raise basic questions. How would one design a leadership studies curriculum without some understanding of the perceptions of men and women toward gender issues? What are the fundamental human values related to classroom gender bias? The inequities of gender bias challenge our most basic personal beliefs. 
Assuming men are even aware of gender issues, they may perceive gender bias behaviors over a broad spectrum of attitudes ranging from appropriate to offensive, from equitable (e.g., men interrupt everyone, not just women) to oblivious. To discuss gender issues in leadership education, I believe an analysis of perceptions might provide a basic building block that could neutralize men's preconceived beliefs about gender, allowing some objective discussions of gender issues in an educational forum. The research might also serve to better inform women of men's attitudes toward gender issues, allowing women to respond to routine classroom micro inequities.

This dissertation attempts to evaluate the perceptions of the influence of gender in the classroom, contributing to our knowledge of gender's influence in higher education. The research reveals similarities and differences in women's and men's perceptions of gender influences. The research also identifies socially constructed classroom behaviors that may, in some fashion, limit efforts to minimize classroom gender bias. In addition, the research unexpectedly reveals the influence of privilege and power (beyond gender) in a graduate classroom. Perhaps by better understanding gender, privilege, and power, we might better limit the marginalizing effects of these three classroom influences.

Assumptions of the Study

Issues about gender bias may be difficult to investigate. Men and women may be reluctant to admit to such behavior and may not understand their participation in gender bias. In addition, Karp and Yoels (1976) observed that college classrooms represent a complex culture that cannot be easily viewed from a single perspective. The motivations behind gender bias must also be complex, and qualitative research may only begin to 
determine why gender bias is not perceived as a problem and continues to undermine women's graduate education experience. ${ }^{4}$

This research assumes that comparative, qualitative interviews of men and women concerning their doctoral program experience might reveal subtleties, producing insight into conscious or subconscious motivations behind gender bias. Interviewing doctoral program graduates may limit research results. These graduates are older, more mature, and should be more sensitive to classroom decorum, possibly experiencing fewer incidents of gender bias in the graduate classroom. On the other hand, older graduates (particularly White males) may be defensive of their privileged social status and reluctant to acknowledge gender bias (Clay-Warner, 2001). In either case, doctoral program graduates represent a challenge as a sample population.

USD School of Education doctoral program graduates include both full-time and part-time students. Students include professionals, executives, military (mostly Navy) leaders, and university staff members. Thus the School of Education doctoral program student population provides an unusual mixture of demographics, making findings difficult to translate to other studies involving advanced degree programs (unless similar student demographics exist in that program).

The study interviewed former USD Ed.D. students who graduated between 1990 and 2004. This sample population (198 graduates) assumes the interviewees' experiences are similar to those of non-graduates. Obviously this assumption has limitations-nongraduates may have left the program because of gender bias.

\footnotetext{
${ }^{4}$ While beyond the scope of this dissertation, research involving the group-value model of procedural justice and social identity theory may provide insight into why men participate in gender bias (ClayWarner, 2001; Kurth, Spiller, \& Travis, 2000).
} 
The dissertation assumes that gender correlates to biological sex in the sample population. However, as studied by Archer and Lloyd (2002); Kimmel (2000); Deaux (1984); and Glenn (1999), socially constructed gender differs from biological sex. Deaux focused her studies "not on how men and women actually differ, but how people think [italics in original] they differ" (p. 110). For example, Deaux observed that women exhibit male judgment (although not to the same extent as men) and vice versa. Deaux concluded that gender stereotypes influence perceptions of others and "people eventually play out their stereotype" (p. 114). Kimmel noted that "gender identity, Freud maintained, was a crucial part of personality development-perhaps the [italics in original] most crucial part. Gender was acquired, molded through interactions with family members and with the larger society" (p. 66). Thus, assuming that biological sex equates to masculinity or femininity is not always true, even though individuals may assume a gender role based on biological sex as they "play out their stereotypes" (p. 66). However, for the purposes of this research, the imperfect proxy of sex for gender is used. A final assumption is that some men will be sensitive to gender influences in the classroom. The research assumes that at least some men in the sample population are sensitive to gender influences, creating informative examples during qualitative interviews. If all men are insensitive to gender issues, qualitative interview questions are designed to encourage male interviewees to consider interview questions from a woman's point of view.

Gilligan (1982) observed that, in general, men's and women's social development emphasized different moral imperatives. Gilligan's impersonal male ethic of justice emphasized individual rights, fair play, and equality without personalizing decisions and 
behaviors. Gilligan's female ethic of care started with interpersonal relationships, sensitivity to loyalty, personal responsibility, and peacemaking. In her final chapter, Gilligan asserted:

My research suggests that men and women may speak different languages that they assume are the same, using similar words to encode disparate experiences of self and social relationships. Because these languages share an overlapping moral vocabulary, they contain a propensity for systematic mistranslation, creating misunderstandings which impede communication and limit the potential for cooperation and care in relationships. (p. 173)

Based on the concepts of a "different voice," men (and some women) may be oblivious to micro inequities, concluding that female and male students have equal opportunities to participate in classroom discussions, to challenge (e.g., interrupt) others, and to join in classroom teasing (belittling). Essentially, men may view the classroom as an equitable environment, providing all students similar academic opportunities (based on the "rules") to participate in classroom discussions and similar risks of being the brunt of a joke or stereotyped by other students. Thus, men may be expected to respond differently compared to women, but some male interviewees should express opinions on gender influences in the graduate classroom.

\section{Delimitations of the Study}

The study is limited to graduates of the University of San Diego Doctor of Education degree program. The study investigates differences and similarities in educational experiences based on gender only, and does not attempt to evaluate educational experiences based on other factors including race, ethnicity, age, family 
status, political beliefs, sexual preferences, or socioeconomic status. Furthermore, the study does not attempt to resolve conflicts among published research findings concerning what behaviors constitute gender bias and the severity of gender bias in higher education. The study assumes gender bias exists in American colleges and universities. Based on research by Alemán (1997); Banks (1988); Bennett (1982); Canada and Pringle (1995); Dey, Korn, and Sax (1996); Foster (1999); Hall and Sandler (1982); Hayes (2000); Hayes and Smith (1994); Henley and Thorne (1977); Hess-Almubarak (1994); Hite (1985); Hugo (1990); Kelley and Parsons (2000); Kite and Balogh (1997); Lee, Marks, and Byrd (1994); Myers and Dugan (1996); Owens, Smothers, and Love (2003); Rosenfeld and Jarrard (1985); Sadker and Sadker (1985, 1990); Sandler et al. (1996); and Smithson (1990), this assumption seems reasonable. While some may argue that researchers are strongly influenced by "views and values" (Cooper \& Bosco, 1999, p. 480) diluting some gender bias research efforts, adequate separate research efforts exist to assume gender bias influences a woman's education.

\section{Limitations of the Study}

Study limitations include (a) respondents may not accurately recall details concerning classroom experiences; (b) respondents, particularly men, may not be forthcoming in acknowledging gender bias behaviors; (c) other classroom influences including age, race, ethnicity, class schedules, socioeconomic factors, and family issues may strongly influence academic experiences; and (d) the researcher's interviewing skills, background, and status (i.e., older White male) may adversely affect interview sessions. 
Specific Terminology

The key terms used in the dissertation are defined below:

Gender: A person's gender differs from her or his biological sex. A product of social construction, gender represents a person's social preferences toward masculine behaviors, feminine behaviors, or both (androgynous). As observed by Archer and Lloyd (2002), "There is a reason to maintain a distinction between the terms 'sex' and 'gender' .. .sex refers to the binary categories 'male' and 'female', and gender to the attributes associated to a greater or lesser extent with the two sexes" (p. 17).

Gender bias: Defined as micro inequities by Mary Rowe (1977), gender bias behaviors represent everyday, socially accepted behaviors, prejudices, and events that marginalize women's efforts toward equity. A single micro inequity may seem insignificant; however, the aggregate effect of gender bias establishes an environment that impedes women's opportunities to gain social equity compared to men. Gender bias is not currently recognized as gender discrimination and sexual harassment, both of which are violations of the Civil Rights Act of 1964.

Non-traditional student: A college student over 24 years old. (Fritschner, 2000; Howard \& Henney, 1998; Howard et al., 1996)

Sex: Biological sex is determined by a person's reproductive organs. Gender is determined by a person's socially constructed perception of whether that person is male, female, or androgynous, and may differ from a person's biological sex.

Social construction: Social construction is the product of historical society influences, meanings, behaviors, and accepted values that are applied to men and women as a social group. Social construction defines acceptability in everyday life. For example, 
social construction influences acceptable dress codes, manners, language, classroom participation norms, gender values, and relationships among peers.

\section{Background of the Doctoral Program in Education}

The researcher interviewed graduates from the USD Ed.D. Program. The School of Education has offered an Ed.D. Program since 1979. The USD Ed.D. Program differs from traditional doctoral programs in that it allows part-time students to participate. The students (as represented by the 42 interviewees in the dissertation research) tend to be older, with very few younger than 30 years old. Students also represent a variety of professional fields, and many have achieved some measure of success in their chosen profession before entering the doctoral program.

Dissertation interviewees graduated from the USD Ed.D. Program between 1990 and 2004. One interviewee started his studies in 1980, recalling that there were about 10 students in the program with equal numbers of female and male students. He observed that classes included the same group of students, who formed a tight-knit, self-governing group that supported each other. The USD Ed.D. Program has continued to grow and currently has 104 students and 7 core faculty members.

Dissertation interviewees graduated from four separate, but related, doctoral courses of study. Most interviewees participated in the on-campus course of study, attending classes each semester and completing a dissertation as part of the course requirements. Eight interviewees participated in an International Studies Cohort that included students from the United States, Canada, and several Pacific Rim countries and islands. This course of study included distance learning (e.g., telecommunication) classes 
and on-campus residency sessions that lasted as long as 8 months. The International Studies course of study has been discontinued.

Inadvertently, an Invitation to Participate letter was sent to a graduate of the USDSan Diego State University (SDSU) Joint Doctoral Program, which was established in 1999 as a collaborative effort in specialized studies. Students in this program attend classes at both USD and SDSU, working with faculties from both institutions.

In the spring of 1998, USD initiated a Navy Doctoral Cohort, which provided a course of instruction structured for active duty Navy personnel. This program featured an intensive, 2-year schedule to complete required courses followed by a dissertation effort. When the Navy Doctoral Cohort was discontinued in the fall of 1999, some remaining students transferred to the on-campus course of study. One interviewee and the researcher began their studies in the Navy Doctoral Cohort.

Inferences drawn from interviewee statements suggest a transition in the doctoral classroom environment at USD. In the $1990 \mathrm{~s}$, there were fewer doctoral students than are in the program in the 2000 s. Students took more classes together and class size tended to be smaller. Cornelius et al. (1990) and Crawford and MacLeod (1990) performed research that suggested class size influences student participation and the class environment. As the number of doctoral students increased in the 2000 s, on-campus students did not seem to form acquaintances with their fellow students as previous students had.

A second factor may also have contributed to the transition in the USD doctoral program between the 1990 s and 2000 s. In the 1990s, students were required to pass a comprehensive examination to achieve doctoral candidate status. In the early $2000 \mathrm{~s}$, the 
comprehensive examination was replaced with a requirement that students write an acceptable qualifying paper to advance to candidate status. To prepare for the comprehensive examination, students formed study groups. Study groups produced lasting relationships among students and allowed them to debate study questions and examine class issues in a small, personal setting. For example, in her interview, Lorrie described her mixed gender study group as "an oasis." "I found that the men in that group were supportive, understanding of women's experiences in the school." In her interview, Jane noted, "my study group [of three women and one man] got me through. . .that was probably the most enjoyable part [of my studies]." Given the larger number of doctoral students, the larger class sizes, and the elimination of the comprehensive examination in the 2000 s, the current doctoral program might be viewed as more individualistic and less interpersonal than in previous years.

This dissertation examines the perceptions of USD Ed.D Program students who graduated between 1990 and 2004. During this period, the School of Education experienced a transition from a small student population and male-dominated faculty in 1990 , to recently become the School of Leadership and Education Sciences (SOLES), ${ }^{5}$ with approximately 1000 students and a diverse faculty in 2005 . To summarize and characterize this transition, on April 7, 2005, the researcher discussed gender at the School of Education with the past and current Deans, Dr. Edward DeRoche and Dr. Paula

\footnotetext{
${ }^{5}$ All of the research interviewees graduated and most of the dissertation was written before the School of Education became the School of Leadership and Education Sciences. Therefore, to avoid confusion, the dissertation will, for the most part, refer to the School of Education.
} 
Cordeiro ${ }^{6}$ respectively, asking their perceptions of the environment "with respect to gender during your tenure as the Dean" (cited from personal email, March 30, 2005).

During the interview, Dr. DeRoche noted that, in the early 1990s, education was a female-dominated profession and about $90 \%$ of the students were female; however, the School of Education had a predominantly male faculty with men in dominant faculty positions. Many faculty members were protective of their own status and position and resistant to change. As a result, Dr. DeRoche felt he should carefully and slowly make changes at the School of Education, such as adding new faculty members including women. Dr. DeRoche indicated he had always been impressed by the quality of students at USD, but felt the small faculty in the early 1990s limited diversity. For example, he noted that a student may take several courses from the same instructor during doctoral program coursework.

Dr. Paula Cordeiro became Dean of the School of Education in 1998. Early in the conversation, she summarized the growth at the School of Education noting that, in 1998, there were 15 faculty members, approximately 500 students, and limited grant fundingin 2005 , these numbers had grown to 32 faculty, 1000 students, and $\$ 5$ million in grants. Dr. Cordeiro concluded that the School of Education was a very different school today than it was in 1998 . To add context to the discussion, Dr. Cordeiro reflected on the history of the School of Education and its origin as a department in a women's college, meaning all the students were women.

Dr. Cordeiro emphasized her efforts to bring diversity to the school's faculty, particularly on the need to offer role models to a wide variety of students. (Dr. DeRoche

\footnotetext{
${ }^{6}$ Drs. Cordeiro and DeRoche reviewed this section and both signed a release authorizing this section to be included in my dissertation.
} 
also lauded the increased diversity, intellectual stimulation, and openness to change among new faculty members.) Dr. Cordeiro commented on the challenges of building faculty diversity, citing her efforts to hire a full-time, female, associate dean as an example. Dr. Cordeiro seemed pleased with the status of the School of Education in 2005 , reflecting on the increased balance in the faculty particularly in support of dissertation efforts.

Dr. Cordeiro perceived that gender does influence the environment at SOLES in 2005.

In summary, this section provides insight into the USD Ed.D. Program. Interviewee perceptions of gender's influence in the classroom may differ based on when they graduated and their course of study. The part-time nature of the program and the older, more mature student population, however, remain constants throughout the interviewee sample population.

Background of the Interviewer

I am a married (29 years) White male in my mid 50s with two adult children-a daughter and a son. I am a big man ( 6 feet, 6 inches tall and 275 pounds), with a conservative background emphasizing traditional American values. Before starting my dissertation research, my background constructed my attitudes, opinions, and stereotypes of women in academics (and society in general). I grew up in Louisiana and Mississippi and was strongly schooled by my father in Southern American values toward women as the "fairer sex." I attended the United States Naval Academy (in the early 1970s) before women were admitted, and I served 25 years in the Navy specializing in engineering, nuclear power, and ship maintenance. My Navy leadership training emphasized 
adherence to procedures, a hierarchical power and authority structure, and getting the job done. Since retiring from the Navy, I have been employed as an executive for a large defense contractor.

When I retired from the Navy in 1998, I enrolled in the doctoral program at the University of San Diego. As part of my course work, I took electives ${ }^{7}$ that facilitated self reflection on my weaknesses in interpersonal relations, particularly my insensitivity toward gender issues. I recall an incident in July 2001 graduate class. A White female student in her late-20s made a suggestion during a large group session that was ignored by group members. A few minutes later, an older White male student made the same suggestion and the group was willing to discuss the merits of his idea. The frustrated young woman stood up (to gain some measure of power and recognition) and challenged the group as to why her suggestion was now being considered after being reintroduced by a White male. I had been oblivious to the woman's mistreatment until she bravely challenged the group on its gender bias.

My enlightenment occurred in an ethics class as a middle-aged, female Hispanic student vented her frustration at the older White male professor when he ignored her efforts to discuss Hispanic issues embedded in a reading assignment. After class, I talked to three peers (White female students in my age group) about the incident. All three women indicated they had seen the incident as inevitable, given other classroom occurrences involving the Hispanic woman and the professor in which he had placated the woman-in the words of my peers, the professor had patted her on the head. This brief conversation and my insensitivity to recognize classroom gender bias clearly

\footnotetext{
${ }^{7}$ These courses included 1 week of sensitivity training (including some gender issues), two courses on leadership for change: chaos, complexity, resistance, and courage, and a conflict management course.
} 
identified a weakness in my personal and leadership skills. When presented with the opportunity to research gender bias, I enthusiastically embraced this topic, which I knew virtually nothing about.

After my proposal defense in October 2004, my committee required a different methodology and, during subsequent research, I reviewed Krohne's 1991 dissertation. In her dissertation, Krohne evaluated her own biases as a precursor to her research, ${ }^{8}$ emphasizing the "difference between what we believe to be true and what we know to be true" (p. 84). This exercise forced her to consider her opinions and set aside these opinions in advance of qualitative interviews and analyses. (Such an exercise is similar to the concept of "epoche" in phenomenology (Patton, 2002), which emphasizes abstaining from preconceived judgment during research efforts.) I found this exercise particularly enlightening.

In keeping with Krohne's (1991) methodology, the following list (prepared in November 2004) reflected my preconceptions concerning gender bias:

1. I believe most men have limited understanding of gender bias behaviors and the impact of these behaviors on women.

2. I do not understand why women tolerate demeaning gender bias behaviors. As a man, I would not tolerate these behaviors if I were the victim.

3. I believe that men subconsciously do not consider women to be equals, particularly in my middle-aged generation.

4. Based on personal experience in one of my graduate classes, I believe men would feel uncomfortable in a classroom characterized by feminine class norms.

\footnotetext{
${ }^{8}$ McIntosh (1988) provides another example of self-reflection on personal biases.
} 
5. I believe White males are insensitive to their position of privilege in American society (McIntosh, 1988).

6. I believe men commit acts designed to establish dominance in a group. Furthermore, I believe men are consciously confrontational to establish their position of authority or to save face when challenged.

7. I believe many men have never been asked (by academia) to consider a situation from a woman's point of view.

8. I believe American society places too much emphasis on differences in our culture (e.g., gender, racial, ethnical), failing to consider how we may be similar.

9. Based on my personal observations, I believe graduate classrooms, as a minimum, tolerate masculine values. I believe masculine classroom environments are the accepted norm at the University of San Diego.

10. I believe the media presents socially constructed stereotypes of men and women, reinforcing gender bias in American society.

I do not pretend to be able to comprehend gender bias in society from a woman's perspective - I am not a woman. Therefore, my subject knowledge is based on my research, inquisitiveness, recent observations, humbling self assessment, and commitment to fairness and equality.

\section{Summary}

While well documented in primary schools and the undergraduate classroom, gender bias research that compares the perspectives of both women and men appears limited, particularly in the graduate classroom. In addition, current research provides conflicting conclusions, suggesting further study is appropriate. Additional research may 
also provide insight into leadership education programs, and how effectively those programs accept diversity (e.g., gender) in the graduate classroom.

A better understanding of gender and its role in leadership studies would seem consistent with the mission of the University of San Diego's School of Leadership and Education Sciences. The School's mission statement asserts in part, "It is our responsibility to prepare students with the professional knowledge, skills, and ethical perspectives they will need for effective leadership and practice in a diverse society" (available on the USD Web page at <http://www.sandiego.edu $>$ ). Understanding diversity in society would certainly include studying gender issues as part of a leadership education program.

Because the researcher is an older White male and physically imposing, the research methodology must limit the possibility that interviewees might be intimidated or turned off during interviews. Additionally, because of the limited reference material available regarding gender bias in the graduate classroom, research efforts have a limited foundation for an in-depth investigation, and instead must attempt to establish broader insight into the influence of gender in the graduate classroom.

Chapter 2 reviews the literature about gender and graduate classrooms. It synthesizes gender bias micro inequities and documents conflicting conclusions concerning the effects of gender bias on women's educational efforts. Because the dissertation compares the perceptions of male and female graduate students regarding gender, the literature review attempts to establish that women and men have differing perceptions of gender influences and that graduate students' perceptions differ from those of undergraduate students. 
Chapter 3 reviews the dissertation methodology. The research used a generic qualitative study (Merriam, 1998) and telephone interviews to gather data about doctoral program graduates' perceptions of the influence of gender in the classroom. The sample population consisted of former students who graduated from the University of San Diego Ed.D. Program between 1990 and 2004.

Chapter 4 summarizes the results of the qualitative interviews. The researcher interviewed 42 volunteers-- 22 women and 20 men-and recorded almost 22 hours of data. Chapter 4 analyzes responses to interview questions, and evaluates the similarities and differences between female and male interviewee responses and the overall insight gained from each question. The chapter concludes with an analysis of special cases and a summary of findings.

Chapter 5 provides the dissertation's Implications and Recommendations. Because the research evaluated many interviews and focused on the breadth of responses (as opposed to a few, in-depth interviews), opportunities for new theories, hypotheses, or broad generalities are limited. However, the interviews did produce several unexpected findings that may be worthy of further academic research. Chapter 5 answers each research question and provides recommended additional study topics. 


\title{
CHAPTER 2. LITERATURE REVIEW
}

\author{
Introduction
}

This dissertation investigates doctoral program graduates' perceptions of the influence of gender in the classroom, comparing the similarities and differences between women and men. The literature review begins with an examination of gender bias and its reported adverse impact on female college students. This examination of gender bias builds a foundation for the research effort by synthesizing recent literature to establish the existence of gender bias and its marginalizing effects on women. Gender bias research, however, produces conflicting conclusions concerning behaviors and associated influences, and their correlation to gender bias. These conflicts suggest that further investigation might provide insight into the nature of gender bias in the college classroom environment, producing a better understanding of how to address gender issues in a leadership studies program curriculum.

The dissertation focuses on the graduate classroom and suggests this environment differs from the undergraduate environment. This assertion is predicated on research that identifies differences between traditional and non-traditional (over 24 years old) students. de Groot (1980); Fritschner (2000); Howard et al. (1996); and Howard and Henney (1998) observed increased participation among older, non-traditional students. Richardson and King (1998) observed, "there is no sound evidence that adult students perform less well [in the classroom]. . .and argued that the quality of university courses can be enriched by the admission of adult students" (p. 81). Classrooms filled with nontraditional students should experience different dynamics than traditional undergraduate classes, which are predominately populated by younger, less mature students. In 
summary, while undergraduate classes may have some students over the age of 30 , graduate classrooms will have few, if any, 20-year-olds. The chapter attempts to substantiate these differences as documented in the literature.

The literature review concludes by summarizing the differences in classroom experiences for female and male students. Investigating these experiences might provide the insight necessary to better understand gender's influence in graduate classrooms.

The literature review may appear somewhat dated. For example, the list of references that discuss gender bias in the Chapter 1 Delimitations of the Study section includes only four references published since 1999. However, some recent articles provide similar perspectives on gender bias compared to older references. For example, Owens et al.'s (2003) article examining gender bias in the nation's schools suggests gender bias still exist:

After 25 years of research, documentation reveals numerous examples where girls are denied opportunities to excel in the classroom. The sexism is subtle, and the bias very often is unconscious. Girls are rewarded for their conformity to classroom rules by simply being ignored, thus they pay a huge price for their compliance. Sex segregation, both during play and in the classroom, polarizes the sexes and contributes to female invisibility. (p. 133)

Sellman and Treinen (2004) concluded, "Although the issue of gender equity has concerned educators since at least the 1960 s, gender bias continues to be perpetuated throughout the curriculum-in classroom interactions, instructional material, pedagogy, and instructor evaluations" (p. 286). 
A Synthesis of Commonly Held Perceptions of Gender Bias

To fully appreciate the potential impact of gender bias in the classroom, one should appreciate the breadth of reported gender bias behaviors. Popular literature stereotypes gender bias, describing behaviors, prejudices, and societal values that marginalize women in Western college classrooms. For example, Myers and Dugan (1996) studied the negative effects of "unfair gender behavior in the [graduate] classroom" (p. 339), including anger, distractions, and a loss of confidence in the instructor. To review commonly reported gender bias behaviors, this section synthesizes the literature on gender bias using the observations of the researcher in a postulated evaluation of American college and university classrooms during a prolonged period of study. Walcott (1994) advocated such storytelling in qualitative research, noting:

To be able to tell (which, in academia, essentially means to be able to write) a story well is crucial to the enterprise. When we cannot engage others to read our stories—our completed and complete accounts - then our efforts at descriptive research are for naught. (p. 17)

This synthesis does not include all behaviors and practices that are considered to reflect gender bias, only frequently used examples. In addition, these observations only focus on gender bias and do not address actions commonly viewed as sexual discrimination or harassment. This view of gender bias coincides with Kelley and Parsons' (2000) distinction among sexual coercion, unwanted sexual attention, and gender harassment (e.g., gender bias). Kelley and Parsons define gender harassment as "a broad range of verbal and nonverbal behaviors that convey insulting, hostile, and degrading attitudes about women" (p. 550). 
On my postulated research effort, I would evaluate college classrooms through a series of non-participative observations. In some classrooms, I note that a few students (mostly men) dominate student responses during class discussions, accounting for about $79 \%$ of student comments in class (Fritschner, 2000; Karp \& Yoels, 1976). About half of the students might participate only once during a 1-hour class. The remaining $20 \%$ of the students are silent (Sandler et al., 1996). (In my observation notes, I comment that silence may indicate insecurity driven by gender bias and reflects a possible topic for further research [Banks, 1988; Stewart, Cooper, Stewart, \& Friedley, 1996].) For those students who participate, I observe that instructors appear to treat men and women differently. Men are asked more thought-provoking questions (Pearson \& West, 1991), are recognized more often than women by instructors (Lee et al., 1994; Stewart et al.), and are given more positive and negative feedback (Rosenfeld $\&$ Jarrard, 1985). Men are also permitted to join discussions or answer questions without having to raise a hand or ask permission to be given the floor; men also appear to talk longer than women (Hall \& Sandler, 1982). Women receive less instructor feedback, are sometimes expected to raise their hands before speaking (Irvine, 1985; Lee et al.), and do not interrupt ongoing discussions as often as men (Brooks, 1982; Fassinger, 1995; Sadker \& Sadker, 1990).

The language in classroom discussions also differs. In some classes, the instructor addresses women by their first names, such as Janice or Jennifer. One instructor, however, addressed men more formally, calling on Mr. Howard or Mr. Holmes. Female students are sometimes called girls or gals (Beagan, 2001); men are rarely called boys (Hall \& Sandler, 1982). Such differences in formality might have an adverse impact on women's self-esteem, suggesting that women are less capable than men (Sandler et al., 
1996). I also note that, at times, a woman's academic performance or intellectual ability might be subjugated in favor of comments about her physical appearance. For example, rather than asking a female student to comment on the current topic of class discussion, an instructor might complement her attire. In some classes, I observe that women are called "sweetie" or "honey," marginalizing their status as serious college students (Sandler et al.). (I infrequently observe a male student addressed as "hunk" or "stud"). ${ }^{9}$ I also observe sexist language, often in the form of crude humor (Pearson \& West, 1991; Sandler et al.).

I find student group exercises particularly revealing. At times, a small group of students (including members of both genders) might ask a female student to take notes or serve as the group secretary, while male students attempt to assume some leadership role. In a sense, the students, even though theoretically of equal status, ask women to assume traditional female roles involving clerical support (Sandler et al., 1996).

There appear to be some differences depending on the instructor's gender. With female instructors, female student participation increases by almost $75 \%$ compared to classes with male instructors (Karp \& Yoels, 1976). Male student participation appears unaffected by the instructor's gender. Classes with female instructors also appear to include more interaction between the instructor and students (Tisdale, 1993).

Female students may have fewer interactions with faculty both in and out of the classroom (Holmstrom \& Holmstrom, 1974). Male students seem to engage in more informal, out-of-class conversations with male instructors (Drew \& Work, 1998; Levy, 1982). Female students do not avail themselves of this informal feedback and networking

\footnotetext{
${ }^{9}$ Lee et al. (1994) observed several classrooms during their research on sexism in college classrooms. In their paper, Lee et al. reported an incident in which an instructor addressed a male student as "stud" (p. 106).
} 
as much as men. A factor that may contribute to higher levels of male student networking is that most senior, tenured professors are males. At 4-year and graduate universities, female professors tend to be junior associate or assistant professors, and are hired into a contract position versus a tenure-track or tenured position. This factor appears to limit the available female role models for women students (Maitland, 1990; Sadker \& Sadker, 1990; Schroeder \& Mynatt, 1993; Smithson, 1990). As studied by Gilbert (1985), female college students "rated the role-model relationship as more important to their professional development than did male students" (p. 111). Thus, inadequate numbers of senior female faculty members may have an adverse impact on a woman's college education.

I observe apparent inequities in grading systems and class study material. The quality of student papers appears consistent between the two genders; however, women seem to get lower grades regardless of the instructor's gender (King, 1998; Smithson, 1990). Textbook selection, both those used for class and those omitted, seems designed to ignore female accomplishments and authors. In many classes, reading and research assignments do not attempt to overcome these shortcomings (Myers \& Dugan, 1996). Myers and Dugan summarized the shortcomings of graduate class material, noting: Sexism is evident in the material selected for and omitted from graduate courses. These omissions convey the message to students that women scholars in their area do not contribute to the discipline. Women's achievements are often left to courses dealing specifically with gender, such as those offered in women's studies departments. (p. 331)

Finally, class textbooks and study materials seem to be dominated by masculine themes and subjects (Banks, 1988; Hayes \& Smith, 1994; Kimmel, 2000; Lee et al., 1994). For 
example, Glaser and Strauss (1967) consistently refer to generic occupations using male pronouns. A random sample of 50 of the 262 pages in Glaser and Strauss revealed 15 generic occupations ${ }^{10}$ that were subsequently defined by a gender-specific pronoun (such as her, she, him, or his). Of the 68 different findings of generic occupations in these 50 pages, only one (nurse) was subsequently defined by a female pronoun. While Glaser and Strauss' book was written before gender sensitivity gained prominence, instructors commonly reference this book in graduate school studies.

It appears that attitudes toward students differ. College admissions personnel seem concerned about a young mother's ability to care for her children and her husband (Kite \& Balogh, 1997); however, young fathers are rarely questioned about family commitments. Men with families seem to obtain more financial aid than women with families (Levy, 1982). In addition, faculty advisors question a woman's commitment to her academics and a future career and suggest that future family responsibilities may take priority. Hite (1985) studied differences between male and female doctoral students and found role conflict between school and home responsibilities a major difficulty for women-academia may exacerbate this conflict. Research by Home (1998) supports Hite's conclusions. I note that only about half of the American universities offer child day care, which may impede the opportunity for mothers with young children to gain an education (Smithson, 1990).

I observe that aggressive, outspoken women appear to be considered troublemakers. On the other hand, men appear to be considerably more aggressive

\footnotetext{
${ }^{10}$ These occupations include sociologist (referenced 20 times); researcher (20); nurse (1); field worker (4); analyst (11); research team member (1); "true pro" (Glaser \& Strauss, 1967, p. 92) sociologist (1); realistic novelist (1); staff member (1); social scientist consultant (1); writer (2); library researcher (1); author (1); novelist (1); and theorist (2).
} 
(Brooks, 1982) and are viewed as "aggressive"-a non-derogatory label when applied to men. Butler and Geis (1990) observed that, in a mixed gender setting, women are implicitly expected to defer to men-_."a woman who speaks out violates these tacit expectations, and this violation causes negative affect [sic]" (p. 48). Some instructors also avoid popular female issues and will not accept term papers on topics such as feminism (Kite \& Balogh, 1997).

I begin to question if women's educational experiences differ. For example, Belenky, Clinchy, Goldberger, and Tarule (1997) concluded, "Most of the women [e.g., students interviewed] reported that they had often been treated as if they were stupid" (p. 194). Caplan (1993) observed:

The effects that the maleness and heterosexism of the environment have on women academics range from mild irritation to complete devastation. They include interfering with their ability to concentrate, hampering their freedom to work, and destroying or thwarting the creation of a supportive environment. (p. 32)

Tisdale (1993) observed that schools "contribute to reproducing unequal gender and race relations as well"' (p. 204).

Some women experience difficulty in the competitive, win-lose classroom environment (Alemán, 1997). Women appear more comfortable with a caring, nurturing, supportive, communal experience (Alemán; Belenky et al., 1997; Gilligan, 1982; Kramarae \& Treichler, 1990), and the masculine atmosphere (Brooks, 1982; Hall \& Sandler, 1982) places women at a learning disadvantage (Banks, 1988; Canada \& Pringle, 1995). I concluded that "most of the institutions of higher education in this 
country were designed by men, and most continue to be run by men" (Belenky et al., p. 190), and that women "learn how to play the [White male] game with regard to fairly superficial behaviors in order to preserve the self while attending graduate school" (Levy, 1982 , p. 48).

Gender Bias Research: Examples of Conflicting Assertions The previous section synthesizes commonly held perceptions of gender bias in academia. However, disagreement exists concerning some of these perceptions. To substantiate that further gender bias research is appropriate, this section reviews two areas of conflicting assertions concerning behaviors attributed to gender bias. These two frequently studied assertions are: (a) differences in female and male college classroom student participation may be attributed to gender bias, and (b) the instructor's gender contributes to classroom gender bias.

\section{An Analysis of Gender Bias and Classroom Participation}

In her investigation of female friendship's educative value, Alemán (1997) asked, "How does the assertive, suggestive, inquiring, probing, and nurturing female friendship talk of the corridor become the timid, pleasing, and reluctant chat of the classroom?" (p. 120). Alemán observed that even in her (Alemán's) warm, feminist classroom, women observe "conversational reticence and insecurity" following "male norms of classroom participation" (p. 120). Alemán infers that the masculine college classroom inhibits and even silences female students' participation in classroom interactions. Others support Alemán's assertions. For example, Wood and Lenze (1991) evaluated strategies to enhance gender sensitivity in the classroom, asserting that most Western classrooms 
favor male learning and thinking preferences. They summarized the differences between male and female preferences:

Thus, in most classrooms, asserting self is more rewarding than waiting one's turn, individual achievement is valued more highly than collaborative efforts, talking is encouraged more than listening, presenting new ideas is emphasized whereas responding to and synthesizing classmates' ideas is not, competition is stressed more than cooperation, and advancing firm conclusions is more highly regarded than holding tentative ones. (p. 17)

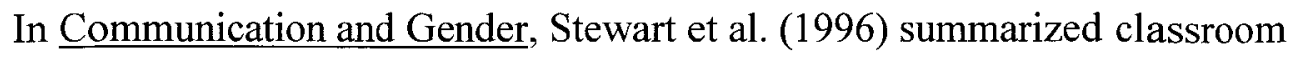
interaction expectations when they stated:

First, teachers may call on male students more often than on female students. Some female students indicate they feel invisible in the classroom. Female students raise their hands often, yet males are more likely to be asked to respond. When female students are asked why they believe teachers call on male students more often, they claim that teachers either do not expect them to know the answer or do not feel their answer would be correct or worthwhile. (p. 157)

Stewart et al. emphasized that gender stereotypes influence instructor expectations concerning student classroom participation. Furthermore, this summary of differences in classroom participation based on gender is echoed in other research as well.

Brooks (1982) observed first-year graduate classes in her study of student dominance behaviors. In her introduction, Brooks stated:

Behavioral characteristics such as self-confidence, assertiveness, competitiveness, rationality, and ambition — which are intrinsic contemporary requirements of 
academic life are simultaneously defined socioculturally as male behavioral prerogatives. These behaviors in women have been found to elicit predominantly negative responses from men and, to a lesser extent, from other women. (p. 684) In her findings, Brooks reaffirmed the dominant behavior of male students, particularly in classes with female professors, noting that "the attribution of higher status to male professors by male students tends to dampen these [male] students' dominance behavior" (p. 688). Brooks' conclusions suggest gender influences classroom dynamics, reducing female student participation.

In her quantitative study of sex-based barriers in law school, Banks (1988) observed that "women, because of gender, are not naturally members of the "club" (p. 138). Because White males set the law school agenda,

They [women] remain silent because they believe that their views carry no weight. They are silent because they believe that women are largely ignored or invisible in law school classrooms. The feeling of alienation is reinforced by the use of sexist textbooks and sexist language. (p. 139)

Banks discovered that $60 \%$ of female respondents to her survey (compared to $43 \%$ of men) seldom or never voluntarily participated in classroom discussions. In addition, 17\% of women (compared to $9 \%$ of men) indicated they were not called on, even though they volunteered to participate in class discussions three or more times. Banks' preliminary findings "suggest that women are silent because the law school classroom environment, structure, and language tend to exclude women or make them feel inferior" (p. 146). In their 1982 report on the classroom environment, Hall and Sandler attributed female student marginalization to overt and inadvertent treatment of female students 
"differently [from men] in the classroom and in related learning situations" (p. 2). Hall and Sandler felt that gender bias contributed to different treatment of women and discouraged women from participating in class. Ultimately, this classroom environment leads women to believe "their participation in class discussion is not expected, and their contributions are not important" (p. 3). Hall and Sandler characterized the classroom as a "masculine setting for discussion" that further inhibited female participation. They concluded that "women students' own styles of speaking may incorporate features that are devalued in the traditional masculine academic context" (p. 9).

In fairness, some of the above-cited literature does acknowledge other classroom influences that inhibit female student class participation. For example, Banks (1988) evaluated professors' attitudes toward students' questions and asked whether professors encouraged or discouraged questions and comments. Banks and Brooks (1982) assessed the influence of the professor's sex (e.g., gender) - this influence will be evaluated in a later section. All these authors suggest that gender differences and biases inhibit female participation in the classroom. Other research provides evidence of influencing factors not associated with student or instructor gender.

Several authors evaluated other factors that influence classroom participation, such as student age, gender, and attendance (Howard et al., 1996); communication apprehension (Daly, 1986); class size (Crawford \& MacLeod, 1990); and college division, class size, and time of the semester (Cornelius et al., 1990). As a starting point, Karp and Yoels (1976) investigated why students do not participate in classroom discussions. Their research provides important insight into the college classroom. They discovered that the instructor accounts for $88 \%$ of classroom interactions and only a few 
students respond to most instructor questions. Students avoid direct confrontation and emphasize "'getting along' [which] means students and teachers avoid any situation that might be potentially embarrassing to one or the other" (p. 426). Students "consolidate responsibility" (p. 429) by allowing the more vocal, aggressive students to respond to instructor questions or comments on class issues; other students enjoy the nonresponsibility of limited participation. In their conclusions, Karp and Yoels observed: For the reasons suggested in the last few pages, it may be argued that most students opt for non-involvement in their college classroom. This being the case, and because organizational features of the college classroom allow for noninvolvement (the consolidation of responsibility, the unwillingness of professors to directly call on specific students, the infrequency of testing), the situation allows for a low commitment on the part of students. The college classroom, then, rather than being a situation where persons must be deeply involved, more closely approximates a situation of "anonymity" where persons' obligations are few. (p.

Given Karp and Yoels' characterization of college classrooms, the following paragraphs provide other research about student participation and classroom discussions.

In their study of undergraduate student participation in a mixed-age classroom, Howard et al. (1996) triangulated classroom observations, student and instructor surveys, and student and instructor interviews to investigate student participation patterns. ${ }^{11}$ Howard et al. discovered that, while men generated 1.72 comments per average class session compared to 1.46 comments for women, "the impact of students' age on verbal

\footnotetext{
${ }^{11}$ Of note, Howard et al. (1996) confirmed research by Karp and Yoels (1976) noting that three to five students accounted for most classroom comments regardless of class size.
} 
participation was much more pronounced than that of gender" (p. 12). For both male and female non-traditional students (over age 24), 56\% participated in class discussions compared to $37.5 \%$ for traditional students. Howard et al. evaluated other influences on participation. They discovered that gender, age, and attendance all reflect a significant predictor of classroom participation. Age and attendance, however, had a larger effect than gender. Howard et al. also investigated reasons why students do not participate in class discussions. Their research revealed similar reasons for men and women.

Ultimately, Howard et al. concluded that:

In general our study showed that when we consider the influences of age, gender, class size, time of day, and week in the semester, "consolidation of responsibility" (as described by Karp and Yoels [1976]) remains the predominant pattern for discussion in the mixed-age college classroom. (p. 23)

Daly (1986) reviewed college communication apprehension and its influence on classroom participation. He noted there exist "students, sometimes labeled as shy, reticent, or communication-apprehensive, who dislike even fear communicating. These students never seem to answer questions aloud, prefer working alone on projects, and often remain virtually unnoticed by teachers and fellow students" (p. 21). Daly suggested that possibly $20 \%$ of the United States population — a speculative figure-may suffer from communication apprehension that degrades individual communication skills. He also cited research that showed a significant relationship between communication apprehension and standardized test scores such as the American College Test (ACT). Daly suggested four explanations for communication apprehension: genetics, positive and 
negative reinforcement, inadequate skill development, and adequate communication models. None of these explanations, however, directly involved gender differences. Crawford and MacLeod (1990) conducted two quantitative surveys to assess student perceptions of classroom climates. The first survey produced 614 useable responses from 267 males ( $11 \%$ were age 25 or older and $9 \%$ were non-Caucasian) and 347 females (13\% were age 25 or older and $13 \%$ were non-Caucasian). The second survey produced 761 useable responses, including 52\% female and 7\% non-Caucasian responders. In their general discussion, Crawford and MacLeod concluded that "class size is clearly the variable of most importance to student participation. . . . Small classes enhance participation for all students regardless of gender" (p. 120).

Based on their preliminary research, Cornelius et al. (1990) observed the following:

Taken together [previous research cited], these results suggest that student participation is determined by multiple factors and that studies that attempt to reduce student participation to one or two factors (such as sex of student or sex of instructor) most likely will misrepresent the true nature of student-faculty interaction in the college classroom. (p. 189)

To study these observations, Cornelius et al. employed classroom observers at Vassar College, Trinity College, and Central Connecticut State University to collect coded records of interactive comments and behaviors between instructors and students. Cornelius et al. used trained student observers (mostly female psychology majors) to collect data in 107 college art, social science, and natural science classes. They concluded that the type of curriculum, class size, and time of the semester were related to the type 
and amount of student-faculty classroom interactions. In addition, Cornelius et al. noted that the sex of the student and instructor were not significant variables in determining classroom interactions. They concluded:

It is important to note, however, that despite some of the differences that were found across the three colleges, at none of them was any indication found of consistent differential treatment of male and females students by their instructors. Nor was any indication found that male students consistently "controlled" classroom interaction patterns. In light of these findings it is necessary to evaluate further why the perception of sex differences in classroom participation remains so strong. (p. 196)

In summary, women's limited classroom participation reflects a variety of environmental and individual influences, including gender bias. However, suggestions that gender reflects the dominant influence discouraging female classroom participation remain controversial —other influences deserve equal consideration. As previously noted, this classroom participation review was to neither substantiate nor suppress arguments involving gender bias; it simply suggests that further gender bias research, particularly of student perceptions of gender in the classroom, might be appropriate.

\section{An Analysis of Gender Bias and Instructors}

In the previous review of gender bias and classroom participation, various authors' positions regarding the influence of gender bias on classroom participation usually required limited interpretation — author positions were fairly straightforward. However, in evaluating whether an instructor's gender contributes to gender bias, some literature reviews require deeper reflection to gain insight. 
Hall and Sandler's 1982 report on "The Classroom Climate: A Chilly One for Women?" represents one of the cornerstone and more frequently quoted references in gender bias literature. In their report, Hall and Sandler suggested both male and female faculty marginalize women in the college classroom. They asserted, "Most faculty want to treat all students fairly and as individuals with particular talents and abilities" (p. 2), but recognized:

Both men and women faculty [boldface in original] - even those who are most concerned about sex discrimination—may communicate to their students limiting preconceptions about appropriate and expected behaviors, abilities, career directions and personal goals which are based on sex rather than on individual interest and ability. (p. 2)

In general, Hall and Sandler's report appears to indicate that instructor gender does not strongly correlate to classroom gender bias. However, Hall and Sandler's report is based on anecdotal evidence, and these anecdotes suggest a different perspective.

Hall and Sandler (1982) cited approximately 65 separate "Voices from the Campus" and other anecdotes to substantiate their report's conclusions. These anecdotes subliminally imply that male instructors participate in gender bias more than female instructors. To substantiate this implication, using a simple analysis of the report, Hall and Sandler's anecdotes might be subdivided into four categories:

1. Anecdotes that specifically cited a male instructor as the offender $(20$ anecdotes). Examples included, "Students in one of my classes did a tally and found that male professors called on men more than women students" (Bogart, 1981, no page number given, cited in Hall \& Sandler, 1982, p. 1). A second example stated: 
Professors (all male) consistently call statisticians 'he.' One has said three times in class 'the statistician of the future will wear a mini-calculator on his belt [boldface in original],' even though one half of the class are women training to be statisticians. (Heyman, 1977, p. 131, cited in Hall \& Sandler, p. 8)

Another example asserted, "I told my advisor I wanted to continue towards [sic] a Ph.D. He said, 'A pretty girl like you will certainly get married. Why don't you stop with an M.A.?"' (Bogart, 1981, no page number given, cited in Hall \& Sandler, p. 10).

2. Anecdotes that implied a male instructor is the offender (11 anecdotes).

Examples included, "I was discussing my work in a public setting, when a professor cut me off and asked me if I had freckles all over my body" (Bogart, 1981, no page number given, cited in Hall \& Sandler, 1982, p. 3). A second example was, "I have yet to hear a professor comment on the daily appearance of a male colleague. I have yet to go through a week without some comment pertaining to my appearance" (Women Students' Coalition, 1980, p. 8, cited in Hall \& Sandler, p. 5). Another example was, "I have received comments such as 'You're not really serious about the degree, are you?' Or, 'Well, it doesn't matter if you finish your thesis this year. You probably won't use it for much anyway"" (Bogart, no page number given, cited in Hall \& Sandler, p. 10).

3. Anecdotes that specifically cited a female instructor as the offender (one anecdote). This example asserted, "If [the] instructor can't answer questions (he or she) says, "You girls don't understand"' (Heyman, 1977, p. 59, cited in Hall \& Sandler, 1982, p. 8).

4. Anecdotes that were not gender-specific or did not involve instructors (33 anecdotes). Examples included, "I am even more ashamed to admit that out of my desire 
to be taken seriously as a physicist I was eager to avoid identification with other women students who [sic] I felt could not be taken seriously" (Ruddick \& Daniels, 1977, p.86, cited in Hall \& Sandler, 1982, p. 4). Another example was, "What I find damaging and disheartening are the underlying attitudes. . the surprise I see when a woman does well in an exam-the condescending smile when she doesn't" (Heyman, 1977, p. 126, cited in Hall \& Sandler, p. 6). A final example was, "Women are addressed by first names; men by their last" (Heyman, p. 59, cited in Hall \& Sandler, p. 8).

This analysis of anecdotes suggests that while Hall and Sandler (1982) stated, "Men and women faculty alike may ask questions and then look to men students only" (p. 3), their anecdotal basis for such conclusions may indicate male instructors are more likely to treat women unfairly. Other references also provide anecdotal evidence implying male instructors are more likely to commit gender bias. (See Beagan, 2001, p. 596; Crawford \& MacLeod, 1990, p. 119; Kite \& Balogh, 1997, p. 274; and Smithson, 1990, p. 7.) For example, Beagan's 2001 quantitative study of micro inequities in Canadian medical school provided some anecdotal examples such as, "We were at a woman's bedside, middle-aged woman, and Dr. Jones was trying to demonstrate how to palpate the spleen, and he goes, 'See, just like making love to a woman'" (p. 596). Finally, Sandler et al.'s follow-on "chilly classroom" report in 1996 provided a continued assortment of gender bias anecdotal evidence. Given this apparent conflict in anecdotal evidence versus conclusions, will other research associate male instructors with gender bias behaviors?

Rosenfeld and Jarrard (1985) studied the influence of perceived professorial sexism on the classroom climate. They surveyed 194 undergraduate students in speech communication classes to identify student preferences for liked and disliked classes, what 
climate variables ${ }^{12}$ produced significant discriminators for liked or disliked classes, and student perceptions of professorial sexism. Rosenfeld and Jarrard found that the same two climate variables (professorial supportiveness and involvement) were most relevant for both male and female professors for differentiating liked and disliked classes, although "less exaggerated" (p. 211) for female professors. They also noted "that professors [regardless of gender] in liked classes were perceived as less sexist than those in disliked classes, and male professors were perceived as more sexist than female professors" (p. 209). The study concluded that, "Although perceived sexism in male professors affected students' descriptions of classroom climate, no parallel outcome was found for classes with female professors" (p. 211). Rosenfeld and Jarrard's explanation for this finding included the small number of responses completed for female professors, female professors being perceived as less sexist, and female behaviors (such as smiling) that might offset perceptions of sexism.

Rosenfeld and Jarrard's (1985) methodology may be flawed, thereby limiting the accuracy of their findings. Surveyed participants were asked to report on a single class in which they were a student in the current or previous semester (other than the class in which they completed the survey). Students may have reported on classes based on a variety of biases such as course material, class schedule, or professorial mannerisms, and these biases might have influenced student perceptions of professor sexism. In addition, a class and professor might be labeled as a disliked class, sexist professor based on the opinion of only one student because the study did not seem to combine student opinions of the same class or professor into a single composite score. Rosenfeld and Jarrard's

\footnotetext{
${ }^{12}$ Climate variables included supportiveness, involvement, teacher control, order and organization, completion, and task orientation.
} 
discussion asserted that "preliminary analyses revealed that. . female professors are less sexist than male professors" (p. 211); however, their reported methodology may not support this assertion.

Levy (1982) reviewed problems associated with women surviving in the White male academic environment. Based on anecdotal evidence, she asserted, "Female graduate students are treated differently by male professors" (p. 46). She concluded her work with numerous recommendations of behaviors that women should avoid as college graduate students and stated these behaviors "could permanently damage my professional, equal status if done in a White male institution" (p. 54). Levy's conclusions suggest that White males (e.g., instructors) exhibited biases against women.

Other research efforts do not conclude that instructor gender contributes to classroom gender bias. In their 1990 quantitative study to assess classroom climates, Crawford and MacLeod concluded the classroom climate consisted of three aspects (pp. 109-110): (a) "What the class is like for everybody;" (b) "What the class is like for me [the individual];" and (c) "What the teacher does in the class." They found all three aspects were highly related to class size:

Students' perceptions of the individual climate ("what the class is like for me") and the teacher's contribution ("what the teacher does in the class") are related to teacher gender but not to student gender. Male and female instructors may behave differently, with women somewhat more likely to engage their students in active participation and men somewhat more likely to engage in negative and offensive behavior, but these teacher behaviors are not directed more at women than men students, and they have similar effects for women and men. (p. 110) 
Crawford and MacLeod observed that female instructors created a more participatory environment compared to male instructors, and women were more attuned to interpersonal teaching methods. Male instructors were more likely to use both positive and offensive humor. They concluded, "Our results indicate that students believe neither female nor male faculty actively discriminate against female students" (p. 121).

Sternglanz and Lyberger-Ficek (1977) investigated sex differences in studentinstructor interactions. They observed 60 college classrooms and recorded the interaction characteristics among class participants. Class sizes ranged from 9 to 115 students (mean: 38.0 students in each class). Sixty-two percent of the 2,284 observed students were male, as were 49 of the 60 instructors. Based on their observations, they concluded:

Male students were the majority sex more often than females in classes taught by male lecturers; there was no sex difference for classes taught by female lecturers. Male students engaged in proportionately more student-teacher interactions than female students in male-taught classes; there was no sex difference in femaletaught classes. Neither male nor female professors appeared to respond differently to male and female students. (p. 345)

Boersma, Gay, Jones, Morrison, and Remick (1981) studied differences in college student-teacher interactions. They observed 50 undergraduate classes by matching female-taught courses to male-taught courses based on course material, grade level, and class size. In these classes, $46 \%$ of the 2,163 observed students were female. Boersma et al. recorded classroom interaction characteristics, including the speaker's sex, instructor's sex, length of comment, type of comment (e.g., student statement, student question, instructor call for questions, instructor statement), and other observable interaction 
characteristics. In addition, at the end of the semester, Boersma et al. requested that instructors and students in the 50 observed classes complete questionnaires that included questions on student demographics, attitudes toward instructors, student after-class visitation patterns, and instructor perceptions of student behaviors. In their conclusions, Boersma et al. asserted:

Our observational data indicated no difference in the proportion of interactions in which male and female students were involved in the college classroom, regardless of teacher's sex or class subject. Unlike Sternglanz and LybergerFicek's (1977) subjects, males in our sample were no more likely than females to respond first to a teacher's initiating comment, nor were males any more apt to initiate interaction with the teacher. (p. 782)

Questionnaire results indicated students reported no differences in female or male instructor behavior (a weakly defined attribute) and "observations, enrollment, and attendance data all consistently suggest there is no apparent difference in a teacher's behavior based on students' sex" (Boersma et al., 1981, p. 782). They also observed that student after-class instructor visitations of either male or female instructors correlated to student major and not student gender.

Boersma et al. (1981) discussed differences in their study compared to others such as Karp and Yoels (1976) and Sternglanz and Lyberger-Ficek (1977). They suggested differences in conclusions might be influenced by study methodology, such as the number of classes observed (Karp and Yoels only observed 10 classes), the proportion of men and women in the class, course material, and class matching (by instructor gender, class size, and course material). Boersma et al. summarized: 
Our data clearly do not support the conclusion of earlier studies that differences in student question and participation rates are related to the students' or teachers' sex. While we did find some differences between males and females, these were more a difference of style than of actual participation rates, and occurred mainly in female-taught classes. (p. 783)

Brooks' (1982) research involved quantification of spontaneous verbal behavior to investigate student dominance in female and male professor classrooms. Brooks did not specifically evaluate instructor gender compared to classroom climate and gender bias. However, she did observe differences in male and female student behavior depending on the instructor's gender. Male and female students exhibited similar levels of participation in male instructor classes. In female instructor classes, male students spoke more often and for longer durations than female students. (This finding differs from other research efforts by Boersma et al. [1981] and Sternglanz and Lyberger-Ficek [1977].) Brooks offered several explanations for differences in male student participation patterns, such as male students attempting to reassert dominance over women and the possibility of different teaching styles - male professors emphasized lectures as a teaching methodology while female professors emphasized class discussion.

Brooks (1982) suggested that because female instructors emphasized more participation, male students took the initiative and increased their levels of participation compared to classes taught by a male instructor. However, this theory did not explain why female student participation did not also increase. Other research (Fassinger, 1995) contradicts Brooks' conclusions about female student participation with female 
instructors, and may provide some explanation for why Brooks' concepts of male dominance are not the only plausible explanation for increased male student participation.

Fassinger (1995) also investigated the impact of teaching styles on the classroom climate by conducting quantitative research to assess student and instructor contributions to student non-participation in the classroom. Fassinger surveyed 1,059 students $(60 \%$ of them female) using three basic factors as independent variables: class traits, student traits, and professor traits. She found that female students experienced increased confidence, comprehension, and participation (contrary to Brooks [1982]) in classes with female professors. She also discovered that both male and female students experienced a "chillier" environment in classes with male instructors.

Later in her paper, Fassinger (1995) asserted there were "no significant interaction effects of gender with any study variables" (p. 91), leading her to ask the question, "Do professors have any impact on class participation?" (p. 92). Based on her research, Fassinger suggested an instructor's influence on class participation is based on course design and instructor teaching styles, not instructor gender (similar to the findings of Boersma et al., 1981). She concluded:

We began this inquiry curious about the role gender plays in classroom interaction. We conclude that student gender is a significant component in class participation. Males are more likely to offer comments or raise questions in their classes. Females respond to the emotional climate of a class more than do males, and most importantly, females' participation is related to their confidence. In contrast, faculty gender has no significant impact on class participation. (p. 94) 
This section reviewed various anecdotal, qualitative, and quantitative research efforts on the instructor's role in classroom gender bias. Some research efforts may generate conclusions that are possibly unsupported by research (Hall \& Sandler, 1982; Rosenfeld \& Jarrard, 1985), and quantitative studies can only draw conclusions based on the methodology (e.g., classroom observations) or survey questions asked, leading to different findings (compare Boersma et al. [1981] to Brooks [1982] to Fassinger [1995]). Conflicting findings imply further research is necessary to better understand what students might perceive as inequitable classroom treatment based on gender.

The Influences of Student Age in a Classroom Environment

This dissertation compares the perceptions of female and male graduate students about the influence of gender in the graduate classroom. This study topic implies graduate student perceptions might differ from those of undergraduate students, and suggests that student age and life experiences produce differences in classroom behaviors and the classroom environment. Research studies assert that behavioral differences between older (graduate) students and younger undergraduate college students should exist. The assertion that graduate student behaviors differ from those of undergraduate students provides an important element for this dissertation, because there is limited qualitative research efforts about graduate student perceptions of gender bias.

Research involving the influence of age on student classroom behaviors includes two general areas: (a) changes in female student participation and confidence over 4 years of undergraduate education and (b) differences between traditional (under 25 years old) and non-traditional college students. An analysis of both areas suggests a similar 
conclusion-women gain confidence and participate more in classroom discussions as they grow older.

Fritschner (2000), Heller et al. (1985), and Auster and MacRone (1994) reported similar observations of undergraduate students at each grade level (e.g., freshmen through seniors). Fritschner's research included multiple classroom observations and sociological interviews to evaluate how students and instructors "assign 'meaning' [e.g., definitions of student participation] in the classroom situation" (p. 343). Fritschner discovered that $47 \%$ of females participated in class discussions during upper-level undergraduate courses compared to only $17 \%$ in introductory courses. (Male participation remained fairly consistent in introductory, mid-level, and upper-level courses.) Fritschner also evaluated non-traditional student participation compared to traditional student participation and noted that "non-traditional female students had the highest percentage [participation] increase (23\% at the introductory level to $56 \%$ at the upper-division level)" (p. 347).

Heller et al. (1985) surveyed 429 undergraduate students, including 216 women, to determine student perceptions of Hall and Sandler's (1982) chilly climate. Heller et al.'s research evaluated results from each of the four undergraduate class levels. They concluded that, while male students' confidence does not increase during the 4 years of undergraduate study, "beginning with the sophomore year, women's confidence increases so that, by the senior year, women are significantly more confident of their academic ability than are freshmen women" (p. 455). They also observed that, by graduation, women's experiences reduced the "difference that exists between women and men at matriculation" (p. 458). 
In their 1994 qualitative study of classroom settings, Auster and MacRone investigated students' degree of comfort and the impact it had on classroom participation. Using student interviewers and a survey instrument dominated by closed-ended questions, interviewers reviewed perceived faculty behaviors with 132 randomly selected students. They discovered that "the percentages of both men and women reporting that they felt very comfortable making contributions increased with college year. Although differences by college year were not significant for men, they were so for women" ( $p$. 295 ) and "by the senior year, men and women were nearly equally likely to report feeling very comfortable making contributions in class" (p. 295). Auster and MacRone's findings suggest that women gain assertiveness and increase participation during their years of undergraduate studies.

Howard et al. (1996) and Howard and Henney (1998) researched mixed-age college classrooms and reported that, "due to their different life experiences, nontraditional students' definition of the situation in the college classroom is likely to differ considerably from that of traditional students" (Howard \& Henney, p. 384). In their observations of 247 different students in 13 courses, Howard et al. observed that nontraditional students participated more in class discussions ( $56 \%$ of non-traditional students participated compared to $37.5 \%$ of traditional students). For students making two or more comments in a class, non-traditional students doubled the percent participation rate of traditional students. Other variables such as gender, time of day of the class, and class attendance also influenced class participation; but, for each of three regression models, Howard et al. found that age had the largest effect on classroom participation. 
Howard et al.'s 1996 study examined 13 introductory courses, only 1 of which was taught by a male instructor. In 1998, Howard and Henney's research sought "to fill the void and contribute to the ongoing debate regarding the impact of student age, student gender, instructor gender, and course level on student participation" (p. 385). Their study included courses taught by equal numbers of male and female instructors in introductory through upper-level classes. Their findings supported previous research results by Howard et al. —non-traditional students participated in class discussions at a rate three times greater than that of traditional students. Howard and Henney noted that "class size (attendance) and student age are better predictors of student participation than is student gender" (p. 397). They concluded:

It appears that younger female students experience and interpret the college classroom differently than do older females. Traditional college age students, male or female, participate at a very low rate in courses taught by males; however, when the instructor is female, traditional females are significantly more likely to both initiate interactions and respond to instructor initiated interactions. At the same time, traditional males continue to participate at the same lower rate- thus falling behind their female counterparts in female-taught classes. (p. 397) The literature suggests that undergraduate classroom research may not be generalizable to graduate classrooms where students are older and presumably have more diversified life experiences. Thus, additional research may be required to gain insight and understanding into the influences of gender in graduate classrooms. 
Gender Differences in the Classroom

In his 2004 literature review paper, Blanton evaluated recommendations to reduce college gender bias and asked if these recommendations were consistent with socially constructed differences between male and female college students. His research proposed three differences between men and women in the college classroom: (a) differing gender ethics, (b) classroom communication preferences, and (c) classroom environment preferences.

Gilligan (1982) differentiated between women's ethic of care and men's ethic of justice. Supported by research by Kramarae and Treichler (1990), Markus and Oyserman (1989), and Smithson (1990), women emphasize relations and concern for others. Men prefer an ethic of justice that supports fairness and reciprocity. Men prefer individualism and independence, believing that a classroom environment represents a "level playing field" for both female and male students.

Blanton (2004) surmised that men and women communicate differently in a classroom environment. Women communicate to develop relations and nurture those relations (Kramarae \& Treichler, 1990), and use classroom discussions as an opportunity to be supportive. Men use interactions to further power and personal status (Sandler et al., 1996). Men speak for longer time periods (possibly to dominate discussions) and formulate responses during ongoing interactions. Women formulate responses first and then raise their hands to seek recognition. For non-verbal communications, women take up less space and avoid excessive gestures; men use gestures to display dominance (Frieze \& Ramsey, 1976; Henley \& Thorne, 1977). 
Women and men prefer different classroom environments. As noted by Alemán (1997) and Auster and MacRone (1994), classrooms emphasize masculine values such as aggressive interactions and logical discussions. Women, however, prefer harmony and consensus. Men want assertive arguments that lead to logical conclusions. Women desire classroom environments that develop relations and discuss personal experiences (Kramarae \& Treichler, 1990). Ultimately, women prefer a supportive environment while men prefer an environment that emphasizes individual competence.

Differences between women and men suggest that perceptions of the influence of gender in the classroom will differ between men and women. Differences between female and male students also provide two issues of interest. First, in view of gender bias and women's sensitivity to classroom harmony, women might be expected to register stronger perceptions of classroom gender influence.

Second, quantitative research surveys may not adequately consider perceptual and ethical differences between female and male students. For example, in their 1998 report, Howard and Henney surveyed seven reasons for student participation in classroom discussion, such as seeking clarification, a desire to contribute to the discussion, concern for course grade, and a desire to make the class interesting. However, Howard and Henney's survey did not include responses that reflect women's ethic of care, such as a desire to support other students in the class or to build classroom relationships. The survey also neglected possible male responses such as a desire to establish personal status. ${ }^{13}$ Survey questions limited student response options and possibly led to

\footnotetext{
${ }^{13}$ Survey questions concerning male classroom dominance might be problematic. Men may recognize that, at times, their motivation is to control classroom interactions, possibly challenging the instructor. However, men might be unlikely to fully acknowledge such motivations on a survey instrument.
} 
conclusions that might have differed had female student ethics or male classroom preferences been addressed by the survey instrument.

Literature Review Summary

The literature evaluates gender bias in the graduate classroom. However, in some areas, research may be inconclusive-studies provide differing conclusions about gender bias and its influence in the classroom. For the graduate classroom, where students are older, studies provide limited insight into basic issues concerning the influence of gender. Do women articulate strong objections to gender bias behaviors? Do men understand gender bias and the impact it has on women? Do women tolerate gender bias and accept social inequities that might impede academic opportunities? Do men (consciously or unconsciously) dominate class discussions to retain position or power? The answers to such questions might provide essential information about everyday graduate classrooms, and enable students, faculty, and administrators to develop a course of action that effectively and efficiently reduces classroom gender bias.

Further gender bias research might benefit from additional quantitative studies. However, quantitative research about an emotional, deeply ingrained cultural norm remains problematic. Research (Dey et al., 1996) demonstrates that women's reported sensitivity to gender bias differs from men's. Surveys might require leading questions to focus the target population on gender issues. Women may be socially conditioned to accept gender inequities as "normal," or men may be reluctant or embarrassed to reveal hidden motivations behind marginalizing behaviors. Qualitative research could expand academia's understanding of the classroom experience and support an evaluation of female and male perceptual similarities and differences concerning gender issues in the 
classroom. (In this regard, a shortcoming of quantitative research is the focus on significant differences; this shortcoming minimizes the insight gained from an analysis of similarities.) Research could not only help to enhance classroom egalitarianism, but also might awaken men to social inequities and enlighten them on alternative classroom pedagogies and perspectives of everyday life. As a personal reflection, qualitative research may also demonstrate how little men and women actually understand one another. 


\section{CHAPTER 3. METHODOLOGY}

Introduction

This dissertation investigates doctoral program graduates' perceptions of the influence of gender in the classroom and evaluates the similarities and differences in those perceptions. These comparisons help provide a foundation for future studies of gender influences in the graduate classroom. In addition, an investigation of the similarities and differences between male and female student perceptions toward classroom gender might contribute to a better understand of gender studies in a leadership education program.

Gaining insight into the role of gender (and thus gender bias) in the graduate classroom requires some foundation on which to build. Yet, as noted in Chapters 1 and 2, conclusions concerning the influence of gender bias differ, gender research in the graduate classroom is limited, and undergraduate gender bias research may not be generalizable to the graduate classroom. Therefore, quantitative research questions might lack foundation and quantitative research focuses on statistically significant differences, ignoring similarities in survey responses. As a result, the methodology will emphasize qualitative inquiry and evaluation techniques.

A qualitative dissertation might include face-to-face interviews with 8 to 20 participants. For example, Kuzel (1999) suggested a sample size of 12 to 20 participants in qualitative research. In qualitative dissertations on the related topic of sexual harassment, Krohne (1991) interviewed 8 participants while Hess-Almubarak (1994) interviewed 13. However, this small sample size may not be adequate to capture the broad spectrum of perceptions that reflect a diverse society. Of particular interest are 
potential participants who might have limited or possibly no opinion on gender in the graduate classroom, and would be reluctant to volunteer for a time-consuming, in-person interview. On the other hand, increasing the sample size to capture diverse perspectives may require an excessive amount of time and be impractical for a dissertation research effort. The solution to both these issues could involve using telephone interview techniques instead of in-person interviews. "No opinion" participants might consent to a 30-minute telephone call, and the effort required for a telephone interview is less than inperson interviewing (Shuy, 2002). These factors would allow the researcher to increase the sample size. Although telephone interviews lose the advantages of personal interaction and nonverbal cues (Rubin \& Rubin, 1995), they do support a larger and potentially more diverse participant population. Thus, compared to other qualitative dissertations, this research effort increased the breadth and diversity of respondents while limiting the depth of interviewee responses.

The remainder of Chapter 3 discusses these areas:

1. A brief "executive summary" of the methodology.

2. A review of the dissertation methodology, including generic qualitative studies, telephone interviews, and qualitative interview analysis.

3. The author as a research instrument.

4. Pilot and study interview results.

\section{Methodology Executive Summary}

This section summarizes the methodology, providing the reader a high level overview of research procedures used. The remainder of Chapter 3 provides detailed methodology information. 
As discussed in Merriam (1998), the researcher used a generic qualitative study to investigate the influence of gender in the graduate classroom. Merriam summarized the characteristics of a generic qualitative study as:

- "Includes description, interpretation, and understanding

- Identifies recurrent patterns in the form of themes and categories

- May delineate a process" (p. 12)

To achieve some consistency in interviewee backgrounds, the prospective participants consisted of the 198 former students of USD's Ed.D. Program who graduated between 1990 and 2004. The School of Education mailed Invitation to Participate letters (Appendix A) to graduates. The Invitation to Participate letter included qualitative interview questions (Appendix B), allowing graduates to assess whether they wanted to participate in telephone interviews. ${ }^{14}$ Graduates who volunteered for interviews returned a signed Consent Form (Appendix C) to the researcher. The researcher planned to evenly divide volunteers between the genders, and evenly distribute participants among graduation years. This plan attempted to provide some variation in participant graduate school experiences over time, in addition to gaining the perceptions of both genders.

Prior to beginning actual interviews, the researcher conducted pilot interviews to evaluate and refine qualitative interview questions. The researcher contacted four acquaintances-two current USD Ed.D. Program male students and two recent USD

\footnotetext{
${ }^{14}$ Secrist (1996) and Stanger (1999) mailed qualitative research questions to participants in advance of interviews and observed that some interviewees prepared for the interview ahead of time, using the written questions to prepare notes in advance. Therefore, the Qualitative Interview Questions (Appendix B) deliberately included space after each question for interviewee notes in hopes that interviewees would reflect on gender issues prior to the actual telephone call.
} 
Ed.D. Program female graduates-and refined questions using practice telephone interviews, a one-on-one review session, and a group meeting.

The researcher planned to limit participation to approximately 30 interviewees, 50\% more than Kuzel's (1999) maximum recommended sample size. However, 42 USD Ed.D. Program graduates ( 22 women and 20 men) volunteered to participate and all 42 were interviewed. For each interview, the researcher called the interviewee to arrange a time for the telephone interview and answer any interviewee questions. At the prearranged time, the researcher called the interviewee and conducted the qualitative interview using Appendix B interview questions. ${ }^{15}$ To aid in the interview process, the researcher prepared an Interview Checklist (Appendix D) to improve the consistency and quality of telephone interviews. The researcher recorded each interview using a telephone cassette recording device and a backup digital recording unit.

Because of the large number of interviews, the researcher hired a professional service to transcribe most of the audio interview cassette tapes into a word processing document (the transcription). After receiving each transcription, the researcher compared the transcription document against the digital recording of that interview, making necessary corrections to the transcription. (The researcher mailed a copy of the corrected transcription to the interviewee for proofing and comments.) The researcher then formatted the corrected transcription to provide space for handwritten coding notes. After coding each transcription, the researcher prepared handwritten notes that

\footnotetext{
${ }^{15}$ In some interview quotes, the researcher discusses a written response to a question. Some interviewees mailed annotated qualitative interview questions to the researcher with their Consent Form. During these telephone interviews, the researcher would read each question and the written response to remind the interviewee of his or her written answers. The researcher would then ask the interviewee to discuss the written responses.
} 
summarized the coded transcription data. At the completion of this step, the researcher had produced two 3-inch binders of the coded transcriptions and handwritten summary notes for each of the 42 interviews.

Independent of the transcription preparation, correction, and coding effort, the researcher reviewed each audio interview and prepared handwritten notes of the key interview elements. The researcher used these notes to prepare the interviewee vignettes found in Appendix E.

To analyze interviewee responses to each qualitative interview question, the researcher used data from each of the four data documents - the coded transcriptions and handwritten summary notes, and the handwritten key interview elements and Appendix E vignettes. The researcher reviewed data from each interviewee's response to each question, summarizing the 42 responses in handwritten notes that were used to prepare the interview results and analyses in Chapter 4.

The researcher also evaluated possible relationships among responses to several questions to identify potential themes and alternative analysis subgroups based on nongender interviewee demographics or responses. To perform these evaluations, the researcher prepared a sortable analysis matrix that summarized interviewee response data; Appendix F provides an example of one analysis matrix.

As noted, the remainder of the Chapter 3 provides detailed information about the methodology, attempting to justify the methodology as a valid research process. Topics include a dissertation methodology review, a self-evaluation of the researcher as a research instrument, and a summary of pilot and research interview results. 


\section{Dissertation Methodology Review}

This section reviews the dissertation research methodology, including generic qualitative study concepts and a methodology justification; a discussion of telephone interview methods and a justification for telephone interviews to collect data; and a summary of qualitative analysis concepts.

\section{Generic Qualitative Studies}

Merriam (1998) described five common types of qualitative research in education, including a "basic or generic qualitative study" (p. 11). She stated:

The term basic or generic qualitative study [italics in original] refers to studies that exemplify the characteristics of qualitative research discussed earlier. Many qualitative studies in education do not focus on culture or build a grounded theory; nor are they intensive case studies of a single unit or bounded system. Rather, researchers who conduct these studies, which are probably the most common form of qualitative research in education, simply seek to discover and understand a phenomenon, a process, or the perspectives and worldviews of the people involved. (p. 11)

Caelli, Ray, and Mill (2003) supported the concept of generic qualitative research that might possibly combine several approaches and noted, "Generally, the focus of the study is on understanding an experience or an event" (p. 4). They also observed a growth in the number of generic qualitative studies. More recently, Todres and Galvin (2005) employed a generic qualitative study "to generate a broad thematic understanding of the caring narrative" (p. 2). Their open-ended breadth inquiry "allowed the respondent 
maximum freedom in expressing the range, scope, and boundaries of the complex experience" (p. 5).

While using somewhat different terminology, Patton (2002) appeared to support the concepts of a generic qualitative study. In his discussion of mixing data, design, and analysis (p. 248), Patton observed, "The ideal-typical qualitative methods strategy is made up of three parts: (1) qualitative data, (2) a holistic-inductive design of naturalistic inquiry, and (3) content or case analysis. . . Measurement, design, and analysis alternatives can be mixed to create eclectic designs" (p. 248). In addition to supporting the notion of a generic qualitative study, Patton has suggested such a study might require three elements: qualitative data, a naturalistic inquiry, and a content or case analysis.

Patton (2002) identified three types of qualitative data: interviews, observations, and documents. He defined interviews as "open-ended questions and probes [that] yield in-depth responses about people's experiences, perceptions, opinions, feelings, and knowledge. Data consist of verbatim quotations with sufficient context to be interpretable" (p. 4).

Patton's (2002) second element called for a holistic-inductive design of naturalistic inquiry. Funk \& Wagnalls (1993) defined the noun holism as "the theory that the whole. . is greater than the sum of its parts" (p. 356). Janesick (1994) wrote, "Qualitative design is holistic. It looks at the larger picture, the whole picture, and begins with a search for understanding of the whole" (p. 212). Patton observed that a "holistic approach assumes that the whole is understood as a complex system that is greater than the sum of its parts" (p. 59). 
Ary, Jacobs, and Razavieh (1996) summarized the inductive analysis in qualitative research as:

From the onset of the first interview or observation, the qualitative inquirer is reflecting on the meaning of what he or she has heard and seen, developing hunches (working hypotheses) about what it means and seeking to confirm or disconfirm those hunches in subsequent interviews or observation. This process of data analysis is inductive - it proceeds from data to hypotheses to theory. (p. 481) Inductive analyses uses interview responses to identify themes or patterns and possible hypotheses, and gains insight into a phenomenon (e.g., gender bias) as the sum of the individual interviewee perceptions. As summarized by Lincoln and Guba (1985):

The process of data analysis, then, is essentially a synthetic one, in which the constructions that have emerged (been shaped by) inquirer-source interactions are reconstructed into meaningful wholes. Data analysis is thus not a matter of data reduction [italics in original], as is frequently claimed, but of induction [italics in original]. (p. 333)

Lincoln and Guba (1985) asserted, "But it is precisely because the matter [of naturalistic inquiry] is so involved that it is not possible to provide a simple definition of what naturalism is" (p. 8); they refused to provide a one-sentence definition of naturalism. However, they later presented five axioms of the naturalistic paradigm (pp. 36-38) that can be summarized as follows:

1. The nature of reality is multiple, constructed, and holistic.

2. The interviewee and interviewer inseparably interact.

3. Only time- and context-bounded generalization is possible. 
4. Cause and effect are indistinguishable.

5. Inquiry is value-bounded by the interviewer; investigative paradigms; substantive theory (about gender bias); context; and the congruence of the problem statement, theories, and context.

Lincoln and Guba's (1985) axioms add insight into the substance of a naturalistic study. And, in spite of their apparent refusal to define the term, Lincoln and Guba summarized the "prime directives" (p. 8) of a naturalistic inquiry as follows:

What is salient to us is that, first, no manipulation on the part of the inquirer is implied, and, second, the inquirer imposes no a priori units on the outcome. Naturalistic investigation is what the naturalistic investigator does, and these two tenets are the prime directives. (p. 8)

Patton (2002, p. 40) summarized naturalistic inquiry as a study of natural, realworld situations free of manipulation. Naturalistic inquiry may start with open-ended qualitative questions, but places no constraints on responses. Thus, to meet the intent of Patton's second qualitative strategy element, a study must include a (holistic) sample population with limited participant constraints such as gender, date of graduation, minority status, or age. Interviews are unstructured, unconstrained, but responses may not be unbiased. In keeping with Lincoln and Guba (1985), the study should also recognize the role of interview participants, carefully reconsider attempts to generalize, and acknowledge the possibility of multiple constructed realities.

Patton's (2002) third element requires a case or content analysis. Patton's use of the term content analysis appears to differ from other authors. For example, van Manen (1990) defined a content analysis as: 
Content analysis posits its criteria beforehand by identifying certain words or phrases that reveal, for example, the extent to which a text displays gender bias. The method of content analysis implies that it already knows what the meaning is of the subject that it examines: for example, the meaning of "gender," "femininity," or "sexuality." (p. 29)

Ary et al. (1996); Denzin and Lincoln (1998); Lincoln and Guba (1985); and Merriam (1998) agree with van Manen's definition. However, later in his book, Patton (2002) generalized content analysis "to refer to any qualitative data reduction and sensemaking effort that takes a volume of qualitative material and attempts to identify core consistencies and meaning [boldface in original]... . The core meanings found through content analysis are often called patterns or themes" (p. 453). These patterns and themes inductively result from the meticulous coding, analyses, and reflection on interview data.

Lincoln and Guba (1985) seemed to support Patton's (2002) generalization of content analysis. They noted, "Inductive data analysis bear remarkable similarities to content analysis [italics in original], a process aimed at uncovering embedded information and making it explicit" (p. 203). Lincoln and Guba asserted that inductive data analysis included two essential subprocesses: unitizing and categorizing. "Unitizing is the process of coding [italics in original]" while "categorizing is a process whereby previously unitized data are organized into categories that provide descriptive or inferential information" (p. 203). Lincoln and Guba observed that categorizing was equivalent to Glaser and Strauss' (1967) constant comparative method. Other authors propose similar analysis methods using different terminology. van Manen (1990) referred 
to a similar concept as a "Theme analysis'.. .the process of recovering the theme or themes that are embodied and dramatized in the evolving meaning and imagery of the work" (p. 78). Todres and Galvin (2005) also used a "thematic analysis" (p. 3) in their generic qualitative study.

In summary, to synthesize Patton's (2002) requirements for a generic qualitative study, the study should use qualitative interview data, a holistic naturalistic inquiry, and inductive, thematic analysis. Thus, the following key study characteristics of this dissertation seem to satisfy Patton's synthesized requirements:

1. Telephone interviews to collect qualitative data.

2. Diversity in the sample population demographics that support a holistic inquiry.

3. A natural, unconstrained inquiry free from manipulation.

4. An inductive data analysis featuring coded interview transcripts to identify themes and, possibly, hypotheses.

\section{Telephone Interviews in Qualitative Research}

The researcher conducted qualitative interviews using the telephone instead of traditional in-person interviews. The researcher selected telephone interviews for four specific reasons:

1. To encourage participation by graduates who might have limited opinions on gender in the classroom and would decline an in-person interview for that reason. During preparations for pilot interviews, one potential participant wrote suggesting that the researcher interview another graduate: "But the gender thing was never big for me really. Perhaps I've just spent too much time in a male dominated workplace" (personal e-mail, 
10 December 2004). It is just this type of respondent that the researcher hopes to reach through the convenience of a telephone interview. As noted by Greenfield, Midanik, and Rogers (2000), the telephone interview "is widely considered to increase respondent perceptions and anonymity" (p. 278).

2. To increase the sample size without creating an unacceptable administrative burden involving time for interviews and interview analyses. Lavrakas (1998) suggested that telephone interviews should last between 20 and 30 minutes while in-person interviews may last 30 to 40 minutes or longer.

3. To allow graduates who may not live in the local San Diego area to participate in the research effort.

4. To minimize the possibility of any unintentional intimidation on the part of the interviewer during an in-person interview-recall the interviewer is 6 feet 6 inches tall.

This section addresses three issues regarding using the telephone for qualitative interviews: (a) the principal advantages and disadvantages of telephone interviews, (b) the suitability of telephone interviews for qualitative research, and (c) whether there are appropriate techniques that improve telephone interview effectiveness.

\section{Telephone Interviews - Advantages and Disadvantages}

Several authors discuss the advantages of telephone interviews. Some, such as Luvrakas (1998), provide a detailed discussion on telephone survey sampling and interviewing methods but emphasize quantitative surveys. Others suggest advantages to telephone interviews that may be applied to qualitative surveys, including:

1. The anonymity of telephone interviews to support sensitive topics (Fenig, Levav, Kohn, \& Yelin, 1993; Greenfield et al., 2000; Sturges \& Hanrahan, 2004). For 
example, Sturges and Hanrahan observed, "For topics that are sensitive because they are embarrassing, interviewing by telephone may increase data quality" (p. 108).

2. The ability to interview hard-to-access respondents (Fenig et al., 1993; Rubin \& Rubin, 1995; Sturges \& Hanrahan, 2004). Rubin and Rubin observed that telephone interviews may be necessary when time or money (to travel) limit accessibility (such as USD graduates living outside the San Diego area).

3. Reduced time and money required for telephone interviews (Fenig et al., 1993; Miller \& Cannell, 1982; Rubin \& Rubin, 1995; Shuy, 2002; Sturges \& Hanrahan, 2004). The interviewer planned to interview approximately 30 graduates - the time required to transcribe and analyze this number of qualitative interviews was of concern to the interviewer.

Telephone interviews do have limitations. For example, the onset of respondent fatigue may occur more quickly for telephone interviews. Some limitations, such as potential respondents that may not have telephone access (Lavrakas, 1998), do not seem likely for this dissertation's sample population. However, the limitation of greatest concern involves the interviewer's inability to benefit from nonverbal respondent cues (Garbett \& McCormack, 2001; Miller \& Cannell, 1982; Rubin \& Rubin, 1995; Sturges \& Hanrahan, 2004). As observed by Rubin and Rubin, "In phone interviews, all sorts of conversational cues are missing, making for difficult interviewing under the best of circumstances" (p. 141).

As will be discussed, there are techniques to minimize the absence of nonverbal cues. Before examining telephone interview techniques, however, the researcher will 
discuss whether the literature provides examples of acceptable qualitative data collection from telephone interviews.

\section{The Telephone Interview in Qualitative Research}

The literature suggests that telephone interviews may be suitable for data collection in qualitative research. The literature on this issue can be divided into two groups: (a) references that assert the telephone interview is suitable for researching complex questions and sensitive issues, and (b) articles that specifically compare results from in-person and telephone qualitative interviews on a single research subject.

Qualitative research involves in-depth responses to somewhat open-ended questions. By their very nature, qualitative questions are complex compared to quantitative survey questions. Some research indicates that telephone interviews are suitable for complex and emotional topics (such as gender bias). For example, Fenig et al. (1993) "compared telephone with face-to-face interviewing in a community psychiatric survey" (p. 896). Fenig et al. studied demoralization among women who survived the Holocaust in World War II compared to pre-state Israeli women from the World War II era. Their discussion asserted, "The willingness of Holocaust survivors to discuss aspects of their lives by telephone indicates that this method can be used, with the necessary precaution, even in highly sensitive populations" (p. 897). This assertion demonstrates that telephone interviews may provide acceptable data for sensitive topics and complex questions.

Rogers (1976) tested the quality of responses for telephone versus in-person interviews. Her research addressed several "nagging questions" (p. 51) about telephone interviews including, "How good are telephone interviews? Can the interviewer ask 
complex questions and get the answers just as well on the telephone as in person?" (p. 51). Rogers measured interview quality as the "ability to answer complex items, willingness to provide personal information, response validity, and consistency of information" (p. 52). Rogers' research examined the perceptions of New York City local citizens to an initiative that decentralized city services. Rogers summarized, "The results of this experiment show that the quality of data obtained on complex attitudinal and knowledge items as well as on personal items is comparable to that collected in person" (p. 65).

Other research also supports telephone interviews for complex issues or sensitive topics. Greenfield et al. (2000) evaluated alcohol consumption estimates for telephone and face-to-face surveys and concluded that "results offer some reassurance that telephone interviews can perform in a generally equitable fashion to more costly inperson interviewing" (p. 283). Greenfield et al. did recognize the need for increased representation among lower income respondents-an attribute that may not be applicable to individuals holding a Doctor of Education degree.

This discussion is not intended to suggest that telephone interviews provide a superior data collection methodology compared to in-person interviews. As summarized by Shuy (2002), face-to-face interviews appear "better suited than telephone interviewing for handling complex issues" (p. 552) and "eliciting answers to the most sensitive questions" (p. 553). This discussion is merely intended to suggest that telephone interviewing is adequate for complex questions and sensitive issues and for the purposes of this dissertation. 
Unlike quantitative surveys, qualitative interviews involve in-depth responses to open-ended questions. Therefore simply citing successful telephone quantitative surveys as justification for using this medium seems inadequate. However, some references that compare telephone to in-person interview results in qualitative research do support the telephone interview methodology.

Sturges and Hanrahan (2004) compared telephone and face-to-face qualitative interviewing during a study of the perceptions of jail visitations. They performed 43 semi-structured interviews of correctional officers and inmate visitors, including 22 telephone interviews. They compared the data quality of the two interview methods based on metrics such as interview transcript page counts, and on a qualitative evaluation of the nature and depth of responses. They concluded "that mode of interview did not influence the data to any significant degree" (p. 113). Sturges and Hanrahan noted that "comparison of the interview transcripts revealed no significant differences in the interviews. With some qualifications, we conclude that telephone interviews can be used productively in qualitative research" (p. 107). They also observed that respondents were satisfied with their methodology choice (telephone versus in-person interviews) and respondents felt "they were able to express themselves freely" (p. 113).

Garbett and McCormack (2001) performed a "small-scale qualitative telephone interview study. . .to explore [nurse] practitioners' views of practice development" (p. 94). Using snowball sampling, they interviewed 26 practitioners to identify the attributes of practice development. They concluded, "The telephone interview approach proved fruitful to the extent that it was manageable given the limited resources available. 
However, the brevity of the conversations meant that deeper exploration of ideas was difficult" (p. 96).

Sobo, Simmes, Landsverk, and Kurtin (2003) discussed the "qualitative telephone interview component" (p. 399) of a rapid assessment ${ }^{16}$ of children's health programs. They used qualitative interviews of "key informants" (p. 401) after discovering that program records were inadequate and would not support a planned quantitative analysis. Sobo et al. trained interviewers on appropriate techniques such as building rapport with the interviewee and the use of silence to "coax the interviewee to continue" (p. 402). They interviewed 48 respondents using seven focused, open-ended questions. Interviews typically lasted between 45 and 60 minutes. Sobo et al. noted the results were not generalizable because of the small sample size, but did conclude that telephone interviews "immensely enriched the picture that the evaluation team formed. . of [community-based organization] CBO-based outreach and enrollment efforts" (p. 407). They observed:

Properly executed, rapid telephone interviews can provide the kind of rich narrative data necessary for illuminating complex, dynamic processes and various stakeholder groups' views. Further, the use of focused open-ended questions firmly guides interviewees to speak to the topic of interest while allowing them to organize their answers in terms of their own priorities as well as to talk about aspects of the topic in question that are important to them. (p. 405)

\footnotetext{
${ }^{16}$ Sobo et al. (2003) referred to this effort as a "rapid assessment" because of limited time duration to collect and analyze qualitative data. In addition, interview results were not transcribed verbatim, but were analyzed using note-taking and preliminary analysis techniques.
} 
Telephone Interview Techniques

While the research indicates that telephone interviewing may be adequate for complex, sensitive issues, the question arises, "Are there appropriate techniques that improve telephone interview effectiveness?" Several sources suggest there are such techniques and these techniques, along with the researcher's experiences during pilot interviews, were incorporated into the Interview Checklist (Appendix D).

Rubin and Rubin (1995) suggested that researchers should establish a foundation for telephone interviews in advance of the actual interview. They advocated an advance telephone call to allow the interviewee to ask questions about the project and to establish a rapport between the interviewer and interviewee. (The researcher used an advance telephone call to answer interviewee questions and schedule the actual interview.)

This advance telephone call also develops a sense of commitment, permitting the interviewee to "understand the interview is a serious undertaking" (Miller \& Cannell, 1982, p. 253). In addition to commitment, Miller and Cannell advocated giving instructions to the interviewee to clarify the interview goals and tasks toward achieving that goal. The Invitation to Participate letter (Appendix A) and Interview Checklist introduction (Appendix D) reinforced interviewee instructions. Miller and Cannell also evaluated "feedback to the respondents on how well they have carried out the response task" (p. 255); however, their conclusions suggest that feedback has limited benefits "over and above commitment and instruction" (p. 264).

Several authors discuss lack of nonverbal cues as a disadvantage of telephone interviews. To overcome this shortcoming, Shuy (2002) suggested constant verbal responses and the use of casual, conversational language including "abundant feedback 
markers" (p. 550) to ensure the interviewer verbally acknowledged interviewee responses. Sobo et al. (2003) used silence (by the interviewer) to encourage the interviewee to continue. They also suggested an "echo probe" (p. 402) that repeated the interviewee's last word or phrase in the form of a question and encouraged further interviewee responses.

Shuy (2002) suggested interviewers avoid "I" power statements such as "I want you to. .." (p. 550). Shuy evaluated power language during interviews and his "study revealed that male interviewers used 'I' power statements far more frequently on the telephone (but not in person) than did female interviewers, suggesting a mode weakness of the telephone interviews, at least for male interviewers" (p. 550).

The researcher incorporated power statements and other reminders into the Interview Checklist (Appendix D). Some reminders, such as emphasizing verbal responses (feedback markers), positive feedback and avoiding power words, were based on literature recommendations. Other reminders were based on the researcher's review of pilot interview results. These reminders provided a reference to the researcher during interviews, with the intent of improving interview quality.

Qualitative Interview Analyses

Qualitative interview analyses were fairly straightforward. The researcher coded qualitative interview transcripts to identify "information about the data and interpretive constructs related to the analysis" (Merriam, 1998, p. 164). As noted by Rubin and Rubin (1995), "Coding is the process of grouping interviewees' responses into categories that bring together the similar ideas, concepts, or themes" (p. 238) of the research effort. 
Coding categories were fairly simple and emphasized the intent of the research - to investigate the research questions of this dissertation.

Following transcript coding, the analysis first evaluated each interviewee, looking for responses to questions that indicate common perceptions toward classroom gender influences. While the dissertation emphasized an evaluation of women's and men's perceptions of gender in the classroom, the final assessment also considered other analysis groups besides gender.

Qualitative questions 5 through 13 in Appendix B provide data concerning the influences of gender in the classroom. In analyzing interview transcripts, the researcher evaluated each question individually by analyzing the similarities and differences in the perceptions of women and men. For each question, the researcher also summarized potential themes revealed in interviewee responses.

After individual question evaluations, the researcher evaluated the questions as a whole, comparing similarities and differences in women's and men's responses based on all interview data. This analysis step used a view from the balcony compared to the dance floor (Heifetz, 1994) and provided a holistic evaluation of interview data. As noted by Rubin and Rubin (1995), the data analysis ends when the researcher has "found overarching themes and put them in the context of broader theory and answered the question 'So what?'” (p. 256).

\section{Jerry Blanton as a Research Instrument}

Patton (2002) observed that,

Critics of qualitative inquiry have charged that the approach is too subjective [italics in original], in large part because the researcher is the instrument of both 
data collection and data interpretation and because a qualitative strategy includes having personal contact with and getting close to the people and situations under study. (p. 50)

However, such arguments ignore the insight gained from differing perspectives. Eisner (1991) asserted that "rather than regarding uniformity and standardization as the summum bonum, educational criticism views unique insight as the higher good" (pp. 3435). Eisner observed that "individuals experience the world in unique ways" (p. 48) creating new knowledge. These differing perspectives based on unique personal experiences provide a rich diversity to our life world. Thus, the researcher becomes a key ingredient in the recipe for a qualitative study. Manning (1999) summarized the researcher as an instrument stating, "Different from quantitative paper and pencil surveys or instruments, the human as instrument is able to sense feelings, probe promising areas, and closely observe the nuances of human communication" (pp. 19-20).

As the researcher, my role may provide a unique perspective on classroom gender bias based on two somewhat conflicting points of view. While I was completing my graduate coursework, I was oblivious to gender bias and its marginalizing impact on women. During my early coursework at the University of San Diego as well as three previous college degree efforts, I never studied gender issues. I was among the students who dominated classroom interactions; I frequently interrupted others (including the instructor); I was inattentive to nonverbal communications and cues. I saw the classroom from one perspective-my own - and believed participation and interaction based on Gilligan's (1982) ethic of justice produced an egalitarian environment. 
My dissertation research forced me to consider a second point of view. Gender bias, as I am learning, is inequitable. And, while the literature at times is inconclusive, my research and personal experience lead me to conclude that gender bias influences classroom interactions. However, my literature research does not provide the necessary insight to better understand the essence of gender bias-I have not yet discovered the fundamental values that appear to reinforce the classroom masculine value system that subjugates women. Therefore, I am open to "see what is to be seen" (Eisner, 1991, p. 33), to "see a situation from several points of view" (Eisner, p. 47) such that "each frame of reference provides a different view and a different interpretation of a state of affairs" (Eisner, p. 49).

This dual perspective has led to important personal reflection. I now ask myself, "Can I recognize gender influences from two points of view-that of the predator and that of the prey?" Furthermore, can I suppress my instinctive (aggressive) reactions and play the role of observer, rather than participant, in qualitative interviews? As Patton (2002) noted, "Qualitative inquiry, because the human being is the instrument of data collection, requires that the investigator carefully reflect on, deal with, and report potential sources of bias and error" (p. 51). This will be my challenge-to set aside biases. In this effort, "self-awareness, then, can be an asset in both fieldwork and analysis" (Patton, p. 64). If nothing else, my research has increased my self-awareness. There is an ethic of care (Gilligan, 1982)-I must balance awareness of this ethic against a more familiar ethic of justice.

Given my background, some may question my ability to successfully conduct a qualitative study of gender bias. Such concerns are not surprising. In my defense, I offer 
the following observations. First, the purpose of this dissertation is to gain insight into the influence of gender in a graduate education program. After extensive research, I have gained some measure of scholarly knowledge on the topic. I recognize my past shortcoming and have a strong desire to complete this effort with a high degree of academic professionalism and not produce an effort characterized by male dominance.

Second, my target population consists of graduates from an accredited doctoral program. Therefore, I believe any insincerity or academic inadequacies on my part should be quickly challenged by members of my sample population. To a certain extent, my target population increases the challenges of a qualitative dissertation.

Finally, I believe that Maslow's self-actualization may be unachievable-we all have many "rough edges" in our character. Trying to achieve self-actualization is a noteworthy effort, however, and may represent a continuous process of "filing off the rough edges." My past perceptions of gender represent a rough edge - this research reflects my "hardened-steel file."

Held (1997) discussed the male-dominated sex/gender system as a fundamental variable in social life throughout recorded history and in all cultures. She noted that the sex/gender system

takes on different forms and intensities in different cultures, periods of history, and classes. But beneath the variations, all societies divide themselves into the masculine and the feminine, and constrain individuals into what are taken to be the appropriate roles and relations for men and for women. Now that the sex/gender system has become visible to us, we can see it everywhere. (p. 883) I have recently had this experience-I now see the sex/gender system everywhere. 
Study Interview Results

This section reviews pilot interview results and provides a high-level, pseudoquantitative evaluation of the qualitative interviews used to collect actual research data.

\section{Pilot Interviews}

To test qualitative survey questions and refine researcher telephone interview techniques, two current USD doctoral students and two USD Ed.D. Program graduates participated in practice interviews and qualitative survey reviews. The researcher was acquainted with the four participants from common professional, personal, or academic endeavors, and trusted the participants to provide challenging feedback and question responses during interview and review sessions. The researcher conducted practice interviews over a 4-week period, scheduling sessions at the participants' convenience. The researcher provided all participants with an advance copy of the Invitation to Participate letter (Appendix A) and draft qualitative survey questions.

The first two sessions involved practice, one-on-one telephone interviews with the two male participants. Both male participants were current USD doctoral students working on their dissertations. Both students attended the researcher's dissertation proposal defense and were somewhat familiar with the research topic. During the practice interviews, the researcher and participant not only asked and answered survey questions, but also engaged in interactive discussions of the questions and telephone interview techniques. Based on male participants' feedback, the researcher added new demographic questions and revised the wording of several qualitative survey questions.

Approximately 2 weeks after the initial practice interviews, the researcher met with a female 2002 USD Ed.D. Program graduate to review the revised interview 
questions. The researcher and graduate reviewed each question word-for-word and discussed not only the question's wording, but also her responses to the questions. Following this review session, the researcher revised the qualitative survey instrument again and sent an updated copy to the fourth practice interview participant.

The fourth participant was a female 2003 USD Ed.D. Program graduate. This practice session began with a mock telephone interview designed to simulate an actual data-gathering interview. During the mock interview, the qualitative survey questions and answers were tape recorded without stopping to evaluate questions and researcher interview techniques. The mock interview lasted approximately 17 minutes. The researcher and participant then discussed the interview questions and interviewer techniques. Interestingly, during this informal discussion, the participant revealed an example of classroom gender bias that was not discussed in her interview question responses.

Following the mock interview, the researcher reviewed interview tapes and prepared a list of questions to discuss with the pilot interview participants. The researcher then held a dinner meeting with three of the four participants to get additional questions answered and the participants' final comments. The conversation among the two female participants, the researcher, and a male participant revealed a diversity of opinions about gender influences in the classroom. It also, to some extent, supported the researcher's plan to conduct many short telephone interviews (gaining breadth and diversity in responses) rather than a few in-depth, in-person interviews. 


\section{Qualitative Interview Results}

The University of San Diego mailed 183 Invitation to Participate letters (Appendix A) to former USD Ed.D. Program students who graduated between 1990 and 2004. USD did not have valid addresses for 15 graduates. Of the 198 graduates from 1990 to $2004,62 \%$ were female. Forty-two graduates from the four USD Ed.D. courses of study volunteered to participate in the dissertation research yielding a $23 \%$ response rate. Of the 42 volunteers, 22 were women and 20 were men. The volunteers included seven Canadians, one Pacific Islander, and seven graduates who do not reside in California.

The average interview lasted 31.3 minutes with a standard deviation of 10.6 minutes. On average, men's interviews lasted slightly longer than women's interviews (32.6 minutes compared to 30.1 minutes). The shortest interview (a male graduate) lasted 13 minutes and 4 seconds. The four longest interviews were all more than 46.5 minutes and were conducted with men; the longest female interview was slightly less than 43 minutes. In total, the researcher recorded 21 hours and 55.4 minutes of interviews.

The researcher used two independent reviews of each interview in support of data analyses. For the first review, because of the large volume of interview material (495 pages of single-spaced transcripts), the researcher hired a transcription service to review and transcribe 39 of the 42 interviews. (The researcher transcribed three interviews before painfully recognizing the need for assistance.) For each transcribed interview, the researcher compared the transcription to the audio interview and corrected the transcription as necessary. The researcher then coded the corrected transcriptions and 
prepared hand-written notes that summarized each interview and interview coding results.

In a second independent review, the researcher reviewed each audio interview and prepared hand-written notes of key interview elements. The researcher then used these notes to write a vignette of each interviewee (Appendix E). Thus the researcher prepared four documents to aid in interview data analyses: the transcribed, coded interviews and associated hand-written summary notes, and the vignettes and associated hand-written notes.

\section{Methodology Summary}

This dissertation is based on the observation that current literature provides few qualitative investigations of gender bias in the graduate classroom. As a result, comparisons of female versus male perceptions of classroom gender bias are rare and limit academia's understanding of the influence of gender in a graduate classroom. The methodology proposes to investigate the influence of gender as a proxy for classroom gender bias, using a generic, qualitative study and telephone interviews to collect data. The dissertation compares the perceptions of 42 female and male doctoral program graduates and examines similarities and differences in response to selected questions. By analyzing these responses, the researcher hopes to evaluate and characterize gender influences in the graduate classroom and also provide some insight into gender studies as a recommended element of a leadership study program. 


\section{CHAPTER 4. INTERVIEW RESULTS AND ANALYSES}

\section{Introduction}

This dissertation investigates gender bias in the graduate classroom by studying the influence of gender in the USD Ed.D. Program. Chapters 1 and 2 documented shortcomings in comparative research on female and male perceptions of the influence of gender in the graduate classroom. Chapter 1 proposed research questions that investigated the similarities and differences of these perceptions. A research question also asked what these perceptions might reveal about a leadership education program and efforts to reduce classroom gender bias. Chapter 2 reviewed gender bias literature, noting inconsistencies in research findings and the scarcity of qualitative studies of gender influences in the graduate classroom. Chapter 3 proposed a generic qualitative research methodology, using telephone interviews to collect data from USD Ed.D. Program graduates. The researcher used this methodology to examine the perceptions of classroom gender influences for 42 volunteers who graduated from the USD Ed.D. Program between 1990 and 2004.

Chapter 4 records the results of the 42 interviews. Initially, the chapter analyzes responses to demographic questions, and then reviews responses to questions concerning interviewee perceptions of the influence of gender in the graduate classroom. For gender influence questions, each review includes a brief introduction and analysis, followed by copious quotes from the interviewees to substantiate analysis results.

Next, Chapter 4 reviews four alternative analysis groups that do not necessarily use gender as a requirement for group membership. Finally the chapter considers the 
question, "What appears to drive interviewee perceptions of gender in graduate classrooms?"

Throughout the remainder of the dissertation, the researcher liberally quotes interviewee responses to retain their thoughts related to gender influences, and to preserve the rich interview results for further study. Some quotes contain apparent inconsistencies; at times, the researcher allows these quotes to stand on their own merit with limited comment.

\section{Interview Results}

This section documents the 42 interview responses, including an analysis of demographic questions and each gender influence question (Appendix B, questions 5 through 13). In a later section, the researcher discusses the influence of powerful personalities, focusing on two faculty members code-named Drs. Buckley and Hopper. These two faculty members are frequently referenced in the responses to gender influence questions.

\section{An Analysis of Demographic Questions}

The qualitative interviews included four demographic questions:

1. What year did you graduate from USD?

2. Could you tell me how old you are today? Less than 40 years old? In your 40 s? In your 50s? Sixty or older?

3. What has been your primary career field since you graduated?

4. Did you consider yourself a minority in the classroom and, if so, what was your minority status? 
Table 1 summarizes the interviewees' year of graduation. For graduation years from 1990 to 1994 there were 13 volunteers; from 1995 to 1999 , there were 19 volunteers including 7 Canadians; and from 2000 to 2004, there were 10 volunteers. Using 5-year periods based on year of graduation to evaluate interviewee distribution appears consistent with USD Ed.D. Program history. In the early 1990s, the program had a smaller enrollment and men filled most key faculty positions. In the late 1990s, the USD Ed.D. Program transitioned to a new dean and added new faculty members. In the early 2000 s, the program grew in enrollment and grant funding. Curriculum changes, such as the elimination of a comprehensive examination, appeared to influence student interactions. Therefore, the (roughly) even distribution of volunteers over 5-year periods appears to adequately represent the USD Ed.D. Program from 1990 to 2004.

For question 2, each interviewee's age is included in her or his vignette. (One interviewee declined to provide her age.) Thirty-one of the remaining 41 interviewees are now 50 years old or older, reflecting a mature USD Ed.D. Program student population. On average, interviewees were 8 years younger when they graduated. Only one interviewee was less than 30 years old at graduation.

Each interviewee's vignette provides her or his primary career field since graduation. Interviewees can be characterized as white-collar professionals. Twenty-two interviewees work (or have worked prior to retirement) in the education field.

Question 4 asked interviewees whether they considered themselves a minority in the classroom during their doctoral studies at USD. More than half (22) said yes. Several interviewees identified more than one minority status category. 
Table 1. Interviewees by year of graduation.

\begin{tabular}{|c|c|c|c|}
\hline \multirow[b]{2}{*}{ Year } & \multirow[b]{2}{*}{ Total Graduates } & \multicolumn{2}{|c|}{ Interviewees } \\
\hline & & Female & Male \\
\hline 1990 & 18 & 3 & 3 \\
\hline 1991 & 12 & 1 & 2 \\
\hline 1992 & 10 & 2 & 0 \\
\hline 1993 & 9 & 1 & 0 \\
\hline 1994 & 13 & 1 & 0 \\
\hline 1995 & 11 & 1 & 2 \\
\hline 1996 & 9 & 1 & 2 \\
\hline 1997 & 12 & 2 & 1 \\
\hline 1998 & 18 & 3 & 4 \\
\hline 1999 & 12 & 1 & 2 \\
\hline 2000 & 8 & 0 & 0 \\
\hline 2001 & 19 & 1 & 1 \\
\hline 2002 & 11 & 0 & 0 \\
\hline 2003 & 25 & 4 & 2 \\
\hline 2004 & 11 & 1 & 1 \\
\hline Totals & 198 & 22 & 20 \\
\hline
\end{tabular}


The most commonly identified minority status categories were age, gender, and race or ethnicity. Eight interviewees felt they were minorities because they were older than other students. One interviewee believed he was a minority because he was younger than other students. Eight interviewees identified race or ethnicity as their minority status. Three of these individuals identified their minority status as White male. In addition to the three White males, six other interviewees identified gender as their minority status.

Six graduates said they were minorities because of their background or education, such as science, engineering, or the military. Other identified minorities included nationality, happily married, physical disability, religion, and life perspective.

Thomasina stated that, as a White Canadian female, she was in the majority and “it certainly wasn't a disadvantage." Ben observed, "Well that's a loaded question, you know. What is a minority? I've always been a minority in the sense that I don't fit in anywhere."

Two interviewees identified sexual orientation as their minority status. One graduate from the early 1990s asserted, "I was told very clearly that if the administration knew about my sexual orientation they would prevent me from graduating."

In summary, interviewee minority status provided unexpected results and, to some extent, suggested diversity in the classroom. More than half of the interviewees identified themselves as a minority, and minority statuses included traditional majority categories such as White male. Graduates were not only aware of gender, ethnicity, and race as a minority status, but also recognized age as a contributor to class diversity. In addition, informal, post-question discussions with interviewees suggested that some identified minority statuses might surprise other interviewees. 


\section{An Analysis of Gender Influence Questions}

Interview questions 5 through 13 investigated the interviewees' perceptions of the influence of gender in the graduate classroom. The researcher analyzed each question and compared the similarities and differences in female and male responses. In conjunction with this comparative analysis, the researcher attempted an evaluation of each question to gain broader insight into classroom gender influences.

\section{Question 5}

Question 5 asked, "When you think back to your classroom studies at USD, what is the first thing that comes to mind?" The question was purposely benign, designed to develop a rapport between interviewer and interviewee. However, the question had a subtle objective: Will gender bias examples be among graduates' first memories of the classroom?

As shown in Figure 1, interviewee responses could be grouped into five general categories: (a) interviewees who described a positive USD Ed.D. Program experience; (b) interviewees who described a negative USD Ed.D. Program experience; (c) interviewees who were critical of the USD Ed.D. Program; (d) interviewees who questioned their ability in their doctoral studies; and (e) interviewees who provided other responses.

Immediately prior to asking question 5 , the researcher would emphasize that the interview questions pertained to the interviewee's perceptions of the influence of gender in the graduate classroom. However, only 6 of the 42 responses included gender topics. One possible explanation for the few responses that include gender might simply be that question 5 did not specifically ask for interviewees' recollections of gender in the classroom, therefore interviewees' responses reflect a general summary of their 
perceptions of the USD Ed.D. Program. Another explanation suggests that gender topics may be less important to interviewees when asked about their first recollections of their doctoral studies. A third explanation suggests that the relative insignificance of individual gender bias micro inequities does not produce a lasting impression on USD Ed.D. Program graduates. Therefore graduates might not immediately recall seemingly insignificant classroom events involving gender inequities. For this question, the lack of an aggressive response identifying gender bias influences in the classroom might suggest that gender influences on graduate studies require further quantitative research to identify the statistical significance of gender influences in the graduate classroom.

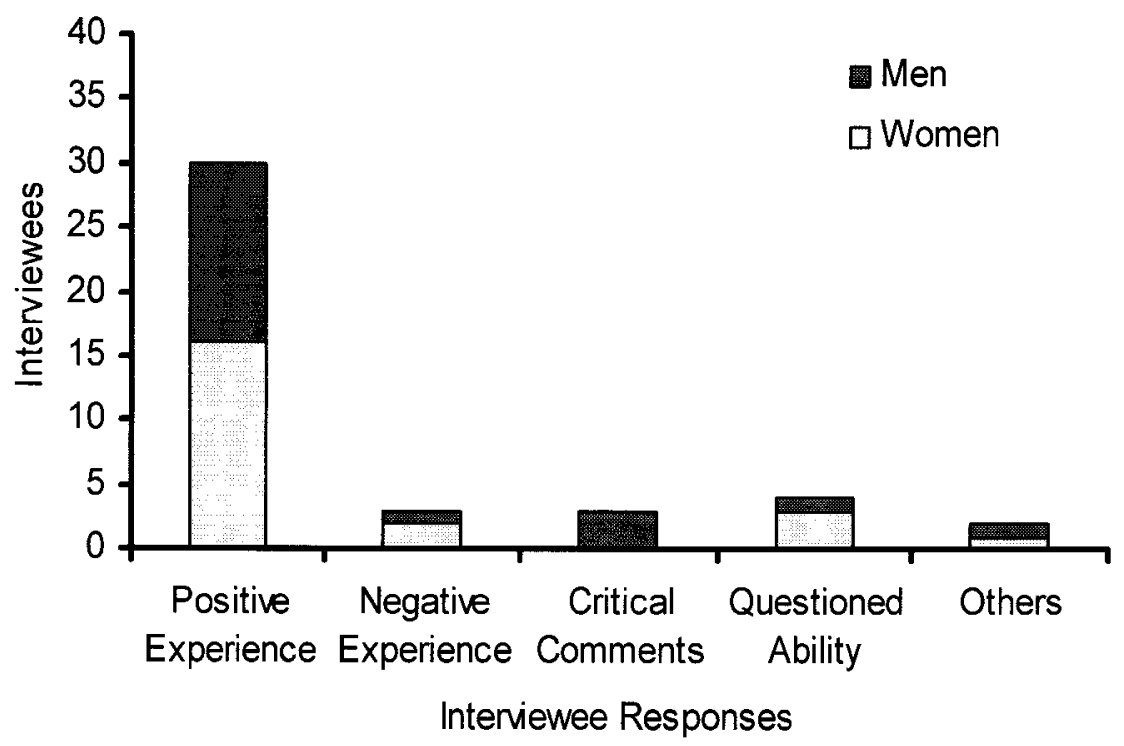

Figure 1. Interviewee Responses to Question 5

The number of female and male responses in each category were approximately the same. Thirty interviewees commented on a positive educational experience and 
described the USD Ed.D. Program as diversified, enjoyable, challenging, stimulating, and exciting. Sixteen women and 14 men favorably replied to question 5 . Three graduates did not enjoy their graduate studies at USD. Three graduates criticized the USD Ed.D.

Program. Two of these graduates had been contract USD instructors and their criticisms of USD appeared to mix fact with their experience as contract instructors. Four graduates described their Ed.D. experience as positive, but initially questioned their ability to academically succeed. Two interviewee responses to question 5 could not be easily categorized with the other responses. Table 2 provides sample responses from each of the five categories.

Table 2. Data table for interviewee responses to question 5.

\begin{tabular}{|l|l|}
\hline \multicolumn{2}{|c|}{ Interviewees Who Described a Positive USD Ed.D. Program Experience } \\
\hline James & $\begin{array}{l}\text { James stated, "I think it [the USD Ed.D. Program] was a real } \\
\text { opportunity. . .I'd go back tomorrow for a post-doctorate course." }\end{array}$ \\
\hline Lewis & $\begin{array}{l}\text { When asked if he enjoyed his experience at USD, Lewis replied, "Yes, } \\
\text { absolutely; I just loved it." Lewis explained that his reason for } \\
\text { pursuing a doctorate degree "was purely self development." }\end{array}$ \\
\hline Mary & $\begin{array}{l}\text { Mary enjoyed the "collaborative atmosphere" at USD: "I felt that my } \\
\text { core beliefs about education and learning were valued and I had a sense } \\
\text { of, uh, being included within the classroom setting. In other words, I } \\
\text { felt socially safe." }\end{array}$ \\
\hline Rose & $\begin{array}{l}\text { Rose commented that she enjoyed the "excitement and the challenge } \\
\text { and the stimulation of being in classes with people that I respected; [she } \\
\text { quietly added] I miss it." }\end{array}$ \\
\hline Don Interviewees Who Described a Negative USD Ed.D. Program Experience \\
\hline $\begin{array}{l}\text { A Latino male, Don began his response by expressing dissatisfaction } \\
\text { with his doctoral program experience: I felt "very dissatisfied in the } \\
\text { way I was supported," Don observed, "I was not in the club." He talked } \\
\text { of White privilege and was particularly critical of White women. Don } \\
\text { was financially disadvantaged; he worked full-time and took out } \\
\text { "massive loans" to complete his studies. Don was frustrated that he } \\
\text { "did not have the full-time student experience." }\end{array}$ \\
\hline $\begin{array}{l}\text { A health industry professional, Jane was not prepared for the transition } \\
\text { to a leadership studies curriculum. She described her effort as "lots of } \\
\text { hard work." She asserted that she enjoyed the people associated with } \\
\text { the USD Ed.D. Program and that the program "was interesting and } \\
\text { challenging, but it was not a lot of fun." }\end{array}$ \\
\hline
\end{tabular}




\begin{tabular}{|c|c|}
\hline Lorrie & $\begin{array}{l}\text { Lorrie described her graduate experience as a "constant struggle." She } \\
\text { routinely criticized masculine reading lists and study material: "I felt } \\
\text { erased as a woman. Our experiences [as documented in feminine } \\
\text { reference material] were not valued." (Lorrie's physical disabilities } \\
\text { combined with campus facility access limitations also contributed to } \\
\text { her frustration.) Lorrie commented, "I did not enjoy my [USD Ed.D. } \\
\text { Program] experience." }\end{array}$ \\
\hline \multicolumn{2}{|c|}{ Interviewees Who Were Critical of the USD Ed.D. Program } \\
\hline Wilfred & $\begin{array}{l}\text { Wilfred expressed frustrations about the "number of females in the } \\
\text { program" and about taking several courses from Dr. Hopper that } \\
\text { emphasized "the female lens"--in Wilfred's words, "enough is } \\
\text { enough." Wilfred also observed that Dr. Buckley put "roadblocks in } \\
\text { front of it [the International Studies Cohort]" although Wilfred } \\
\text { "respected his [Dr. Buckley's] knowledge as an informed person." }\end{array}$ \\
\hline \multicolumn{2}{|r|}{ Interviewees Who Questioned Their Ability In Their Doctoral Studies } \\
\hline Penelope & $\begin{array}{l}\text { Penelope recalled "feeling like I wasn't as smart as the other students." } \\
\text { She attributed this feeling to being "put down" because of her gender. }\end{array}$ \\
\hline Ronald & $\begin{array}{l}\text { Ronald expressed reservations concerning "how far out of my... } \\
\text { comfort zone and my knowledge zone educational leadership could } \\
\text { go." }\end{array}$ \\
\hline Thomasina & $\begin{array}{l}\text { Thomasina commented on "the terror of getting there [USD]," opining, } \\
\text { "I was totally out of my league." }\end{array}$ \\
\hline \multicolumn{2}{|r|}{ Interviewees Who Provided Other Responses } \\
\hline Agnes & $\begin{array}{l}\text { Agnes asserted, "I went in [to the USD Ed.D. Program] with a different } \\
\text { goal" (to get published). "I tended to be a bit of a maverick. . .I broke } \\
\text { a lot of rules along the way." Agnes went on to discuss her personal } \\
\text { goals and her dissertation experience. }\end{array}$ \\
\hline Ben & $\begin{array}{l}\text { Ben commented on his program-long conflict with Dr. Buckley and his } \\
\text { personal views on his studies and his dissertation efforts. }\end{array}$ \\
\hline
\end{tabular}

As noted, six graduates discussed gender topics in response to question 5. Lorrie criticized course reading material, classified the class instruction as masculine, and felt coursework ignored women's experiences. Edward discussed ongoing gender debates in an introductory course. He commented on the strong voices representing both genders and observed that some students (women) did not want to understand other perspectives on issues. Penelope stated that Dr. Buckley made her feel uncomfortable, primarily by his tone of voice: "I think it wasn't so much what was said, but how it was said." Ronald 
observed that "the emphasis of the [USD Ed.D.] program on feminism was a real stretch," but concluded, "I was able to cope with it." Rose described a powerful event in which a female student was unprepared to deal with being the focal point of a class discussion and subsequently left the USD Ed.D. Program. Rose observed that this woman "dropped out strictly because of what she [the woman who left the program] would consider. . .a gender issue." Finally, Wilfred felt the program had an imbalance between male and female participants, including faculty and students.

Men appeared more critical of the USD Ed.D. Program and women were more likely to question their ability to complete in a doctoral studies effort. While the number of responses in these two categories was relatively small, the researcher speculated that these responses along with data from Table 2 suggest that women might be willing to (sometimes apprehensively) adjust to an environment while men might be more critical when the environment does not meet their expectations. For example, Mary felt "socially safe" while Wilfred became frustrated by repeated exposure to the "female lens."

\section{Question 6}

Question 6 asked, "If I asked you to tell me about one classroom event that you remember involving gender in the classroom, what is that event and why?" For this question, one difference in responses was interesting. When the female interviewees described gender-related events, those events involved both women and men as key players. When the male interviewees described gender-related events, they portrayed women as the key players. In every case, the 10 males described events in which the key players were women. For 6 of 11 women, however, the key players in the described events were also women. This difference in perception suggests women might take a 
broader view of gender issues and gender events, whereas men might limit their perceptions of "gender events" to those events involving women as the focus of attention. Another explanation suggests that men do not view classroom events involving other men as gender-related events. Men might consider such classroom events as influenced by the other man's personality or background, and may not readily acknowledge that men might be subject to classroom gender influences.

Question 6 also produced similarities in female and male responses. Of interest, approximately equal numbers from both genders had limited recollections or opinions of classroom events involving gender. This figure suggests that in a graduate classroom, approximately one in four students might be insensitive to the subtleties of gender bias and this insensitivity might contribute to a demeaned student's frustration.

As shown in Figure 2, male and female responses can be subdivided into four categories: (a) responses that described a class event involving gender (10 women and 10 men); (b) responses that asserted the interviewee had limited opinions on classroom gender (six women and five men); (c) responses that discussed gender-related classroom assignments or study material (three women and four men); and (d) non-gender related responses (three women and one man).

Table 3 provides supporting data for each of these four categories. For completeness, the table includes a quote from each interviewee that had limited opinions on gender influences in the classroom. 


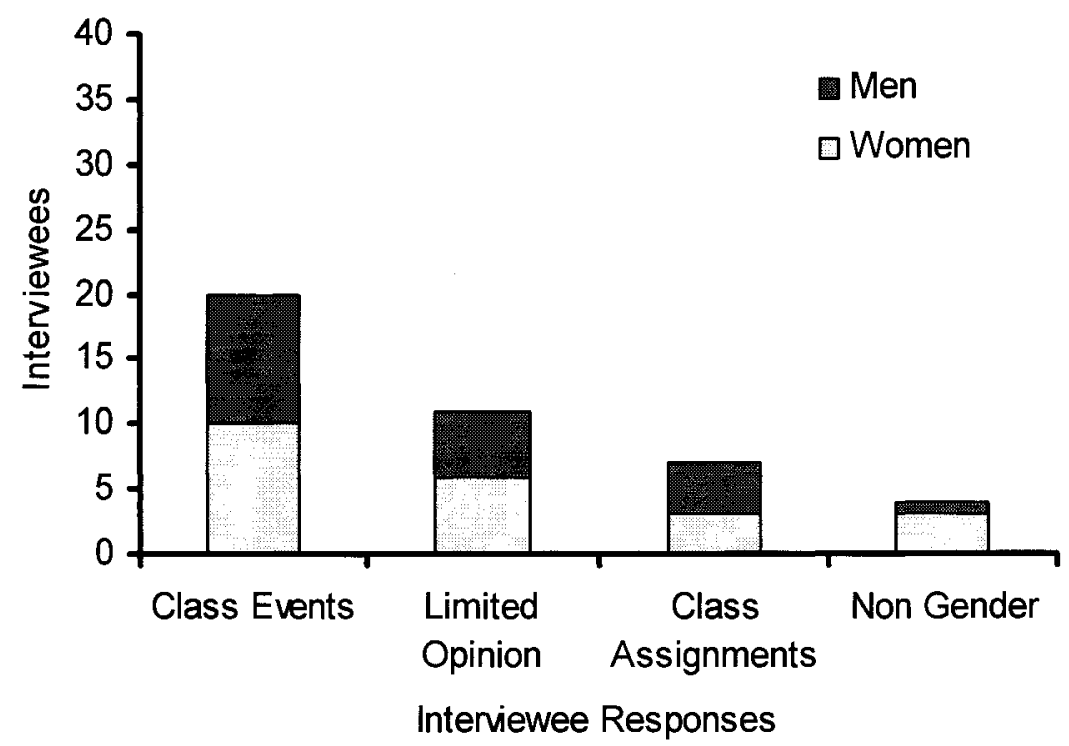

Figure 2. Interviewee Responses to Question 6

Table 3. Data table for interviewee responses to question 6.

\begin{tabular}{|l|l|}
\hline \multicolumn{1}{|c|}{} & Responses that Described a Class Event Involving Gender \\
\hline Agnes & $\begin{array}{l}\text { Agnes recalled the night that Dr. Buckley "was so hard on a young } \\
\text { woman. . who happened to be quite quiet and shy that he literally drove } \\
\text { her right out of the program." She noted that Dr. Buckley was hard on } \\
\text { the woman: "When he finally got her to answer something, he jumped } \\
\text { on her. . .I thought it was unbelievably cruel." }\end{array}$ \\
\hline Annie & $\begin{array}{l}\text { Annie recalled two female students who were very vocal about gender } \\
\text { bias in the classroom. In response to this negativity, she wrote a paper on } \\
\text { androgynous leadership and asked why not "focus on leadership as } \\
\text { leadership and not separate [out] females." }\end{array}$ \\
\hline Ben & $\begin{array}{l}\text { Ben recalled a class with a strong feminist who presented a "feminist } \\
\text { interpretation" of the lyrics to "The Greatest" sung by Whitney Houston. } \\
\text { Ben observed the song was written about Muhammad Ali by Wes } \\
\text { Montgomery, not Whitney Houston. The woman "took great offense to } \\
\text { my correcting her, and I considered that to be a gender issue. . .I just } \\
\text { maybe burst her little bubble by pointing out it [the song] was written by } \\
\text { a man." }\end{array}$ \\
\hline Don & $\begin{array}{l}\text { Don told of a male guest presenter who, during his lecture, proceeded to } \\
\text { remove his tie and coat, unbutton his shirt, and sample the vegetables } \\
\text { and dip. Don considered this potential faculty member to be posturing } \\
\text { and called the presenter a "Tom Jones impersonator." He expressed } \\
\text { concern that "there were some folks who seemed oblivious [to the }\end{array}$ \\
\hline
\end{tabular}




\begin{tabular}{|c|c|}
\hline & $\begin{array}{l}\text { presenter's informality], mostly the instructor who was a White } \\
\text { woman." Don commented that the White female instructor "represents } \\
\text { to me the gender part of the White woman who supports whatever the } \\
\text { male-you know, alpha male-the White male archetype leader will } \\
\text { do." }\end{array}$ \\
\hline Mario & $\begin{array}{l}\text { Mario recalled a class event with a positive outcome. One class } \\
\text { emphasized making participants uncomfortable and trusting in the } \\
\text { silence of the class. Mario described a "pro female" woman as "tough } \\
\text { and hard around the edges, especially toward males." The woman felt } \\
\text { she was not equitably treated and "males didn't appreciate her input." } \\
\text { Mario said the woman experienced an epiphany during the class, telling } \\
\text { a male student, "It finally dawned on her all this time that she was } \\
\text { basically had that [protective] shell up all the time." }\end{array}$ \\
\hline Mitch & $\begin{array}{l}\text { Mitch recalled criticizing class reading material that he felt was "quite } \\
\text { inadequate." Two female students became angry and the female } \\
\text { instructor sided with the two women. Mitch later noted that gender } \\
\text { issues were openly discussed throughout the USD Ed.D. Program, and } \\
\text { asserted that the "Rost model [(Rost, 1991)], you might characterize it as } \\
\text { having an awful lot of female values in it. . . It talks about relationships; } \\
\text { it talks about inclusion." }\end{array}$ \\
\hline Penelope & $\begin{array}{l}\text { In contrast to the other female interviewees' gender-related experiences, } \\
\text { Penelope recalled a positive event involving gender. She talked of a } \\
\text { course on women in leadership, describing it as an "empowering and } \\
\text { wonderful, wonderful course. . . That class was life changing for me." } \\
\text { Penelope then described a lunch with her daughter, who was also a } \\
\text { graduate student at a major university. Their luncheon discussions } \\
\text { (which completely left out Penelope's husband) focused on "parts of the } \\
\text { world where women were really, really diminished; really } \\
\text { disadvantaged." }\end{array}$ \\
\hline \multicolumn{2}{|c|}{ Responses from Interviewees with Limited Opinions on Classroom Gender } \\
\hline $\mathrm{Al}$ & $\begin{array}{l}\text { "To be honest, I can't think of one [event] that I would relate to gender } \\
\text { at all." }\end{array}$ \\
\hline Betsy & $\begin{array}{l}\text { "I don't remember things that seemed very specific to gender. . . It is } \\
\text { something I really didn't notice that much; you know, gender } \\
\text { differences." }\end{array}$ \\
\hline Buford & $\begin{array}{l}\text { "I do not remember an act that I thought was gender in the classroom. } \\
\text { Now, in outside discussions with people, obviously when you got to } \\
\text { know them a little better, then obviously gender showed." }\end{array}$ \\
\hline David & $\begin{array}{l}\text { "There just weren't that many times when I. . .could say that gender } \\
\text { really got into it all. It doesn't cross my mind that often." }\end{array}$ \\
\hline Gina & $\begin{array}{l}\text { "I would not even know how to answer that one [question 6]. I'm } \\
\text { sorry. . . . I felt that [gender] doesn't pertain to me." }\end{array}$ \\
\hline Grace & "I don't know that I can recall an event that involved gender." \\
\hline Jane & $\begin{array}{l}\text { When asked if she could recall a class event involving gender, Jane } \\
\text { replied, "No, not particularly." }\end{array}$ \\
\hline Marie & "I can't really think of anything negative [about gender] to report." \\
\hline
\end{tabular}




\begin{tabular}{|c|c|}
\hline Mary & "I don't remember. . . any particular [gender-related] event." \\
\hline Stennis & $\begin{array}{l}\text { "When I knew I was going to have this interview, I kept trying to think } \\
\text { [of] some sort of gender thing I could tell you about; I really can't." }\end{array}$ \\
\hline Thomas & "I couldn't recall any of them [events] dealing with gender issues." \\
\hline \multicolumn{2}{|r|}{ Responses that Discussed Gender-related Classroom Assignments } \\
\hline Nancy & $\begin{array}{l}\text { Nancy's written answer was, "Discussion of leadership styles. The } \\
\text { differences between men and women." She also recalled talking "about } \\
\text { power and how men do it differently than women because they have } \\
\text { their own sense of power. . . . Women come at it [leadership] from a } \\
\text { different angle." }\end{array}$ \\
\hline Phil & $\begin{array}{l}\text { Phil discussed an insightful course asserting, "I mean it was a life } \\
\text { changing experience, actually. I began to much more understand the } \\
\text { female experience." }\end{array}$ \\
\hline Richard & $\begin{array}{l}\text { Richard talked of his adult development class and Carol Gilligan's } \\
\text { (1982) book that "challenged the linear paradigm of the prior father of } \\
\text { adult development." }\end{array}$ \\
\hline Ronald & $\begin{array}{l}\text { Ronald recalled a course in which he gave a presentation on "the } \\
\text { challenges of a female superintendent in an old-boys-network-dominated } \\
\text { school district." }\end{array}$ \\
\hline \multicolumn{2}{|r|}{ Non-gender Related Responses } \\
\hline Carol & $\begin{array}{l}\text { Carol, a First Nation Canadian, remembered a class in which she was } \\
\text { able to use her history background to contribute to the class discussion: } \\
\text { "I was a minority and I felt, wow, I've got knowledge and I am able to } \\
\text { share it." }\end{array}$ \\
\hline Diana & $\begin{array}{l}\text { A Hispanic woman, Diana recalled a class in which a White female } \\
\text { professor asserted that "gender was the most impacting of all the } \\
\text { differences." In response, an African American male student "became } \\
\text { very upset and said that no, that he thought race was." In the follow-on } \\
\text { discussion, Diana asked, "Why are we even bothering to compare which } \\
\text { discrimination is more impacting or less impacting. . . As a woman } \\
\text {.. you view it [discrimination] as a gender issue. As a Hispanic woman, } \\
\text { you are [a] little confused." }\end{array}$ \\
\hline Goldie & $\begin{array}{l}\text { Goldie discussed an incident with a student who was a Naval officer } \\
\text { noting, "I was not used to involving myself with the military model." }\end{array}$ \\
\hline James & $\begin{array}{l}\text { James recalled the three First Nation (indigenous population) women in } \\
\text { his International Studies Cohort. He felt these women enriched classes } \\
\text { with "the culture of the Canadian aboriginal-also the status of gender, } \\
\text { the place of gender in that culture." }\end{array}$ \\
\hline & 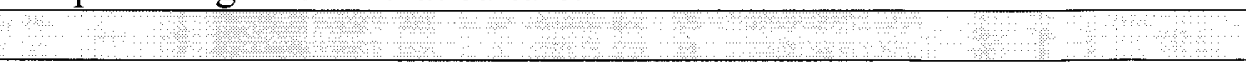 \\
\hline
\end{tabular}




\section{Question 7}

Question 7 asked, "For interactions with fellow students of the opposite gender, what do you remember about these interactions during your classes at USD?" As shown in Figure 3, four interviewees had negative opinions of their peers of the opposite gender.

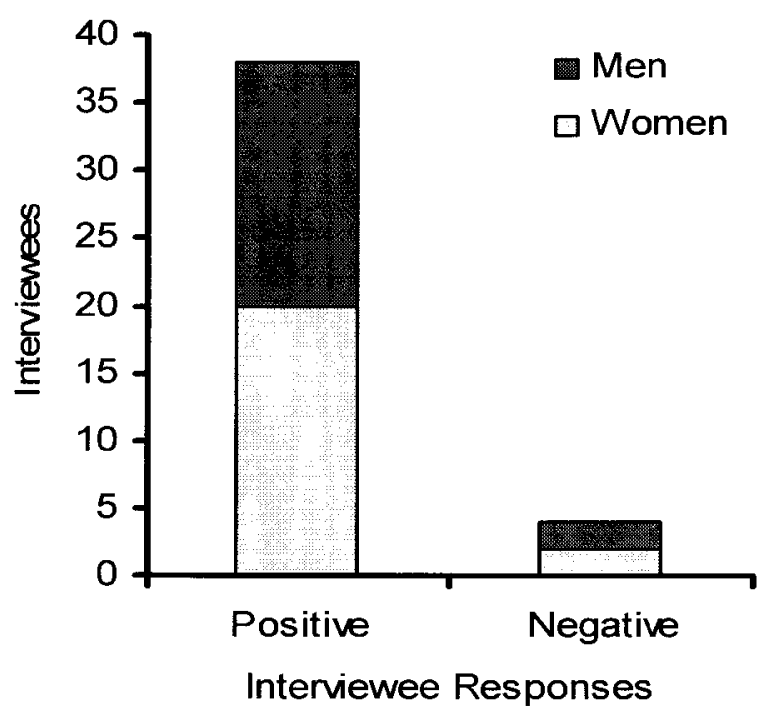

Figure 3. Interviewee Responses to Question 7

Like questions 5 and 6 , this question provided the opportunity for a very broad range of non-specific answers and, like questions 5 and 6, responses from women and men proved to be numerically more similar than different. This observation suggests a possible common theme: If viewed strictly from the number of responses to interview questions based on broad, generic categories, women and men appear to have similar views of gender influences in the graduate classroom. However, as shown in the vignettes (Appendix E), interviewees represent diverse backgrounds and life experiences. This individuality, this diversity suggests that doctoral program research data subdivided and 
analyzed by gender might represent too broad a generalization. Such research might carefully reconsider the applicability of gender as a common denominator.

Table 4 provides representative data from interviewee responses to question 7 . Four interviewees provided somewhat negative responses and the researcher summarized all their answers. The researcher also summarized other responses as representative of the positive answers. While this dissertation investigates gender influences, responses sometimes imply that other biases influence classroom environments. Diana and Barbara alluded to the influence of ethnicity and race while Carl and Nancy introduced the influence of age in the classroom environment. Agnes and Grace identified their perspective as androgynous; as will be discussed later, androgynous women viewed gender in the classroom somewhat differently.

Finally, two interviewees could not recall much about interactions with the opposite gender. In response to what he remembered about interactions with females, Mitch replied, "nothing in particular." Danielle asserted, "I don't remember a single male except Dr. Buckley, and he wasn't a student."

Table 4. Data table for interviewee responses to question 7.

\begin{tabular}{|l|l|}
\hline \multicolumn{2}{|c|}{ Interviewees Who Expressed Positive Opinions of their Peers } \\
\hline Agnes & $\begin{array}{l}\text { Agnes felt interactions "were all very positive. I was particularly close } \\
\text { to some of the minority men." Agnes added, "I get along great with } \\
\text { men. I'm a tomboy. ....that's the language that I understand." However, } \\
\text { Agnes was also observant and objective. For some male students whom } \\
\text { she later called "male jerks," Agnes noted "quite a few of the White } \\
\text { males in our program were quite pompous and egotistical. . . .I find that } \\
\text { kind of a male particularly abrasive and I simply don't deal with it." } \\
\text { Agnes considered herself a "great communicator. ... grew up with } \\
\text { three brothers." She concluded her answer stating, "There were others } \\
\text { [male students] that I enjoyed very much, but I don't know; it just } \\
\text { seemed so competitive." While Agnes felt comfortable with men, she } \\
\text { did not embrace some aspects of a masculine classroom such as } \\
\text { competitiveness. }\end{array}$ \\
\hline
\end{tabular}




\begin{tabular}{|c|c|}
\hline Annie & $\begin{array}{l}\text { A tomboy and sports buff, Annie felt she had good relations with male } \\
\text { students with one exception. A certain male student, who sometimes } \\
\text { brought his wife to class, was demeaning to women including his wife: } \\
\text { "The way he treated his wife was the way he treated the women in the } \\
\text { program.... which was kind of [for him to] listen and then [for the } \\
\text { woman to] not be heard." }\end{array}$ \\
\hline Barbara & $\begin{array}{l}\text { An African American, Barbara commented, "we were learning from } \\
\text { each other.... It was more than just gender, it was the background," } \\
\text { including students' professional positions. }\end{array}$ \\
\hline Carl & $\begin{array}{l}\text { Carl reflected on the mix between older and younger students during } \\
\text { overseas studies: "I can remember Hong Kong; the kids [younger, } \\
\text { mostly female students] would all go out... The older guys probably } \\
\text { had a cigar and brandy at the Mandarin Hotel." }\end{array}$ \\
\hline David & $\begin{array}{l}\text { David viewed class interactions with women as "very positive" but } \\
\text { believed that gender was not a significant classroom influence: "I don't } \\
\text { recall ever discussing in the classroom the whole issue of gender of } \\
\text { this, that, and the other, although we have gotten into it when we got } \\
\text { into some ethics and value issues." }\end{array}$ \\
\hline Diana & $\begin{array}{l}\text { Diana replied, "With my fellow students, they [interactions] were } \\
\text { always comfortable." When asked to reflect on the word comfortable, } \\
\text { Diana responded, "It doesn't matter to me if they were males or White. } \\
\text { Now, interestingly enough, they were all White except for me in my } \\
\text { study group." }\end{array}$ \\
\hline Grace & $\begin{array}{l}\text { Grace found interactions with male students "very challenging, very } \\
\text { stimulating." She observed that "my perceptions now may be flavored } \\
\text { by the fact that, since ' } 86, \text { I have worked in a male-dominated world." }\end{array}$ \\
\hline James & $\begin{array}{l}\text { James considered this a tough question, recalling his cohort of } 4 \text { men } \\
\text { and } 11 \text { women: "We kind of treated each other as contemporaries } \\
\ldots \text {..We were all in this together, and maybe that's the cohort idea in } \\
\text { that gender has no basis within a cohort." James continued his answer } \\
\text { with thoughts about diversity commenting, "I would not think that it } \\
\text { [gender] played a significant role [in the classroom]... . maybe I'm } \\
\text { coming from a competitive basis because I'm male.". }\end{array}$ \\
\hline Nancy & $\begin{array}{l}\text { Nancy noted she was the youngest in the cohort and "gender never } \\
\text { became an issue." However, she did observe, "Age did play a bit of a } \\
\text { role in it because everybody did look out for me... .I felt all right about } \\
\text { it. . . . but they [fellow students] gave me space to grow on my own." }\end{array}$ \\
\hline Richard & $\begin{array}{l}\text { Richard viewed the classroom as genderless, observing, "My } \\
\text { perception is they [students] were human beings first and gender } \\
\text { secondary and gender was not a primary factor in my developing my } \\
\text { perceptions." He considered gender to be "invisible" because "from my } \\
\text { perception. . I'm not thinking 'Oh, this is a woman speaking,' it's a } \\
\text { person speaking." Richard closed his answer with, "I wasn't filtering } \\
\text { based on gender." }\end{array}$ \\
\hline Rose & $\begin{array}{l}\text { Rose commented: } \\
\text { I had some male colleagues who I found intellectually }\end{array}$ \\
\hline
\end{tabular}




\begin{tabular}{|c|c|}
\hline & $\begin{array}{l}\text { stimulating and with whom I developed wonderful, ongoing } \\
\text { friendships. I had some interaction with male colleagues who I } \\
\text { thought were complete idiots. And I guess in my arrogance } \\
\text { figured that they were unaware. . . of their status in society and } \\
\text { the privilege that they have. . . I used the use the word } \\
\text { arrogance a lot. I don't any more; I just use ignorance. }\end{array}$ \\
\hline $\begin{array}{l}\text { Thomasina } \\
\text { and Wilfred }\end{array}$ & $\begin{array}{l}\text { Thomasina and Wilfred lived in the same Canadian town and their } \\
\text { responses were very similar. The interviewer asked Thomasina whether } \\
\text { female students were stronger than males and she replied, "Oh } \\
\text { absolutely yes. . . Our group had a really strong female component." A } \\
\text { member of the same cohort, Wilfred commented (in response to } \\
\text { another question), "and of these [students] of the brightest ones were } \\
\text { females by far. . . They outshone us [men] in terms of their ability." }\end{array}$ \\
\hline \multicolumn{2}{|r|}{ Interviewees Who Expressed Negative Opinions of their Peers } \\
\hline Ben & $\begin{array}{l}\text { When asked what he remembered about classroom interactions with } \\
\text { women, Ben replied, "Well, not a whole lot. Like I say, there were. . .a } \\
\text { number of feminists. There were. . . several openly gay women. I didn't } \\
\text { personally have any problems with them." Ben went on to describe an } \\
\text { incident involving a woman who was "rather feminine" and } \\
\text { became very upset when she found out I had gotten a divorce } \\
\text { from my wife and had another girlfriend. I had the impression- } \\
\text { this could be totally wrong. ... that she [the rather feminine } \\
\text { student] thought she should have had a shot at it [being Ben's } \\
\text { girlfriend]. }\end{array}$ \\
\hline Don & $\begin{array}{l}\text { Don felt interactions between gender, ethnicity, and race were "linked. } \\
\text { I mean kind of raceousnicity." Like Lorrie, Don found support from his } \\
\text { three closest friends (all females) of his study group: "We all kind of } \\
\text { shared for different reasons the sense of, call it minority, if not in the } \\
\text { dominant group for different reasons." While his study group was } \\
\text { supportive, for others, Don observed, "I cannot experience nice } \\
\text { folks. . .not really engaging in some of the issues that I really cared } \\
\text { about." }\end{array}$ \\
\hline Lorrie & $\begin{array}{l}\text { Lorrie asserted that, "for the most part, my recollections are that the } \\
\text { male students followed the lead particularly of the male instructors." } \\
\text { However, she praised the men in her study group, describing them as } \\
\text { "supportive, understanding of women's experiences at the school and } \\
\text { very supportive. It was like an oasis." }\end{array}$ \\
\hline Maureen & $\begin{array}{l}\text { Maureen recalled two younger men who "had absolutely. . .no respect } \\
\text { for some of those teachers and classes." During Maureen's studies, } \\
\text { classes were smaller and students knew each other. Maureen } \\
\text { commented that the two males would gripe and complain_-"they } \\
\text { would badmouth the classes." Maureen described the two men as } \\
\text { "pompous and arrogant." }\end{array}$ \\
\hline
\end{tabular}


Question 8

Question 8 asked, "In your graduate classes, did you ever perceive that men and women were treated differently and why do you feel this way?" As shown in Figure 4, 16 interviewees felt women and men were treated differently in graduate classes.

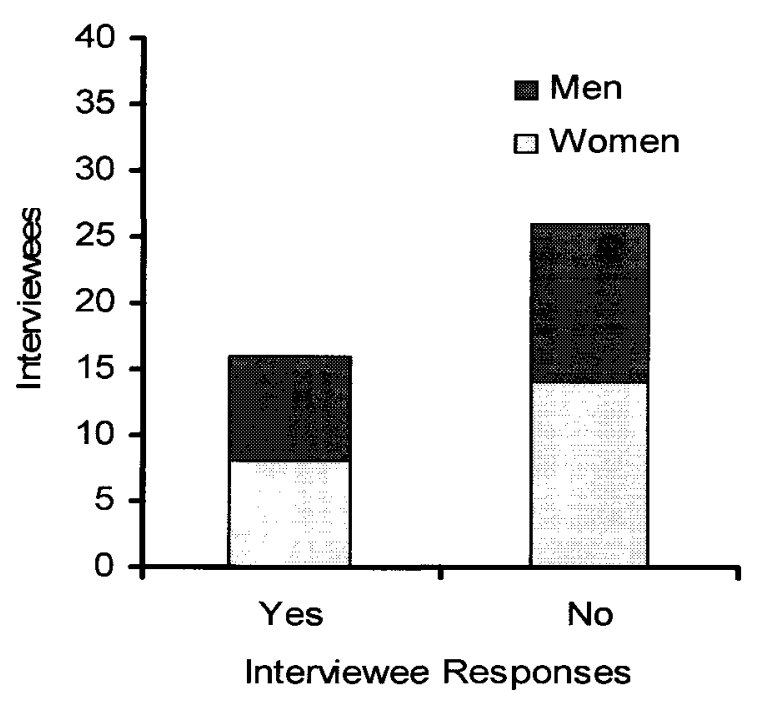

Figure 4. Interviewee Responses to Question 8

Numerically, responses continue to show more similarities than differences in female and male interviewee answers. Twenty-six did not believe that women and men were treated differently in the classroom. Sixteen interviewees ( 8 women and 8 men) did provide examples of women and men treated differently in the classroom.

Differences did exist among answers, however, depending on whether the interviewee felt women and men were treated differently. With some exceptions (such as Betsy and Phil), most interviewees who did not believe women and men were treated differently provided relatively short, confident responses to question 8 . These interviewees apparently rejected the existence of subtle, gender-based differences in 
student treatment and did not appear to reflect on the possibility of such differences. For these short responses, the researcher speculated that the interviewee's perception of gender-based differences in student treatment may have gone unobserved, may have been viewed as relatively insignificant (e.g., micro inequities), or may have been tolerated as the socially constructed norms of acceptable classroom behavior. Table 5 summarizes data from the differing interviewee responses to question 8 .

Table 5. Data table for interviewee responses to question 8.

\begin{tabular}{|c|c|}
\hline \multicolumn{2}{|r|}{ Interviewees Who Felt Women and Men Were Treated Differently } \\
\hline Annie & $\begin{array}{l}\text { Annie felt there was one class when men and women were treated } \\
\text { differently: "It's hard to pinpoint what I mean, but that distinctions } \\
\text { were made between male and female. . . From the female perspective, I } \\
\text { felt like females were expected to be femalie [sic], flirty, less able, } \\
\text { meeker." }\end{array}$ \\
\hline Ben & $\begin{array}{l}\text { Ben observed, "there was only one. . . particular female professor [Dr. } \\
\text { Hopper] who quite clearly treated men differently in a classroom." Ben } \\
\text { commented: } \\
\text { She would tend to criticize anything a male would say, and tend } \\
\text { to encourage anything a female would say in the class--tend to } \\
\text { not call on males and would call more frequently on females. I } \\
\text { wasn't the only one who felt this way about this particular } \\
\text { individual. } \\
\text { Ben went on to unfavorably compare Dr. Hopper's "intellectual } \\
\text { capacity" with three male professors: "She was the lowest common } \\
\text { denominator." Ben finished his answer: } \\
\text { But the women in the class. . particularly the young students } \\
\text { who tend not to be that intellectual anyway; they liked her [Dr. } \\
\text { Hopper] a lot. So. . .I didn't think that much of her, but, then I } \\
\text { have higher standards. }\end{array}$ \\
\hline Don & $\begin{array}{l}\text { Don thought "there was a mold to which women were more acceptable } \\
\text {. . . the mold of women for some males. . would be the quiet and not } \\
\text { challenging; and then the role I think for someone like Dr. Hopper } \\
\text { would kind of be like Dr. Hopper." He continued his analysis: "the } \\
\text { intersection of gender mold and ethnicity, to use it as kind of example } \\
\text { [sic]; I know it is much more complicated." He then switched the topic } \\
\text { to his advisor, observing that she had a tough time at USD: "She didn't } \\
\text { fit the nice, quiet kind of mold that she might be seen in as a } \\
\text { woman. . . So she really had some clashes with some of the } \\
\text { patriarchs." Don's advisor clashed with both male and female faculty } \\
\text { members but for different reasons: }\end{array}$ \\
\hline
\end{tabular}




\begin{tabular}{|c|c|}
\hline & $\begin{array}{l}\text { The clash [with male faculty] was more about gender dynamics } \\
\text { and the other clash [with female faculty] was more, like, in } \\
\text { suffrage; you know, women's rights movements. I mean they } \\
\text { started out, you know, White women's rights and it's been often } \\
\text { disconnected. }\end{array}$ \\
\hline Diana & $\begin{array}{l}\text { Diana answered that there was one unnamed male professor that she } \\
\text { "had a very hard time with:" } \\
\text { I could not tell if I was having a hard time because I was a } \\
\text { woman or because I was a woman and Hispanic. It seemed to } \\
\text { me he always preferred males. . . looking at the males and } \\
\text { having the males answer and giving more value to male } \\
\text { opinion. }\end{array}$ \\
\hline Lorrie & $\begin{array}{l}\text { Lorrie told of an incident during a final examination when Dr. Buckley } \\
\text { passed envelopes to some (but not all) of the female students. These } \\
\text { envelopes contained a note to the student. "As it turned out, the note } \\
\text { expressed his [Dr. Buckley's] appreciation for our presence in his class, } \\
\text { but they were extremely divisive because everybody noticed." Lorrie } \\
\text { continued, "It [the incident] certainly heightened the issues around } \\
\text { gender... When we got together later and found out the contents of } \\
\text { them [the envelopes], people were furious. . that was quite divisive, } \\
\text { but the gender thing came in there, too." }\end{array}$ \\
\hline Penelope & $\begin{array}{l}\text { Penelope answered, "Yes, I did in some classes.... I felt that the } \\
\text { conversations were very much directed toward the men, and women } \\
\text { had to be pretty assertive." Not being assertive, Penelope "felt very } \\
\text { much on the periphery." When asked what classroom element made her } \\
\text { feel on the periphery, she answered, "The style of the professor," } \\
\text { adding that only Dr. Buckley made her feel this way. She observed Dr. } \\
\text { Buckley "has been very nice to me... . Out of class, he was always, } \\
\text { very, very pleasant... I have grown to believe it was more his style } \\
\text { than anything else." }\end{array}$ \\
\hline Rose & $\begin{array}{l}\text { Rose recalled a woman who "started talking [in a class] about } \\
\text { feminists - why none of the readings include women" and the male } \\
\text { professor "made incredibly disparaging comments about feminism and } \\
\text { feminists." }\end{array}$ \\
\hline Wilfred & $\begin{array}{l}\text { Wilfred replied "Oh, yeah... Why do I say this? Just basically the } \\
\text { selections of readings.... the literature. . . as I said, were always from a } \\
\text { perspective of a feminist viewpoint." He added, "It wasn't that I dislike } \\
\text { females. I wish that there had been a bigger balance of gender [in the } \\
\text { program]." }\end{array}$ \\
\hline \multicolumn{2}{|r|}{ Interviewees Who Felt Women and Men Were Not Treated Differently } \\
\hline Barbara & $\begin{array}{l}\text { Barbara commented, "Either I didn't see it [women and men treated } \\
\text { differently]. I don't think we really were, not in those [USD Ed.D. } \\
\text { Program] classes." }\end{array}$ \\
\hline Betsy & $\begin{array}{l}\text { Betsy responded, "I didn't perceive that they [women and men] were } \\
\text { treated differently." Betsy tried to visualize the classroom and class } \\
\text { interactions and concluded, "I just couldn't come up with anything." }\end{array}$ \\
\hline
\end{tabular}




\begin{tabular}{|c|c|}
\hline & $\begin{array}{l}\text { She then talked about an adult development class and "the fact that } \\
\text { women's voices had not been heard." She observed that, for "moral } \\
\text { world development," only men had been studied. Betsy's perceptions } \\
\text { appeared to focus on the task (or question) at hand. She noted, "Gender } \\
\text { was addressed as an interesting academic subject and something we } \\
\text { should all be concerned about. ...As leaders, we should be aware that, } \\
\text { for a very long time - that is mankind's history - women's voices have } \\
\text { been pretty much suppressed." }\end{array}$ \\
\hline David & $\begin{array}{l}\text { When asked if he felt the two genders were treated differently, David } \\
\text { replied, "I really didn't." He continued with his opinions on Dr. } \\
\text { Buckley, whom he considered among the dominant professors in the } \\
\text { program. David observed: } \\
\text { If you didn't take his [Dr. Buckley's] bluff and you stood up to } \\
\text { him and you had valid reasons why you disagreed, he was very } \\
\text { accepting. But it was sometimes, I think, tougher on the women } \\
\text { in the classroom to confront him.... when they strongly } \\
\text { disagreed. }\end{array}$ \\
\hline Grace & $\begin{array}{l}\text { "No. . .I didn't perceive that [women and men were treated } \\
\text { differently]." "I like competition. I'm a competitive person. . . I'm } \\
\text { fairly androgynous." }\end{array}$ \\
\hline Jane & $\begin{array}{l}\text { Interviewees frequently provided perceptions involving faculty issues. } \\
\text { Jane observed, "The only ones that I might have thought were treated } \\
\text { differently is, I'm not always sure that the women professors got their } \\
\text { fair shake... I just think that they worked so much harder to hold their } \\
\text { own." }\end{array}$ \\
\hline Mary & Mary answered the question, "No, not by my professors." \\
\hline Stennis & $\begin{array}{l}\text { Stennis replied, "No I really didn't" (see a different treatment of men } \\
\text { and women). He then praised Dr. Hopper, identifying her as one of his } \\
\text { favorite professors. He concluded, "I'm trying to think back, either the } \\
\text { male or female professors, and I don't recall any differentiation } \\
\text { whatever. I really didn't.". }\end{array}$ \\
\hline Thomas & $\begin{array}{l}\text { "No, never... . That [differing treatment of women and men] wouldn't } \\
\text { have been tolerated. . . The students would have brought it to the } \\
\text { attention of the professor." }\end{array}$ \\
\hline Thor & "In a general sense. . I I don't think so; I don't think so." \\
\hline
\end{tabular}

During several interviews, responses suggested the interviewee was attempting to be politically correct or might have an ax to grind. For example, in response to this question, one male interviewee did seem to have an ax to grind. He used an example of a Filipino couple who were both students at USD. The Filipino man was required to repeat 
a statistics class although "he was far from the worst student in the stats class." The Filipino woman "got a lot of grief," possibly for not taking enough credits in a semester. The interviewee felt "they [USD] were really trying to force her out of the program." When asked if this incident was related to culture or ethnicity, the interviewee replied, "I really felt that some of these people said something or did something along the way that upset the wrong person and put them on the shit list." He continued, "In this case, I don't think ethnicity had anything to do with it." The interviewee seemed to dismiss other possible explanations for the Filipino couple's problems other than they were on "the shit list."

\section{Questions 9 and 10}

Questions 9 and 10 were: (a) "During a class, did you ever feel misunderstood or put down by some class event or an individual's behavior because of your gender? If so, can you please describe this event or behavior?" and (b) "After a class session, do you recall any incident in which you deeply regretted your actions, believing these actions might have been demeaning toward a student of the opposite gender? If so, please describe the incident. Did you take any follow on action to make amends for the incident?" These two questions were related and asked the interviewee whether she or he had been the victim of a classroom demeaning action or had perpetrated such an action.

As shown in Figure 5, 27 interviewees answered both questions no; they had been neither the victim nor the perpetrator of a demeaning act. Twelve of these responses were short, to-the-point answers. Three interviewees answered both questions yes; later paragraphs will review each of their responses. Of the 11 interviewees (6 male and 5 female) responding yes to question 9 , approximately half felt they had been the victim of 
an isolated act. A total of seven interviewees responded that they may have committed demeaning acts toward a student of the opposite gender; however, the examples provided by interviewees appear to lack any intended malice toward the other party. Table 6 summarizes selected responses in the four categories outline above.

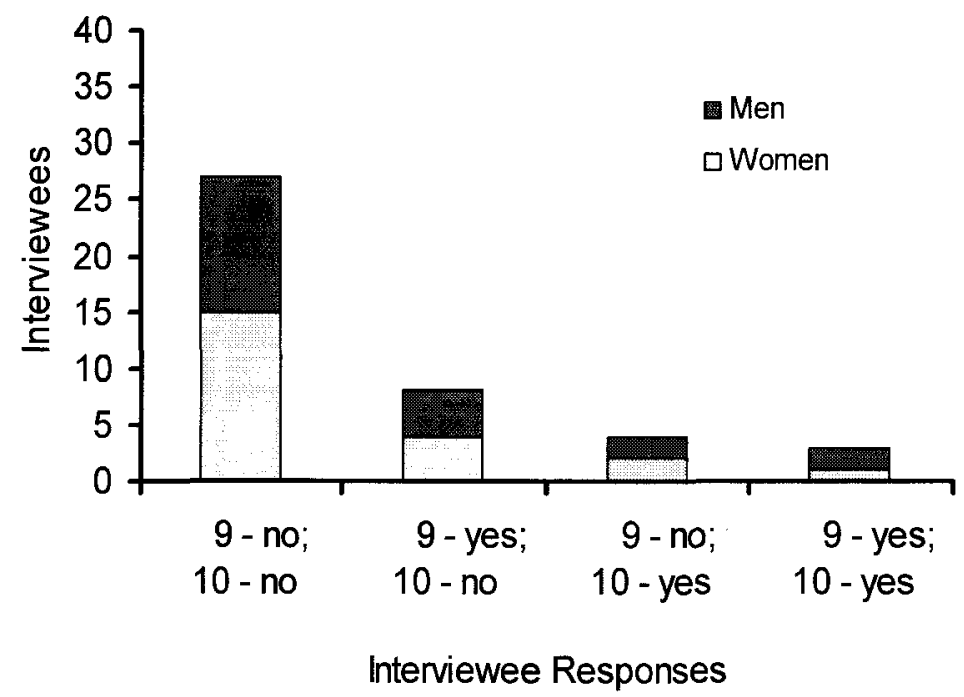

Figure 5. Interviewee Responses to Questions 9 and 10

The low number of interviewees admitting to a demeaning act suggests graduates may not recall unflattering classroom events or may not be willing to admit to such events. Gender bias literature, however, implies that these events do occur. Perhaps this implication does not hold true in the graduate classroom; graduate students may be more tolerant of demeaning acts or may not commit such acts. On the other hand, at times an interviewee would pause to reflect on gender influence questions and offer an insightful self-evaluation of her or his behavior. (For example, see responses from Diana, Milburn, Phil and Rose in Table 6.) The researcher speculated that discussions of sensitive topics, 
such as gender, may encourage an interviewee to reflect on her or his past shortcomings;

classroom debates on sensitive topics may also be limited, but beneficial, in a graduate

leadership program.

Table 6. Data table for interviewee responses to questions 9 and 10.

\begin{tabular}{|c|c|}
\hline \multicolumn{2}{|r|}{ Negative Responses to Questions 9 and 10 (No/No) } \\
\hline Agnes & $\begin{array}{l}\text { Agnes' answers reflected her maturity. When asked if she had been } \\
\text { demeaned, Agnes replied, "I can't really pinpoint anything except, well, } \\
\text { that group [of male jerks discussed in question } 8 \text { ] we just talked about." } \\
\text { Agnes said it was not her style to demean others. She then continued, } \\
\text { "And occasionally, if I would stand up after class, some of the younger } \\
\text { members of class would say, 'Gee, I'm really. . happy you said that. } \\
\text { You know, I was thinking it but you had the courage to say it."" Agnes } \\
\text { concluded her answer with, "I considered myself a role model." }\end{array}$ \\
\hline Genie & $\begin{array}{l}\text { When asked whether she had been demeaned in a class, Genie (a } \\
\text { tomboy) answered, "No, never." She paused before answering whether } \\
\text { she had demeaned a fellow student, and then commented, "I can be } \\
\text { pretty rambunctious myself." Genie explained, "I think if there were any } \\
\text { interactions in that way, it was all in good fun. . . the spirit of the day } \\
\text { and so. . .I don't think anyone was peeved because I was negative } \\
\text { toward them because of their gender." At the end of her answer, Genie } \\
\text { added, "I had to take issue with some of the things they [men] had to } \\
\text { say. . .[men] saying stupid things." }\end{array}$ \\
\hline Lenny & $\begin{array}{l}\text { Lenny's answers represent the interviewees who responded with short, } \\
\text { to-the-point, negative replies. Lenny did not believe he had been } \\
\text { demeaned in a class, responding, "No, I didn't have that experience." He } \\
\text { also felt he had not mistreated others, replying, "No, I don't think so; } \\
\text { I'm hoping everybody's the same." While to the point, Lenny's reply } \\
\text { reflected a mindset expressed by other interviewees as well-the notion } \\
\text { that "everybody's the same." However, people (genders) are different } \\
\text { and a leadership approach founded on the concept that "everybody's the } \\
\text { same" may be problematic. }\end{array}$ \\
\hline Lewis & $\begin{array}{l}\text { Lewis did not feel demeaned, but recalled being occasionally chastised } \\
\text { by a woman who would confront him with "what do you know about } \\
\text { that [gender-related topic]." He would respond, "I would have to remind } \\
\text { them that for } 8 \text { years I was single and I raised my little children, and I } \\
\text { can tell you how much a jar of mayonnaise cost." Lewis tolerated such } \\
\text { confrontations, considering them "a harmless jest, not a serious } \\
\text { reproach." When asked if he had been demeaning toward a female } \\
\text { student, Lewis asserted, "No. If I demeaned anybody, I was equal } \\
\text { opportunity to demean, I suppose." }\end{array}$ \\
\hline \multicolumn{2}{|c|}{ Positive Response to Question 9; Negative Response to Question 10 (Yes/No) } \\
\hline Diana & $\begin{array}{l}\text { Diana related an incident involving a very religious Hispanic woman; } \\
\text { Diana described the woman's attitude as, "I'm on the side of God." }\end{array}$ \\
\hline
\end{tabular}




\begin{tabular}{|c|c|}
\hline & $\begin{array}{l}\text { Diana recalled that other students, both women and men, would make } \\
\text { fun of the religious student: "I could see she was hurt; her feelings were } \\
\text { hurt. . . .I would try not to go there. On the other hand, I really didn't } \\
\text { defend her." Diana reflected on these incidents, asking, "I wondered if } \\
\text { she hadn't been Hispanic, if they would have done that [teased the } \\
\text { woman]." Diana became unhappy when the woman was teased. }\end{array}$ \\
\hline Edward & $\begin{array}{l}\text { Edward felt he had been misunderstood in a class: "Yes, I came to the } \\
\text { aid of a woman, defended the woman. Some women, however, took my } \\
\text { words out of context and thought I was putting them down. Most } \\
\text { women, however, understood me." While he did not put down women, } \\
\text { Edward did "attack men on one or two occasions because of their views } \\
\text { of women. I regretted my actions on those occasions." }\end{array}$ \\
\hline Lorrie & $\begin{array}{l}\text { Lorrie continued her complaint of limited reading material by female } \\
\text { authors and asked why reading lists could not be updated to include } \\
\text { female authors. She commented, "It was hard to get around drawing the } \\
\text { conclusion that women's contributions were less valued." Lorrie } \\
\text { observed that Dr. Hopper "used texts like woman's way of knowing, } \\
\text { indicating that women have different ways of viewing the world than } \\
\text { men. It's actually a perspective that I don't agree with." When asked if } \\
\text { she might have demeaned others, Lorrie answered, "That seems } \\
\text { fascinating. I probably was, maybe. I don't know. I'm going to think } \\
\text { about that." Lorrie then commented that there might have been times } \\
\text { when the women in her study group used the men in the study group. }\end{array}$ \\
\hline Mitch & $\begin{array}{l}\text { Mitch answered, "Yes, I do have to say that I have experienced that } \\
\text { [being put down]." Like Lewis, Mitch could "recall once or twice } \\
\text { someone [a woman] saying, "Well, you know, you're a man. No wonder } \\
\text { you wouldn't understand that." He observed that it was "important to } \\
\text { emphasize that there was-at least to the best of my knowledge-no } \\
\text { animosity there." }\end{array}$ \\
\hline Phil & $\begin{array}{l}\text { Phil recalled an isolated incident in a seminar when a young woman } \\
\text { "was acting almost hostile toward me and to another older guy. And I } \\
\text { was puzzled by it. I didn't know her." Phil discovered that he "reminded } \\
\text { her of some male authority figure in her life that really hurt her." }\end{array}$ \\
\hline \multicolumn{2}{|c|}{ Negative Response to Question 9; Positive Response to Question 10 (No/Yes) } \\
\hline Gina & $\begin{array}{l}\text { Gina noted, "I did not have a female communication style and I just } \\
\text { wouldn't. . .connect with that, you know, like women cry kind of thing." } \\
\text { Gina did believe she could be overbearing: "Yeah, I think I have left } \\
\text { sometimes feeling, like, well, maybe I debated too strongly before I } \\
\text { came on." However, Gina would try to make amends: } \\
\text { I would go back and say. ... .It's like the male style; can you } \\
\text { picture the guy kinda coming up and punching your arm and } \\
\text { going, hey, buddy, I hope I didn't run over you there. ... They'd } \\
\text { say "no, no, you're fine; don't worry about it." I'm your } \\
\text { anomaly. }\end{array}$ \\
\hline Nancy & $\begin{array}{l}\text { Nancy recalled a group project in which a male student had not properly } \\
\text { completed the assignment. (Milburn recalled a similar incident with a }\end{array}$ \\
\hline
\end{tabular}




\begin{tabular}{|c|c|}
\hline & $\begin{array}{l}\text { female student.) Frustrated, Nancy "made a statement out in public that } \\
\text {...I later apologized for and clarified. And that was the end of it." }\end{array}$ \\
\hline 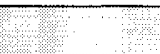 & Positive Response to Questions 9 and 10 (Yes/Yes) \\
\hline Milburn & $\begin{array}{l}\text { Like Nancy, Milburn recalled a female student whom he felt ignored } \\
\text { assignment requirements. Milburn advised the female student, "this is } \\
\text { not going to fly. She instantly jumped on how I was treating her like a } \\
\text { stupid female." The professor supported Milburn's interpretation of the } \\
\text { assignment requirements and the pair received an acceptable grade for } \\
\text { their efforts. However, Milburn later told the female student, "you made } \\
\text { my semester miserable." When asked if he had committed demeaning } \\
\text { acts, Milburn noted: } \\
\text { I'm sure there was a time but I cannot recall it. I remember } \\
\text { myself being as PC [politically correct] as possible....I'm sure } \\
\text { there were some incidents where I said something that bothered } \\
\text { somebody but nobody ever approached me, and I never } \\
\text { approached them. }\end{array}$ \\
\hline Rose & $\begin{array}{l}\text { Rose felt maligned in the classroom and evasively responded, "I can't } \\
\text { think of a specific event"--Rose didn't like to provide examples. She } \\
\text { then acknowledged the answer was yes, commenting that she did have } \\
\text { disagreements with military men: "There wasn't the same level of } \\
\text { respect of what are they saying." She explained, "Here's the problem } \\
\text {....People consider me intelligent and so sometimes they overlook } \\
\text { other stuff [my gender] because they think I'm intelligent. ...They } \\
\text { know I have the expertise." The researcher then asked, "So they listen to } \\
\text { you in spite of the fact that you are a woman?" Rose replied "exactly." } \\
\text { Later in the interview, Rose continued to discuss her issues with military } \\
\text { men: } \\
\text { I don't remember an incident, but I would imagine because of } \\
\text { what I said to you about military guys and how I felt they treated } \\
\text { me that I probably looked down on them. So, yeah, because I } \\
\text { thought they were arrogant, like I said, so I know they were } \\
\text { unaware of their arrogance, so I probably dismissed them. }\end{array}$ \\
\hline
\end{tabular}

Ben's responded yes to both questions 9 and 10 . His answers provide insight into his unique personality and the diversity he might bring to a classroom. Unfortunately, his responses are difficult to paraphrase and still reflect his personality and outlook on life. Therefore, his responses are included with only slight modification. 
Interviewer: The next two questions are kind of the opposites of each other. The first question asks if you personally ever felt misunderstood or put down by some event in the class or by some individual's behavior because you were a man. Ben: Well, I'm misunderstood all the time even today. Even as we speak right now, I'm being misunderstood, but that's not unusual in my life. Because I. . .I think it is possible because I tend to look like. . .beer swigging, fat, slovenly looking; so, the people. . .don't really stop to find out what's there, often take me to be a nerd and, in a lot of ways, I sort of encourage because it is a greater power position to be underestimated. But, yeah, all my life, not just at USD, I've had women misinterpret what I've said or done.

Ben continued his answer with a discussion of how people tend to see themselves in him. Concerned, the interviewer asked Ben, "Do you feel like I misunderstand you right now?" Ben replied no; he was referring to a group of faculty members at the university where he works. After reviewing discussions with his fellow faculty members, Ben noted:

It is interesting that people stick around or are sort of forced to figure out generally to find out that their first impressions [of me] were not accurate. And there was a case, actually several cases, of a more staunchly feminist student. . . . And she actually came to my defense in this case. . . A student of mine accused me of making advances when in fact she had made advances. Her husband was in the Navy. He had left for WestPac [the Western Pacific Ocean] and was gone for 6 months at sea. One night in class, [she was] very suggestive about, "Well, you know, I'm home alone now." You know, I indicated that I wasn't interested and I 
think that pissed her off. And so she complained. And one of the students at USD who was also a PE teacher and gay, and actually came to my defense and said, "Well, you just don't understand it."

The interviewer then asked Ben whether he recalled any incidents in which he might have been demeaning toward a woman. Ben replied:

Most of my regrets about treatment of women happened before I met a gay guy who kept trying to solicit my affections. And I discovered at that point what "no" actually meant. And I developed an appreciation for women who are not interested. But, no, I don't recall doing anything-I mean, I've done many things that I regret—but nothing; nothing in so far as treating a woman differently than a man. ...We used to banter back and forth but nothing, nothing that wasn't understood as academically based. And certainly nothing gender related. I mean, my personal life completely fulfilled my interests in women and then, so women. . .I've treated them. . like any other human being walking around. I wouldn't go so far to say I treating [sic] like objects, they were just-I treated them the same way I treated men. I didn't make any particular differentiation between the genders. I think there were some women who might have been disappointed by that, not because they particularly wanted me, but because they enjoyed attention. And other women just didn't really care. . . So, nothing I've regretted. As a matter of fact, a lot of things I was proud of myself. Ben may not be aware of the apparent conflict in his views. He felt he treated women as he treated men, but he viewed women differently. For example, he did not assert that men "enjoyed attention." 
Question 11

Question 11 asked, "One question about class norms at USD. . .and for the purposes of this survey, class norms are the accepted behaviors and values in a classroom ...would you consider the classroom environment to be gender neutral, masculine, or feminine? Why?" More so than previous questions, this question provided differences in answers between the two genders, both in how women and men perceived class norms and in the logic used to substantiate those perceptions. Figure 6 summarizes interviewee perceptions of class norms. Of interest, more women than men thought the classroom environment was masculine, while more men than women perceived that class norms were feminine. More than half of the interviewees felt class norms were gender neutral.

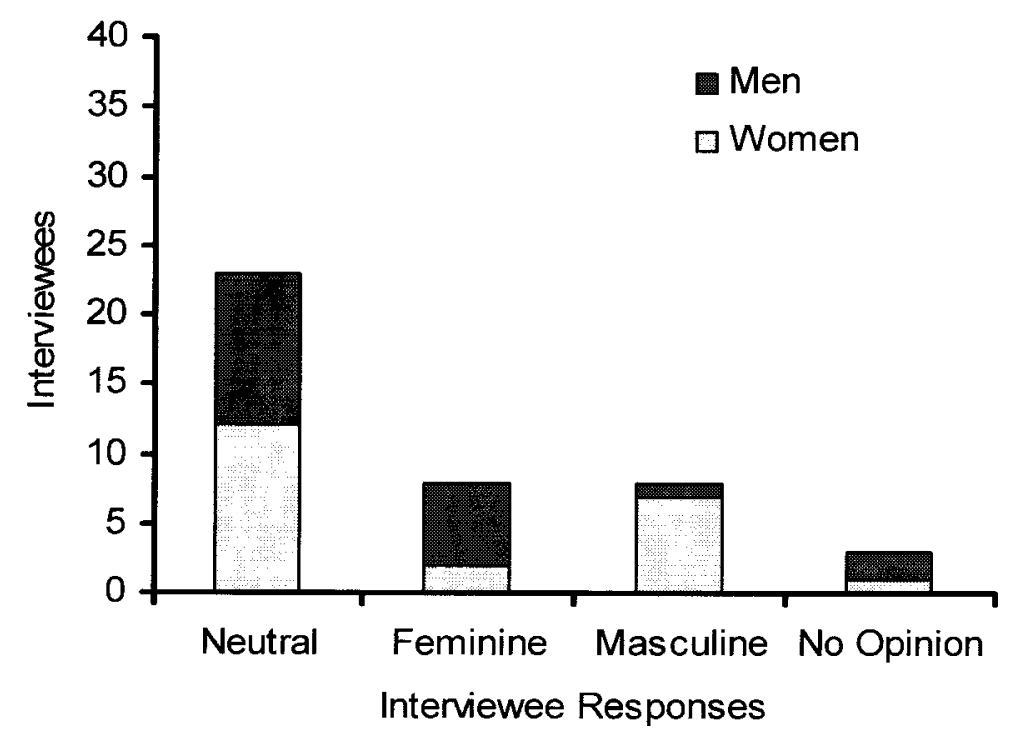

Figure 6. Interviewee Responses to Question 11

Interviewees' rationale for their responses included five logic approaches. These are summarized below, and will be discussed in greater detail. 
1. Class norms were determined by the class composition, including (a) instructor teaching style or gender, (b) the ratio of women to men in the class, (c) class material (masculine or feminine), and (d) the class makeup (students and instructors).

2. Class norms were determined by a process of elimination. If the class environment was neither masculine nor feminine, class norms must be gender neutral.

3. Classes were equitable; all students could participate. Therefore, class norms were gender neutral.

4. Compared to some interviewees' masculine work environment, class norms were either feminine (Marie, David) or gender neutral (Lewis).

5. To determine class norms, interviewees applied a logical analysis reflecting the differences between men and women. (Alemán, 1997; Banks, 1988; Belenky et al., 1997; Brooks, 1982; Canada \& Pringle, 1995; Gilligan, 1982; Hall \& Sandler, 1982; Kramarae \& Treichler, 1990; Levy, 1982.)

The class composition logic approach deserves some explanation. Penelope observed, "I think it [class norms] depends on class content and the composition of the people in the class." Penelope's class composition logic suggests that class norms are a product of the physical, objective characteristics of a class; for example, the instructor is a woman, therefore class norms are feminine. However, this argument ignores a subjective evaluation of the class environment. The instructor may be a woman or may use feminine class study material, but strong-willed male or androgynous students may create competitive, non-supportive, aggressive (masculine) class norms. Therefore the class composition logic might be viewed as somewhat superficial, ignoring underlying, subtle class dynamics. 
Table 7 summarizes selected responses to question 11 . Where possible, the interviewee's logic approach is included in Table 7 data.

Table 7. Data table for interviewee responses to question 11.

\begin{tabular}{|c|c|}
\hline \multicolumn{2}{|r|}{ Gender Neutral Response } \\
\hline $\mathrm{Al}$ & $\begin{array}{l}\text { Al observed, "I didn't see any preferences toward either sex [process of } \\
\text { elimination]. . . We didn't focus on gender per se, unless it was part of } \\
\text { an article or chapter in a book; I don't recall, to be honest." Al's } \\
\text { comment requires some pause for reflection; he implied that } \\
\text { discussions in a graduate classroom do not look past the veneer of an } \\
\text { article or book chapter to examine underlying gender issues. }\end{array}$ \\
\hline Annie & $\begin{array}{l}\text { Annie simply stated, "I thought about it a lot and couldn't come up } \\
\text { with anything that would show me anything else [besides gender } \\
\text { neutral]." (process of elimination) }\end{array}$ \\
\hline Barbara & $\begin{array}{l}\text { Barbara asserted, "everyone had input; everyone spoke. . . .We got used } \\
\text { to saying what we needed to say." (equitable environment) }\end{array}$ \\
\hline Lenny & $\begin{array}{l}\text { Lenny noted "there was no singling of one gender over another } \\
\text { gender." (equitable environment) }\end{array}$ \\
\hline Nancy & $\begin{array}{l}\text { Nancy replied gender neutral because "the focus was. . information } \\
\text { learned and how to apply it." (class composition) }\end{array}$ \\
\hline \multicolumn{2}{|r|}{ Feminine Response } \\
\hline Carl & $\begin{array}{l}\text { In characterizing class norms as feminine, Carl used class composition } \\
\text { logic: "I bet you about } 70 \% \text { of my classes were women. . . it is pure } \\
\text { numbers. . . .a higher level of females than White males." } 17 \text { " }\end{array}$ \\
\hline David & $\begin{array}{l}\text { David noted, "Going from that heavily masculine environment [the } \\
\text { military] that left me the impression when I was there that the } \\
\text { environment leaned toward the feminine. But I am not so sure that was } \\
\text { the personal difference because it [class norm] was so different." }\end{array}$ \\
\hline Marie & $\begin{array}{l}\text { Marie observed that, "in my mind, it [class norms] seemed feminine } \\
\ldots \text {. .I used to work in engineering and I've dealt with a male-dominated } \\
\text { [masculine] field." }\end{array}$ \\
\hline Phil & $\begin{array}{l}\text { Phil felt that the instructor's gender (class composition) established } \\
\text { class norms: } \\
\text { I'd say it comes down to a little bit on the feminine side, not in } \\
\text { a discriminatory sense but in a voice of the professors who were } \\
\text { teaching. It is the School of Education, and most of them } \\
\text { [professors] were women. }\end{array}$ \\
\hline \multicolumn{2}{|r|}{ Masculine Response } \\
\hline Diana & $\begin{array}{l}\text { Diana noted students "would participate and state your point of view } \\
\text { and defend it or argue it. . . .our norms in women are, for most women, } \\
\text { are you try to be nice." She added, "The classrooms were more }\end{array}$ \\
\hline
\end{tabular}

\footnotetext{
${ }^{17}$ Canada and Pringle (1995) suggested that, in a class with $70 \%$ female students, men begin to intimidate women, creating a masculine class environment.
} 


\begin{tabular}{|l|l|}
\hline & $\begin{array}{l}\text { masculine-oriented and that was admired. You could, like those who } \\
\text { could knock someone's argument off the table." (gender difference) }\end{array}$ \\
\hline Don & $\begin{array}{l}\text { Don offered, "The way people participated, I think, was very, very } \\
\text { individualistic." He concluded his thoughts with, "It was really in some } \\
\text { cases like a shark fest about participating. . . like real assertive." } \\
\text { (gender difference) }\end{array}$ \\
\hline Genie & $\begin{array}{l}\text { Genie responded, "It depends on how I define masculine and feminine. } \\
\text { If I define masculine as more assertive and more independent and kind } \\
\text { of aggressive. . then I would say [class norms were] more masculine." } \\
\text { She went on to define feminine as "more gentle and kind" and closed } \\
\text { with the comment, "If you wanted to participate in the dialogue, you } \\
\text { couldn't, you wouldn't, sometimes wait your turn." (gender difference) }\end{array}$ \\
\hline Buford & $\begin{array}{l}\text { In his written answers to interview questions, Buford asserted, "Every } \\
\text { class is different. Certainly some classes were masculine, and some } \\
\text { were feminine; there was no such thing as being completely neutral." } \\
\text { During the telephone interview, Buford commented, "I thought about } \\
\text { that [written] statement a lot, and I think. . it was pretty accurate." }\end{array}$ \\
\hline
\end{tabular}

Table 8 documents interviewee logic compared to gender for responses to the qualitative question about class norms. Three female interviewees used two logic approaches, thus the total number of entries in Table 8 is 45 instead of 42 . Table 8 data reflects noticeable differences between women and men. Women are more likely to judge class norms using an evaluation of gender differences or a simple process of elimination; both are based on whether they observed gender influences in the class. Twelve of 20 men judged class norms by the class composition: What is the instructor's gender? What is the gender of class study material? Who is in the class (e.g., peers)? Are there more women than men in the class? From this data, one might observe that men tend to evaluate class norms somewhat objectively-what do they see in the classroom? Women tend to evaluate class norms subjectively — do they feel that gender influences exist in the classroom or not? 
In analyzing interviewee logic, another point of interest emerges. Only 9 of the 42 interviewees used a logic of gender differences in determining class norms. (Although process of elimination logic did include gender in the process, this logic reflected a fairly simple analysis of class norms.) For a doctoral program that emphasizes diversity, it would appear that graduates may not be well-versed in how gender differences influence class norms.

Table 8. Interviewee gender compared to analysis logic approach.

\begin{tabular}{lcc} 
& \multicolumn{2}{c}{ Gender } \\
\cline { 2 - 3 } Logic Approach & Women & Men \\
\hline Class Composition & 5 & 12 \\
Process of Elimination & 7 & 2 \\
Equitable Classroom & 4 & 3 \\
Masculine Background & 1 & 2 \\
Gender Differences & 8 & 1 \\
\hline
\end{tabular}

Table 9 compares analysis logic to class norms and documents the principal logic used for each class norm. The process of elimination and equitable classroom logic systems were used in conjunction with the gender-neutral norm only. Of the eight interviewees who classified class norms as masculine, seven cited a logic of gender difference while two believed the instructor's gender created a masculine classroom. (Danielle used both logic analyses methods, which accounts for the discrepancy between the number of students and the analysis logic methods.) 
Table 9. Class norms compared to analysis logic approach.

\begin{tabular}{lcccc}
\hline & \multicolumn{4}{c}{ Class Norms } \\
\cline { 2 - 5 } & Neutral & Feminine & Masculine & $\begin{array}{c}\text { None } \\
\text { Provided }\end{array}$ \\
\hline Logic Approach & 7 & 5 & 2 & 3 \\
Process of Elimination & 9 & 0 & 0 & 0 \\
Equitable Classroom & 7 & 0 & 0 & 0 \\
Masculine Background & 1 & 2 & 0 & 0 \\
Gender Differences & 1 & 1 & 7 & 0 \\
\hline
\end{tabular}

Class norm logic approaches provide an important observation: most interviewees appear somewhat insensitive to gender influences with respect to class norms. Twentythree interviewees believed class norms were gender neutral, and a relatively small number of interviewees considered gender differences in their responses. When considering this observation, one possible explanation is interviewee tolerance of status quo class norms - interviewees observed class norms that they had always observed during college classes. A second explanation suggests that, if interviewees had not been exposed to discussions of gender differences and class norms, then their responses would reflect some insensitivity toward the topic of gender neutral, masculine, or feminine class norms in the graduate classroom. 
Question 12

Question 12 asked, "Have you considered how a member of the opposite gender would respond to your answers? What do you think they would say?" Question 12 responses appear quite similar between women and men when divided into the following general categories:

1. Interviewees who believed the opposite gender would, for the most part, agree with their answers.

2. Interviewees who believed the opposite gender would disagree with their answers.

3. Interviewees who believed a member of the opposite gender would agree or disagree depending on the personality of the individual.

4. Interviewees who responded, "I don't know," when asked what a member of the opposite gender would say.

Figure 7 summarizes female and male responses for each of the four categories. Twenty-two interviewees believed a student of the opposite gender would, for the most part, agree with the interviewee's responses to previous qualitative survey questions. Two interviewees provided responses that could be viewed as in this category and in the "I Don't Know" category. The data in the figure seems somewhat benign except for the low number of men who felt responses depended on the individual providing the answers. Table 10 summarized interviewee data for each of the four categories of responses to question 12 . 


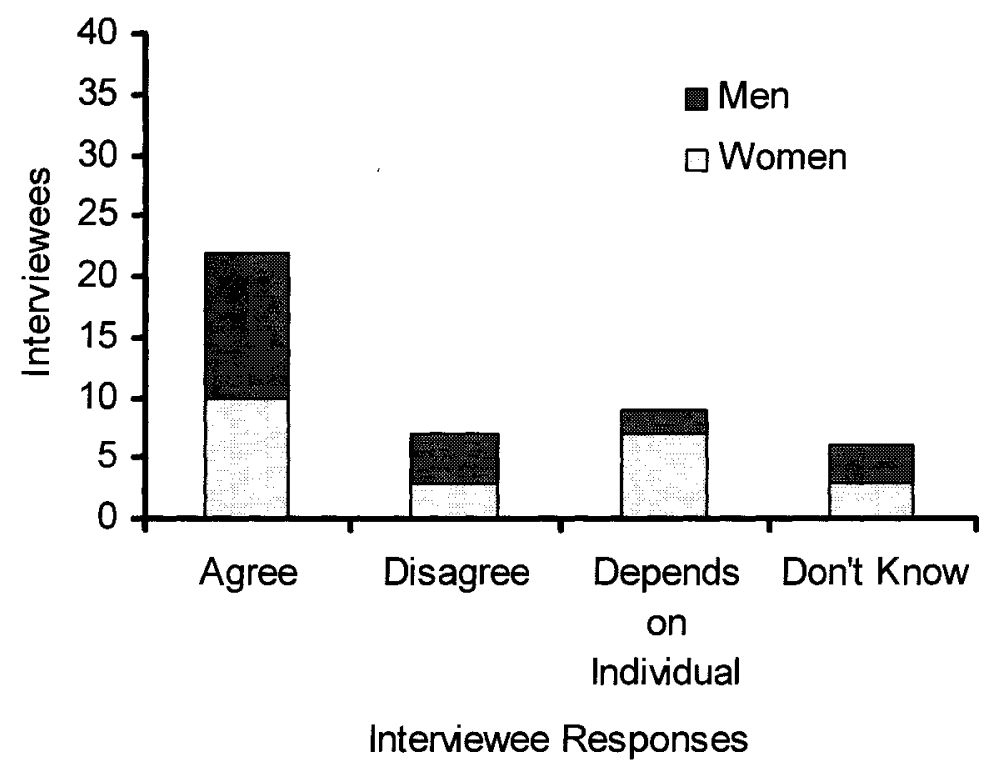

Figure 7. Interviewee Responses to Question 12

Several interviewee responses reflect possible indecisiveness; words such as "I think" and "I guess" frequently appear in Table 10. This indecisiveness suggests some interviewees have not considered gender issues from the perspective of the opposite gender. (Another possible explanation is the research question asked interviewees what they "think" a member of the opposite gender would say and interviewee answers parrot the question asked.) The researcher speculated that, to some extent, because the USD Ed.D. Program curriculum does not offer a course in diversity, the opportunity for educational studies on gender issues (such as the difference between women and men) might be limited.

Table 10. Data table for interviewee responses to question 12.

\begin{tabular}{|l|l|}
\hline \multicolumn{2}{|c|}{ Interviewees Who Believed the Opposite Gender Would Agree with Their Answers } \\
\hline Carol & $\begin{array}{l}\text { "I would like to think that they [men] would respond in the same way, } \\
\text { given the fact that we're adults." }\end{array}$ \\
\hline
\end{tabular}




\begin{tabular}{|c|c|}
\hline David & $\begin{array}{l}\text { David felt that women would agree with his answers and stated, "I think } \\
\text { they [women] would find them [his answers to previous questions] } \\
\text { interesting. . .I would hope. . .they would find that they indicate that I do } \\
\text { my best to be tolerant of a lot of points of view." David went on to talk } \\
\text { of his military experience, observing, "I personally believe that it was } \\
\text { very good for the military to bring women in because I think it pulled } \\
\text { the organization in some direction it needed to go. It certainly changed } \\
\text { my language at work." }\end{array}$ \\
\hline Richard & $\begin{array}{l}\text { Richard asserted, "I think they [women] would probably say that they } \\
\text { [his answers] were sensitive and insightful." He explained: } \\
\text { I think females are stronger with those answers than men. And I } \\
\text { think it's a wiring thing-I think women tend to be just a } \\
\text { combination being about biological and environment, nature and } \\
\text { nurture. But I think women bring a [sic] equality to an } \\
\text { environment- - stronger, typically more strongly, than men do. }\end{array}$ \\
\hline Ronald & $\begin{array}{l}\text { Ronald's response was somewhat typical of many interviewees. He } \\
\text { commented, "I would think. . . most of the women would agree on what I } \\
\text { said." }\end{array}$ \\
\hline \multicolumn{2}{|c|}{ Interviewees Who Believed the Opposite Gender Would Disagree with Their Answers } \\
\hline Don & $\begin{array}{l}\text { Don's response introduced ethnicity into his answer: "I think they } \\
\text { [women] would struggle more with what I described as, of this kind of } \\
\text { White woman component of culture." He went on to discuss ethnic and } \\
\text { gender issues at USD, claiming that White women were "the biggest } \\
\text { beneficiary of affirmative action. I mean, it is kind of a social construct } \\
\text { beyond the pigment." }\end{array}$ \\
\hline James & $\begin{array}{l}\text { James felt that "some of the female responses may be significantly } \\
\text { different from mine. I would guess they [women] probably thought there } \\
\text { was more gender bias. . .than I see through my lens." }\end{array}$ \\
\hline Lorrie & $\begin{array}{l}\text { Lorrie responded, "I think an average man would become pretty } \\
\text { defensive pretty quickly." }\end{array}$ \\
\hline Milburn & $\begin{array}{l}\text { Milburn stated, "I have a feeling they would probably say I'm a little } \\
\text { gender inconsiderate and additionally that I've got a bit of an ax to } \\
\text { grind." He continued this discussion with, "Everybody's perception of } \\
\text { reality is very different." When asked to provide an example of being } \\
\text { gender inconsiderate, Milburn replied, "thoughts and statements that } \\
\text { they [women] might find uncomfortable hearing or they might feel are } \\
\text { inappropriate." When asked if he had been challenged on his views, } \\
\text { Milburn replied, "I mainly kept my mouth shut. I'd think things and just } \\
\text { walk away so I got into very few discussions with people." Such an } \\
\text { attitude might be viewed as a strategy to avoid a difficult topic (gender). }\end{array}$ \\
\hline \multicolumn{2}{|r|}{$\begin{array}{l}\text { Interviewees Who Believed Responses from the Opposite Gender } \\
\text { Depended on the Individual }\end{array}$} \\
\hline Agnes & $\begin{array}{l}\text { Agnes explained, "an intelligent, thoughtful man would agree [with her } \\
\text { previous answers], but one who felt threatened by a woman or any } \\
\text { woman would not agree. And the younger the man, the more threatened } \\
\text { they tend to be." }\end{array}$ \\
\hline
\end{tabular}




\begin{tabular}{|l|l|}
\hline Diana & $\begin{array}{r}\text { Diana asserted, "Well, it depends on the male." She explained: } \\
\text { I think that, in our group, it would have been probably more the } \\
\text { male that. . would have been more willing to recognize that } \\
\text { these were male behaviors and discuss it. On the other hand, they } \\
\text { would also say something like, "Well, that's the world. You just } \\
\text { gonna be out there in the world." }\end{array}$ \\
\hline Lewis & $\begin{array}{l}\text { Lewis recalled "well I guess it is gonna depend on the woman." He later } \\
\text { added "from my perspective, everything seemed to be. . pretty } \\
\text { equitable. It didn't seem to me that there were any special privileges for } \\
\text { anybody but then who knows." }\end{array}$ \\
\hline Rose & $\begin{array}{l}\text { Rose replied, "Well, the question is unfair." She explained, "I can't } \\
\text { answer the question because I couldn't put all men into one category." }\end{array}$ \\
\hline Ben & $\begin{array}{l}\text { Interviewees Who Responded "I don't know" } \\
\text { replied, "I have no clue. Who can understand women?" He finished his } \\
\text { answer with, "I've met many women I don't understand. So, I don't } \\
\text { know. . .I guess you'd have to ask them." }\end{array}$ \\
\hline Danielle & $\begin{array}{l}\text { Danielle asserted, "I don't think we would be that far off. . .I don't } \\
\text { know; I never asked a guy." }\end{array}$ \\
\hline Jane & $\begin{array}{l}\text { Jane's initial response was "I don't know" followed by laughter. She } \\
\text { continued: "No, I don't know-probably like to think they [men] were } \\
\text { in charge." Jane explained that "most men like to think that [they are in } \\
\text { charge], period." Jane then observed that professors were able "to keep } \\
\text { thinks on an even keel." However, one must wonder, are leadership } \\
\text { study classes on an even keel able to explore the deeper issues involving } \\
\text { gender, or does such an environment only polish the veneer and ignore } \\
\text { underlying differences between women and men? }\end{array}$ \\
\hline $\begin{array}{l}\text { Marie replied, "I have no clue. I don't know. I would think they'd agree, } \\
\text { but that's because I think I'm right. Yeah, I don't know." }\end{array}$ \\
\hline Marie
\end{tabular}

Question 13

Question 13 asked, "As a last, very open-ended question, based on your perceptions, do you believe there were gender inequities in the graduate classroom at USD and what images or recollections drive this perception?" Question 13 served to reconfirm answers to question 8 , which asked whether men and women were treated differently in the graduate classroom.

As summarized in Figure 8, 32 interviewees (17 women and 15 men) felt there were no gender inequities in the graduate classroom. Ten interviewees ( 5 women and 5 
men) felt there were inequities, and 9 of the 10 believed men and women were treated differently. Barbara did not see differences in the treatment of men and women but did know of inequities although not within her group. She explained, "I think it was an individual feeling that there was bias against them [some women]. And I might say it might have been somewhat. . a few of them might have been ethnicity."

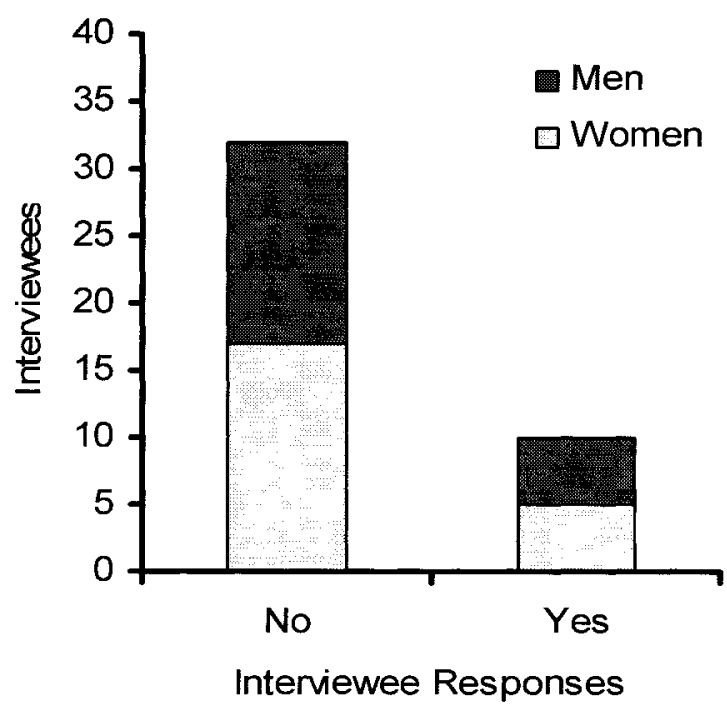

Figure 8. Interviewee Responses to Question 13

Seven interviewees indicated men and women were treated differently, but there were no gender inequities. For these interviewees, however, responses to questions 8 and 13 did seem consistent. When asked if women and men were treated differently, Annie recalled a single incident in which men and women were treated differently. For question 13, she replied, "I mean, right away I put no [for her answer to the question]." Maureen also recalled a single incident of differences between the treatment of women and men. Danielle observed that there were some classes where faculty members preferred males 
or females; when asked about inequities, she replied, "I don't think there were. . .I don't know."

David and Agnes felt Dr. Buckley treated women and men differently but did not believe there were gender inequities. Mitch believed Dr. Hopper might have favored women and treated the genders differently, but, for question 13 concerning gender inequities in the classroom, replied, "No, absolutely not—even with Dr. Hopper." While Ben's overall answers differed, his responses were similar for questions 8 and 13.

Interviewee responses (including Ben's response) are summarized in Table 11.

Table 11. Data table for interviewee responses to question 13.

\begin{tabular}{|c|c|}
\hline \multicolumn{2}{|c|}{ Interviewees Who Felt There Were Not Gender Inequities in the Graduate Classroom } \\
\hline Agnes & $\begin{array}{l}\text { Agnes replied, "I felt there were very few inequities." She then added: } \\
\text { But the academic method is to challenge and to pick apart ideas } \\
\text { and not always in a supportive manner, and I felt many women } \\
\text { were threatened by this. I was not because I'm so comfortable } \\
\text { with male and male style. } \\
\text { Agnes' comments reflect her concerns with being different as a woman, } \\
\text { and yet being expected to conform to a male academic method. There is } \\
\text { a paradox here-women and men are different, but should not be } \\
\text { treated differently? }\end{array}$ \\
\hline Ben & $\begin{array}{l}\text { Ben replied: } \\
\text { My perception is no [gender inequities]. I would guess that } \\
\text { there are some who would disagree with that. And those who } \\
\text { would disagree would tend to be those who did not have the } \\
\text { intellectual tools that were needed for a highly theoretical } \\
\text { curriculum. There were many, particularly women, in that; } \\
\text { primarily because it's the School of Education. . and so many } \\
\text { women are involved in education. Many of these people signed } \\
\text { up for this course, this program, not really understanding how } \\
\text { highly theoretical it was going to be. }\end{array}$ \\
\hline Betsy & $\begin{array}{l}\text { Betsy appeared uncomfortable and apologetic with her response to } \\
\text { question } 13 \text {. She began her answer about inequities in the classroom } \\
\text { with, "not that I was aware of. Of course, I didn't see everybody's } \\
\text { grades either." When asked about her comments on grades, Betsy } \\
\text { replied, "Oh, just sort of laughing. Well, I was just sort of kidding } \\
\text { about. . .were there more As among male students. . . I don't think so." } \\
\text { She continued, "See, I'm trying to think. Were they [males] called on } \\
\text { more to give their opinion? Were their opinions met more favorably?" } \\
\text { She concluded, "I don't recall differences in gender on those types of }\end{array}$ \\
\hline
\end{tabular}




\begin{tabular}{|c|c|}
\hline & $\begin{array}{l}\text { things which I would view as markers of inequity, if you will. I was } \\
\text { sort of joking about the grades." }\end{array}$ \\
\hline David & $\begin{array}{l}\text { David "didn't see very many, if any [gender inequities]." However, he } \\
\text { described the Miller Analogies Test, a requirement for USD Ed.D. } \\
\text { Program entry, as a "highly cultured, gender-biased instrument." He } \\
\text { felt that the test favored a "young male growing up in the } 50 \text { s and } 60 \text { s } \\
\text { in classic America of the time." He continued: } \\
\text { But as I was taking that test, I became aware that, if you were a } \\
\text { woman, if you had grown up in one of the inner city things as a } \\
\text { minority, that the kinds of questions that were being asked were } \\
\text { very prejudicial. }\end{array}$ \\
\hline Genie & $\begin{array}{l}\text { Genie quickly answered, "Inequalities? No." She then added, "Now } \\
\text { that's why I think it [the USD Ed.D. Program] is pretty masculine. } \\
\text { Sometimes a lot of women have a lot of, you know, masculine-I don't } \\
\text { think masculine only belongs to men." }\end{array}$ \\
\hline Lewis & $\begin{array}{l}\text { A government civil service manager, Lewis answered, "No, there's no } \\
\text { way I can answer yes because I don't have a single example [of an } \\
\text { inequity] in my mind." Lewis then discussed his leadership philosophy } \\
\text { at work: "I would often counsel some of the other male managers } \\
\text {. .just because you have a female manager working for you. . .you } \\
\text { don't treat them differently or value their opinions differently than } \\
\text { anybody else." Lewis' management approach represents a paradox; he } \\
\text { does not advocate treating female managers differently from male } \\
\text { managers; but, if one believes social construction (Deaux, 1984; } \\
\text { Kimmel, 2000), women and men are different. Therefore, a leadership } \\
\text { philosophy that views men and women as the same may be } \\
\text { problematic. }\end{array}$ \\
\hline Richard & $\begin{array}{l}\text { For question 8, Richard said, "The simple answer is no," but he went } \\
\text { on to present an example in which women were favored. Richard } \\
\text { indicated there were not inequities in the classroom but felt there were } \\
\text { inequities among the faculty. Richard replied, "I don't think so much in } \\
\text { the classroom. . .but I think among the faculty there was [inequity]." } \\
\text { Richard spoke of the "conflict between [a male professor] and a } \\
\text { [female] professor that left because of a gender conflict. . . It was a } \\
\text { pretty heated discussion." Richard perceived a philosophical difference } \\
\text { about gender among the faculty, noting "it leaked into the classroom." } \\
\text { He observed, "I think there were some very traditional views of gender } \\
\text { from [the male professor] that were challenged by [the professor who } \\
\text { left USD]." Other interviewees also commented on perceived discord } \\
\text { among faculty members. For example, when discussing gender } \\
\text { inequities, James, Jane, and Milburn also opined about faculty } \\
\text { disagreements. }\end{array}$ \\
\hline \multicolumn{2}{|c|}{ Interviewees Who Felt There Were Gender Inequities in the Graduate Classroom } \\
\hline Barbara & $\begin{array}{l}\text { Barbara observed, "I know there were [inequities] at times but not in } \\
\text { the group, the cohort group that I worked with." She continued, "There } \\
\text { were individuals [women] who saw it [inequities]. But then, if you look }\end{array}$ \\
\hline
\end{tabular}




\begin{tabular}{|c|c|}
\hline & $\begin{array}{l}\text { at the overall group, I don't think we really thought so." Barbara's } \\
\text { suggestion that one "look at the overall group" takes a macro look at } \\
\text { gender, possibly ignoring the subtleties of gender bias. }\end{array}$ \\
\hline Don & $\begin{array}{l}\text { Don offered, "Yeah, and this is now a reverse where, yeah, it [inequity] } \\
\text { is layered. It is not just gender related." Don told of the capstone class } \\
\text { where the female professor "was basically the gatekeeper" as the final } \\
\text { reader for comprehensive papers. Don wrote a paper that was critical of } \\
\text { USD. He reviewed privilege and used USD classes as examples. Don } \\
\text { was required to rewrite his paper although another female student in his } \\
\text { study group received a "plus-plus" on her paper on the same topic. } \\
\text { Don's colleagues suggested he do "the make nice and-this is a White } \\
\text { woman thing-don't challenge, don't rock the boat, be positive, be } \\
\text { nice." On his next paper, Don "did a happy face. . much more } \\
\text { positive" paper and got a plus-plus with the comment, "Oh, great } \\
\text { work." Don felt "this is, like, a lack of integrity." }\end{array}$ \\
\hline Lorrie & $\begin{array}{l}\text { Always outspoken, Lorrie replied, "Yes I do." She perceived } \\
\text { "differences between expectations for male students and female } \\
\text { students." She explained: } \\
\text { Males were expected to speak right up, be very competitive-- } \\
\text { compete with one another as well as with the instructors. It was } \\
\text { like a caricature of how men are supposed to behave in society. } \\
\text { And women were supposed to be quieter, could get away with } \\
\text { more, were excused more. } \\
\text { Lorrie also recalled that she "had a woman as an advisor who was not } \\
\text { supportive of me at all." She took the issue to Dr. Buckley who } \\
\text { "smoothed the ground for me in terms of my proposal." She continued, } \\
\text { "So here is this male professor with whom I experienced a good deal of } \\
\text { gender inequity smoothing the pathway for me as [a] woman so I could } \\
\text { graduate." Lorrie concluded, "So it is an inequity, but inequities have } \\
\text { both positive and negative implications." }\end{array}$ \\
\hline Milburn & $\begin{array}{l}\text { Milburn began his response by asking the researcher to define } \\
\text { inequities. He commented, "And yeah, I think there were certain } \\
\text { inequities in not only gender but also culture." He then told of a paper } \\
\text { he had submitted to a female faculty member who told Milburn his } \\
\text { paper was sexist and derogatory against women. Unhappy with that } \\
\text { feedback, Milburn replaced the woman on his dissertation committee. } \\
\text { He considered the incident to be "a gender inequity. If I had been a } \\
\text { female student and written the same thing that would have never come } \\
\text { out." }\end{array}$ \\
\hline
\end{tabular}

Female interviewees' perceptions of gender inequities do not appear to correlate to whether these women offered examples of gender bias during their interview. Nine of 
22 female interviewees offered examples of gender bias as identified in the literature; however, only three of the nine female interviewees indicated that gender inequities existed in the USD Ed.D. Program. (Apparently, some examples of gender bias were not viewed as egregious.) Annie, Lorrie, Danielle, Diana, Goldie, and Agnes provided examples of a male-dominated classroom - four of these six felt class norms were masculine. Agnes also commented that men interrupt in the classroom. Lorrie felt she was viewed as confrontational and observed, "I was expected to do good written work but be quiet in class." (Butler and Geis [1990] reviewed similar behaviors that marginalize women in the classroom.) Lorrie and Rose believed class study material was masculine and ignored women's accomplishments. Penelope perceived a male professor was intimidating in the classroom and "felt pretty much on the periphery." Penelope and Genie both indicated a woman had to aggressively speak up to participate in class discussions.

As a related note, interviewees did not mention other frequently discussed gender bias behaviors. This observation is not intended to imply that these behaviors did not happen; however, they were not mentioned during interviews. For example, Sandler et al. (1996) noted that men complement women on their physical appearance rather than academic ability. Sandler et al. and Pearson and West (1991) observed that women were the victims of sexist language and crude humor. The fact that the (female) interviewees did not offer either of these two behaviors may indicate that mature male graduate students have outgrown such actions. On the other hand, the limited number of gender bias examples and the fact that some examples do not appear to be viewed as inequities may indicate a tolerance on the part of women and men for such behaviors. 


\section{Interview Analyses}

The first part of Chapter 4 reviewed interview results for demographic and gender influence questions, grouping interviewee responses to qualitative interview questions into general categories. This section analyzes interviewee responses and focuses on other findings. First, the section examines alternative analysis groups based on such factors as ethnic and racial minorities, androgynous females, and interviewees with limited opinions about classroom gender. These alternative analysis groups provide important data that support Chapter 5 analyses of dissertation research questions. The section then analyzes powerful personalities and powerful events that appear to influence interviewee perceptions of gender influence in the graduate classroom.

Alternate analysis groups provide subtle, non-gender based commonalities among interviewees, contributing insight into the findings about research questions. For example, when attempting to surface classroom gender bias issues, women seeking allies may find limited support from the limited gender opinion group or androgynous females. The discussion of powerful personalities and powerful events and their influence on interviewee gender perceptions also provides insight into gender bias issues. In a class taught by a powerful individual, micro inequities may seem secondary to other classroom dynamics.

\section{Alternative Analysis Groups}

During interview data analyses, the researcher identified commonalities and themes among interviewee groups that were not necessarily driven by a comparison of male and female data. The researcher identified four alternative analysis groups: (a) interviewees whose minority status appeared to influence their perceptions of the USD 
Ed.D. Program; (b) female interviewees with a self-reported androgynous background that appeared to influence their responses during interviews; (c) interviewees who expressed limited opinions about classroom gender; and (d) the second Canadian (International) Cohort whose interview results provided insightful observations into the dynamics of a graduate leadership studies program classroom.

Minority Status Interviewees

Excluding the three men who identified their minority status as White males, five interviewees identified race or ethnicity as a minority status. These interviewees made comments related to their minority status during the interviews; these comments suggested that minority status may have played an important role in minority interviewee responses to questions about the influence of gender in their graduate studies at USD.

While answering interview questions, Barbara made references to her minority status. For example, when asked if she had been demeaned in a class, she asserted that she was used to "dealing with people who try and demean you." After completing the interview questions, Barbara opined about diversity studies in the USD Ed.D. Program:

You have to be able to identify that there is a difference in leadership in different cultures in different people. And so, instead of identifying this is leadership, let's research. What can be considered leadership in the other cultures, in the other groups? And you have to do a little more digging.

Barbara later indicated that her primary study interest as a graduate student at USD was leadership in the African American community. While she focused on classroom gender as the interview topic, Barbara alluded to her minority interests during the interview. 
A First Nation Canadian, Carol quickly set her priorities. When asked what first came to mind about her class studies, Carol replied, "I guess being a minority; it wasn't dealing with any gender issues." She then added that being a minority was the first thing that came to mind because "it [her minority status] was a visible minority," which she felt was an advantage and helped her focus on why she was at USD. Carol recalled a class in which she was able to use her history education to add to a class discussion. She commented that "it just reaffirmed that I did have something to offer." Carol never felt mistreated by her classmates because of her minority status, but did believe "some of the faculty" may have slighted her.

Early in the interview Diana talked about her experiences as a "light, light colored Hispanic" woman:

But, on-site, most people don't realize I'm Hispanic. So it was funny because I know once in the classroom we did have a discussion and this other woman who was Hispanic said, "Well, we women of color." And somebody else said, "Well, who is the other woman of color? Who are you talking about?" And she said, “Well, Diana." And they were all, "What?" Of course they know I'm Hispanic, but in their minds, I guess. . . . it doesn't register automatically because they don't see the dark skin.

As previously discussed, Diana recalled an event when a White female professor "made the remark. . .that gender was the most impacting of all the differences." An African American male student "became very upset and said that no, that he thought race was. Race was such an issue and everything." Diana continued: 
What never was said by anyone which afterwards we all thought was clearly obvious answer was, why are we even bothering to compare which discrimination [is] more impacting or less impacting? Discrimination is discrimination and it depends on what is being discriminated. Obviously if you are an African American male, you are going to view it as part of a race issue. And as a woman, you know, you view it as a gender issue. As a Hispanic woman, you are little confused.

Diana later observed, "People don't like to be discriminated, but you're always hiding it with people you think are going to discriminate against you. . . .in the end [discrimination] ends up working more against you but, you know, who am I?"

Lenny's interview was very short. When asked what first came to mind about his USD studies, Lenny responded that he was the only Latino in the class: "I didn't see it as a plus as far advantage or disadvantage [sic]. I just looked around and there was no one else that looked like me in the class." Apparently, in each class, Lenny was reminded of his Hispanic heritage.

While Barbara, Carol, Diana, and Lenny appeared to believe their minority status was an element contributing to gender issues, Don's interview suggested that he believed his Latino heritage was the issue. As previously noted, when asked if he considered himself a minority, Don replied, "I very much considered myself a minority in the classroom. . . And that was very significant in how I experienced the program." When asked of his first recollections of the USD Ed.D. classroom, Don's responses were "privilege," "socioeconomic status," and not being in the "club." He spoke of several classmates who were not working full-time or "seemed to have an amount of resources at 
their disposal," while Don worked full-time and had to borrow money to complete his education. He referred to a "White woman's club" and a "White woman's mess" that he felt was "a more significant topic than the White male deal, the patriarchal deal." Don reflected on "the role that women took up" and described this role as a "White woman archetype." He felt White female professors were clueless about "diversity stuff" and believed gender, ethnicity, and race were "linked. I mean, that kind of raceousnicity and that kind of stuff is linked." Don's interview revealed his passion about the inequities he experienced as a Latino, and his responses focused on his perceptions of White privilege, White patriarchs, the White women's club, socioeconomic issues, and Latino inequities in society.

Two other interviewees revealed ethnic inequities during their interviews - both were Caucasian women. When discussing gender inequities, Gwen noted, "Had you asked about status, there might be status inequities." She then told of a high-ranking local politician who attended USD and may have received an advantage during her studies. Gwen also observed that the politician was a regular topic of discussion during her graduate studies. Gwen explained her rationale for her perspective:

I'm coming from a different perspective because where I live [on a Pacific island], I'm the minority. I mean, you can't [tell] by last name, but I'm Caucasian and I'm living in an environment where Caucasians make up less than $10 \%$ of the population.

It was interesting that Gwen did not reveal her minority status until late in the interview. Ultimately, Gwen apparently recognized that "discrimination is discrimination" (to quote Diana). 
Leilani worked in Hawaii public school administration for 18 years before leaving her job and Hawaii. She recalled:

Well, I will tell you that having been a Caucasian woman in Hawaii I know inequity when I see it. . . I was working over there in the educational arena, which was, as you probably know, primarily Japanese. And I had a wonderful woman who happened to be Chinese with whom I worked for many years and she said to me, "you have five strikes against you." And I said, "What!" And she said, "You're blonde, you're Caucasian, you're a woman, you're tall, and you're smart." And she was absolutely right. It was very difficult for me, which was one of the reasons I finally decided to give up after 18 years.

While at USD, Leilani never saw anything similar to the inequities she experienced in the Hawaiian school system.

By design, the dissertation was limited to a study of gender inequities - to have included other societal shortcomings might have proved an impossible study effort. And, as Diana noted, "discrimination is discrimination." In a graduate leadership study program, diversity influences include gender, race, ethnicity, age, and sexual preference, and the interaction of these diversity influences may not be well understood. Perhaps if a leadership program were to facilitate case studies in diversity, its students might not only appreciate each individual influence, but also better understand a society that attempts to blend diversity influences in a single classroom, a single community, or a single nation.

\section{The Androgynous Females}

During interviews, the researcher noted that about one third of female participants described their personal backgrounds or work environments as androgynous or 
masculine. Agnes, Annie, and Genie were tomboys; Gina had a masculine upbringing;

Grace currently works in a "male-dominated world;" and Marie and Mary were in a male-dominated engineering field before attending USD. During interviews, these seven women identified similar attitudes about gender and described a somewhat neutral (or androgynous) outlook toward men and gender issues. Table 12 provides examples of androgynous female statements from their interviews:

Table 12. Selected Androgynous Female Interview Responses.

\begin{tabular}{|c|c|}
\hline \multicolumn{2}{|r|}{ Responses that Identified Female Interviewees as Androgynous } \\
\hline Agnes & $\begin{array}{l}\text { "I get along great with men. I'm a tomboy. I get along great with men. } \\
\text { That's the language that I understand." Later Agnes added, "In many } \\
\text { ways, I get along better with men than I do with women because I } \\
\text { speak their [men's] language." }\end{array}$ \\
\hline Annie & $\begin{array}{l}\text { "All the other [interactions with men] were relationships of respect, } \\
\text { interactions of respect, camaraderie, mutual support. .I'm a sports } \\
\text { buff, so we talked sports with them [men]... .Oh, yeah, I'm } \\
\text { somewhat of a tomboy." }\end{array}$ \\
\hline Genie & $\begin{array}{l}\text { After describing some men as "a little more rambunctious than } \\
\text { others," Genie offered, "I can be pretty rambunctious myself." She } \\
\text { then acknowledged she was a tomboy. }\end{array}$ \\
\hline Gina & $\begin{array}{l}\text { "I operate more like a male. . than I do like a female. So, I felt like } \\
\text { my experience there was all about trying to earn respect and, as a } \\
\text { stereotypical male, the way I did that was by debate and conflict of } \\
\text { ideas and really going head-to-head with people." }\end{array}$ \\
\hline Grace & $\begin{array}{l}\text { ". . since ' } 86, \text { I have worked in a male-dominated world. . . . Because } \\
\text { I fly so much, I fly first [class] and it's very common for me to be the } \\
\text { only woman in the first class section. I work with all predominant } \\
\text { males in my connections with other companies." }\end{array}$ \\
\hline Marie & $\begin{array}{l}\text { "I used to work in engineering, and I've dealt with a male-dominated } \\
\text { field. And it was a very different environment than classroom school } \\
\text { teacher or classroom environment-even the men [in the classroom } \\
\text { environment] seemed nurturing and those kinds of values." }\end{array}$ \\
\hline Mary & $\begin{array}{l}\text { "I would have to say, I have exceptional collaboration with men." } \\
\text { During a class exercise, Mary, a mechanical engineer, interviewed a } \\
\text { retired Navy captain and was "very eager to learn more about } \\
\text { mechanical engineering practices onboard a Navy [aircraft] carrier." }\end{array}$ \\
\hline
\end{tabular}


These women's answers to interview questions represented fairly consistent, androgynous responses. Six of the seven felt their graduate experience at USD was positive; Agnes entered USD with her own agenda. In describing classroom events involving gender, four of the seven (Marie, Gina, Mary, and Grace) offered no strong opinions about gender. Only 2 of the other 15 women had no strong opinions about gender. None of the seven women described their interactions with men as negative or felt that a man would disagree with their answers. Two women (Agnes and Annie) felt men and women were treated differently, but both offered isolated incidents as justification for their answers. Only Annie felt she had been demeaned in class (an isolated incident) and only Gina believed she might have demeaned others because she "debated too strongly. . .you know, too firm in position."

While the androgynous females' perceptions of class norms varied, half used a logic that reflected either an understanding of gender differences or a process of elimination (Agnes, Genie, Annie, and Grace). Marie's logic was based on her engineering background. Gina felt class norms were based on the class composition (instructor's gender) — a response category more commonly offered by men. Finally, Mary felt class norms were neutral because the class was an equitable environment. All seven women did not believe gender inequities existed in the USD Ed.D. classroom.

The researcher analyzed androgynous females for two primary reasons. First, androgynous females, by their own admission, felt comfortable in a masculine environment; a similar subgroup of male interviewees who might feel comfortable in a feminine environment could not be so easily identified. (For example, only one Latino male [Don] felt class norms were masculine; only Edward indicated he was raised by 
three women and had an androgynous caring and genuine leadership style.) Second, the androgynous females represent a subgroup that might ally with each other and males in the classroom. As a result, women may be reluctant to challenge gender bias given other (androgynous) women may have agreed with men on some gender issue (Haslett \& Lipman, 1997).

The Limited Gender Opinion Group

Eleven interviewees expressed limited opinions on gender when asked to describe a classroom event involving gender. This group's responses to other questions were similar and supported their limited gender opinions. (Appendix F contains the analysis matrix for the limited gender group.) Table 3 (question 6) provides responses from the 11 interviewees with limited opinions on the influence of gender in the graduate classroom.

None of the members of the limited opinion group offered examples of gender events when describing what first came to mind about their graduate studies, all had positive comments about members of the opposite gender, and none felt a member of the opposite gender would disagree with their interview question answers. In describing class norms, no group members described class norms as masculine. Three felt class norms were feminine (Marie, Betsy, and David), two were undecided (Buford and Gina), and the remainder described class norms as gender neutral.

When considering whether women and men were treated differently, Marie was undecided and two men answered yes to this question. Buford described an isolated event in which a female instructor took exception to Buford's taking exception to class material. David believed Dr. Buckley was the only professor that "could come close" to treating women and men differently. 
Only Gina felt she might have been involved in a demeaning action. Gina (an androgynous female) felt she might have "debated too strongly" but would try to make amends in a male style and would tell a student, "Hey, buddy, I hope I didn't run over you there." Only Buford saw gender inequities based on the imbalance between the female majority and men. He observed that "things may have, I guess, slid that way [in favor of women]."

In summary, some USD Ed.D. Program students may have limited opinions or perceptions about classroom gender. They see the classroom as equitable, not particularly aggressive (not masculine class norms), and believe women and men understand each other and get along with each other. Half of the androgynous females (Marie, Grace, Gina, and Mary) are also in this group.

This group may contribute to continued classroom micro inequities. Their perceptions of limited gender issues may unintentionally discourage an open discussion of controversial gender issues. And, as frustrated students search for "the confidant and the ally" (Heifetz, 1994, p. 268) to support debate on gender issues, group members with limited gender opinions may appear insensitive to gender influences as a graduate classroom issue.

\section{The Second Canadian Cohort}

While analyzing interview data, the researcher quickly recognized the noticeable differences in the 42 interviewee perceptions of similar topics. For example, Maureen felt Dr. Buckley favored men, Lorrie believed he favored women, and Gina thought he favored neither gender. Given the variances in interviewee perceptions, the researcher began to question interviewee classroom experiences, wondering if they took at least 
some classes with other study participants. For example, it might be possible that interviewees took few if any classes together, and different perspectives resulted from interviewees taking classes from a professor at different times.

Unfortunately, data cannot identify whether interviewees actually have common experiences in the same class and yet different perceptions of that class. (For example, Agnes, Gina, Penelope, Mitch, and David graduated over a 3-year period but had very different perspectives of Dr. Buckley.) The year of graduation is not a good indicator that graduates were in the same classes together. Some interviewees took slightly more than 3 years to graduate while others took more than 7 years. The question becomes, "Is it possible for interviewees to have such diverse perceptions of USD Ed.D. classrooms even though they may have taken classes together?" Fortunately, the interview data does provide one example of interviewees who were in the same classes and yet have widely varying perceptions of classroom interactions.

During their USD residency period of about 8 months, the second Canadian (International) Cohort eventually included 11 students. Of these students, three were White men and three were First Nation Canadian women—-the other students were White women. Four members of this cohort (including one First Nation female) participated in the study. According to Nancy, these four members "went through every single course together as a group" and lived together during their 8-month residency at USD. However, their perceptions of those 8 months differ.

Nancy asserted, "While we were down there [at USD], we were literally were a family." Nancy felt the three First Nation women "had a phenomenal impact on our group." One of the First Nation women was training to be an Elder, and "her whole 
spirituality and that nurturing and mothering instinct kept the group together and then we learned a lot."

A First Nation Canadian, Carol felt her minority status was an advantage "because of the focus of why I was there [at USD]." Carol perceived the cohort's men were helpful, did not think men and women were treated differently, and did not see inequities in the classroom. More significantly, she felt she was well treated at USD and did not feel slighted by her classmates because of her minority status.

A third cohort member, James, appreciated the three "female aboriginal:" "What they brought to that class. . .was the uniqueness of not only the culture of the Canadian aboriginal, also the status of gender, the place of gender in that culture."

Ronald, however, saw the First Nation women as introducing "real issues in our cohort between First Nation and non-First Nation." He explained, "The minute you had quite a high percentage, you know, almost $25 \%$ of the class was First Nation; you've got perspectives on certain things around leadership and styles of leadership." When asked for an example, Ronald offered:

Good leadership is about value-added, about improving things. With the strong First Nation presence there, that desire, that philosophical goal, was very much flavored with a bitterness towards the past and, you know, and the undoing of wrongs. And. . that was something that probably neither male nor female Caucasian could really relate to.

Ronald closed by commenting, "I guess you have to walk in those shoes to know why." As this example suggests, perceptions of class events in the same classroom may strongly differ. Therefore, the perceptual differences of the 42 interviewees does not 
necessarily mean they were in different classes (but had the same professor); they could have different perceptions of the same (or similar) events or class participants.

Apparently, students interpret class events based on more than the instructor, peers, and class subject material.

This example also suggests a possible shortcoming in USD Ed.D. studies. Given the very different perspectives of First Nation students in the Canadian Cohort classroom (and ignoring the fact that the First Nation students were all women), the researcher speculated that classroom discussion may have avoided controversial issues - apparently strong negative feelings about First Nation female students did not surface during class (or casual) interactions. However, a leadership studies program that emphasizes diversity would seem to desire some controlled conversation about selected, sensitive topics. Apparently, with respect to Native Americans, such a conversation did not occur. Alternate Analysis Groups - Summary

The alternate analysis groups possess a common theme: all four suggest feminine topics such as gender bias may not be viewed as a point of emphasis by some graduate students. Minority groups may demand greater emphasis on minority issues, androgynous females may side with men on some issues, and students with limited gender opinions may be somewhat insensitive to gender issues. Finally, as shown in the second Canadian cohort, students may not reveal sensitive, controversial opinions during class discussion. Assuming half the graduate class is male, females (and possibly males such as Edward) who identify gender inequities may find few allies among their peers and may be reluctant to challenge micro inequities. As previously discussed, Haslett and Lipman (1997) observed that women may tolerate gender bias because of "the seeming 
'smallness' of each instance" (p. 38). Students may also tolerate micro inequities because they are apprehensive to raise controversial issues and not receive peer (or instructor) support if such issues are challenged in the classroom.

\section{What Drives Interviewee Perceptions of Graduate Classroom Gender?}

Chapter 4 recounts interviewee perceptions of gender in the graduate classroom. The obvious question becomes, "What appears to drive these perceptions?" Are there common themes that reoccur as interviewees recall classroom gender influences? The data suggest that gender perceptions appear strongly influenced by powerful personalities and powerful events. Using examples, this section attempts to document these two themes.

For powerful personalities, interviewees mentioned two professors, Drs. Buckley and Hopper, far more often than any others. ${ }^{18}$ In fairness, Dr. Buckley and Dr. Hopper may have been frequently discussed because they were among the few professors who taught in the USD Ed.D. Program when the majority of the interviewees were attending classes. They also appeared to be among the more controversial personalities on the faculty. Analyzing comments about these professors served two purposes: to provide examples of how powerful personalities influenced interviewee perceptions of classroom gender, and to document graduates' widely varying perceptions of the same two individuals and their classroom environments. This section should not be viewed as a criticism of either professor. There were more positive than negative interviewee comments made about the professors.

\footnotetext{
18 Twenty-nine of 42 interviewees discussed Dr. Buckley, Dr. Hopper, or both. Of the remaining 13 interviewees, approximately half did not mention any USD faculty member by name.
} 
This section also reviews examples of powerful events and the influence of those events on interviewee perceptions of gender. These powerful events not only reflect the vivid memories of classroom events, but also demonstrate that some strong perceptions of gender may be based on second-hand or one-sided information and may not necessarily represent a factually based, objective point of view.

The data on Dr. Buckley, Dr. Hopper, and powerful events appears to be influenced by the interviewees' gender. For example, more women than men expressed unfavorable comments about Dr. Buckley. In describing powerful events, men and women tend to recall events involving the opposite gender. For responses about Dr. Hopper, women's responses were split evenly between positive and neutral comments; about half the men's comments were negative-other male comments about Dr. Hopper were evenly divided between positive and neutral comments. This data suggest that interviewee perceptions of the influence of gender are stronger when the key actors are of the opposite gender-women tend to recall perceptions involving men and vice versa. Dr. Buckley.

Twenty-two interviewees discussed Dr. Buckley during their interviewees. Of those 22 interviewees, 12 ( 6 women and 6 men) had favorable comments, 5 (4 women and 1 man) had unfavorable comments, and 5 (3 women and 2 men) offered a somewhat neutral position. To summarize interviewee comments, Table 13 provides selected interviewee responses that, in part, represent the vastly divergent opinions about Dr. Buckley and his influence on perceptions of classroom gender. 
Table 13. Interviewee Responses about Dr. Buckley.

\begin{tabular}{|c|c|}
\hline$=$ & Favorable Responses about Dr. Buckley \\
\hline Ben & $\begin{array}{l}\text { Ben described his "program-long conflict with Dr. Buckley." Dr. } \\
\text { Buckley was on Ben's dissertation committee and, during Ben's } \\
\text { dissertation defense, Dr. Buckley "and I got into this tirade. . . and I } \\
\text { had had the foresight not to make Dr. Buckley the chair of my } \\
\text { committee." Apparently Ben viewed Dr. Buckley as having some } \\
\text { weaknesses and described Dr. Buckley as a "willful sort of person." } \\
\text { Ben, however, felt he was among the few students that got along with } \\
\text { Dr. Buckley. Ben described a Dr. Buckley class as one of the three } \\
\text { "most influential classes in my life." He characterized Dr. Buckley's } \\
\text { classes as a "masculine, academic exercise in confrontation and } \\
\text { argument." }\end{array}$ \\
\hline Danielle & $\begin{array}{l}\text { When describing interactions with male students, Danielle } \\
\text { commented, "God, I don't remember a single male, except Dr. } \\
\text { Buckley, and he wasn't a student." Although she first considered Dr. } \\
\text { Buckley sexist, she observed, "his bark was much worse that his bite." } \\
\text { She liked Dr. Buckley, but noted, "he's a tough cookie. . . and } \\
\text { certainly favored males over females." She declared, "He is an icon," } \\
\text { and "decorum was really important in Dr. Buckley's class." }\end{array}$ \\
\hline David & $\begin{array}{l}\text { David considered Dr. Buckley "one of the dominant people in the } \\
\text { whole program." David liked Dr. Buckley, but felt women and men } \\
\text { might view Dr. Buckley differently: } \\
\text { If you didn't take his bluff and you stood up to him and you } \\
\text { had valid reasons why you disagreed, he was very accepting. } \\
\text { But it was sometimes. . tougher on the women in the } \\
\text { classroom to confront him when he was saying something that } \\
\text { they strongly disagreed with. }\end{array}$ \\
\hline Gina & $\begin{array}{l}\text { Gina described her first recollections of classes at USD as "debating } \\
\text { Dr. Buckley." She explained, "I went round and round with Dr. } \\
\text { Buckley. I enjoyed it." (Gina would later comment, "When I grew up, } \\
\text { my father would sit at the table and we would debate.") Gina } \\
\text { volunteered, "I even had to rewrite a paper for Dr. Buckley. . .It was } \\
\text { a great paper but it was not to his standard. He made me rewrite it and } \\
\text { I have no doubt he would have made some guy rewrite it, too." }\end{array}$ \\
\hline Wilfred & $\begin{array}{l}\text { Wilfred viewed Dr. Buckley as "a grumpy old man, and a lot of } \\
\text { students didn't like him. . . But, you know, I didn't mind him." } \\
\text { Wilfred "respected his [Dr. Buckley's] knowledge as an informed } \\
\text { person." }\end{array}$ \\
\hline & Negative Responses about Dr. Buckley \\
\hline Don & $\begin{array}{l}\text { Don recalled his first meeting with Dr. Buckley. Don concluded he } \\
\text { was not coming to USD if Dr. Buckley represented the USD faculty. } \\
\text { Don felt Dr. Buckley cut people off and demeaned women. Don } \\
\text { believed Dr. Buckley expected women to be "quiet and not } \\
\text { challenging" and felt Dr. Buckley viewed the "role of women as } \\
\text { subservient-as not having as much to say was reinforced." Don felt }\end{array}$ \\
\hline
\end{tabular}




\begin{tabular}{|c|c|}
\hline & $\begin{array}{l}\text { both Drs. Buckley and Hopper "represent something larger. They're } \\
\text { kind of archetype..." }\end{array}$ \\
\hline $\begin{array}{l}\text { Female } \\
\text { Interviewee }\end{array}$ & $\begin{array}{l}\text { During one interview, a female interviewee became uncomfortable } \\
\text { discussing Dr. Buckley and was concerned he might discover what } \\
\text { she said during the interview. In his class, she felt powerless. }\end{array}$ \\
\hline Maureen & $\begin{array}{l}\text { Maureen recalled an incident in which she and two other female } \\
\text { students complained to Dr. Buckley about another professor and an } \\
\text { emotional classroom exercise. The three women felt the exercise got } \\
\text { out of hand and emotionally injured another female student. Dr. } \\
\text { Buckley "basically said. . .'you're crazy; forget it."' She observed that } \\
\text { nothing was done; "it was like we didn't exist." She acknowledged } \\
\text { Dr. Buckley was "a very intelligent person. .. but as a human being, } \\
\text { an individual in the teaching profession, I didn't respect him on that } \\
\text { part by the end [of my USD studies]." She also noted "the only person } \\
\text { I think really had gender bias about students was Dr. Buckley." }\end{array}$ \\
\hline Rose & $\begin{array}{l}\text { Dr. Buckley could elicit strong emotions from interviewees. During a } \\
\text { conversation after the formal interview completed, Rose asserted, "Dr. } \\
\text { Buckley I use as my example when I am teaching of the worst } \\
\text { teacher, professor, instructor I've ever had in my entire life." }\end{array}$ \\
\hline & Neutral Responses about Dr. Buckley \\
\hline Lewis & $\begin{array}{l}\text { Lewis described Dr. Buckley as "pretty garrulous" and "crotchety and } \\
\text { close-minded, perhaps." Lewis also commented, "I am never aware of } \\
\text { any woman complaining about it [Dr. Buckley's rough demeanor]." }\end{array}$ \\
\hline Lorrie & $\begin{array}{l}\text { Lorrie seemed to continually take issue with Dr. Buckley, asserting he } \\
\text { taught "a leadership course where all texts were completely } \\
\text { masculine - masculine authors, masculine pronouns, masculine telling } \\
\text { experiences." At one time, Dr. Buckley told her to "get over it and } \\
\text { perhaps a consciousness-raising group for me might be a good idea." } \\
\text { She described Dr. Buckley as "very scathing" but added, "I have a } \\
\text { good deal of admiration for Dr. Buckley." Dr. Buckley helped Lorrie } \\
\text { with her dissertation topic and "smoothed the ground" for her to } \\
\text { graduate. Lorrie felt Dr. Buckley treated women and men differently; } \\
\text { he } \\
\text { certainly was harder on male students than he was on females. } \\
\text { You could get away, for instance, as a woman-if your paper } \\
\text { was late or you had some excuse or he wanted a lot of } \\
\text { contributions during the class-if you sat quietly, you could be } \\
\text { excused as a woman. Male students were not let off the hook } \\
\text { like that. There were very clear behavioral norms for men. }\end{array}$ \\
\hline
\end{tabular}

Dr. Hopper.

Dr. Hopper's feminine approach and course material also seemed to influence interviewee perceptions. Seventeen interviewees mentioned Dr. Hopper in their 
interviews. Because her courses focused on feminine and gender topics, this large number of interviewee comments was not surprising. To provide a flavor for interviewee perceptions of Dr. Hopper, the researcher summarized data from six interviews.

Lorrie did not agree with Dr. Hopper's perspectives on women's issues. She did observe, however, that Dr. Hopper 'brought women's materials in and actually presented the perspective which I now describe as maternalistic. She used texts like woman's way of knowing, indicating that women have different ways of viewing the world than men." Lorrie continued, "But her inclusion of those materials gave me a chance to assess the extent to which I agreed with those arguments or didn't [agree]."

Wilfred took at least three classes from Dr. Hopper and grew tired of repetitive feminine study material. He felt "she was a very strong feminist and she always looked through the feminist lens." Later he commented, "It was about the third class with Dr. Hopper and was before the class and we started and I said, 'I've had enough of it [Dr. Hopper's feminine class material]."’

Nancy and Stennis briefly talked of Dr. Hopper's class. Nancy explained, “We talked about leadership; we talked about power and how men do it [power] differently than women because they have their own sense of power." Stennis described Dr. Hopper as one of his favorite professors and took all her classes he could.

Penelope described Dr. Hopper's women's study course:

It was one of those empowering and wonderful, wonderful courses. So sometimes I felt that there were gender issues that were negative. There were every bit as many if not more that were really positive. That class was life changing for me. 
Phil took several of Dr. Hopper's courses and "was thoroughly moved by the experience." He believed, "She was trying to bring out female aspects of that [moral development] as I recall:"

It was an eye-opening experience for me. I mean, it was a life-changing experience, actually. I began to much more understand the female experience. I don't pretend to really understand that relative to where I was before; I think it was an eye-opening experience.

Phil believed Dr. Hopper "somewhat intentionally structured the course so as to try to provoke an enhanced awareness on the part of men of women's issues." He recognized that some students felt Dr. Hopper emphasized feminism—Phil did not agree:

I didn't think she was pushing the feminist side at all. I thought what she was doing was in a very constructive way bringing greater awareness to we males who often have blind spots when it comes to understanding what women are experiencing in the workplace, private personal relationships, down the line. Powerful Events.

When discussing questions, interviewees offered powerful events that appeared to shape their perceptions of gender. This section reviews four such events. In the first event, a female professor left USD after what four interviewees viewed as philosophical and gender-based disagreements with other faculty members. The remaining three events were each discussed by a single interviewee.

Of the five men that graduated from the on-campus program in the 2 years after a female professor left USD, four mentioned her departure during their interview. (Apparently men felt very strongly about this event.) This professor's departure not only 
reflected a powerful event, but also provided insight into interviewee perceptions of gender. What were the information sources that influenced these four male interviewees' perceptions? Because it is doubtful that these four men had first-hand knowledge of behind-closed-door discussions, their perceptions were probably formed by one-sided perspectives or second-hand information. This example suggested that interviewee perceptions of classroom gender influences may not be based on objective or factual evidence.

Richard summarized his perceptions of faculty disagreements involving the female professor who left USD as follows:

It was a pretty heated conflict. And it appears part of it was differences in philosophy about the nature of leadership....I think there were some very traditional views of gender from [a male professor] that were challenged by [the female professor].

Milburn commented, "I don't know all the details;" but he believed a lawyer was involved "and there [were] some threats of lawsuits." Milburn felt the parties agreed to a legal settlement.

Don was apparently close to the female professor. He described her as connected with civil rights, farm workers, and people of color: "She was really identified with, you know, kind of ethnic group." Don believed she was not in the club and "had some clashes with some of the patriarchs." Don felt the female professor clashed with male faculty members over gender dynamics and with female faculty members about women's rights. He noted that "she brought her part to that tension" but did not support the "male patriarchal expression." 
The following are additional examples of powerful events; some were discussed in other sections of the dissertation. However, the researcher has summarized these events as further representations of the influence that powerful events had on interviewee gender perceptions.

After some thought, Maureen replied, "You know, in a way I do [think there was different treatment of women and men], but it was just my perception." She recalled a class when Dr. Buckley "without any warning, he picked myself and another girl to put us in two groups to lead the entire discussion; the whole class." Not prepared to lead a 3hour discussion, Maureen observed, "He didn't pick a guy. He picked two women." She felt demeaned and had problems with the assignment; Dr. Buckley "didn't try to help us." At the end of the exercise, Dr. Buckley said, "That shows you how detailed you have to be' which was maybe his point. But I just didn't think it was fair. I wish he would have chosen me and a guy."

Mario described a class designed to "trust in the silence;" the class was "very uncomfortable for everybody." During the class, a "pro female" student had an "epiphany or vision" and started to cry. She felt "males didn't appreciate her input, appreciate her feelings:"

She always had that slant to it that she. . had that the color of glasses that she wore was they [men] didn't trust her, didn't basically give her a grain of saltgive her her due because she was a female. And finally she realized that that wasn't the case. . . people are people. They are who they are.

Agnes recalled "the night that Dr. Buckley was so hard on a young woman. . that he literally drove her right out of the program." The young woman was "shy and not 
forthcoming" in discussing class topics. When she finally answered, Dr. Buckley "jumped on her and she left the room in tears and left the program....I thought that was unbelievably cruel." When asked whether women and men were treated differently, Agnes replied, "Dr. Buckley certainly treated them differently." She did not recall any other class or instructor that treated men and women differently.

\section{Summary}

In Chapter 2, the researcher synthesized commonly held perceptions about gender bias based on a literature review. To summarize interviewee perceptions of gender in the classroom, the researcher offers a similar synthesis of the USD Ed.D. Program classroom based on interview analyses.

In a class of 21 doctoral students (the number of interviewees divided by two), approximately $25 \%$ of the students do not consider gender issues to be significant. Two or three ethnic or racial minorities in the class might believe gender topics to be a lower priority than minority issues. At least one female student is outspoken and believes some professors underemphasize women's issues. At least one White male in the class may believe he is intellectually superior and unknowingly marginalizes women and possibly minorities as well. One, possibly two women feel intimidated and excluded in the class, but may not reveal their anxieties to others.

Informal subgroups of students with similar views of gender may exist in the graduate classroom. Possibly one in three female students may exhibit androgynous values and feel more comfortable around men than women. Some students view gender issues as secondary. Age differences may also exist, and older students may believe their 
age makes them a minority in the classroom. Some White males may also believe they are in the minority, particularly if the classroom includes more female than male students.

At times, a professor might take a controversial position on some topic, possibly challenging students to defend their responses. This controversial position may not be adequately debated among students who, unbeknownst to each other, have widely varying perceptions of the professor and whether the professor is treating students equitably. About $40 \%$ of the students believe women and men are treated differently and one in four students believe this class environment is inequitable.

In a class, a student may or may not see gender in the same light as a peer in the adjacent chair. Based on interview analyses, this synthesis appears to reflect the influence of gender in the USD Ed.D. classroom.

Interviewee responses to questions reveal similarities and differences in the women's and men's perceptions of classroom gender influences. These two research questions are addressed in greater detail in Chapter 5. In addition, the data reveal four alternate analysis groups that may unconsciously serve to limit classroom debate on gender topics. Finally, interviewee gender perceptions appear strongly influenced by powerful personalities and powerful events; interviewee responses do not appear to discuss routine, everyday class events (that may include micro inequities).

A final observation: There does not appear to be widespread, systemic gender bias in the USD Ed.D. Program. For example, only 6 of 42 interviewees mentioned gender when recalling what first came to mind about their USD Ed.D. studies. Of the nine female interviewees who discussed examples of gender bias, only three believed inequities existed in the USD Ed.D. classroom. While some interviewees provided 
creditable examples of gender inequities, these inequities appear isolated to individuals and not the school environment in general. In addition, interviewee perceptions of powerful personalities and their influence on gender in the graduate classroom significantly differ. This observation should not be viewed as a healthy diagnosis; however, neither is the USD Ed.D. Program terminally ill from a gender bias cancer. 


\section{CHAPTER 5. OBSERVATIONS AND RECOMMENDATIONS}

Introduction

This study investigated the similarities and differences in female and male perceptions of gender influence in the graduate classroom. Chapter 4 documented detailed analyses of qualitative interview questions and identified several alternate analysis groups. Chapter 5 offers an inductive analysis of each of the three research questions. Recall that the methodology emphasizes qualitative research based on the breadth of many telephone interviews instead of more detailed, in-person interviews using a smaller sample size. For this reason, opportunities for hypotheses may be limited. However, Chapter 5 does offer some insight into important classroom gender issues such as male privilege and socially constructed beliefs of accepted classroom decorum related to gender.

As in Chapter 4, the researcher uses data tables to present quotes and information relative to the research topic. Some entries in Chapter 5 data tables duplicate previous entries from the dissertation. The researcher deliberately reused data as appropriate to emphasize some point of discussion and for the convenience of the reader.

The First Research Question

The first research question examines the similarities in female and male perceptions of gender influence in the graduate classroom. The researcher identified four similarities in the responses of female and male interviewees. For each of these similarities, several interviewee responses serve as anecdotal examples of the similarity. Other possible similarities might exist, but anecdotal examples to support these similarities are limited. 
The first similarity involves the "quantitative" results of the qualitative interview response categories. For most questions, response categories (as represented by Figures 1 through 8) included approximately the same number of male and female responses. For example, six women and five men had limited opinions about gender in response to the question about a class event involving gender; eight women and eight men believed women and men were treated differently in the classroom; and five women and five men felt there were gender inequities in the USD Ed.D. classroom. Therefore, the researcher initially concluded that female and male interviewee responses were more similar than different.

The researcher's quantitative assessment of qualitative data was shortsighted, but not necessarily unexpected. First, as an engineer, the researcher's instinctive response to data analysis was to "look at the numbers"- to quantify the data. Second, Clay-Warner (2001) observed that "research in social identity theory demonstrates that individuals selectively perceive cues about their group's [e.g. men's] status in order to maintain selfesteem" (pp. 226-227). To some extent, avoiding the data details may have represented an unconscious effort to maintain male self esteem. The researcher suggests that these reflections are noteworthy; other men may subconsciously perform similar analysis to maintain their male self-esteem.

Recalling the influence of powerful personalities and power events on interviewee gender perceptions, a second similarity recognizes that interviewees most often recounted out-of-the-ordinary class events; few (if any) recounted routine class events. For example, while nine female interviewees revealed examples of gender bias during their interview, only three of the nine indicated that gender inequities occurred in the USD 
Ed.D. Program. Only six interviewees recalled gender events when asked to recount what first comes to mind about their graduate studies at USD. In addition, some frequently cited gender bias behaviors, such as sexist language and crude humor (Pearson \& West, 1991; Sandler et al., 1996), did not surface during interviews. This similarity suggests that gender bias may not be viewed as an out-of-the-ordinary occurrence. Thus, gender bias (inequities) may be viewed as everyday events and not worthy of special recognition.

For the next similarity, both female and male interviewees talked of outspoken faculty members and students who appeared to silence themselves. Table 14 provides brief examples of responses that involved outspoken individuals and how others perceived these individuals. (The discussion about powerful personalities in Chapter 4 also provided insight into the perceptions of outspoken individuals.) Apparently outspoken individuals might contribute to (or detract from) a class discussion, but may eventually silence themselves by their aggressive posture.

There also appears to be a gender bias in the perceptions of outspoken individuals - men tend to criticize outspoken women and vice versa. For example, Edward liked the strong male (voice) even though Edward did not necessarily agree with the male voice's position on all issues; however, Edward disliked the two strong female voices.

Paradoxically, both male and female interviewees appeared to have similar opinions of outspoken individuals (particularly women), believing they were not silent (in the class), but were silenced by their actions. This similarity alludes to the power of 
socially constructed classroom gender roles; men can be more aggressive, women should not (Brooks, 1982; Butler \& Geis, 1990).

Table 14. Sample responses about outspoken individuals.

\begin{tabular}{|c|c|}
\hline Agnes & $\begin{array}{l}\text { Agnes talked of the pompous and egotistical white males who "didn't } \\
\text { really have much to say to any of the women in the class or to the } \\
\text { minority men. And I find that kind of a male particularly abrasive and } \\
\text { I simply don't deal with it." }\end{array}$ \\
\hline Annie & $\begin{array}{l}\text { Annie talked of three female students who were quite vocal about } \\
\text { gender bias. In response to these three women, Annie wrote a paper } \\
\text { about androgynous leadership that focused on "why do we even need } \\
\text { to separate the genders? Why can't we just focus on leadership as } \\
\text { leadership and not separate females." }\end{array}$ \\
\hline Edward & $\begin{array}{l}\text { Edward spoke of "several strong voices on both the male and female } \\
\text { side" in his introductory leadership studies course; Edward's strong } \\
\text { voices included two female students and one male student. He } \\
\text { recalled that the male and female strong voices frequently argued in } \\
\text { class and noted the principal male strong voice "doesn't like women." } \\
\text { Edward concluded that both the male and female strong voices "said } \\
\text { they wanted to understand [each other]; but, in actuality, they were } \\
\text { unable or unwilling just to sit down and really consider it } \\
\text { [understanding each other]." }\end{array}$ \\
\hline Lorrie & $\begin{array}{l}\text { Lorrie agreed that she was viewed as confrontational and commented, } \\
\text { "I rarely had a class where my feeling wasn't that I was expected to } \\
\text { do good work but be quiet in class." }\end{array}$ \\
\hline Mitch & $\begin{array}{l}\text { Mitch discussed an ethics textbook; "I found it pretty inadequate." } \\
\text { When he revealed his feelings in class, "a couple of females } \\
\text {. . became really angry about the whole thing actually." The two } \\
\text { women vented their anger at female and male students who took the } \\
\text { opposite position about the text; the instructor (Dr. Hopper) sided with } \\
\text { the two angry women. Later, when asked to describe class norms, } \\
\text { Mitch said he felt norms "were gender neutral, except in Dr. Hopper's } \\
\text { class. Isn't that awful but it is true. Other than that [Dr. Hopper's } \\
\text { class] and again, the guys would just turn and say 'Well, that's Dr. } \\
\text { Hopper."' }\end{array}$ \\
\hline Wilfred & $\begin{array}{l}\text { Wilfred grew tired of repeated courses with Dr. Hopper that studied } \\
\text { leadership through a "female lens." During his third course with Dr. } \\
\text { Hopper, Wilfred told Dr. Hopper, "I just don't want to listen to this } \\
\text { different voice [(Gilligan, 1982)] stuff every day." }\end{array}$ \\
\hline & 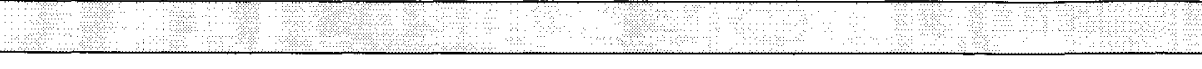 \\
\hline
\end{tabular}

The final similarity involves the nature of comments that interviewees made about members of both genders - in general, women tended to sympathize with other women 
and criticize men, and vice versa. Table 15 provides several examples of this similarity.

To some extent, interview questions may have contributed to this similarity, asking interviewees to discuss events involving the opposite gender or the differences in how men and women were treated in the graduate classroom. On the other hand, interviewees would volunteer events that reflected this trend, describing negative interactions with instructors or students of the opposite gender or supporting a member of the same gender.

As will be discussed, assuming that men still dominate in Western society, female interviewee criticisms of men might be understandable, reflecting these women's frustration with gender inequities. However, male interviewees also criticized womenparticularly female professors. Perhaps men feel a similar frustration with what they might view as gender inequities when women are in a "power position" such as a class instructor. This observation suggests that interviewee perceptions of gender inequities might be characterized as power inequities; clearly this is a topic deserving further research.

Table 15. Sample interviewee responses about gender sympathies and criticisms.

\begin{tabular}{|l|l|}
\hline Agnes & $\begin{array}{c}\text { Agnes talked of a lecture she gave at a private school: } \\
\text { There were probably close to } 100 \text { kids in the room-males } \\
\text { and females - and I was. . telling them about different } \\
\text { language styles. . .between males and females. And before I } \\
\text { knew it, the men, the guys, the young men were getting } \\
\text { extremely upset. They were feeling very threatened about } \\
\text { what I was saying. . that the women were going to be reaching } \\
\text { equality one of these days. And they almost couldn't keep } \\
\text { them quiet and at that moment, three Black, three Black } \\
\text { women, beautiful Black girls at the back of the room, and they } \\
\text { yelled at those men and they said, "She's absolutely right." } \\
\text { And I just loved it. }\end{array}$ \\
\hline Annie & $\begin{array}{l}\text { Annie was critical of a male student whose wife often came to Ed.D. } \\
\text { Program classes: } \\
\text { She sat around and kind of knitted or crocheted while she } \\
\text { waited for him-but not always in class, sometimes in the }\end{array}$ \\
\hline
\end{tabular}




\begin{tabular}{|c|c|}
\hline & $\begin{array}{l}\text { lounge area.... . But we saw interactions [with the male } \\
\text { student]. . .and notice that the way he treated his wife was the } \\
\text { way he treated the women in the [USD Ed.D.] program. } \\
\text { Annie later explained that male student made it clear "that her [his } \\
\text { wife] and any female opinion were not necessarily valued.". }\end{array}$ \\
\hline Diana & $\begin{array}{l}\text { Diana noted "there was one student but he was kind of, he just } \\
\text { thought he was smarter. . .better than everybody." She also recalled } \\
\text { another female Hispanic student who was "very righteous" and } \\
\text { "sometimes some of the other [female and male] students would make } \\
\text { fun of her because of that [her religious views]." Diana later } \\
\text { questioned whether the Hispanic woman was teased because of her } \\
\text { religious views or because of her ethnicity and gender. When asked } \\
\text { how she felt when students made fun of the other Hispanic woman, } \\
\text { Diana replied, "I felt unhappy. I felt. . .it was not fair." }\end{array}$ \\
\hline Don & $\begin{array}{l}\text { As previously noted, Don was particularly critical of White women. } \\
\text { At the end of the interview, Don concluded, "Well, only I'm thinking } \\
\text { out loud about what it means, I guess-how this idea of White woman } \\
\text { mess or whatever. How that, I think, is a more significant topic that } \\
\text { the White male deal, the patriarchal deal." }\end{array}$ \\
\hline Edward & $\begin{array}{l}\text { Edward observed "it's funny now listening to my comments because I } \\
\text { think I contradicted myself because early on I said I didn't think, you } \\
\text { know, that women were given preferential treatment." He suggested } \\
\text { that women might be given preferential treatment "if they played this } \\
\text { [gender] card." He cited an example of a female student whose } \\
\text { dissertation was selected as "the best dissertation for that year." } \\
\text { Edward had not read the dissertation but suggested the female student } \\
\text { won the award because of a friendship with a senior female faculty } \\
\text { member. }\end{array}$ \\
\hline Milburn & $\begin{array}{l}\text { Milburn could be critical of female faculty members and sympathetic } \\
\text { with male faculty members. He recalled a } \\
\text { piece he wrote for a class and turned it into a short story. And } \\
\text { I wanted her [a female faculty member] to read it and give me } \\
\text { some feedback. And she read it and her statement was that my } \\
\text { story was very sexist and derogatory against women teachers. } \\
\text { And when I heard that I never went back to her. } \\
\text { Milburn later asserted that "if I had been a female student and written } \\
\text { the same think, that [my story was sexist] would have never come } \\
\text { out." He then talked of a male instructor who "really fought for the } \\
\text { students. And he [the male instructor] went head-to-head with several } \\
\text { of the female professors at the School of Ed [sic] and this was totally } \\
\text { gender. I mean he didn't get his [teaching] contract renewed." }\end{array}$ \\
\hline Nancy & $\begin{array}{l}\text { Nancy recalled a group project in which a male student did not } \\
\text { complete his part of the assignment. Nancy "got angry with him } \\
\text { because we weren't able to move forward and all the other [student } \\
\text { project] groups were moving forward." (Milburn recalled a similar } \\
\text { event with a female student.) }\end{array}$ \\
\hline
\end{tabular}




\begin{tabular}{|c|c|}
\hline Phil & $\begin{array}{l}\text { Phil recalled a class incident in which } \\
\text { one young woman was acting almost hostile toward me and to } \\
\text { another older guy. And I was puzzled by it-I didn't know } \\
\text { her. . . .Well, during some of the discussion, it finally came out } \\
\text { that I. . .reminded her of some male authority figure in her life } \\
\text { that really hurt her. } \\
\text { Phil later observed } \\
\text { I don't think there were inequities [in the USD Ed.D. } \\
\text { classroom], but I think there were differences. And I believe it } \\
\text { comes down to the differences between men and women in a } \\
\text { gender sense, in that there was recognition by the women } \\
\text { professors that some women students need a different type of } \\
\text { support [such as "extra understanding" during "an emotional } \\
\text { time. . at home"], and maybe more support than the guys did. } \\
\text { And it [support] was given to them [female students] if it was } \\
\text { asked [for]. }\end{array}$ \\
\hline Rose & $\begin{array}{l}\text { Rose cited a simple example of women and men being treated } \\
\text { differently. In a class, a female student } \\
\text { spoke in her writings about feminists. . . Oh my God, she } \\
\text { started talking about feminists. Why none of the readings [in } \\
\text { the Ed.D. program] include women and. . . [the male } \\
\text { professor] made incredibly disparaging comments about } \\
\text { feminism and feminists and I wouldn't admit that if I were } \\
\text { you. And then, the whole set of interactions continued into the } \\
\text {...class. . .and, oh, it was just brutal. He [the male professor] } \\
\text { was just not kind and made a point about talking about } \\
\text { feminists this and feminists that. It was just not kind at all. It } \\
\text { surprises me. I like the man a lot. }\end{array}$ \\
\hline
\end{tabular}

The Second Research Question

The second research question examines the differences in female and male perceptions of gender influence in the graduate classroom. Chapter 4 addressed some differences in female and male perceptions of classroom gender influences. For example, female and male perceptions of class norms differed. In general, female interviewees classified class norms as gender neutral or masculine using analysis logics emphasizing gender differences and a process of elimination. Male interviewees viewed class norms 
as neutral or feminine, emphasizing a class composition analysis logic. Some female interviewees revealed they were androgynous, while few male interviewees (such as Edward) stated they were androgynous. However, to fully answer to this research question requires a qualitative assessment of what women and men said, including the differences, the conflicts, and the subtleties in interviewee responses. When deeply examined, these responses reveal differences between women and men in their views toward male privilege.

McIntosh (1988) discussed men's unwillingness to recognize their privilege in society, noting, "Denials which amount to taboos surround the subject of advantages which men gain from women's disadvantages. These denials protect male privilege from being fully recognized, acknowledged, lessened, or ended" (p. 1). McIntosh then discussed the parallels between male privilege and White privilege "which is similarly denied and protected, but alive and real in its effects" (p. 1). The remainder of McIntosh's paper emphasized White privilege, but continued to intertwine the topics of male privilege and White privilege.

Ultimately McIntosh (1988) concluded "the word 'privilege' now seems to me misleading. Its connotations are too positive to fit the conditions and behaviors which 'privilege systems' produce" (p. 12). McIntosh noted that "'privilege' carries the connotation of being something everyone must want" (p. 12). She concluded that privilege consisted of "unearned advantage and conferred dominance [underlined in original]" (p. 14) and noted that "a man's sex provides advantage for him whether or not he approves of the way in which dominance has been conferred on his group" (p. 18). Thus male privilege is the unearned and unrecognized advantage of being a man. 
In their research on gender in the college classroom, Canada and Pringle (1995) examined "the social construction of gender differences in classroom interactions" ( $\mathrm{p}$. 161), including topics such as gender bias and male privilege. They observed the "tendencies of male students to expect and to exert male privilege, and. . .[introduce] gender politics in the classroom" (p. 180). In their conclusions, Canada and Pringle stated:

The tolerance for the gender politic, the tolerance for quiet students and dominant students in the classroom, and the tolerance for letting things sort themselves out as they will seem to us to guarantee the status quo as our society as a whole denies it, and that, as the literature amply documents, is far too frequently at the expense of female students. (p. 182)

Canada and Pringle appear to suggest a linkage between male privilege and gender bias.

The answer to the second research question assumes that male (and White ${ }^{19}$ ) privilege exists, and that gender bias and male privilege behaviors and influences overlap. Given this assumption, interviewee responses appear to reinforce the existence of male privilege in the USD Ed.D. classroom; these responses also reflect a difference in women's and men's perceptions of the influence of gender (e.g., male privilege).

As an example, interviewee responses to question 6 (describe a classroom event involving gender) allude to the influence of male privilege. Male interviewees recalled events in which only women were the key players while female interviewees recalled events involving both men and women. This observation suggests that men may identify "gender events" as feminine and "do not see themselves as having gendered identities"

\footnotetext{
${ }^{19}$ While the dissertation emphasizes gender bias and male privilege, selected quotes by Diana and Don may reveal perceptions of the influence of White privilege in the USD Ed.D. classroom.
} 
(McIntosh, 1988, p. 15). Apparently female interviewees feel both women and men have gendered identities.

Table 16 provides sample female responses related to male privilege. These responses suggest several themes. First, the phrase "male-dominance" (or equivalent) appears in several female responses. Male responses infrequently use similar terms and the term "female-dominance" is noticeably absent from interviewee transcriptions.

Second, when compared to male interviewees' perceptions of women, female interviewees appear to express a much deeper recognition of male students' shortcomings, using powerful words such as arrogant, idiots, stupid, and dominant. Female interviewees appear to recognize male privilege more so than male interviewees, and reflect on "how prominent male values and behaviors are" (Diana).

Finally, female interviewees appear to express frustration over male privilege. They talk of dominance and intimidation, and adopt masculine class norms to academically compete. Female interviewees value studies of women's voices and efforts to achieve gender equality in academia, but characterize progress as slow. They appear to recognize that equality demands confrontation of men who consciously or unconsciously think men are in charge.

Table 16. Sample female responses about male privilege.

\begin{tabular}{|l|l|}
\hline Agnes & $\begin{array}{l}\text { Agnes provided an example of male privilege in her discussion of the } \\
\text { "male jerks." She described, "White males in our program who were } \\
\text { quite pompous and quite egotistical and they didn't really have much } \\
\text { to say to any of the women in the class or to the minority males." She } \\
\text { later added the "egotistical group of about four or five men tried to } \\
\text { dominate—often dominated the discussions in the classroom and were } \\
\text { famous for interrupting any woman's point of view." (She described } \\
\text { interrupting as "a male style of communication.") Agnes noted that in } \\
\text { academia, "men tend to dominate the style [pedagogy]." "We're } \\
\text { progressing [toward gender equality], but we're progressing slowly." }\end{array}$ \\
\hline
\end{tabular}




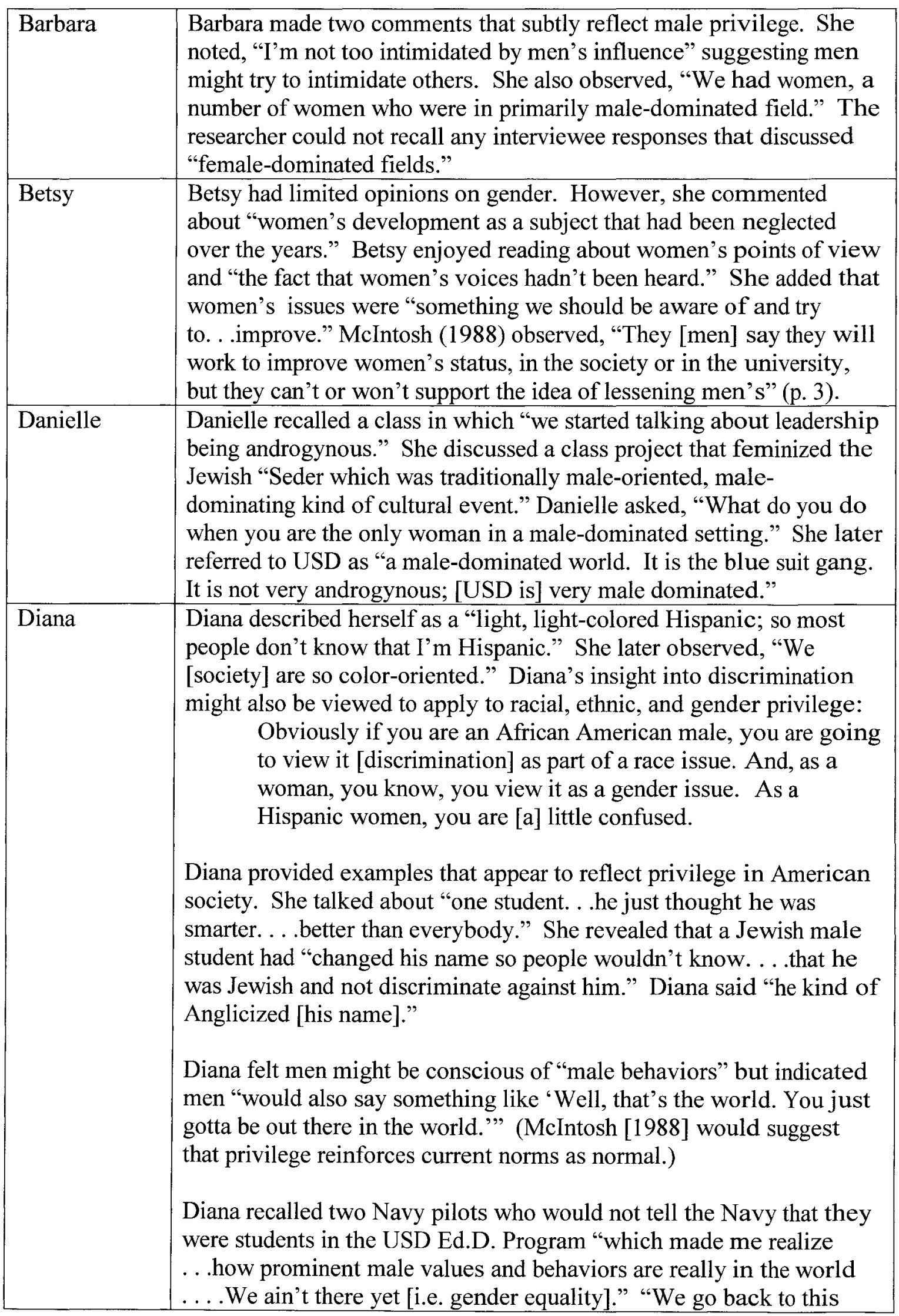




\begin{tabular}{|c|c|}
\hline & $\begin{array}{l}\text { dominant, cultural dominance. ... You just gotta learn to deal with it } \\
\text { kind of response." }\end{array}$ \\
\hline Genie & $\begin{array}{l}\text { Genie described herself as a "rambunctious" tomboy and enjoyed } \\
\text { classroom interactions as "all in good fun. You know, just spirited } \\
\text {...in the spirit of the day." However, Genie "had to take issue with } \\
\text { some of the things they [men] had to say. . saying stupid things." She } \\
\text { emphasized that "you [men in general] can say some pretty stupid } \\
\text { things." Genie observed, "In my own mind, it's pretty clear that there } \\
\text { aren't any gender [inequities]-it's just inequalities. Some people } \\
\text { would just see it based on how they were in the world." "I wonder } \\
\text { whether or not people of color felt differently because I don't know. } \\
\text { You know, I'm not of color so I don't know." }\end{array}$ \\
\hline Jane & $\begin{array}{l}\text { Jane insightfully observed that men would "probably like to think } \\
\text { they were in charge." "I don't think that most men want to think that } \\
\text { women are in charge." When asked if men tried to be in charge in the } \\
\text { graduate classroom, Jane replied that she thought women in the class } \\
\text { would not allow men to take charge: "It was just a good balance and I } \\
\text { just think they [men] were probably smart enough to realize that [men } \\
\text { taking charge of the class] wasn't going to work." }\end{array}$ \\
\hline Lorrie & $\begin{array}{l}\text { By her own words, Lorrie was "confrontational" and her USD Ed.D. } \\
\text { experience was "a constant struggle." For example, Lorrie described } \\
\text { one male professor as an "overpowering class presence"-possibly } \\
\text { suggesting a dominance relationship in that class. } \\
\text { Lorrie asserted that "the Null Curriculum is what is not present." She } \\
\text { added, "And the class norm in terms of the Null Curriculum was this } \\
\text { absence of female authors and references [in Ed.D. classes]." } \\
\text { McIntosh (1988) wrote: } \\
\text { The denial of men's overprivileged state takes many forms in } \\
\text { discussion of curriculum change work. Some claim that men } \\
\text { must be central in the curriculum because they have done most } \\
\text { of what is important or distinctive in life or in civilization. (p. } \\
\text { 3) }\end{array}$ \\
\hline Nancy & $\begin{array}{l}\text { Nancy's summary of gender and leadership might also be viewed as a } \\
\text { backdrop for male privilege: } \\
\text { We talked about leadership; we talked about power and how } \\
\text { men do it differently than women because they [men] have } \\
\text { their own sense of power. . because they were brought up } \\
\text { differently or socialize differently. ... Women come at it } \\
\text { [leadership] from a different angle. . . .It's [a women's } \\
\text { leadership perspective] different, not better, just different. }\end{array}$ \\
\hline Penelope & $\begin{array}{l}\text { Penelope felt men and women were treated differently in the USD } \\
\text { Ed.D. classroom: "The conversations were very much directed more } \\
\text { toward men and women had to be pretty assertive." "I felt very much } \\
\text { on the periphery." Penelope appeared to look for affirmation and } \\
\text { observed, "I know that there were other women who thought the same }\end{array}$ \\
\hline
\end{tabular}




\begin{tabular}{|l|l|}
\hline & $\begin{array}{l}\text { way that I felt" about a "very masculine dominant experience" in a } \\
\text { certain male professor's class. Penelope preferred a "safe" class } \\
\text { where "I felt there wasn't going to be judgment. The norms of the } \\
\text { class were very well set." }\end{array}$ \\
$\begin{array}{l}\text { Penelope did not think men would "have the emotional undertones [in } \\
\text { their responses to qualitative interview questions] that I had in times } \\
\text { especially where I felt very uncomfortable." Penelope later asserted } \\
\text { there was "a total male dominance in the classroom." "I think, in } \\
\text { general, it was a male dominant discussion. I was not the only one that } \\
\text { felt this way." }\end{array}$ \\
$\begin{array}{l}\text { "I had some interactions with male colleagues who I thought were } \\
\text { complete idiots. And, I guess in my arrogance, figure that they were } \\
\text { unaware.... Unaware of their. . status in society and the privilege } \\
\text { that they have." Rose continued, "I used to use the word "arrogance' } \\
\text { a lot. I don't any more; I just use 'ignorance." The researcher } \\
\text { speculated on the correlation between the word ignorance and its root } \\
\text { ignore. With respect to privilege, the two words appear strongly } \\
\text { correlated- does being ignorant of the benefits of privilege equate to } \\
\text { ignoring the impact of those benefits on others? }\end{array}$ \\
\hline
\end{tabular}

Table 17 provides sample male responses related to male privilege. In general, men contradict expressed views believing they treat others (in academia) equitably, but yet subtly demeaning women. Men consider confrontation as an academic exercise and do not consider the influence that male privilege might have on a heated debate. Men tolerate other points of view, view a "guy's thing" as acceptable justification for exclusion, and voluntarily defend the "defenseless." Men look at the world through a male lens and some view females as emotional, advantaged, or not interested in a "highly theoretical" graduate program in leadership studies (Ben). Men "are taught not to recognize male privilege" (McIntosh, 1988, p. 1), working "from a base of unacknowledged privilege" (McIntosh, p. 4).

Table 17. Sample male responses about male privilege.

\begin{tabular}{|l|l|}
\hline Ben & $\begin{array}{l}\text { Ben praised male professors describing them as "genius" and } \\
\text { "fabulous," but was critical of female professors. For example, he } \\
\text { described one female professor as a "typically [sic] psychologist who }\end{array}$ \\
\hline
\end{tabular}




\begin{tabular}{|c|c|}
\hline & $\begin{array}{l}\text { treated everybody badly." (Ben's undergraduate degree was in } \\
\text { psychology.) } \\
\text { Ben asserted, "Every class was highly theoretical. And. . . a lot of } \\
\text { students, mostly women, were not interested in that. ...I don't know } \\
\text { whether they had the tools or not [for a "highly theoretical" } \\
\text { program]." "I was just rejuvenated [by the USD Ed.D. Program]" and } \\
\text { became a "world-class scholar." }\end{array}$ \\
\hline Buford & $\begin{array}{l}\text { Early in the interview, Buford asked who runs the USD Ed.D. } \\
\text { Program. The researcher replied, "The head of the School of } \\
\text { Education is Paula Cordiero." Buford commented, "I don't know } \\
\text { him." } \\
\text { Buford's answers reflected both his age and gender. He referred to } \\
\text { the researcher as "young man" and noted "obviously I think very } \\
\text { highly of the students I met there [at USD] - both boys and girls." } \\
\text { Buford felt he and other men did not take debates or challenges } \\
\text { personally, describing disagreements as "professional. I never } \\
\text { thought it was personal." Other male interviewees (Mitch, Lewis) } \\
\text { expressed similar views of student interactions. McIntosh (1988) } \\
\text { observed that privilege provides "cultural permission not to hear } \\
\text { voices. . or a tepid cultural tolerance for hearing or acting on such } \\
\text { voices" (pp. 11-12). By not viewing disagreements as personal, men } \\
\text { may not reflect on how their privilege influenced the disagreement. }\end{array}$ \\
\hline Carl & $\begin{array}{l}\text { Carl volunteered that he was "a White male" and added his minority } \\
\text { status included his older age. Carl referred to older men as "male } \\
\text { gray hairs" and felt younger students might be intimated by older, } \\
\text { "father-like" doctoral students. (Apparently younger students may not } \\
\text { have been intimidated by "mother-like" doctoral students.) } \\
\text { In a weekend seminar, Carl established a volunteer, male-only small } \\
\text { group session to discuss "why do guys not communicate well?" He } \\
\text { acknowledged that women might have viewed the members of the } \\
\text { male-only group as "gender bullies" but did not regret his actions, } \\
\text { asserting the group was a "sort of guy's thing." (The researcher can } \\
\text { only speculate on how men might view a women-only small group } \\
\text { session.) } \\
\text { When asked if he believed gender inequities existed in the USD Ed.D. } \\
\text { classroom, Carl equated inequities to student grades and said, "So I } \\
\text { don't think I really felt there was any inadequacies at all or } \\
\text { inequalities in being male [added for emphasis]." }\end{array}$ \\
\hline David & $\begin{array}{l}\text { David observed that there "tended to be a lot of women in the [USD } \\
\text { Ed.d.] program." While he did not consider himself a minority in the } \\
\text { classroom, he volunteered that he was a "mainly White male, etcetera, } \\
\text { etcetera; I just don't even think about it [gender]." David appeared }\end{array}$ \\
\hline
\end{tabular}




\begin{tabular}{|c|c|}
\hline & $\begin{array}{l}\text { sensitive to gender dominance, noting in his work environment he was } \\
\text { often a "member of the dominant group." However, he also stated, "I } \\
\text { do my best to be tolerant of a lot of points of views." "I think in most } \\
\text { cases, I have promoted women." McIntosh (1988) observed that the } \\
\text { privileged "are taught to think of their lives as morally neutral, } \\
\text { normative, and average" (p. 4). }\end{array}$ \\
\hline Don & $\begin{array}{l}\text { A Latino, Don's interview focused on White privilege. When asked } \\
\text { what first came to mind about his USD Ed.D. studies, Don replied } \\
\text { "privilege," "socioeconomic status, and. . .it seemed to be a club." } \\
\text { (Don was not in the "club.") Don talked of the "White women who } \\
\text { supports whatever the male, you know alpha male, the White male } \\
\text { archetype leader will do." Don referred to the "White woman's club," } \\
\text { "the dominant [White male] group," and described academia as "a } \\
\text { very particularly kind of [White] male patriarchal expression." }\end{array}$ \\
\hline Edward & $\begin{array}{l}\text { Edward was the one male interviewee who felt he had an androgynous } \\
\text { leadership style: On a "masculine-feminine [leadership] scale," "I fall } \\
\text { more toward the center but more toward the feminine side than the } \\
\text { masculine side. I was raised by three women." He noted, "And so, I } \\
\text { can relate to that feminine style. That's how I lead, you know. I'm a } \\
\text { very caring people [sic]. I love my people [who work for me]." "I'm } \\
\text { a very impassive kind of person. I can. . .read the non verbals going } \\
\text { on." } \\
\text { Edward was critical of some female students whom he felt } \\
\text { manipulated the class by seeking sympathy: "They played the gender } \\
\text { card [by being emotional in class]...[and] tugged at [the] heart strings } \\
\text { of others." Edward "came to the aid of [a] woman; I defended the } \\
\text { woman" but other women criticized him for his unsolicited chivalry. } \\
\text { Edward also attacked men "because of their views of women." He } \\
\text { felt women had an advantage in the USD Ed.D. class: "I think more } \\
\text { men would say women had a leg up on men based on their [women's] } \\
\text { gender." Edward also thought that "a few women were a little weak } \\
\text { [as students]" and were given preferential treatment. As McIntosh } \\
\text { (1988) notes, when the privileged "work to the benefit of others, this } \\
\text { is seen as work which will allow 'them' to be more like "us"" (p. 4). }\end{array}$ \\
\hline Lewis & $\begin{array}{l}\text { Lewis pursued his Ed.D. studies as "purely self-development." He } \\
\text { noted that "trying to figure out people's motives is an amazingly } \\
\text { difficult thing." } \\
\text { Lewis talked of incidents in which a woman would say to him, "What } \\
\text { would you know about it [a gender topic]." He felt such challenges } \\
\text { were a "harmless jest, not a serious reproach." (See Buford and Mitch } \\
\text { for similar incidents.) } \\
\text { At the end of the interview, Lewis challenged the researcher, asking } \\
\text { "what caused you to even think that there were gender inequities at }\end{array}$ \\
\hline
\end{tabular}




\begin{tabular}{|c|c|}
\hline & $\begin{array}{l}\text { this particular university [USD]." McIntosh (1988) noted, "Our male } \\
\text { colleagues do not have a great deal to lose in supporting Women's } \\
\text { Studies, but they do not have a great deal to lose if they oppose it } \\
\text { either" (p. 14). }\end{array}$ \\
\hline Mitch & $\begin{array}{l}\text { Mitch revealed a class in which he was critical of an ethics text, } \\
\text { noting that "coming from my very Western, very male-dominated, } \\
\text { linear perspective of ethics that she [the text's author] at that point } \\
\text { developed it, to be quite inadequate." Mitch observed that two female } \\
\text { students became angry with his position on the text and the female } \\
\text { professor's response "was a little one-sided" in favor of the two } \\
\text { women. Mitch later indicated he appreciated women who (like him), } \\
\text { entered into "a good critical analysis of [leadership] theory } \\
\text {... without a lot of emotional connection." } \\
\text { During his studies at USD, Mitch recalled a woman saying, "Well, } \\
\text { you know you're a man. No wonder you don't understand that } \\
\text { [gender issue]." Like Lewis and Buford, Mitch did not feel there was } \\
\text { "animosity in this statement." }\end{array}$ \\
\hline Phil & $\begin{array}{l}\text { Phil described his minority status as "older White male." He viewed } \\
\text { this status as positive, observing his status represented "something } \\
\text { that we were able to bring to the program as opposed to a negative." } \\
\text { Phil spoke highly of Dr. Hopper who was trying "in a very } \\
\text { constructive way [to] bring greater awareness to we males who often } \\
\text { have blind spots when it comes to understanding what women are } \\
\text { experiencing." However, Phil also asserted "there was a recognition } \\
\text { by the women professors that some women students need a different } \\
\text { type of support, and maybe more support than the guys did. And it } \\
\text { was given to them if it was asked." When asked to provide an } \\
\text { example of a "different type of support," Phil replied a woman might } \\
\text { be having "an emotional time at home." }\end{array}$ \\
\hline Wilfred & $\begin{array}{l}\text { Early in the interview, Wilfred asked, "If there is no gender influence } \\
\text { in this [USD Ed.D.] program, what prompted you to select this } \\
\text { topic?" While Wilfred's initial comment suggests he did not see any } \\
\text { gender influences in the graduate classroom, he later indicated he was } \\
\text { not interested in looking at the world through a "female lens." He } \\
\text { noted, "Where I was looking for leadership, I didn't really care if it } \\
\text { was male or female. I really didn't care." But later he said he was } \\
\text { tired of literature that was "always from a perspective of a feminist } \\
\text { point of view." McIntosh (1988) noted, "We need more } \\
\text { understanding of the ways in which white [or male] 'privilege' } \\
\text { damages white people [or males]" (p. 15). }\end{array}$ \\
\hline
\end{tabular}


In one related area, female and male interviewees were somewhat in agreement: both genders expressed opinions about female study topics and many suggested the USD Ed.D. Program provided their first exposure to the study of women's issues. However, few interviewees talked of study material about male topics. Perhaps male topics were not emphasized because interviewees perceived that class study material was already replete with male authors and examples. Overexposed to male issues, perhaps academia sees little benefit in further emphasizing male privilege through dedicated study. On the other hand, perhaps a comparison of male privilege (in the context of social construction) to minority issues might reinforce diversity as a leadership study topic.

In summary, McIntosh (1988) observed that "'privilege' may confer power" (p. 12). Men appear to be ignorant of, or ignore, this power; women appear more sensitive to its influence on women's graduate studies.

Research Question 3: Leadership Education Programs and Gender

The first two research questions examined the similarities and differences in the perceptions of women and men concerning gender influences in the graduate classroom. The third research question asked what interviewee perceptions of gender reveal about a leadership education program and efforts to reduce classroom gender bias. In essence, this research question addresses two issues: (a) what interviewee perceptions reveal about a leadership education program and (b) what interviewee perceptions reveal about efforts to reduce classroom gender bias. These two issues are addressed separately.

Interviewee Perceptions and a Leadership Education Program

When evaluating what interviewees' gender perceptions reveal about a leadership education program, their perceptions about class norms provide noteworthy insight. Half 
the interviewees believe class norms are gender neutral and the logic that most interviewees applied to classify class norms does not emphasize gender differences. By its very nature, to classify class norms as feminine, masculine, or gender neutral should include some consideration of gender differences. To believe class norms are feminine or gender neutral because the instructor is a woman or because most students in a class are women appears to ignore (or be ignorant of) the subtle inequities in language and actions that marginalize a student. For example, Diana (Table 15) told of a Hispanic woman who was teased by other students; Ben (Table 3) provided less than flattering comments about a female student's misinterpretation of a Whitney Houston song.

In further evaluating perceptions of class norms, only one man (Don, a Latino) believed class norms were masculine and Don was also the only man whose perception of class norms was based on an understanding of the differences between the genders. Only two men (Al and Stennis) applied a process of elimination logic to decide class norms were gender neutral, and both had previously expressed limited opinions about gender. Thus, the relatively few interviewees that classified class norms based on gender differences and the variety of logics used to classify class norms suggest that a common understanding of gender issues in the USD Ed.D. classroom may be limited.

The differences in interviewee responses related to male privilege also suggest that classroom gender issues may not be well understood, particularly among male interviewees. Female interviewees appear to understand men's shortcomings and are frustrated by such classroom issues as male dominance. Male interviewees appear to be ignorant of the "conferred dominance" (McIntosh, 1988, p. 12) they enjoy from male privilege. 
Answers to other questions also suggest gender issues may not be well understood in the USD Ed.D. classroom. For example, only about one in four of the interviewees believe inequities exist in the USD Ed.D. classroom. Interviewees appeared somewhat indecisive when asked how the opposite gender might respond to the interviewee's responses to questions. In addition, as shown in the Chapter 4 discussion of the second Canadian cohort, students who take several classes together may be unaware of powerful biases concerning other students or groups of students.

Other factors may reveal insight into interviewees' understanding of gender influence the classroom as well. About $40 \%$ of the interviewees believed men and women were treated differently, approximately one in three females may be androgynous, and minorities may consider gender a secondary issue. Perhaps interviewees view gender through different lenses (and perhaps a leadership studies program should help focus these lenses), or perhaps interviewees do not have a common understanding of the influences of gender in the graduate classroom.

So, what do these perceptions reveal about a single leadership education program? First, to some extent, Agnes summarized these perceptions when she asserted she "wanted to study women" for her dissertation and "I went to the Nursing Department [at USD] and I took classes in feminist prospective because I wanted to see how other women thought." These perceptions (and Agnes) appear to suggest that USD Ed.D. Program studies may not adequately address gender topics in study programs. While some classes may tangentially consider gender topics, in-depth study and debate about gender appears limited - there is not a course that emphasizes case studies of diversity topics such as gender, race, ethnicity, sexual orientation, and age. And, in a leadership 
study program, the medium for exposing many students to a topic is a course dedicated to that topic.

\section{Interviewee Perceptions and Efforts to Reduce Classroom Gender Bias}

As noted in Chapter 1, social construction defines acceptability in everyday life, including classroom participation norms, gender values, and relationships among peers. To understand how to (possibly) minimize classroom gender bias, educators might need to understand the socially constructed beliefs that may perpetuate gender inequities in the graduate classroom.

Based on a review of the dissertation data, the researcher proposes three (new) socially constructed beliefs about gender that may subtly influence the USD Ed.D. classroom. During interviews, these beliefs were sometimes specifically stated and also could be inferred from interviewee remarks and data themes. The following pages introduce these beliefs. More research is required, however, to explore the nature of these beliefs and to understand their influence on gender inequalities in the graduate classroom. Heifetz (1994) described the concept of "getting to the balcony" as:

Consider the experience of dancing on a dance floor in contrast with standing on the balcony and watching other people dance. Engaged in the dance, it is nearly impossible to get a sense of the patterns made by everyone on the floor. Motion makes the observation difficult. Indeed, we often get carried away by the dance .... To discern the larger patterns on the dance floor - to see who is dancing with whom, in what groups, in what location, and who is sitting out which kind of dance - we have to stop moving and get to the balcony. (pp. 252-253) 
Applying Heifetz's analogy (with slight modification), the researcher proposes three socially constructed beliefs about graduate classroom gender: macro gender, the difference paradox, and the veneer effect. Macro gender represents the view from the balcony; the difference paradox and the veneer effect reflect the view from the dance studio floor.

\section{Macro Gender}

Macro gender is the view from the balcony. From the balcony, one can appreciate the apparent harmony of the dance but will not see the partner who occasionally steps on another's toe or the couple out of step with each other. In macro gender, if one takes a high-level view of gender in the classroom, one will probably not see gender bias micro inequities. As an example, characterizing class norms as gender neutral by a process of elimination reflects macro gender. Barbara best illustrated macro gender when she commented, "There were individuals [women] who saw it [gender inequities]. But then if you look at the overall group, I don't think we really thought so [e.g. that inequities existed at USD]." Table 18 provides additional examples of macro gender in the dissertation data.

\section{The Difference Paradox}

The difference paradox represents a view from the dance studio floor. A leadership concept, the difference paradox represents the dance instructor's point of view. The instructor cannot teach all the dance students as though they have similar needs. In the dance, some must lead and some must follow; some want to waltz and some want to square dance. Graduate students (people) are different. 
Simply stated, the difference paradox reflects the belief that women and men are different but should not be treated differently. When a shy female student is driven out of the USD Ed.D. Program by an aggressive professor, this is the difference paradox in action. The female student is different from other students, but is not treated as an individual. The difference paradox does not suggest that a leader should change his or her group leadership style, but rather when dealing with an individual, leadership should be tempered by the situation and the individual. For example, Agnes appeared to be sensitive to the difference paradox: "But the academic method is to challenge and to pick apart ideas and not always in a supportive manner, and I felt many women were threatened by this." Leilani's perspective appeared to differ: "I think men are expected to do the kind of interacting and arguing and verbal muscling more than women are. And I don't know that affected any of the women. . .but it might have." Table 18 provides additional examples of the difference paradox in the dissertation data.

\section{The Veneer Effect}

The veneer effect is the view of the dance student who must ask inquisitive questions, try new steps, and not be afraid of criticism or failure. The student must take a single dance move and try to place that move within the context of the dance. The student must also realize that the beauty of the final dance provides an attractive layer that overlays hours of hard practice (or emotional classroom gender debate).

Funk \& Wagnalls (1993) define the noun veneer as "a mere show or pleasing appearance." As a verb, veneer is defined as "to conceal with an attractive or deceptive layer" (p. 902). The veneer effect occurs when class gender discussions reflect a mere show and address obvious issues without considering the underlying implications of this 
deceptive layer. The veneer effect avoids deep, visceral gender issues and focuses class discussions on an attractive overlay of superficial gender topics. The veneer effect hides controversial, confrontational gender emotions such as Genie's feelings that men say stupid things, Rose's revelation that some men are idiots, Jane's assertion that men "would like to think they were in charge," or Agnes' contempt for the four or five pompous White "male jerks." (Male interviewees did not provide similar powerful criticisms of women.) Table 18 provides additional examples of the veneer effect in the dissertation data. Not all are negative. Danielle and Mario discuss class events that reveal positive gender influences, while Gina provides perceptive insight into female and male graduate student motivations.

Table 18. Data table for socially constructed beliefs about classroom gender.

\begin{tabular}{|l|l|}
\hline David & $\begin{array}{l}\text { Data Reflecting Macro Gender } \\
\text { gender really got into it all. It doesn't cross my mind very often." If } \\
\text { gender does not cross one's mind, what is the likelihood one will see } \\
\text { gender micro inequities? }\end{array}$ \\
\hline Lewis & $\begin{array}{l}\text { After completing interview questions, Lewis challenged the researcher } \\
\text { and asked, "What caused you to even think that there were gender } \\
\text { inequities at this particular university?" He later described female } \\
\text { students as goal-oriented and noted that if women had been mistreated, } \\
\text { "They would not have let it lay. They would have been talking to } \\
\text { somebody about it because they didn't appear to me to be women who } \\
\text { were going to tolerate too much nonsense." In Navy slang, the view } \\
\text { from the dance floor equates to saying, "The devil is in the details." } \\
\text { Lewis' view appears to minimize the subtleties of gender in the } \\
\text { classroom; appearances are deceiving and the dissertation data } \\
\text { suggested some women did tolerate nonsense. }\end{array}$ \\
\hline Mario & $\begin{array}{l}\text { Mario spoke of changes in the USD administration that promoted } \\
\text { women to senior positions such as the Dean of the School of Education. } \\
\text { Mario noted, "Let's say it [the new administration] was a good } \\
\text { representation of both sides [genders] of the house. Pretty much it was } \\
\text { balanced, I thought." In Mario's logic, if the number of senior school } \\
\text { officials was balanced between women and men, there should be } \\
\text { limited gender inequities in the graduate classroom. }\end{array}$ \\
\hline Milburn & $\begin{array}{l}\text { Milburn felt a paper he wrote was unduly criticized as sexist. He } \\
\text { described this incident as "a gender inequity. If I had been a female }\end{array}$ \\
\hline
\end{tabular}




\begin{tabular}{|c|c|}
\hline & $\begin{array}{l}\text { student and written the same thing, that [criticism] would have never } \\
\text { come out." From the balcony, one views criticism as inequitable; from } \\
\text { the dance floor, one asks why the reviewer felt the paper was sexist. }\end{array}$ \\
\hline Question 11 & $\begin{array}{l}\text { Question } 11 \text { asked interviewees if class norms were masculine, } \\
\text { feminine, or gender neutral. In their responses, some interviewees } \\
\text { applied a logic system involving a process of elimination to identify } \\
\text { class norms as gender neutral. A process of elimination implies a macro } \\
\text { gender belief system. From the balcony, if one does not observe } \\
\text { masculine or feminine behaviors, class norms must be gender neutral. } \\
\text { Other logic systems also reflect macro gender. To identify class norms } \\
\text { as feminine because the instructor was a woman or the class had more } \\
\text { women than men suggests macro gender logic-from the balcony, } \\
\text { more women than men equals feminine class norms. }\end{array}$ \\
\hline Thomasina & $\begin{array}{l}\text { Thomasina felt class norms were gender neutral and noted, "we } \\
\text { discussed male leaders and female leaders and. . the differences in } \\
\text { leadership styles." Thomasina also felt there were no inequities in the } \\
\text { USD classroom; she did not observe any demeaning acts; and she } \\
\text { believed women and men were treated the same. She also commented } \\
\text { that women were better students but men were better leaders. When } \\
\text { asked if she was a minority, Thomasina asserted she was in the } \\
\text { majority. She was ethnically White, female, and Canadian, and that was } \\
\text { an advantage. A member of the majority may possess limited views of } \\
\text { gender from the balcony. }\end{array}$ \\
\hline & Data Reflecting the Difference Paradox \\
\hline $\mathrm{Al}$ and Lenny & $\begin{array}{l}\text { Al proclaimed, "I think we all were equal even though everybody was } \\
\text { from. . quite varied backgrounds." He added, "Everybody treated } \\
\text { everybody else like equals." Lenny expressed a similar concept. When } \\
\text { asked if he had committed demeaning actions, Lenny replied, "No, I } \\
\text { don't think so. I'm hoping everybody's the same." As this } \\
\text { dissertation's data show, others do not agree that "everybody's the } \\
\text { same." For example, some interviewees believed women and men were } \\
\text { not equitably treated in the graduate classroom. }\end{array}$ \\
\hline Ben & $\begin{array}{l}\text { Ben provided additional insight into the difference paradox. One of his } \\
\text { answers suggested a possible conflict with the notions of the difference } \\
\text { paradox: } \\
\text {...so women, I mean, if anything, I've treated them, well, I've } \\
\text { treated them like any other human being walking around. I } \\
\text { wouldn't go so far to say I treating [sic] like objects, they were } \\
\text { just like-I treated them the same way I treated men. I didn't } \\
\text { make any particular differentiation between the two genders. I } \\
\text { think there are some women who might have been disappointed } \\
\text { by that, not because they particularly wanted me, but because } \\
\text { they enjoyed the attention. And other women just didn't really } \\
\text { care. }\end{array}$ \\
\hline Edward & $\begin{array}{l}\text { Edward believed men and women were treated differently in the } \\
\text { graduate classroom and that there were gender inequities at USD. He }\end{array}$ \\
\hline
\end{tabular}




\begin{tabular}{|c|c|}
\hline & $\begin{array}{l}\text { felt class norms were neutral, however, and explained, "a vast majority } \\
\text { of classmates understood it's about the character of the individual, not } \\
\text { gender." How can women and men be treated differently, how can } \\
\text { gender inequities exist, and yet gender not influence the character of an } \\
\text { individual? }\end{array}$ \\
\hline Genie & $\begin{array}{l}\text { Genie noted that masculine norms were assertive, independent, and } \\
\text { aggressive while feminine norms were gentle and kind. Genie } \\
\text { recognized that the two genders were different. However, her } \\
\text { subsequent description of class norms revealed that women were } \\
\text { expected to conform to masculine class norms: "If you wanted to } \\
\text { participate in the dialogue, you couldn't, you wouldn't sometimes wait } \\
\text { your turn." Later in her interview, Genie questioned the "cultural } \\
\text { diversity" in her workplace: } \\
\text { What I came away with was that there wasn't any specific } \\
\text { inequality around it [the workplace], but the environment was a } \\
\text { White male European environment. So, if you came from a } \\
\text { different background than that and you didn't know how to } \\
\text { operate in that environment successfully, you had strikes against } \\
\text { you. } \\
\text { Genie did not believe there were any "specific inequalities," although if } \\
\text { one did not know how to operate in a "White male European } \\
\text { environment... .you had strikes against you." }\end{array}$ \\
\hline 2 & Data Reflecting the Veneer Effect \\
\hline $\mathrm{Al}$ & $\begin{array}{l}\text { Al observed, "We didn't focus on gender per se, unless it was part of an } \\
\text { article or chapter in a book or something." Al also observed that "most } \\
\text { of the people I felt pretty close to were women and we did have a lot of } \\
\text { conversations. . .before class." He also noted his group (of fellow } \\
\text { students) "did a nice job of keeping it [classes] neutral." In reflection, } \\
\text { why discuss issues before class and why keep a leadership class } \\
\text { neutral; upcoming examples will resurface these concerns. }\end{array}$ \\
\hline Betsy & $\begin{array}{l}\text { Betsy recalled an adult development class with "specific books and } \\
\text { study focused on women, and women's development as a subject that } \\
\text { had been neglected over the years." She continued, "this gender was } \\
\text { addressed as an interesting academic subject and something we should } \\
\text { all be concerned about." }\end{array}$ \\
\hline Danielle & $\begin{array}{l}\text { Danielle provided a positive example of classroom gender discussions. } \\
\text { She told of a group assignment that performed a "Jewish Seder as a } \\
\text { cultural experience." During this educational exercise, the group used } \\
\text { an orange to "womanize the Seder which was a traditionally male- } \\
\text { oriented, male-dominating, kind of cultural event." }\end{array}$ \\
\hline Gina & $\begin{array}{l}\text { At times during her interview, Gina would offer deep, reflective } \\
\text { perceptions of men and women in the graduate classroom. Now an } \\
\text { Assistant Professor of Leadership, Gina's current position may have } \\
\text { influenced these perceptions. Such perceptions may also be appropriate } \\
\text { in a graduate classroom debate. As one example, Gina offered, "I think } \\
\text { graduate students have a greater need to prove themselves. So the need, }\end{array}$ \\
\hline
\end{tabular}




\begin{tabular}{|c|c|}
\hline & $\begin{array}{l}\text { the way I see it, is there is a stereotypical male-female driver. Females } \\
\text { typically need love and the males typically desire respect." }\end{array}$ \\
\hline Jane (and Al) & $\begin{array}{l}\text { Jane lauded the professors for keeping "things on an even keel. And I } \\
\text { think that they did an excellent job of doing that." Why would Jane } \\
\text { want leadership classes to be on an even keel? Why would Al desire a } \\
\text { neutral class environment? Leadership involves controversy and (at } \\
\text { times) making unpopular decisions. An even keel suggests a don't- } \\
\text { rock-the-boat approach to management, and may be preferable to } \\
\text { women who seek classroom cooperation and camaraderie. }\end{array}$ \\
\hline Mario & $\begin{array}{l}\text { Mario discussed a powerful classroom event in which a female student } \\
\text { experienced an "epiphany" about her negative views toward men. He } \\
\text { observed that "she kind of lightened up after that." Such events might } \\
\text { force graduate students to consider new perspectives of gender. }\end{array}$ \\
\hline Milburn & $\begin{array}{l}\text { Milburn was concerned that he might be viewed as "a little gender } \\
\text { inconsiderate" and that he might say things that women would find } \\
\text { inappropriate. He commented that he "mainly kept my mouth } \\
\text { shut. . I'd think things and just walk away. So I got into very few } \\
\text { discussions with people." In the absence of classroom gender } \\
\text { discussions, peer feedback for Milburn might be limited. }\end{array}$ \\
\hline $\begin{array}{l}\text { Several } \\
\text { Interviewees }\end{array}$ & $\begin{array}{l}\text { Al talked of discussions with female students before class. Don, } \\
\text { Edward, Lewis, Buford, and Mitch also referred to out-of-class } \\
\text { discussions, some of which were somewhat heated. As noted by } \\
\text { Danielle, in classes "it seemed like everything had to be polite; very } \\
\text { structured." However, polite classroom conversations avoid difficult } \\
\text { gender topics, leaving these to after-class discussions. }\end{array}$ \\
\hline
\end{tabular}

The three socially constructed beliefs about acceptable classroom behaviors provide insight into why gender bias remains an issue in academia. Macro gender may provide a subconscious excuse to ignore micro inequities; the difference paradox may provide a subconscious excuse to ignore individual differences in personalities and preferences in the classroom; and the veneer effect appears to reveal why sensitive, classroom debate avoids emotional topics, such as gender bias. To invite classroom debate on these three socially constructed behaviors may make both women and men uncomfortable. Such a discussion might challenge a woman's desire for collaboration and camaraderie, and a man's subconscious desire to perpetuate male privilege. While 
some students may prefer a safe, don't-rock-the-boat environment, others may question whether "the lack of incidents [in the classroom] was abnormal" (Buford).

\section{Recommendations for Further Studies}

This dissertation attempted to capture the breadth of gender perspectives from the USD Ed.D. classroom. Because the study emphasized a breadth of perceptions, it does not provide the detailed data necessary to support accepted qualitative analysis conclusions such as grounded theories, generalized findings, or phenomenological essence. However, the data does provide a myriad of potential follow-on research topics that might spark some future study effort. Potential follow-on research topics (in no particular order of emphasis) include the following:

1. The USD Ed.D. Program may differ from other leadership study doctoral programs. Students attend classes part-time, are relatively older and more mature, and have often achieved some success in their chosen professional field. A study that compares USD Ed.D. Program gender study data with other leadership study doctoral programs should be considered.

2. The dissertation assumes that undergraduate gender bias studies are not generalizable to the graduate classroom and that a similar study of full-time, younger, undergraduate students might yield different results. To some extent, dissertation results appear to confirm this assumption. Doctoral program graduates (particularly women) are assertive, and most are not easily intimidated. A study to validate this assumption should still be considered.

3. The dissertation assumes some overlap exist in the concepts of gender bias and the concepts of male privilege. The research also suggests a possible correlation 
between gender bias and power. When some men consider "White male" a minority status or when men become frustrated in a female-majority classroom, the response may reflect perceptions related to an unfamiliar loss of power or male privilege. While this dissertation provides limited emphasis on the relationships among power, gender bias, and male privilege, further study of these relationships should be considered.

4. The dissertation proposes three socially constructed beliefs about classroom gender. A follow-on study should be considered to evaluate the existence of each socially constructed belief and its possible influence on the classroom and the influences of gender bias.

5. During interviews, some women felt that female graduates of the USD Ed.D. Program exhibited more masculine (or androgynous) traits than other females. A study that explores this observation should be considered.

6. By design, interview questions produced approximate results. For example, approximately $50 \%$ of interviewees felt class norms were gender neutral. These approximate results beg for quantitative research to determine the statistical significance of response data and to conduct analyses of variance of answers to interview questions. A quantitative study of interview question responses should be considered.

7. The dissertation suggests that ethnicity and race influence perceptions of gender in the graduate classroom. This apparent relationship should be explored because it is possible that an ethnic minority student might consider gender a secondary issue. A study of the relationship between gender and other minority factors should be considered. 
8. The dissertation data suggests some female students have androgynous views of gender that differ from other women in the classroom. A study of these possible differences should be considered.

9. During interviews, two women introduced the concept of a safe class environment into the discussion. In literature reviews, references did not specifically discuss a safe classroom environment. The notion of a safe classroom environment and what it might mean to female students should be explored.

The dissertation assumed that the telephone interview was the appropriate medium to gather qualitative research data on the perceptions of graduate classroom gender. This assumption does not appear to require further study. The telephone interview encouraged participation by graduates who had limited opinions on gender in the classroom. The telephone interview supported a larger sample size and included participants who live outside San Diego County. And, to the best of his knowledge, the researcher did not intimidate any interviewees during telephone interviews.

\section{Summary}

Having spent more than 3 years in the study of classroom gender influences, I write this summary in first person.

Early in my dissertation effort, my chairperson advised me that until I could describe my research in one or two sentences, I had not yet adequately defined my dissertation topic. After extensive reflection on her guidance, I described my research effort as follows: 
This dissertation compares the perceptions of male and female graduates concerning the influences of gender on their doctoral education. This dissertation evaluates perceptual similarities and differences to identify the phenomenological essence of gender bias in the graduate classroom.

After my proposal defense and with the insight of my committee, I changed my methodology from a phenomenological investigation to a generic qualitative study. My dissertation, however, continued to emphasize a comparison of the similarities and differences in the perceptions of doctoral program graduates on the influence of gender in the classroom, and what these perceptions reveal about a doctoral leadership study program and gender bias. This summary documents what I have learned.

From a quantitative point of view, I have found that female and male perceptions of graduate classroom gender appear to be more similar than different. An equal number of women and men have limited opinions on gender, perceive women and men to be treated differently in the graduate classroom, perceive class norms as gender neutral, and perceive that gender inequities do not exist in the graduate classroom. Approximately $25 \%$ of female and male USD Ed.D. Program graduates have limited opinions on gender influence in the graduate classroom, another $25 \%$ believe gender inequities exist in the graduate classroom, and the remainder are somewhere in between.

However, qualitative analyses suggest there are differences in female and male perceptions of graduate classroom gender influences, particularly with respect to male privilege. Female interviewees appear more sensitive to the nature and impact of male privilege, while male interviewees appear to ignore its influence in the classroom. 
I have found limited evidence of institutionalized gender bias in the USD Ed.D. Program classroom. For example, only 10 of 42 interviewees felt inequalities existed in the USD Ed.D. classroom. In addition, because of similarities in many interviewee responses regardless of interviewee gender, it appears that a graduate classroom of 42 students may be best analyzed as a group of 42 individuals, and not 22 women and 20 men.

Interviewee perceptions of classroom gender appear driven by powerful personalities and powerful events. Interviewees may ignore ordinary classroom events, including micro inequities. In addition, I believe class subgroups such as androgynous females or students with limited gender opinions may not support class debate on gender bias. Finally male interviewees appear insensitive to the advantages of male privilege. These findings may contribute to continued gender inequalities in the USD Ed.D. Program.

In the classroom, socially constructed beliefs about gender appear to contribute to the perpetuation of classroom gender bias. I believe my investigation has exposed three possible socially constructed beliefs. Students apparently believe that if they view gender from the balcony and do not see micro inequities as a result of this view, such a belief is acceptable. Students apparently believe that if they treat each other the same way (regardless of gender), such a belief is acceptable. Students apparently believe that if they avoid debating sensitive gender issues in the classroom and only admire the deceptive veneer overlay of acceptable topics, such a belief is acceptable.

As a final observation, female and male interviewees appear to have a limited understanding of gender differences and how these differences influence the graduate 
classroom in the USD Ed.D. Program. Further efforts, such as case studies in diversity, appear necessary to prepare students with the professional knowledge they will need for leadership in a diverse society. 


\section{REFERENCES}

Alemán, A. M. M. (1997). Understanding and investigating female friendship's educative values. Journal of Higher Education, 68 (2), 119-159.

Archer, J., \& Lloyd, B. (2002). Sex and gender ( $2^{\text {nd }}$ ed.). Cambridge, England: Cambridge Unversity Press.

Ary, D., Jacobs, L. C., \& Razavieh, A. (1996). Introduction to research in education $\left(5^{\text {th }}\right.$ ed.). Fort Worth: Harcourt Brace College Publishers.

Auster, C. J., \& MacRone, M. (1994). The classroom as a negotiated social setting: An empirical study of the effects of faculty members' behavior on students' participation. Teaching Sociology, 22, 289-300.

Banks, T. L. (1988). Gender bias in the classroom. Journal of Legal Education, 38 $(1 / 2), 137-146$.

Beagan, B. (2001). Micro inequities and everyday inequities: 'Race,' gender, sexuality and class in medical school. Canadian Journal of Sociology, 26 (4), 583-610.

Belenky, M. F., Clinchy, B. M., Goldberger, N. R., \& Tarule, J. M. (1997). Women's ways of knowing: The development of self, voice, and mind. New York: BasicBooks.

Bennett, S. K. (1982). Student perceptions of and expectations for male and female instructors: Evidence relating to the question of gender bias in teaching evaluation. Journal of Educational Psychology, 74 (2), 170-179.

Blanton, G. B. (2004, April). An evaluation of recommendations to reduce college gender bias: Do recommendations consider differences between female and male students. Paper presented at the meeting of the American Association for the Advancement of Curriculum Studies, San Diego, CA.

Boersma, P. D., Gay, D., Jones, R. A., Morrison, L., \& Remick, H. (1981). Sex differences in college student-teacher interactions: Fact or fantasy? Sex Roles, 7 (8), 775-784.

Bogart, K. (1981). Technical manual for the institutional self-study guide on sex equity. Washington, DC: American Institutes for Research. (Cited in Hall and Sandler, 1982.)

Brooks, V. R. (1982). Sex differences in student dominance behavior in female and male professors' classrooms. Sex Roles, 8 (7), 683-690. 
Butler, D., \& Geis, F. L. (1990). Nonverbal affect responses to male and female leaders: Implications for leadership evaluations. Journal of Personality and Social Psychology, 58 (1), 48-59.

Caelli, K., Ray, L., \& Mill, J. (2003). 'Clear as mud': Toward greater clarity in generic qualitative research. International Journal of Qualitative Methods, 2 (2), 1-24. Retrieved September 10, 2005, from the ABSCOhost Academic Search Premier database.

Canada, K., \& Pringle, R. (1995). The role of gender in college classroom interactions: A social context approach. Sociology of Education, 68, 161-186.

Caplan, P. J. (1993). Lifting a ton of feathers: A women's guide for surviving in the academic world. Toronto: University of Toronto Press.

Civil Rights Act, Pub. L. No. 88-352, 42 U.S.C.A § 2000e (1964).

Clay-Warner, J. (2001). Perceiving procedural injustice: The effects of group membership and status. Social Psychology Quarterly, 64 (3), 224-238.

Cooper, E. A., \& Bosco, S. M. (1999). Methodological issues in conducting research on gender in organizations. In G. N. Powell (Ed.) Handbook of gender \& work (pp. 477493). Thousand Oaks, CA: Sage Publications.

Cornelius, R. R., Gray, J. M., \& Constantinople, A. P. (1990). Student-faculty interaction in the college classroom. Journal of Research and Development in Education, 23 (4), 189-197.

Crawford, M., \& MacLeod, M. (1990). Gender in the college classroom: An assessment of the "chilly climate" for women. Sex Roles, 23 (3/4), 101-122.

Daly, J. A. (1986). Communication apprehension in the college classroom. In J. M. Civikly (Ed.) Communicating in college classrooms (pp. 21-31). San Francisco: Jossey-Bass.

Deaux, K. (1984). From individual differences to social categories: Analysis of a decade's research in gender. American Psychologist, 39 (2), 105-116.

de Groot, S. C. (1980). Female and male returnees: Glimpses of two distinct populations. Psychology of Women Quarterly, 5 (2), 358-361.

Denzin, N. K., \& Lincoln, Y. S. (1998). Collecting and interpreting qualitative materials. Thousand Oaks, CA: Sage Publications. 
Dey, E. L., Korn, J. S., \& Sax, L. J. (1996). Betrayed by the academy: The sexual harassment of women college faculty. Journal of Higher Education, 67 (2), 149-173.

Drew, T. L., \& Work, G. G. (1998). Gender-based differences in perception of experiences in higher education. Journal of Higher Education, 69 (5), 542-555.

Eisner, E. W. (1991). The enlightened eye: Qualitative inquiry and the enhancement of educational practice. New York: Macmillan Publishing Company.

Fassinger, P. A. (1995). Understanding classroom interaction: Students' and professors' contributions to students' silence. Journal of Higher Education, 66 (1), 82-96.

Fenig, S., Levav, I., Kohn, R., \& Yelin, N. (1993). Telephone vs face-to-face interviewing in a community psychiatric survey. American Journal of Public Health, 83 (5), 896-898.

Foster, M. (1999). Race, class, and gender in education research: Surveying the political terrain. Educational Policy, 13 (1), 77-85.

Fraher, A. L. (2004). A history of group study and psychodynamic organizations. London: Free Association Books.

Frieze, I. H., \& Ramsey, S. J. (1976). Nonverbal maintenance of traditional sex roles. Journal of Social Issues, 32 (3), 133-141.

Fritschner, L. M. (2000). Inside the undergraduate college classroom. Journal of Higher Education, 71 (3), 342-362.

Funk \& Wagnalls standard dictionary. ( $2^{\text {nd }}$ ed.). (1993). New York: Harper Paperbacks.

Garbett, R., \& McCormack, B. (2001). The experience of practice development: An exploratory telephone interview study. Journal of Clinical Nursing, 10, 94-102.

Gilbert, L. A. (1985). Dimensions of same-gender student-faculty role-model relationships. Sex Roles, 12 (1/2), 111-123.

Gilligan, C. (1982). In a different voice. Cambridge, MA: Harvard University Press.

Glaser, B. G., \& Strauss, A. L. (1967). The discovery of grounded theory: Strategies for qualitative research. Hawthorne, NY: Aldine de Gruyter.

Glenn, E. N. (1999). The social construction and institutionalization of gender and race: An integrative framework. In M. M. Ferree, J. Lorber, \& B. B. Hess (Eds.), Revisioning gender (pp. 3-43). Thousand Oaks, CA: Sage Publications. 
Greenfield, T. K., Midanik, L. T., \& Rogers, J. D. (2000). Effects of telephone versus face-to-face interview modes on reports of alcohol consumption. Addiction, 95 (2), 277-284.

Hall, R. M., \& Sandler, B. R. (1982). The classroom climate: A chilly one for women? Washington, DC: Association of American Colleges.

Haslett, B. B., \& Lipman, S. (1997). Microinequities: up close and personal. In N. Benokraitis (Ed.), Subtle sexism: Current practices and prospects for change (pp. 3453). Thousand Oaks, CA: Sage Publications.

Hayes, E. (2000). Social context. In E. Hayes \& D. D. Flannery with chapters by A. K. Brooks, E. J. Tisdell \& J. M. Hugo, Women as learners: The significance of gender in adult learning (pp. 23-52). San Francisco: Jossey-Bass.

Hayes, E. R., \& Smith, L. (1994). Women in adult education: An analysis of perspectives in major journals. Adult Education Quarterly, 44 (4), 201-221.

Heifetz, R. A. (1994). Leadership without easy answers. Cambridge, MA: The Belknap Press of Harvard University Press.

Held, V. (1997). The sex/gender system. In C. Sommers and F. Sommers (Eds.) Vice \& virtue in everyday life $\left(4^{\text {th }}\right.$ ed.) (pp. 881-892). Fort Worth, TX: Harcourt Brace College Publishers.

Heller, J. F., Puff, C. R., \& Mills, C. J. (1985). Assessment of the chilly college climate for women. Journal of Higher Education, 56 (4), 446-461.

Henley, N., \& Thorne, B. (1977). Womanspeak and manspeak: Sex differences and sexism in communication, verbal and nonverbal. In A. G. Sargent (Ed.), Beyond sex roles (pp. 201-218). St. Paul, MN: West Publishing Company.

Hess-Almubarak, E. (1994). Emigrating to the good life: A qualitative study of gender and ethnic diversity of graduate women (Doctoral dissertation, University of Illinois, 1994). UMI Dissertation Services, Accession No: AA19512391.

Heyman, I. M. (1977). Women students at Berkeley: Views and data on possible sex discrimination in academic programs. Berkeley: University of California, Berkeley: Office of the Chancellor. (Cited in Hall and Sandler, 1982)

Hite, L. M. (1985). Female doctoral students: Their perceptions and concerns. Journal of College Student Personnel, 26, 18-22.

Holmstrom, E. I., \& Holmstrom, R. W. (1974). The plight of the woman doctoral student. American Educational Research Journal, 11 (1), 1-17. 
Home, A. M. (1998). Predicting role conflict, overload and contagion in adult women university students with families and jobs. Adult Education Quarterly, 49 (2), 85-97.

Howard, J. R., \& Henney, A. L. (1998). Student participation and instructor gender in the mixed-age college classroom. Journal of Higher Education, 69 (4), 384-405.

Howard, J. R., Short, L. B., \& Clark, S. M. (1996). Students' participation in the mixedage college classroom. Teaching Sociology, 24, 8-24.

Hugo, J. M. (1990). Adult education history and the issue of gender: Toward a different history of adult education in America. Adult Education Quarterly, 41 (1), 1-16.

Irvine, J. J. (1985). Teacher communication patterns as related to the race and sex of the student. Journal of Educational Research, 78 (3), 338-345.

Jameson, S. H. (1999). Certain adjustment problems of university girls. Journal of Higher Education, 70 (5), 485-493.

Janesick, V. J. (1994). The dance of qualitative research design: Metaphor, methodolatry, and meaning. In N. K. Denzin \& Y. S. Lincoln (Eds.), Handbook of Qualitative Research (pp. 209-219). Thousand Oaks, CA: Sage Publications.

Karp, D. A., \& Yoels, W. C. (1976). The college classroom: Some observations on the meaning of student participation. Sociology and Social Research, 60 (4), 421-439.

Kelley, M. L., \& Parsons, B. (2000). Sexual harassment in the 1990s. Journal of Higher Education, 71 (5), 548-568.

Kimmel, M. S. (2000). The gendered society. New York: Oxford University Press, Inc.

Kindlon, D., \& Thompson, M. (1999). Raising Cain: Protecting the emotional life of boys. New York: Ballantine Publishing Group.

King, J. L. (1998). The effects of gender bias and errors in essay grading. Educational Research Quarterly, 22 (1), 13-25.

Kite, M. E., \& Balogh, D. W. (1997). Warming trends: Improving the chilly campus climate. In N. Benokraitis (Ed.), Subtle sexism: Current practices and prospects for change (pp. 264-278). Thousand Oaks, CA: Sage Publications.

Kramarae, C., \& Treichler, P. A. (1990). Power relationships in the classroom. In S. L. Gabriel \& I. Smithson (Eds.), Gender in the classroom: Power and pedagogy (pp. 4159). Urbana, IL: University of Illinois Press. 
Krohne, K. A. (1991). The effect of sexual harassment on female naval officers: A phenomenological study. Unpublished doctoral dissertation, University of San Diego.

Kurth, S. B., Spiller, B. B., \& Travis, C. B. (2000). Consent, power, and sexual scripts: Deconstructing sexual harassment. In C. B. Travis \& J. W. White (Eds.), Sexuality, society, and feminism (pp. 323-354). Washington, DC: American Psychological Association.

Kuzel, A. J. (1999). Sampling in qualitative inquiry. In B. F. Crabtree \& W. L. Miller (Eds.), Doing qualitative research $\left(2^{\text {nd }}\right.$ ed.) (pp. 33-45). Thousand Oaks, CA: Sage Publications.

Lavrakas, P. J. (1998). Methods for sampling and interviewing in telephone surveys. In L. Bickman \& D. J. Rogers (Eds.), Handbook of applied social research methods (pp. 429-472). Thousand Oaks, CA: Sage Publications.

Lee, V. E., Marks, H. M., \& Byrd, T. (1994). Sexism in single-sex and coeducational independent secondary school classrooms. Sociology of Education, 67, 92-120.

Levy, P. S. (1982). Surviving in a predominantly white male institution. In S. Vartuli (Ed.), Women college students (pp. 45-59). New York: Praeger Publishers.

Lincoln, Y. S., \& Guba, E. G. (1985). Naturalistic inquiry. Beverly Hills, CA: Sage Publications.

McIntosh, P. (1988). White privilege and male privilege: A personal account of coming to see correspondences through work in women's studies. Wellesley, MA: Center for Research on Women, Wellesley College.

Maitland, C. (1990). The inequitable treatment of women faculty in higher education. In L. B. Welch (Ed.), Women in higher education: Changes and challenges (pp. 246254). New York: Praeger Publishers.

Manning, K. (1999). Conducting constructivist inquiry. In K. Manning (Ed.), Giving voice to critical campus issues (pp. 11-27). Lynham, MD: University Press of America.

Markus, H., \& Oyserman, D. (1989). Gender and thought: The role of self-concept. In M. Crawford \& M. Gentry (Eds.), Gender and thought: Psychological perspectives (pp. 100-127). New York: Springer-Verlag.

Meritor Savings Bank v. Vinson, 477 U.S. 57 (1986).

Merriam, S. B. (1998). Qualitative research and case study applications in education. San Francisco: Jossey-Bass. 
Miller, P. V., \& Cannell, C. F. (1982). A study of experimental techniques for telephone interviewing. Public Opinion Quarterly, 46, 250-269.

Myers, D. J., \& Dugan, K. B. (1996). Sexism in graduate classrooms: Consequences for students and faculty. Gender \& Society, 10 (3), 330-350.

Nunn, C. E. (1996). Discussion in the college classroom: Triangulating observational and survey results. Journal of Higher Education, 67 (3), 243-266.

Owens, S. L., Smothers, B. C., \& Love, F. E. (2003). Are girls victims of gender bias in our nation's schools? Journal of Instructional Psychology, 30 (2), 131-136.

Patton, M. Q. (2002). Qualitative research and evaluation methods $\left(3^{\text {rd }} \mathrm{ed}\right.$.). Thousand Oaks, CA: Sage Publications.

Parks, J. B., \& Roberton, M. A. (1998). Contemporary arguments against nonsexist language: Blaubergs (1980) revisited. Sex Roles, 39 (5/6), 445-461.

Pearson, J. C., \& West, R. (1991). An initial investigation of the effects of gender on student questions in the classroom: Developing a descriptive base. Communication Education, 40, 22-32.

Richardson, J. T. E., \& King, E. (1998). Adult students in higher education. Journal of Higher Education, 69 (1), 65-88.

Rogers, T. F. (1976). Interviews by telephone and in person: Quality of responses and field performance. Public Opinion Quarterly, 76 (40), 51-65.

Rosenfeld, L. B., \& Jarrard, M. W. (1985). The effects of perceived sexism in female and male college professors on students' descriptions of classroom climate. Communication Education, 34, 205-213.

Rost, J. C. (1991). Leadership for the twenty-first century. Westport, CT: Praeger Publishers.

Rowe, M. P. (1977). The saturn's rings phenomenon: Micro-inequities and unequal opportunity in the American economy. In P. Bourne \& V. Parness (Eds.), Proceedings, National Science Foundation Conference on Women's Leadership and Authority. Santa Cruz, CA: University of California, Santa Cruz.

Rubin, H. J., \& Rubin, I. S. (1995). Qualitative interviewing: The art of hearing data. Thousand Oaks, CA: Sage Publications.

Ruddick, S., \& Daniels, P. (Eds.) (1977). Working it out: 23 women writers, artists, scientists and scholars talk about their lives and work. New York: Pantheon Books. (Cited in Hall and Sandler, 1982) 
Sadker, M., \& Sadker, D. (1985, March). Sexism in the schoolroom in the ' 80 s. Psychology Today, 54-57.

Sadker, M., \& Sadker, D. (1990). Confronting sexism in the college classroom. In S. L. Gabriel \& I. Smithson (Eds.), Gender in the classroom: Power and pedagogy (pp. 176-187). Urbana, IL: University of Illinois Press.

Sandler, B. R., Silverberg, L. A., \& Hall, R. M. (1996). The chilly classroom climate: A guide to improve the education of women. Washington, DC: National Association for Women in Education.

Schroeder, D. S., \& Mynatt, C. R. (1993). Graduate students' relationships with their male and female major professors. Sex Roles, 40 (5/6), 393-420.

Secrist, J. (1996). Voices of midlife tomboys: a narrative study. Unpublished doctoral dissertation, University of San Diego.

Sellnow, D. D., \& Treinen, K. P. (2004). The role of gender in perceived speaker competence: An analysis of student peer critiques. Communication Education, 53 (3), 286-296.

Shuy, R. W. (2002). In-person versus telephone interviewing. In J. F. Gubrium \& J. A. Holstein (Eds.), Handbook of interview research: Context \& method (pp. 537-555). Thousand Oaks, CA: Sage Publications.

Smithson. I. (1990). Introduction: Investigating gender, power and pedagogy. In S. L. Gabriel \& I. Smithson (Eds.), Gender in the classroom: Power and pedagogy (pp. 127). Urbana, IL: University of Illinois Press.

Sobo, E. J., Simmes, D. R., Landsverk, J. A., \& Kurtin, P. S. (2003). Rapid assessment of qualitative telephone interviews: Lessons from an evaluation of California's Healthy Families Program \& Medi-Cal for Children. American Journal of Evaluation, 24 (3), 399-408.

Sommers, C. H. (2000, May). The war against boys. The Atlantic Monthly, 59-74.

Stanger, L. A. (1999). Lifting the veil off widowhood: Portraits of transformation. Unpublished doctoral dissertation, University of San Diego.

Sternglanz, S. H., \& Lyberger-Ficek, S. (1977). Sex differences in student-teacher interactions in the college classroom. Sex Roles, 3 (4), 345-352.

Stewart, L. P., Cooper, P. J., Stewart, A. D., \& Friedley, S. A. (1996). Communication and gender ( $3{ }^{\text {rd }}$ ed.). Scottsdale, AZ: Gorsuch Scarisbrick. 
Sturges, J. E., \& Hanrahan, K. J. (2004). Comparing telephone and face-to-face qualitative interviewing: A research note. Qualitative Research, 4 (1), 107-118.

Tisdale, E. J. (1993). Interlocking systems of power, privilege, and oppression in adult higher education classes. Adult Education Quarterly, 43 (4), 203-226.

Todres, L., \& Galvin, K. (2005). Pursuing both breadth and depth in qualitative research: Illustrated by a study of the experience of intimate caring for a loved one with Alzheimer's disease. International Journal of Qualitative Methods, 4 (2), 1-11. Retrieved September 17, 2005, from the ABSCOhost Academic Search Premier database.

van Manen, M. (1990). Researching lived experience: Human science for an action sensitive pedagogy. New York: State University of New York Press.

Walcott, H. F. (1994). Transforming qualitative data: Description, analysis, and interpretation. Thousand Oaks, CA: Sage Publications.

Women Students' Coalition (1980, June). The quality of women's education at Harvard University: A survey of sex discrimination in the graduate and professional schools. Cambridge, MA: Harvard University. (Cited in Hall and Sandler, 1982)

Wood, J. T., \& Lenze, L. F. (1991). Strategies to enhance gender sensitivity in communication education. Communication Education, 40, pp. 16-21.

Young, C. (2001, February). Where the boys are: Is America shortchanging male children? Reason, pp. 24-31. 


\title{
APPENDICES
}

\author{
Appendix A \\ Invitation To Participate
}

Date

Dear USD Graduate,

I am a doctoral student in the School of Education at the University of San Diego. My dissertation involves research on the influence of gender in the graduate classroom by evaluating differences and similarities between women and men in their perceptions of classroom gender influences. My sample population includes graduates of the doctoral program from the School of Education.

My dissertation requires in depth, qualitative interviews to gather data. I would appreciate your help in this effort. I am seeking volunteers to participate in a telephone interview - please note that this interview will be tape-recorded. This interview should take approximately 30 minutes. If you would be willing to participate, please sign the enclosed consent form. Please include your phone number and address on the form and return the consent form via regular mail -a self-addressed, stamped envelope is provided to mail the form. If you volunteer to participate, I will call you with additional information and to discuss interview arrangements. While I plan to use as many participants as possible, I may not use all volunteers if the number of responses I receive exceeds my wildest expectations.

I very much appreciate your help in this effort. I have enclosed a copy of my interview questions for your consideration. I am looking for a diverse set of responses to these questions and would appreciate your support, even if you believe your opinions on the topic might be limited.

All study volunteers will be assured complete confidentiality. If you participate in a telephone interview, you will have the opportunity to review the transcripts of your interview prior to completion of my research report. Also, your real name will not be used in the dissertation.

This letter was mailed to you by the University of San Diego administration - your address remains confidential and I do not have access to your personal information.

I thank you in advance of your support. The USD faculty director for this dissertation is identified below. Please feel free to contact her or me with any questions you might have. 
Sincerely,

Gerald B. Blanton

Doctoral Candidate

(858) 675-0490 (home)

Dissertation Director:

Dr. Johanna Hunsaker

University of San Diego, School of Business

(619) 260-4858

hunsaker@sandiego.edu 


\author{
Appendix B \\ Qualitative Interview Questions
}

Gender Influences in the Graduate Classroom:

An Investigation of Female and Male Student Perceptions

Gerald B. Blanton - University of San Diego

Introduction - My research attempts to better understand the influence of gender on graduate studies at the University of San Diego (USD). I would like to start with four questions concerning demographics.

Question 1 - First, what year did you graduate from USD?

Question 2 - Could you tell me how old you are today? Less than 40 years old? In your 40 s? In your 50 s? Sixty or older?

Question 3 - What has been your primary career field since you graduated?

Question 4-Did you consider yourself a minority in the classroom and, if so, what was your minority status?

The following questions concern your perceptions of the influence of gender in the graduate classroom.

Question 5 - When you think back to your classroom studies at USD, what is the first thing that comes to mind?

Question 6 - If I asked you to tell me about one classroom event that you remember involving gender in the classroom, what is that event and why?

Question 7 - For interactions with fellow students of the opposite gender, what do you remember about these interactions during your classes at USD? 
Question 8 - In your graduate classes, did you ever perceive that men and women were treated differently and why do you feel this way?

Question 9 - During a class, did you ever feel misunderstood or put down by some class event or an individual's behavior because of your gender? If so, can you please describe this event or behavior?

Question 10 - After a class session, do you recall any incident in which you deeply regretted your actions, believing these actions might have been demeaning toward a student of the opposite gender? If so, please describe the incident. Did you take any follow on action to make amends for the incident?

Question 11 - One question about class norms at USD ... and for the purposes of this survey, class norms are the accepted behaviors and values in a classroom ... would you consider the classroom environment to be gender neutral, masculine, or feminine? Why?

Question 12 - Have you considered how a member of the opposite gender would respond to your answers? What do you think they would say?

Question 13 - As a last, very open-ended question, based on your perceptions, do you believe there were gender inequities in the graduate classroom at USD and what images or recollections drive this perception? 


\section{Appendix C \\ Consent Form \\ University of San Diego, School of Education \\ CONSENT FORM}

Gerald Blanton, a doctoral student in the School of Education at the University of San Diego, is conducting a study of the influence of gender in the graduate classroom. The purpose of this research is to gain insight into the perceptions of School of Education graduates concerning the influence of gender in a classroom environment.

As a respondent in this study, I understand I will participate in one individual, telephone interview lasting approximately 30 minutes. The data collection will take approximately six weeks. Participation in this study should produce limited emotional or physical discomfort. During the study, I recognize that I will be asked about my perceptions of the influence of gender during my graduate courses at the University of San Diego.

My participation in this study is entirely voluntary and I realize I may refuse to participate or withdraw from the study at any time without penalty. For my telephone interview, I understand that Mr. Blanton will call me at a phone number and time of my choosing.

I understand that the interview will be tape recorded and that Mr. Blanton will prepare a transcript of the interview. My identity in the transcript will remain confidential and I understand the interviewer will use a pseudonym to protect my privacy.

I understand that I will be given a copy of the transcript to review and edit as appropriate. To assure the confidentiality and anonymity of telephone interviews, I understand that a copy of my final, reviewed transcript and a cassette tape of my interview will be retained in a locked container in Mr. Blanton's possession and that only Mr. Blanton and Dr. Hunsaker will have access to this material. In addition, Mr. Blanton will destroy all transcripts and tape recordings associated with his dissertation five years after his graduation.

I understand that the finished dissertation, after acceptance by the University of San Diego, will be published and become part of the public record and Mr. Blanton may choose to prepare a professional paper for publication in an accepted academic journal based on his dissertation.

There are no other agreements, written or verbal, related to this study beyond that expressed in this consent form. I understand that if I have further questions, I may contact Mr. Blanton at (858)675-0490 or email at blantonjerry@aol.com. 
My participation in this research project is voluntary; my signature indicates that I have decided to participate. I have read the information provided in this consent form, and I understand that I will be mailed a signed copy of this consent form for my records.

$\overline{\text { Signature of Participant }} \quad \overline{\text { Date }}$

Printed Name of Participant

Telephone Number of Participant

Street Address including Apartment Number

City

State/Country

Zip Code

Gerald B. Blanton

Date 


\section{Appendix D \\ Interview Checklist}

Introduction Phone Call Date

Interview Date

Time Start Time End

Name

Pseudo name

Hello. My name is Jerry Blanton and I would like to thank-you for supporting my dissertation research-your responses are invaluable. First, I would like to tell you a little about me. I started at the University of San Diego in 1998 after retiring from the Navy. I am married with two adult children, and work for an engineering company in San Diego.

During my classes at USD, I became interested in gender issues and decided to focus my dissertation on an investigation on the influence of gender in the graduate classroom. Before we discuss my qualitative research questions, do you have any questions or concerns?

As a reminder, interviews will be tape recorded and you will be mailed transcripts for your review. Participation is voluntary and your identity will remain confidential.

\section{REMINDERS:}

a. provide constant verbal responses (e.g., feedback markers)

b. provide positive feedback

\section{c. LISTEN TO THE WORDS}

d. probe into answers; focus on the uniqueness of the response

e. avoid "wow" and "that's interesting"

f. what is the interviewee's message, the mood -- what is the person really saying besides just words?

g. avoid being quick to ask the next question - use pauses to encourage added response.

h. avoid power words 
Log of Events:

Received consent form

Mailed copy of signed consent form

Initial phone call

Interview schedule (time/date)

Interview phone number

Interview actual date

Transcripts completed

Transcripts mailed

Transcripts received with comments 


\section{Appendix E \\ Interviewee Vignettes}

As part of the data analyses, the researcher reviewed each audio interview recording and prepared hand-written notes of key interview elements. From these notes, the researcher wrote a vignette for each interviewee. Each vignette includes some interviewee demographic data, but the graduation year and sexual preference - two interviewees were gay — are not included to ensure interviewee confidentiality.

The vignettes reference events and quotes involving faculty members who are code-named Dr. Buckley and Dr. Hopper. As discussed in Chapter 4, one dissertation finding discusses the impact of powerful personalities on interviewee perceptions of gender. During the interviews, 29 of 42 graduates revealed events involving at least one of these two influential professors. Chapter 4 reviews interviewee comments about these two professors, not as a criticism of their teaching styles or personalities, but as examples of the influence they had on interviewee perceptions of gender and the personalities that drive those perceptions.

The following vignettes are sorted alphabetically by gender. The date of the interview is included in parentheses at the beginning of each vignette.

\section{Agnes}

(May 3, 2005) Because her first choice for a pseudo name was taken, Agnes requested "Agnes Birdwhistle" as a pseudo name.

Agnes' interview was fabulous. Strong-willed and expressing powerful, educated opinions, Agnes introduced the term gender bias into the interview well before any formal questions were asked. Early on, Agnes set the tone for the interview. During a discussion of the genesis for her book, Agnes observed that, nationwide, $50 \%$ of doctoral 
students ended up "ABD" (All But Dissertation). Of these, Agnes noted that four of five ABD students were women. Agnes' book represented an effort to address this inequity. Now in her sixties and a senior trainer for an international company, Agnes asserted she was a minority in the classroom:

I was a minority because of my age, but that didn't bother me in the slightest. I was proud of that. .. .I didn't feel that I was a minority because of my gender in the beginning; but that did change as I went through the program.

Agnes prepared for the interview, studying questions in advance of the telephone conversation. Her answers reflected her intense preparation.

When asked to recall what first came to mind about her studies, Agnes offered that she started the doctoral program with a different goal than other students and she graduated having achieved that goal.

I've always tended to be a bit of a maverick. I went in there [USD] with the goal of getting a doctorate so I could get myself published. . . I did it; I broke a lot of rules along the way. I wrote a narrative dissertation which had never been done in the [USD] School of Education.

Agnes emphasized, "I get along beautifully with men. In many ways, I get along better with men than I do women, because I speak the language." (Agnes was a tomboy and had three brothers.) However, when discussing interactions with male students, she demonstrated a critical understanding of men. For several questions, Agnes recalled a group of four or five White "male jerks" who had a negative impact on her studies.

Quite a few of the White males in our program were quite pompous and quite egotistical, and they didn't really have much to say to any of the women in the 
class or to the minority men, and I find that kind of a male particularly abrasive and I simply don't deal with it.

When the discussion moved to the next question, Agnes asserted that "students treated each other differently:"

Well, the egotistical group of about four or five men [male jerks] tried to dominate, often dominating the, uh, the discussions in a classroom and were famous for interrupting any women's point of view. . . . Men traditionally interrupt women - and this is a big generalization — but that's a traditional style unless you call them on it or stop it in some way. That is a habit that many men. . in all of our institutions, that's a male style of communications. And I saw a great deal of that in the classroom.

Agnes could be assertive if she wished. When asked if she had been demeaned in a class, Agnes recalled a class taught by a substitute instructor. Agnes was frustrated by "pompous" males. When the substitute instructor asked Agnes a question, expecting a "mousey little woman. . he didn't get it [a mousey little woman]:"

I answered it [the question] in a very male style-a very straightforward, firm, assertive response. And that teacher just-the body language was amazing-he just sat back in his chair like I had hit him. He was so amazed to hear a woman come out with such an assertive statement.

Agnes concluded, "I think he [the substitute instructor] had some gender bias there, but we took care of that."

Agnes viewed class norms as masculine. She explained: 
As you know, all major institutes — political, academia, government, business, every one of them-have been founded and developed by men and are still, for the most part, run by men. . . in male style. So, when you get into an academic environment, if it's mixed genders, it tends to go on, it tends to be run by the male style. The men tend to dominate the style.

Agnes reflected on how men might perceive her answers, replying, "An intelligent, thoughtful man would agree [with her answers]. But one who felt threatened by a woman, or any woman, would not agree." Agnes noted that younger men feel more threatened by women wanting equality.

Agnes directed her more powerful (and negative) opinions at Dr. Buckley, whom she believed "certainly treated them [women] differently." On the one hand, she declared “the guy's brilliant, you know, you have to give him credit. . . .He's just extremely .. .difficult to deal with." Agnes described Dr. Buckley as a challenge for her, but for other women, he was "a breaker" - those women left the USD Ed.D. Program. Agnes' example of gender influence in the classroom reflected her differences with this instructor when she recalled "the night that Dr. Buckley was so hard on a young woman. . who happened to be quite quiet and shy that he literally drove her right out of the program:" When he [Dr. Buckley] finally got an answer on something, he jumped on her. And she left the room in tears and left the program. And I thought that was unbelievably cruel. I realized later that's the Socratic method of teaching; that's the way he does it. And in my generation of women, that concept of putting out an idea to the public and then having it stomped on or having it challenged was very difficult. 
Agnes never felt she was demeaning toward men, explaining "that's not my style at all." Agnes proudly proclaimed that she had the courage to challenge issues and her age made a difference-_"I considered myself a role model."

Agnes' interview lasted 36 minutes and 41 seconds.

\section{Annie}

(May 5, 2005) Annie described herself as a tomboy.

Annie's primary field of employment since graduating has been "educational leadership"- -she did not explain this answer further. In her fifties, Annie did not consider herself a minority.

When asked about the first thing that came to mind when she recalled her classes at USD, Annie responded, "Oh, my goodness, I'm gonna have to learn to study." She talked about early classes with Dr. Buckley and described him as "really wonderful. I just loved his classes." During one of his classes, Annie wrote a paper on androgynous leadership that asked, "Why do we even need to separate the genders. . .leadership is leadership." Annie was moved to write this paper by three female students who were quite vocal about "gender bias" in the field of educational leadership and the "world of work." (Annie got an A+ on her paper and exclaimed, "I was shocked.")

When describing her interactions with male students, except for one man, Annie described these interactions as "relationships of respect, interactions of respect, camaraderie, mutual support, sharing, questioning and learning together." However, Annie repeatedly discussed one male student who displayed limited respect for women. When asked for an example of this male student's behavior, Annie recalled that "any female opinions were not valued," he would interrupt women by loudly talking but would 
not interrupt men. And, if a woman disagreed with him, "she received a negative response." Annie stated that she and other students had challenged the male student about his attitude, but he did not seem to understand what people were trying to tell him.

Annie's perceptions of gender in the classroom appeared to be strongly influenced by single individuals or singular examples. Annie could only recall one class in which she perceived that women and men were treated differently. In that class, the professor (a woman) "expected [females] to be femalie [sic], flirty, less able, meeker."

Annie felt the classroom was gender neutral, saying, "I couldn't come up with anything that would show me anything else." When asked whether gender inequities existed at USD (question 13), after a long pause Annie responded, "right away I put [in my notes] 'no'. . .I never felt that way."

On several occasions Annie revealed she had reviewed the interview questions, giving thought to her answers. She was interested in the researcher's perceptions of the USD Ed.D. Program and, after answering a question, often asked how other interviewees responded.

Annie's interview lasted 29 minutes and 16 seconds.

\section{Barbara}

(May 17, 2005) Barbara was the only African American graduate to volunteer for an interview. In her fifties, Barbara's brief response to question 10 concerning demeaning behavior toward others provided insight into the subtleties of privilege when she explained, "I'm very careful not to demean anyone, and I'm very used to. . .being with people who try and demean you." 
Barbara works as an administrator at a community college, specializing in disabled student programs. In addition to her minority status, Barbara's 30 years of experience with disabled students shaped her views of leadership. She talked about leadership in different groups, cultures, and people, observing:

You have to be able to identify that there is a difference in leadership in different cultures and different people. And so, instead of identifying this is leadership, let's research. What can we consider leadership in the other cultures, in the other groups? And you have to do a little more digging.

Barbara took classes from both Dr. Buckley and Dr. Hopper. She spoke highly of Dr. Buckley, felt that students either loved or hated him, and noted, "We had a group of us that really loved him." She identified Dr. Hopper as a "good teacher"-possibly a neutral evaluation.

After answering the interview questions, Barbara introduced the term gender bias into the conversation; for example, she agreed that doctoral program reading material was masculine. However, she felt that class norms were gender neutral and explained "everyone had input; everyone spoke." Barbara emphasized she was not intimidated by men and observed that a number of other outspoken female students came from a maledominated field.

Barbara finished her classes 4 years before she graduated. She observed that she was affected by an ongoing staff upheaval and staff turnover in the School of Education. She enjoyed her educational experience, however, and favorably commented on fellow students' diverse backgrounds and the "partnership" she found in her comprehensive examination study group. Direct in her answers, Barbara would take issues "head on." 
She enjoyed the cohort-type atmosphere of her fellow students and would seek out informative conversations with the more interesting, outspoken students.

Barbara's interview lasted 33 minutes and 44 seconds.

\section{Betsy}

(May 15, 2005) Betsy opened the discussion by seeking reassurance that she could contribute to the research effort. She asked:

You [the researcher] stated in your [Invitation to Participate] letter that even if we believed we might have limited opinions [about gender in the classroom], you would still welcome talking to us. . .because I may have limited information, really, to show. That's because I read through the questions and then I just reviewed them a little bit ago, and I don't have really a lot of recollection of. . . being aware of gender differences.

A recent graduate now in her fifties, Betsy is a writer. Her works include health textbooks, instructor manuals, video scripts, test bank questions, high school texts, and, more recently, a book for "middle-aged women who would like to pursue art"--Betsy explained, "I am branching out a little bit." Betsy felt she was not really a minority in the classroom even though she was probably a bit older and, when she walked around the campus, "I really felt like everybody’s grandma."

Betsy pursued a doctoral degree for no particular reason; she had always been interested in getting one. She described her graduate education experience as "enjoyment" and "mind expanding."

True to her opening question, Betsy had few perceptions of classroom gender issues. When asked to describe an event related to gender, she stated, "I really don't 
remember things very specific to gender." Betsy did not believe men and women were treated differently, she could not recall any demeaning mistreatment because of gender, and replied "I just don't recall examples of [gender] inequities."

Betsy's interview ultimately did provide insight into gender issues. When discussing whether women and men were treated differently, Betsy recalled a course that focused on women. Betsy enjoyed reading about the female point of view. She found the class valuable and observed, "Gender was addressed as an interesting academic subject and something we should be concerned about." Continuing this train of thought, she mused about academic studies such as women's studies and minority (African American) studies, and recalled a book from one of her courses. Finally, Betsy observed:

Interesting, though. . .I don't think any of the chapters in the book just had to do with males as males. They [males] were always in a special category-like the Black man, the gay man. That was interesting, now that I think about it.

When asked about class norms, Betsy observed that, "to some degree, I'm going to say [norms were] feminine." Betsy distinguished between the theoretical study of ideas with less emphasis on practical application - a more feminine orientation-compared to the masculine emphasis on problem solving.

Betsy's interview lasted 27 minutes and 22 seconds.

\section{Carol}

(June 6, 2005) Carol is a First Nation (Native American) from Canada who works in the K-12 education field. She is in her fifties. Carol graduated from the international program; her Canadian (International) Cohort was approximately two thirds female and included one student from the United States. 
When asked what first came to mind about her graduate studies, Carol replied, "I guess being a minority; it wasn't dealing with any gender issues." Carol described herself as "a visible minority," which she considered an advantage; it allowed her to focus on her studies.

Carol's undergraduate studies included a degree in history. When describing a classroom event involving gender, she recalled an event in an ethics class. During a review of American history in the ethics class, Carol was able to actively participate in discussions, a success that provided confidence and reaffirmed her Canadian education and that she had something to offer:

I was a minority and I felt, well, wow, I've got knowledge and able to share it and able to speak to a topic that included all students, not just specific to my minority, but to history in general-I felt pretty good about it.

As noted, Carol had limited views on gender. She felt women and men were not treated differently and characterized class norms as gender neutral "and I say that even despite we had a large female [cohort student population]; I think it [gender] was treated equally." She did not believe there were gender inequities in the USD graduate classroom, commenting "nothing stands out." When asked if she had been mistreated because of her gender, Carol replied no. However, when asked if she felt slighted because of her minority status, she replied yes, "by my classmates not. . .well, I think some of the faculty [mistreated her]."

Carol felt men would agree with her answers: "I would like to think they would respond in the same way, given the fact that we're adults, and given the fact that many of the discussions were based on what the course offerings were." 
After discussing the interview questions, Carol reflected on the USD Ed.D. Program. She observed that many of the instructors in the international program were women and that this influenced the program. She bemoaned "office politics" among USD professors and described faculty interactions as a "popularity contest." She perceived that faculty "power struggles" did influence some academic decisions.

Carol enjoyed her studies at USD. Carol's interview lasted 23 and 2/3 minutes.

\section{Danielle}

(May 11, 2005) A college administrator in her late fifties, Danielle identified herself as a minority in several areas — being a woman, an older student, a faculty member at another university, a non-Catholic, and short (in height). Danielle enjoyed her doctoral education, describing it as a very positive experience. She also expressed frustration. After all her class work, dissertation research, and grant work, she was "not considered worthy of a Ph.D." (The School of Education awards a Doctor of Education degree rather than a Ph.D.)

Danielle's interview revealed her frustrations as a professional woman in society. She expressed concerns over women's issues and advocacy for those issues. She described herself as the "parent of three women," providing a powerful indication of her priorities. She also asked, "What do you do when you are the only woman in a male setting?" She referred to this setting as dominated by "blue suits."

When asked about interactions with male students, Danielle had positive recollections but could not recall any male student that "captured my imagination." She did express some disdain for two wealthy male students who were attending USD to start a second career or a "reawakening of their lives." She volunteered her impressions of Dr. 
Buckley: "I really liked him." At first, she believed Dr. Buckley was sexist; gradually she grew to respect him and found his "bark was much worse than his bite." Danielle had mixed feelings on whether Dr. Buckley favored males over females, but enjoyed his "androgynous" view of leadership.

Danielle believed that differences in leadership studies among doctoral program participants were ideological-based rather than gender-based. When asked about class norms, Danielle reflected on the USD environment, which she viewed as intimidating and structured, emphasizing decorum and "very polite discourse." Danielle "felt like there were [unwritten] rules." Ultimately, she described class norms as "masculine, if you're gonna use Gilligan [(1982)]," and observed that class norms sometimes lacked caring, cooperation, and collaboration.

When asked what men might say about her answers, Danielle responded, "I don't know that we would be that far off." Danielle's interview lasted slightly less than 36 minutes.

\section{Diana}

(May 3, 2005) A college administrator in her sixties, Diana's responses reflected her "confusion" as to whether the discrimination she experienced resulted from being Hispanic or female. She revealed that her light skin color would mask her Hispanic background and commented on how American society was "color oriented." (Even thought Diana is light skinned, her name clearly identifies her Hispanic ethnicity.)

Diana favorably recalled her study group of three male and two female students and observed that she felt "very comfortable" within her study group. She noted that 
study group members did not always agree on issues, but the study group experience was a positive influence on her graduate education.

In questions about gender, Diana continually referred to negative experiences involving an unnamed male professor. She perceived he treated students differently, giving "more value" to male students. She also questioned whether this male professor treated her differently because she was Hispanic or because she was a woman. She observed that other female students tended to agree with her perceptions of the male professor and related an incident when an African American female student dropped a class rather than have the unnamed male professor as an instructor. When asked whether women and men were treated differently in the classroom and if there were classroom gender inequities, Diana again referred to this male professor. When discussing gender inequities in the classroom, she used the phrase "cultural dominance" in reference to the male professor and noted that she had been advised by other professors that "you just gotta learn to deal with it [the unnamed professor]."

Diana felt classroom norms were masculine; students emphasized their points of view through the masculine traits of argument and debate. She observed that women "try to be nice" and not confrontational.

Diana's interview lasted about 31 minutes and 30 seconds.

\section{Genie}

(May 17, 2005) Starting telephone interviews with doctoral program graduates tends to be safe; the interviewer can refer to the interviewee as Doctor with limited risk of political incorrectness. Genie quickly diffused this formality, saying "call me Genie." 
In her fifties, Genie is a professional personal life coach, helping people design the life they want to live. When asked whether she viewed herself as a minority, Genie responded no, but went on to explain that, as a student, she was different because she worked several part-time jobs to put herself through the doctoral program. As a result, Genie quickly finished the doctoral program requirements. She found the doctoral program exciting and stimulating, proclaiming, "I loved my program."

Genie discussed her classes with Dr. Hopper, describing her as "great," and with Dr. Buckley, who "had a way about him." Genie felt Dr. Buckley challenged both female and male students but commented, "I did not take it [Dr. Buckley's assertiveness] personally."

When asked whether women and men were treated differently in the classroom, Genie felt an individual's "style," rather than gender, determined how she or he might be treated. A tomboy, Genie noted men might be more aggressive or "rambunctious," but later added, "I tend to be pretty rambunctious myself." When asked whether she might have regretted her actions in a class, Genie indicated that such differences of opinion were in the spirit of debate, and "if there was any interactions in that way [involving differences], it was all in good fun." Genie concluded her response by adding, men "say stupid things."

Genie provided an insightful, textbook answer when discussing class norms; she concluded they were masculine and emphasized traits such as assertiveness, independence, confidence, and aggressiveness. In Genie's view, a feminine classroom would be gentle and kind. Genie concluded, "If you [female or male students] wanted to participate in a dialogue, you couldn't, you wouldn't sometimes wait your turn." 
When asked how a man would view her answers, Genie had "wondered" about the question before the interview, and concluded, "I don't know; I don't have the answers. I think it would depend upon the man." On the topic of gender inequities, Genie observed "a lot of women have a lot of, you know, masculine--I don't think masculine only belongs to men."

After answering interview questions, Genie discussed her perceptions of gender and other diversity issues. She reflected on how "people of color" or ethnic minorities might respond to interview questions. She described a previous work environment as "White male European," and commented that if you came from a different background and did not understand this work environment, you had "strikes" against you.

Genie's interview lasted 28 minutes and 11 seconds.

\section{Gina}

(May 11, 2005) Approximately 45 seconds into the interview, Gina set the tone for the 30-minute discussion, offering, "What can I help you with, my friend?" The first $13^{1 / 2}$ minutes of the interview involved a free-flowing discussion of graduate class experiences. During this discussion, Gina revealed her initial reaction upon reading the qualitative research questions:

Well, I have to just tell you, I read the questions and got really angry, and I wrote, like, all this stuff. And then I thought, oh, I can't do this to this poor man because these are my issues. . .and they're not his issues; these are my issues. Gina clarified this initial reaction; she stated that she was not angry with the interviewer and subsequently concluded, "I felt like. . if you honor men and you honor women, then 
you do well. And after listening to you [the interviewer] talk, that's clearly what you're trying to do."

In her mid-thirties, Gina is current an assistant professor of leadership, and some of her answers reflected her experience in this college teaching position. She judged classroom norms based on the environment created by the professor. When asked if she had been demeaning toward other students, she acknowledged that she might have debated too strongly, but added, "I just figured that's what everybody was there [in the classroom] for," and then added, "a quintessential paradox of leadership. . the task versus the relationship." Gina was among the younger interviewees and yet appeared to understand the differences between women and men. She observed that graduate students have a greater need to prove themselves:

Females typically need love and the males typically desire respect. . .we [graduate students] are trying to earn respect or regard by advancing our education and, in that, I don't think that that knows any bounds on gender. Both men and women need respect.

Gina acknowledged that she operated more like a man than a woman commenting, "I felt like my experience there [at USD] was all about trying to earn respect." She enjoyed classroom debates, the conflict of ideas, and going "head-to-head" with male students. She noted that having "a sense of unity, or harmony, or belongingness, or collectiveness, which to me would be a stereotypical female desire in an environment; that would have never registered with me. . what are you paying for [referring to her graduate studies]?" Gina summarized her classroom interactive style: "I was short, curt, to the point, direct." 
Most of Gina's answers to the qualitative survey questions were short, curt, and direct. When asked how a man might respond to her answers, Gina replied, "I think a man would probably be right on target with me." When asked whether men and women were treated differently, she responded no, and observed that for her the program was intellectual, not emotional. She agreed the program was fair and "iron sharpens iron. . that's what we were there [at USD] to do."

Gina did not believe gender inequities occurred in the graduate classroom at USD. Her response about gender inequities reflected her self-confident, masculine view of the doctoral program: "I was young, I was pregnant, I'm female, and I think I'm cute. So they had every reason to give me inequities."

\section{Goldie}

(May 5, 2005) "I was a child of the sixties."

Now in her sixties, Goldie worked as a consultant after she graduated, but seemed proudest of her recently published book which reviewers praised on www.amazon.com. When Goldie recalled her first impressions of her doctoral education, she described her studies as an intellectual challenge. Goldie grew in her 5 years as a student and achieved a "gradual feeling of self-worth and accomplishment."

Goldie changed her views of the influence of gender as she progressed through the USD Ed.D. Program. Initially shy and not used to the competition in the classroom, Goldie realized her grade depended on her participation and she "couldn't just be silent." Goldie's response when asked whether men and women were treated differently typifies her adjustment to the system, which she felt "was pretty rigorous: I think I felt that, at the 
beginning, I thought it [the system] was male-driven at the first part of my studies. But as I grew in confidence, I found that it was very neutral."

Goldie described her interactions with men as "very pleasant." She did not believe there were inequities in the graduate classroom and characterized class norms as neutral, even though, at the beginning of her studies, Goldie felt classes were a "male-dominated scene."

Goldie could recall only one event involving gender in which she clashed with another male student. Not used to the "military model," Goldie and a "macho" Navy captain had a philosophical disagreement, and one night "we got into it. . .but we ended up good friends." Goldie acknowledged this disagreement may not have been genderrelated and represented a clash of military ideas compared to "a child of the sixties." As she reflected on the incident, Goldie offered this insight: "I don't know who came out the victor, I really don't. I don't think either of us did. . . I learned to respect him through this incident."

When asked whether she had felt put down because of her gender, Goldie quickly replied "no." Then she added, "We had Dr. Buckley — that was in his heyday. And he was a challenge." She commented that Dr. Buckley "demanded a lot of his students" and was a "great teacher."

After completing the formal interview questions, Goldie volunteered, "The school made real adjustments for me." Goldie was diagnosed with an illness and, during the qualifying examination, could not read or write for long periods of time. Dr. Buckley had professors tape-record their questions, allowing Goldie to complete the examination. 
Goldie recalled that the school "tried very hard to meet my needs, and so I was very grateful for that."

Accomplished and open-minded, Goldie was the director of a professional training institute that she had started when she attended USD. Goldie's interview lasted 23 minutes and 41 seconds.

\section{Grace}

(May 6, 2005) Grace was in a southern state on business during her 6:00 a.m. (California time) interview. An executive in a software development and marketing company, Grace is in her fifties. She enjoyed the "stimulating" class interactions and, in her view, good instructors during her coursework at USD.

Grace stated that she "worked in a male-dominated world," and this may have influenced her perceptions of gender in the classroom. She indicated that she liked competition, was very aggressive, and "kinda androgynous" (even though she was not a tomboy in her adolescence). She volunteered the term gender bias when asked if she had been demeaning toward male students. She indicated that she had not been demeaning toward other students but did recall a student who was a Catholic priest and appeared to receive favoritism as a member of the "Catholic club."

Grace provided direct, to-the-point responses to most questions. She felt men "probably would say 'that's right"” when asked how men would view her answers. She did not believe there were classroom gender inequities. In her characterization of class norms, Grace initially responded, "Well, now, that's an interesting question isn't it." After a pause she said, "I would definitely say they were not feminine" and concluded 
they were masculine. When asked why she felt that way, after a long pause, Grace asserted class norms were "more business-like, straightforward, less social."

Grace's interview lasted less than 17 minutes.

Gwen

(May 10,2005) Gwen graduated from the international program and lives on a Pacific island. Because of the 16-hour time zone difference between Gwen's home and California, Gwen unexpectedly called to initiate the interview. Gwen explained that she had relatives in the United States and her telephone service to call them (and the researcher) was inexpensive.

A recent graduate and among the younger interviewees - Gwen is less than 40 years old- Gwen works as a college administrator. She found the international program challenging and thought-provoking, took several classes with Canadian students, and exclaimed, "I loved being a student."

Gwen did not have strong opinions about the influence of gender in the graduate classroom. When asked about her perceptions of interactions with male students, Gwen described males as peers and friends; she observed that "nothing really stands out." She quickly replied that men and women were not treated differently. After pausing and stating, "this is an interesting question," she felt class norms were gender neutral and indicated, "No, I don't believe there are gender inequities [in the classroom]." When asked how men might respond to her answers, Gwen asserted, "I think they would say the same thing [as she had]," but then observed that a person's response would depend on the "lens" through which they observed their environment. 
Late in the interview, Gwen added insight to her answers. "Where I am, I'm the minority," noting that less than $10 \%$ of the population on her Pacific island was Caucasian (like her). She also reflected on women in a leadership studies program, and suggested that women in the doctoral program might exhibit more masculine traits than other females.

After evaluating class norms as gender neutral, Gwen did observe that most leaders and most leadership examples were generally male. At first glance, Gwen's offhanded remark may seem insignificant. However, while the USD Ed.D. Program may emphasize diversity, Gwen's perceptions suggest that leadership appears to be maledominated.

Gwen's interview lasted about 34 minutes and 30 seconds.

\section{Jane}

(May 9, 2005) Over 60 years old and a health industry professional, Jane felt her scientific background placed her in the minority in the classroom; she viewed the educational field as a "foreign language." While Jane described her doctoral studies as interesting and challenging, she was one of only three interviewees-Lorrie and Don were the other two — who did not enjoy their studies, asserting the experience was "not a lot of fun."

Jane offered few opinions about gender in the classroom. She could not recall any classroom events involving gender, and her quick responses to other questions provided limited opinions on classroom gender inequities or different treatment of women and men in the classroom. Jane did believe that women faculty members were impacted by gender bias; they "had it a little rough." 
Jane identified her study group as the most enjoyable part of her education. She believed men were good students and observed there were "very, very bright women in our group."

Jane initiated two discussions related to gender in the classroom. In the first discussion (contrary to Alemàn, 1997; Banks, 1988; Hall \& Sandler, 1982; and Sandler et al., 1996), Jane volunteered that she made a conscious decision to limit her participation in class discussions. She justified her decision as follows: "I knew what I thought and I wanted to hear what other people thought. . . When I'm talking, I'm not learning." Jane indicated that she was not silent because of being intimidated by the classroom environment and noted that, by listening to others, "I learned a lot that way."

When asked how men might respond to her answers, Jane commented, "I don't know - they would like to think they were in charge. . . men like to think that, period." She later reiterated this position saying, "They want to think that men are in charge." When asked whether she had observed this male attitude in the classroom, Jane responded she had not. Professors kept "things on an even keel." She also felt the "strength of the women in the class" prevented men from taking charge-_"men were smart enough to realize that [they were not in charge]." Jane's insight was interesting and consistent with McIntosh (1988) who observed, “I have often noticed men's unwillingness to grant that they are over-privileged in the curriculum" (p. 2)-for men to enjoy over-privilege, they must be in charge.

Jane's interview lasted about 19 minutes. 


\section{Leilani}

(May 23, 2005) Although she now lives in the southwest United States, Leilani was clearly influenced by her employment in the Hawaiian school system — ethnic Japanese dominate the Hawaiian school system administration on Oahu. After working in that system for a prolonged period of time, a Chinese friend advised Leilani that she had "five strikes" against her: Leilani was blonde, Caucasian, female, tall, and smart. Leilani left Hawaii and started a new life that included her USD studies. Leilani summarized her Hawaiian experience: "I know inequity when I see it because I experienced it largely over there [in Hawaii]."

Leilani described her USD experience in positive terms and spoke of the wonderful class interactions, stimulating conversations, and wonderful instructors. She cited Dr. Buckley as among her favorites. For her dissertation, "Dr. Buckley was the chair, and we've remained friends."

Leilani's event involving gender provided a contrast to other interviewee responses to this question. She related a conversation with another female student, describing the student as a short, powerful woman who "did not appear to me to be feminine in any way at all." This powerful women used pink paper for class notes and frequently dressed in pink. Leilani questioned this overemphasis of pink. The women replied that she used pink deliberately; she was often viewed as too strong and used pink to soften her image. Leilani concluded that the woman's deliberate use of pink was ineffective.

Leilani provided another example of a class event involving gender. She discussed a "politically oriented" female professor whom Leilani perceived as being 
more demanding of women than men, "pouring it [academic demands] to us [women]." Leilani felt this professor considered women to be more vulnerable than men. She described an incident in which the professor assigned her an "irrelevant" question for the comprehensive examination that Dr. Buckley replaced with a more reasonable question. (While Dr. Buckley was sometimes perceived as biased against women in the classroom, interviewees provided several examples of positive behavior outside the classroom that reflected a more compassionate side of the man.)

In keeping with her inequitable Hawaiian school system experience, Leilani expressed few opinions regarding gender's influence in the classroom. When asked if women and men were treated differently, she responded, "Not really; not really." Students were "encouraged to pipe up and join in and wrangle and have fun with it." She did not observe any marginalizing or demeaning behaviors and, in her conclusion about gender inequities in the classroom, Leilani recalled inequities in Hawaiian schools and observed she never saw anything similar to her Hawaiian experience at USD.

When asked about class norms, Leilani replied:

That's an interesting question. . .I suppose masculine, but only because I think men are expected to do the kind of interacting and arguing and verbal banter more than women are and I don't know that that affected any of the women but. . .it might have. But I think that probably the tone of the banter might have been sort of masculine.

Leilani considered the interview question on how would a man respond to her answers as "an interesting question, too." She felt a man might object to her response about class norms, but such an objection "depends on the individual makeup of the man 
and how he has been learned and encultured [sic] [by parents] to interact with women." She then concluded that "anybody who is going to make it through a doctoral program has got to have moxie."

Now in her sixties, Leilani is a management consultant and teaches at a community college. Her interview lasted 23 minutes and 10 seconds.

\section{Lorrie}

(May 12, 2005) Lorrie was among the most outspoken respondents to participate in the research interviews. Confident and committed to her causes, she battled marginalization of minorities both during and after her graduate studies. Now in her sixties and speaking with a slight Southern accent, Lorrie described her current position as nonprofit leadership and indicated her graduate studies were directly applicable to her chosen field.

Lorrie identified several areas of minority status. ${ }^{20}$ She spent more than 7 minutes (of a 381/2-minute interview) describing her challenges as a minority. When asked about her treatment with respect to her female minority status, Lorrie quickly noted that the majority of students and instructors were male and that reading assignments were almost exclusively male authors. There was very little included from, either written by women or about women's experiences and, when I raised that issue in one class, the instructor. . .the required readings for this particular course were management text from the early, well through the 1960 s. The language was

\footnotetext{
${ }^{20}$ For the purposes of this dissertation, only Lorrie's minority status as a woman will be addressed. Her other minority statuses did have an impact on her studies, however. For example, Lorrie felt USD was illequipped to accommodate her physical disabilities, creating frequent accessibility problems during her study effort. She noted that she was unable to attend dissertation defenses held on the second floor of a classroom building.
} 
sexist. . .[and] very offensive in relation to how women were to be treated. I raised this issue with the instructor and the instructor basically said that was my problem; I should get over it, and perhaps a consciousness-raising group for me would be a good idea.

Lorrie described her graduate studies as a constant struggle with the curriculum, reading lists, and authors: "I felt erased as a woman. Our experiences were not valued, not solicited in any way." Lorrie continued, "I was expected to do good written work but be quiet in class." Lorrie felt she was viewed as confrontational; she did not enjoy her experiences in the doctoral program.

Lorrie's interactions with Dr. Buckley were a paradoxical mixture of frustration and gratification. She described Dr. Buckley as "really scathing." Teaching courses from masculine text, Dr. Buckley would dismiss her concerns about the nature of his course material. She described this frustration as a "real push-pull for me because I wasn't prepared for the sarcasm or the scathing nature of his comments." On the other hand, when Lorrie's female advisor became non-supportive, Lorrie went to Dr. Buckley with a proposed dissertation topic that Dr. Buckley liked and "smoothed the ground" for her dissertation, allowing her to graduate. Lorrie believed Dr. Buckley would not have supported a male student in a similar manner. He expected men to speak up, be assertive, and compete. Lorrie perceived that Dr. Buckley expected women to be quieter and submissive and held women to a lower standard of academic performance.

Most of Lorrie's answers were tempered by her struggles to achieve equity at USD. When asked about interactions with male students, she replied, "Male students followed the lead particularly of the male instructors." However, in her study group, the 
men were very supportive_- "it was like an oasis." She felt women and men were treated differently, citing Dr. Buckley as an example and declaring he "was bigger than lifeliterally and figuratively." Lorrie perceived the "average man would become pretty defensive pretty quickly" in response to her interview answers. When asked whether she had ever been demeaning toward a man, Lorrie's initial response was, "that seems fascinating." However, after a pause, she continued, "I probably was. . .I'm going to think about that." She then quietly reflected on how she might be viewed by others.

Lorrie did feel she was marginalized because she was a woman. She continued to express frustration about masculine reading material and asked why not use material written by a woman, why not update reading lists? Lorrie concluded "that women's contributions were less valued." She then continued to discuss the lack of feminine reading material; she felt this was a "constant" in Dr. Buckley's class and in other male professors' classes as well. Turning her reflections to the opposite gender, she offered few opinions on female professors except Dr. Hopper, whom she considered maternalistic. She did not agree with Dr. Hopper's point of view.

Now living in a southern state, Lorrie continues political efforts to achieve equality for minority groups.

\section{Marie}

(May 2, 2005) Marie was the second interviewee (before the researcher perfected the volume control settings on his recording devices to ensure the recording was loud enough). Marie was a graduate of the USD-San Diego State University joint doctoral program in educational technology; she was mailed an invitation to participate in error. 
However, her answers provided additional insight into gender in the classroom, and the researcher gladly accepted her offer to participate.

A recent graduate, Marie is an educational software professional in her fiftiesshe recently celebrated a birthday. Her joint degree program was dominated by female students, with women outnumbering men by a 5:1 ratio. She felt that men were not intimidated by such an overwhelming female majority even though she acknowledged there were non-derogatory jokes about "the guys" being outnumbered. Marie opined that "dads and moms [e.g., students] were treated differently. Maybe the moms got a little more attention because, you know, they were obviously pregnant." (Expectant fathers brought sonograms to class.)

Marie appeared to perceive little differences in how women and men were treated in the graduate classroom. She felt the female majority did not necessarily disadvantage men and observed, "Classes were pretty small. Some people liked to talk a lot and some of those people were women and some of those people were men." She did note that "one guy. . .was kind of the class clown." She never felt demeaned in a class and did not perceive she had mistreated another student, responding "I'm not very mean." Marie characterized the classroom as feminine, but then explained that this characterization was compared to her previous educational experience in a male-dominated, engineering environment. When asked how a man would respond to her answers, Marie replied, "I have no clue. I don't know. I would think they'd agree but, you know, that's because I think I'm right."

Marie did not perceive there were gender inequities in the classroom. The interview lasted 22 minutes and 18 seconds. 
Mary

(May 3, 2005) Prior to attending USD graduate school, Mary was a mechanical engineer in the aerospace and medical industries. This background shaped her views: "I was used to working. . .with males as with anybody in my career. . .most of my interactions have been basically with the opposite gender. . . .It [gender issues] never bothered me in particular." Mary explained that, through her engineering background, she developed collaboration skills with men in a male-dominated field that emphasized teamwork, problem solving, goal orientation, and sublimation of personal feelings. Mary appeared to have few perceptions of the influence of gender in the graduate classroom. She did not recall any noteworthy events involving gender; she was not aware of male and female students being treated differently; and she believed class norms were gender neutral and not intimidating or flattering. When asked what men might say about her answers, Mary replied, "I think they might agree with me. . and I think they might be on the same page." When asked whether gender inequities existed in the graduate classroom, Mary asserted, "in terms of my personal experience in the leadership program, I would say not."

Mary was one of two female interviewees to briefly reflect on the concept of a "safe" classroom environment. Quite unexpectedly, when asked what first came to mind about her graduate studies, Mary began by praising the collaborative atmosphere, respect by professors, and sense of inclusion. Then she added, "I felt socially safe. . . I felt very comfortable." Mary explained that she felt her "core beliefs were valued." Another interviewee (Penelope) provided similar comments. 
A recent graduate, Mary is currently an adjunct instructor at a junior college. She declined to provide her age. Mary did not feel she was a minority in the classroom; she did observe that there were more females than males in most classes. She believed her professional engineering background did set her apart from other students. Mary's interview lasted 18 minutes and 39 seconds.

\section{Maureen}

(May 19, 2005) Until she retired last year in her early sixties, Maureen was on the faculty of a junior college physical education department and a tennis coach at the school. During her employment at this junior college, Maureen experienced routine gender bias and read material about the topic. Maureen introduced the term gender bias into the interview and subsequently used the term when discussing Dr. Buckley.

When asked to provide an example of classroom gender influences, Maureen related a class exercise in which students had to review their "lifeline" (life experiences). One female student, who had a particularly hard, unhappy life, began crying when describing her lifeline and eventually left the room in tears after an extended period of emotion. Maureen and two other female students believed the instructor should have stopped the woman's lifeline exercise and were discouraged when the instructor allowed the exercise to continue. The next day, Maureen and the other two women complained to Dr. Buckley; Dr. Buckley ignored them: "He blew us off. . . .It was like we didn't exist." This incident and others led Maureen to conclude that Dr. Buckley was "very aggressive and used his power in the wrong way." On the other hand, she noted "there are other people who practically worshiped the man." 
Maureen favorably recalled her doctoral education experience at USD. She described one female professor as "brilliant" and another male faculty member as "very supportive of women." She believed male students in the program were "fabulous" and she felt "comfortable" with men and enjoyed discussions with them. She believed most classes were gender neutral and, with the exception of Dr. Buckley's classroom, did not believe women and men were treated differently.

Maureen spent several minutes discussing gender bias issues at the junior college where she had been employed. She recalled that the ratio of female-to-male faculty members in the physical education department had significantly declined during her extended employment. She had been directed to serve on a gender study committee, but believed the final report had been compromised and understated the school's problems.

Maureen seemed genuinely interested in the interview topic, as if she hoped gender bias issues might receive new attention in academia. Maureen's personal impressions of gender bias at USD appeared strongly influenced by powerful events and powerful personalities. Her interview lasted 41 minutes and 20 seconds.

\section{Nancy}

(June 2, 2005) Now in her forties, Nancy was the youngest in her International Studies Cohort and the only cohort student who was not a school administrator. With great affection, she described the cohort as a family: "Yeah, it was family. . .we already had some group [cohort] norms as a family. We respected each other." Nancy indicated that her "age did play a bit of a role, because everybody did look out for me." Nancy never felt threatened because of her young age, and asserted, "everybody had something to offer." The 11 cohort members became pseudo self-governing: "If there was 
something amiss, it was discussed as a group. And then, because of the professors that we had, it was prevented and further discussed as a group — it was a level playing field all the way around." Nancy concluded, "I got lucky. . .the cohort, it's a great way to go. . if you can find the right mix, you've got it made."

Nancy described her current career field as education and staff training at an emergency shelter. Nancy was not qualified to teach in the Canadian province where she currently resides; her college degrees were from other provinces. She would have to work for a school board to obtain the necessary qualifications. However, because of her past experience, she was considered too expensive to hire.

Nancy's past experience was fascinating — she was a teacher in a remote mining town of 2,300 residents close to the U.S. border and 200 miles from the governing school board. A staff of 10 teachers taught 150 courses to local high school students in class sizes of 2 to 23 . Nancy felt that her background in dealing with this "isolation" contributed to the uniqueness of her cohort.

Nancy's responses to interview questions reflected an unemotional, objective view of gender, possibly influenced by her practical experiences teaching in a remote mining town. Nancy's "event" involving gender came from a discussion about power and leadership:

We talked about leadership; we talked about power and how men do it [power] differently than women because they have their own sense of power. . .because they were brought up differently; they socialize differently and that affects their leadership style. 
Nancy's cohort included 3 men and 3 First Nation women out of 11 members. When discussing interactions with the cohort's men, she commented that "gender never became an issue in your eyes." She added "never did the conversation ever run men versus women; it was still a knowledge-based discussion." Nancy did not recall men and women being treated differently and felt the classroom was gender neutral. Nancy concluded her written response with, "No, I don't believe that there were any gender inequities - we all learned to be individuals, leaders, without own style \& own power. No one ever said to me 'you do/can't do this because you're a female."'

During her almost 32-minute interview, Nancy provided glimpses of practicality in her comments. For example:

One of the generalizations and stereotypes that we came up with. . that most of your principals in schools are the phys ed [sic] jocks, phys ed [sic] teachers. And if you think about it, they know how to lead a large group of people. . .and women come at it [leadership] from a different angle. We [women] take more of the mothering, tender, because, I mean, we bring up the kids - it's different, not better, just different.

\section{Penelope}

(June 2, 2005) Now in her sixties, Penelope reflected on being older when she graduated and "often feeling like I wasn't as smart as the other students." She indicated in some classes she felt "put down" by a male instructor's "tone of voice," which she felt was related to her gender: 
I am absolutely sure that my own sort of insecurity in regard to my intelligence, in the context of class, was in the ears of the hearer. . .but it was definitely not in all classes at all-and not in the harder classes.

She sought reassurance during the interview, occasionally asking if the researcher had received similar responses from other interviewees.

Now retired, Penelope worked in community services after graduation and still does some consulting. She came from a poor background and lived in parts of the world where women were "diminished." She stated her accomplishments in life were beyond what women normally would do. For example, she was one of only three members of her high school class to graduate from college, even though her father told her she did not need a college education. Penelope did not intend to finish her doctoral program, but was excited by her dissertation topic and finished her degree requirements.

When asked whether she felt that women and men were treated differently, she replied, "Yes I did, in some classes" and explained, "I felt pretty much on the periphery" in Dr. Buckley's class. She later revealed that Dr. Buckley supported her graduate studies and concluded, "I've grown to believe it was more [his] style than anything else." Dr. Buckley "was very nice to me outside the classroom. He was very, sort of, intimidating [in the classroom]." At the end of her interview, she praised Dr. Buckley, describing him as a genius: "He's made wonderful contributions to the field."

While powerfully influenced by Dr. Buckley, most of Penelope's answers to qualitative interview questions were neutral or feminine. She felt class norms were gender neutral depending on the instructor; she did not see widespread gender inequities except in Dr. Buckley's class. When asked whether she felt mistreated, she replied, "I 
made that assumption because I thought I saw quite a pattern [of gender mistreatment]." Penelope perceived that men would not agree with her answers:

I think that, in general, they [men] would not have the emotional undertones that I

had, especially in the times where I felt very uncomfortable. It did not seem to me that the men in my classes [took] the interactions as seriously, which I felt I did. As an example, Penelope characterized class discussions as male dominated-“"there was almost no way to break in."

While discussing class norms, Penelope described her ethics class as "one of the safest classes ever." The second female interviewee (Mary was the other) to introduce the concept of a safe class environment, Penelope clarified that the ethics class had "no judgment;" class norms were set, and the study of ethics was "less controversial." She summarized that "in the [ethics] class, the norms were so clear."

Penelope enjoyed her graduate studies: "I'm pretty excessive compulsive, so I probably worked twice as hard as I needed to." Her interactions with some "self-selected" male students were "generally speaking, very good" and ultimately, in spite of her initial reservations, "We sort of realized that we did know quite a bit."

Penelope's interview lasted 40 minutes and 45 seconds.

\section{Rose}

(May 19, 2005) Rose is a recent graduate of the doctoral program. Now in her fifties, Rose teaches and consults in communications and organizational development. When she teaches, Rose uses Tavistock methods she first learned at USD. (See Fraher [2004] for additional information on Tavistock methods and group study.) 
Early in the interview, Rose suggested that she might "have nothing juicy to give you [the researcher]," and yet her interview was the longest among the female participants, lasting almost 43 minutes. Rose told of an unhappy childhood and how she developed a coping mechanism to forget bad memories. She explained, "If there is stuff I don't like, I forget. ... There are whole years [of my childhood] I don't remember." For this reason, she indicated, "I'm not sure I'm going to help you that much."

Rose enjoyed the excitement, challenge, and stimulation of doctoral classes, quietly adding, "I miss it." As she related her first recollections of her USD classes, Rose revealed an objective view of classroom gender. She recounted an incident in which a "younger, blonde, attractive" woman became the focus of a class gender discussion but was unable to handle being the center of attention. The young woman "dropped out strictly because of what she [the woman] would consider. . .a gender issue." Rose attempted to convince the young woman to stay and, when she left, Rose "felt like it [her dropping out] was so unnecessary" and a loss for the USD Ed.D. Program. When asked whether she believed the young woman was picked on, Rose replied, "In the context of the [instructor's] class, you have to say no; but in the context of where her experience was, and not understanding the context of the class, then you have to say yes."

Rose was one of four female interviewees who criticized men as a group. When asked about her interactions with male students, Rose replied, "In general, they [interactions] were varied;" some men were intellectually stimulating. She then added:

I had some interactions with male colleagues who I thought were complete idiots and, I guess in my arrogance, just figured they were unaware. . .unaware of their 
status in society and the privilege that they enjoy in our society and the fact that other people have not.

Rose felt that men and women were treated differently, and that there were gender inequities in the doctoral classroom. She cited examples from Dr. Buckley's classes, concluding, "I could never understand why people liked him." On the other hand, she thought Dr. Hopper "was absolutely wonderful."

Rose clashed with male Navy personnel in her classes. She felt misunderstood by Navy servicemen:

Sometimes I felt that the, some of the military, I would have to say active duty military guys, did not, didn't take what I did or said as. . there wasn't the same level of respect in terms of what I was saying.

Rose acknowledged beforehand that part of her answers about military servicemen differences would sound conceited. She then explained that she is an intelligent person, but felt disrespected by male military personnel because of her expertise:

So you don't get the respect that you would get, yet you have the same level of expertise and intelligence that a man does; but they [male military] will accept it [a woman's expertise] because they understand the expertise. But they don't like it because it's coming from a woman—does that make sense?

After answering the interview questions, Rose related an additional incident in which a male Navy serviceman delivered a "scary" monologue about Navy servicewomen who became pregnant to avoid arduous duty. Rose remembered the powerful experience because the serviceman was "so venomous." 
Rose characterized class norms as "neutral, because I can't think of an answer for either of the other two [masculine or feminine choices]." When asked what a man might say about her answers, Rose proclaimed, "Well, the question, the question is unfair." She laughed after her reply. Rose explained that a man's perspective on her answers would depend on the man, and concluded, "I can't answer the question because I couldn't put all men into one category."

After answering the last interview question, Rose commented "groovy" with a sense of accomplishment.

\section{Thomasina}

(May 23, 2005) When answering questions about her minority status, Thomasina noted she was, "in fact, in the majority [in her International Studies Cohort]. . Canadian, ethnically White, and female." The interviewer asked whether this was an advantage and she replied, "Well, it certainly wasn't a disadvantage. I think it's maybe a slight advantage to be part of a majority."

Thomasina is a school-based administrator in an entry-level school (grades K-7). While she recognized her majority status, Thomasina's reaction to question 5 about her first recollections of the graduate program reflected insecurity. After a prolonged pause, Thomasina offered, "Well, the terror of getting there [to USD]—of getting to classes." She continued with her initial thoughts on the doctoral program, admitting to a "fear that I didn't belong, I wouldn't belong; that I, you know, I didn't, I wouldn't measure upthat I was totally out of my league." Asked whether she overcame this fear, Thomasina responded that her "initial apprehension. . did go away." 
After completing the qualitative interview questions, Thomasina discussed her job experiences. At the age of 27, she became a school principal and encountered job animosity and discrimination in a rural Canadian region that she described as conservative--women were not in leadership positions in the region. This experience appeared to influence Thomasina's answers to interview questions-gender issues at USD appeared less significant when compared to her job experience.

Thomasina had few opinions on the influence of gender in the classroom. She felt interactions with men were positive and "really respectful." However, she believed females were stronger students than males. After a long pause, she stated she did not think men and women were treated differently; she did not witness marginalizing or demeaning behaviors; and she did not believe gender inequities existed in USD graduate classes. Thomasina believed classroom norms were gender neutral: "In terms of our discussions in and around leadership, certainly we discussed male leaders and female leaders and, you know, differences in leadership styles."

When asked how men might respond to her answers, Thomasina exclaimed, "Oh, I'm just trying to think of what Wilfred would say." (Wilfred and Thomasina lived in the same town and Wilfred was among the few men in her cohort.) When asked to expand her male population for consideration beyond Wilfred, Thomasina observed:

They [men] would probably think that I had a female bias, and I would think that they would also think that, you know, the classes, since. . .it [the classes] had more females than males, that there would be a female bias.

Thomasina described her cohort as close with an active social life. She suggested the cohort's close relationships minimized gender issues. Now in her fifties, Thomasina 
enjoyed her doctoral program experience. Her interview lasted 32 minutes and 39 seconds.

$$
A l
$$

(May 16, 2005) Al's interview was the shortest, lasting slightly more than 13 minutes. Al seemed to have few thoughts about the gender's influence in the graduate classroom. A medical device industry manager, $\mathrm{Al}$ described classroom demographics as an even split between females and males with most students in the "White Caucasian group." Now in his fifties, $\mathrm{Al}$ enjoyed student camaraderie and indicated he "got to know a lot of the folks pretty well."

Observing that students came from different backgrounds, $\mathrm{Al}$ felt "we were equal" and that everyone was treated as an equal. Al could not recall a class event involving gender, believed men and women were not treated differently, and felt the class environment was gender neutral. Al asserted, "We focused on the leadership issues; we didn't focus on gender per se, unless it was part of an article or chapter in a book."

Al noted, "most of the people that I felt pretty close to were women." He did not recall female students being concerned about gender issues and described female students as "pretty strong-willed and pretty independent. . .they could take care of themselves."

Ben

(May 25, 2005) A university professor in his late fifties, Ben described himself as misunderstood, an "oddball," and "different [from other people] in virtually every respect-I don't fit in anywhere." He felt he was frequently underestimated but believed it was a "greater power position to be underestimated." Prior to his doctoral coursework at USD, Ben was an engineer with a college degree in psychology. He completed his 
Ed.D. degree in slightly more than 3 years (while working full time with "two kids in competitive soccer") and now describes himself as a highly published, "world class scholar" in leadership studies.

Ben's classroom experience emphasized theoretical debate and disdain for fellow students who were not committed to solving intellectual problems. He enjoyed challenging classroom discussions but had limited social interactions with fellow students outside of class. He did not join a study group (unlike many of his peers that were interviewed), and described himself as an "egocentric male."

Ben expressed strong views about female students. He believed that there were a number of feminists and lesbians in classes, and "some of the female students clearly just did not like men, in my view." When asked whether women and men were treated differently, Ben indicated one female professor gave preferential treatment to women. When asked how a woman might respond to his answers, Ben replied, "I have no clue; who can understand women? I don't know. . I've met so many women I don't understand. I don't know. I guess you'd have to ask them."

Ben strongly endorsed Dr. Buckley, whom he considered a genius. In his first class with Dr. Buckley, Ben viewed the class as enlightening, stating, "my eyes were opened and I had the knowledge of good and evil" with respect to his education in psychology and "where psychology's failings are in understanding organizations." On the other hand, he expressed disdain for Dr. Hopper, whom he believed favored women; he stated that she was "just sort of the minimal; she was kind of the lowest common denominator" among the faculty.

Ben's interview lasted almost 40 minutes. 


\section{Buford}

(May 16, 2005) A retired Naval aviator, Buford spent "a tremendous amount of time in Vietnam" and commanded a fighter squadron at the end of his career. Direct, assertive, and to the point, he talked about his flying days off the deck of USS Midway (CV 41), and then told the interviewer, "let's get to work." Now in his seventies, Buford teaches master's level classes in the desert area of California and works in management for non-profit charity organizations.

Buford had a dry, sarcastic (military) sense of humor. When asked whether he was a minority in the classroom, Buford laughed and replied, "No, everyone else was."

After a sidebar discussion, the interviewer asked Buford, "Why do you feel like everybody else was a minority?"

Buford rhetorically replied, "Wouldn't you. . . .I was a minority in the class by far because of perspective."

The interviewer sought to clarify Buford's response, asking, "Because of your background, your age, and your experience?"

Buford replied, "Yeah. And personality, obviously."

Buford enjoyed his studies; he objectively stated that professors and students were "very professional" and "mature enough to know what they were studying and what was involved in the whole thing. ... We didn't have any kids that I remember." Buford questioned whether to enter USD: "At that point in my life, to do a doctoral, a doctorate, that program is a whole, long, psychological process." Buford decided the doctoral program was "what I should be doing and what the Lord wanted me doing." Buford 
observed that the doctorate degree would not make any difference in his life, "except to me. .. I worked hard to be a very good student."

Buford's first recollections of the USD Ed.D. Program were, "Pain. It was a very good program." He later clarified this recollection: "I used the word 'pain'. . I would have rather gone to play golf."

Buford did not observe gender issues in the classroom. When asked about an event involving gender, Buford commented on class norms saying, "I did not observe any discrimination concerning gender in the classroom." He believed "every class is different, certainly some classes were masculine and some were feminine; there was no such thing as being completely neutral." He commented that, with respect to gender inequities, "Since the females were numerically greater, things may have seemed that way [feminine]. . . I just don't remember any discussions or action on the subject [of gender inequity]."

Buford's answers reflect his leadership experience and his biases. When he talked of his current graduate students where he now works, Buford noted, "It's a whole different ball game [compared to USD]. . . . There are little boys and there are little girls." On the other hand, for classroom interactions with female USD students, Buford commented, "I personally thought that the people were a joy." It was "not too big a jump for me to get back into their world a little bit." His fellow students "were not in awe of me in my world and my experience, and I thought that was pretty good."

Buford could be honest and self-critical. When asked if he had thought about how a woman might respond to his answers, he bluntly stated, "No, not much." He then 
continued, "I had hoped, and I tried to not stick out like a sore thumb, which I had great difficulty avoiding."

Buford's answers to questions about demeaning classroom behavior reinforced his objective, unemotional personality. He observed that, "people have different backgrounds - part of which is sex - therefore personality differences. Would you expect otherwise?" He never felt that classroom disagreements were personal attacks and spoke highly of fellow students. As a last second thought, he added, "Come to think about it, maybe the lack of incidents was abnormal."

Buford perceived that women and men were treated differently, using a personal experience as an example. In his first class, Buford recalled "a female professor took exception to my background and attitude. I thought I might be in trouble, but it never happened again." With his broad military and business management experience, Buford observed, "I thought I knew something about motivating people and getting along with people and all this other kind of stuff." However, "she [the professor] took exception to my taking an exception [apparently several times]." Buford felt the professor took exception to him because of his gender and his military background. When asked if he tried to intimidate the professor, Buford replied, "I didn't mean to."

Buford commanded a Navy fighter squadron during Vietnam. He flew 443 combat missions over North Vietnam and made over 200 night carrier landings. After his command tour, the Navy wanted him to deploy with an operational battle group staff. Buford told the Navy to "go to hell" and retired-_-"my kids needed me at home. It was that time in my life."

Buford's interview lasted 31 minutes and 15 seconds. 


\section{Carl}

(May 4, 2005) A White male almost 60 years old, Carl identified two characteristics that placed him in a minority status—first, his age as an older student and second, Carl was a businessman and not an academic. Later in the interview, however, Carl suggested that he was accepted into the doctoral program because he was older, because he was a businessman, and because of his gender. He observed that most applicants at an indoctrination meeting were women.

Carl attended three classes at overseas locations. He recalled an incident at one of these classes that involved gender. A psychology class on group dynamics had 15 or so students, including two or three older adults (more than 50 years old) and several younger students. Carl described the younger students as under 30 years old and mostly female. A problem in the class resulted from older male students asking probing questions of their fellow students:

I can recall some of the younger women taking offense to the probing and the openness of the conversation. I was kind of appalled by that. . .and then I find out later that they [the younger female students] were writing very negative things about the professor on their evaluations.

Carl wrote a letter to USD defending the professor. He believed the young women were "out of line" and commented, "Well, wait a minute, what did you [younger women] sign up for here?" When asked whether this incident was gender- or age-related, Carl replied, "Definitely gender." Later he indicated that the younger students might have been intimidated by older, "father-like" students and talked about age differences between the two groups of students. 
When asked whether men and women were treated differently, Carl replied, "I don't think they [women and men] were treated differently by the University or the teachers in any way." He observed that older "guys"-Carl liked the word guysestablished closer relationships with instructors. Carl felt these relationships might be viewed as "good old boys buttering up to the teachers." He suggested that older male students might be viewed as "compatriots" with professors, a behavior that younger students might reject.

Question 10 asked Carl whether he recalled any demeaning incidents toward women that he might have later regretted. In a weekend seminar, Carl and other male "gray hairs" (participants) were accused of not participating seriously in the session. When given the opportunity to form their own group for an evening workshop, Carl and several other men formed a "male only" group to debate the topic, "Why do guys not communicate well?" Carl indicated that the men wanted to talk about the topic as guysemphasizing the word GUYS - and "we didn't want women to be a part of that." Carl acknowledged this male-only group might not be well received: "The women thought we were just trying to be. . .gender bullies." Carl believed this session changed him, helping him to initiate social interactions among friends and family. Carl reflected on his lifechanging experience: "My father, for all his years—-he lived to be 87 -never called me [on the telephone]. . that was sad." When asked whether he regretted his actions with the male-only group, Carl replied he did not; the topic was a "guy subject."

Carl characterized classroom norms as feminine because females were in the majority in most classes. When asked how a woman might respond to his questions, Carl replied, "I don't know" and noted there were not many guys in the USD Ed.D. Program. 
Before starting the program, Carl had already received a Ph.D. from another university, but enrolled at USD because "I was purely. . . interested in the word 'leadership."” Carl felt his Ed.D. experience helped his life in other ways (than academics) and described USD as a "great university." Carl's interview lasted almost 32 minutes.

\section{David}

(May 12, 2005) During his interview, David fondly remembered his mother, who was denied the financial support she needed to attend college because she was a woman. David said she was the smartest person in his family, with an IQ between 180 and 200. In a sense, David felt an obligation to his mother to facilitate a fair classroom environment. In his sixties, David summarized his attitudes: "I've always been kind of pro seeing women participate in equal numbers, and in that class, they [women] very much were, I think, considered equal."

David appeared to recognize his privilege as a White male. When asked if he was a minority, David replied:

Not really. I really never thought about it. I was outnumbered by a few, probably, in terms of men versus women; there tended to be a lot of women in the [Ed.D.] program at that point in time. But, in terms of minority, I never considered myself as such. Being a White male, etcetera, etcetera, I just don't even think about it. Asked if he had ever been demeaning toward women, David responded:

When you are a member of the dominant group, like I usually was, because I usually worked in organizations where the men outnumbered the women at least, 
you know, 8 or 10 to 1 , you tend not to be as conscious of the subordinate group. In our class, we were $50-50$ or better.

David did not appear to recall perceptions of gender's influence in the classroom. He found interactions with women "very positive" and said he "didn't see very many, if any" gender inequities in the classroom.

David, who served in the Navy during the Vietnam conflict, characterized class norms as feminine. He explained his logic for this answer:

Going from that heavily masculine environment [the military], that left me the impression when I was there [at USD] that the environment leaned toward the feminine. But I am not so sure that that was the personal difference [from his military experience] because it was so different. . .we also spent a lot of time talking about feelings, emotions, you know, and those types of [feminine] things. David related his impressions of Dr. Buckley, who "could be a very dominating personality," and he believed that Dr. Buckley came close to treating women and men differently. He felt that Dr. Buckley would accept student challenges to his theories, but noted that is was tougher for women to confront Dr. Buckley. When asked how he felt about Dr. Buckley, David replied, "I liked him."

For question 12, David was asked what women might say about his answers. David replied, "I think they might find them interesting." He hoped that women might find him tolerant, although some women had advised him that he was over-tolerant of women.

After he graduated, David worked in management for an engineering company and then as a consultant and educator. His interview lasted 31 minutes and 20 seconds. 
(May 10, 2005) Don is currently a college instructor in his forties. When asked whether he considered himself a minority, Don replied, "I very much considered myself a minority in the classroom; so I would identify myself as Chicano or Latino. . . [which was] very significant in how I experienced the [Ed.D.] program." Don talked of "privilege" and socioeconomic status. To Don, USD seemed like a "club" - he was not in the club nor did he want to be. With respect to socioeconomic status, Don commented that several classmates did not have to work full-time and appeared to have adequate resources at their disposal. In Don's life experiences, money had always "been significant." While other students could afford tuition, Don had to secure "massive loans" while working a full-time job. He regretted not having the full-time student experience. Summarizing his graduate experience, Don concluded that he "felt satisfied about what I had done-very dissatisfied with the way I felt I was supported." Don was one of three graduates to express dissatisfaction with the USD Ed.D. Program (along with Jane and Lorrie).

In his answers to interview questions, Don frequently used his experiences with Dr. Buckley and Dr. Hopper as examples. He believed both professors "represent kind of something larger - they are kind of archetype." During his application for the Ed.D. Program, he had an interview with Dr. Buckley and immediately thought, "If this guy represents the program, there's no way I'm coming here." Don almost quit the program after a class with Dr. Buckley. In discussions about classroom gender issues, he believed Dr. Buckley would demean women. 
Most of his frustrations focused on Dr. Hopper. When asked to describe an incident involving gender, Don quickly related an event that “just leaps out." In a summer class, Dr. Hopper invited a guest presenter who was inquiring about a position at USD. Dressed in coat and tie, the presenter used masculine examples (such as sports) in his presentation and, over the course of the presentation, proceeded to remove his coat, then his tie, and then helped himself to the relish tray as he talked. Don felt the presenter was showing off and described him as an "alpha male." When the presenter unbuttoned his shirt, Don thought "Oh, my God—-this guy's like a Tom Jones impersonator." He noted that Dr. Hopper appeared oblivious to the presenter's "posturing" and "pretended that this was like a normal presentation." Don summarized Dr. Hopper's passive support role: "She represents to me the gender part of the White woman who supports whatever the male-you know, alpha male—-the White male archetype leader will do."

Don talked about a "White woman archetype" and observed that, while Dr. Hopper and other female professors consider themselves feminists, "in terms of diversity stuff, I thought they were just clueless." He believed "there's something more than just the gender piece" and talked about "the White women club." In his opinion, race (e.g., White women) was as important a discriminator as gender.

Don joined a study group with three female students who became his closest friends during his classes. The study group's members shared minority feelings for different reasons, and Don fondly described the study group as close and supportive. He did not appear to have developed close relations with other students outside his study group. 
When asked if he felt that women and men were treated differently, Don responded, "Well, yeah." He believed each instructor established a "mold" of acceptable behavior for women. For example, Dr. Buckley wanted female students to be quiet and not challenging. Dr. Hopper wanted women to "be like Dr. Hopper," although he recalled Dr. Hopper discouraging a woman of color from pursuing a dissertation topic involving culture and ethnicity. Don felt that "gender mold" and ethnicity were complex and interrelated.

Don recalled his experiences with his academic advisor. Don noted that his advisor identified with minority ethnic and racial groups and supported civil rights issues. While Don believed that the advisor contributed to the tension at USD, she "had [a] real tough time. . she didn't fit the nice, quiet kind of mold that she might be seen in as a woman." He observed that his advisor "had some clashes with some of the [USD] patriarchs." He also believed she clashed with other female faculty members for different reasons (other than clashes with patriarchs), such as White women's rights. He acknowledged that his advisor helped him graduate, motivating him during difficult times.

Don felt class norms were masculine, asserting, "although there were a lot of women in the program, I think it was still very masculine." As justification for this position, he commented that successful classroom participation required a student to be assertive and individualistic — a "shark fest" compared to collaborative (feminine) participation. He described class norms as a "culture of what people stepped up to" and "this is academics - I find kind of a very, particularly a male, patriarchal expression." $\mathrm{He}$ 
then observed that women were "cultured to respond to that [a masculine, patriarchal expression]."

Don believed there were gender inequities in the graduate classroom. In one Don's final classes, Dr. Hopper became the "gatekeeper" for students to continue in the USD Ed.D. Program, reviewing and grading student papers in this required course. In one paper, Don took a confrontational position on privilege at USD. He and a female study group member submitted papers on the topic; the woman received a "plus-plus" (a good grade) while Don was told to rewrite and resubmit his paper. His study group friends suggested he take a less challenging position and phrase his arguments in a positive tone. In Don's words, he needed to write a nice, "happy face" paper. Following his female friends' suggestions, Don got a "plus-plus" on his next paper, but indicated "to me, this [writing style] was very gender."

Don frequently commented on the "White women component of the culture," and felt "White women are the biggest beneficiaries of affirmative action." He believed "this idea of White womaness" was more significant than privilege in White males, possibly because White males are in power and under greater scrutiny than White females.

Don's interview lasted about 37 minutes and 30 seconds.

\section{Edward}

(June 22, 2005) Edward is a married military officer; he was in the process of changing duty assignments and moving to another state during the interview. The final interviewee, Edward rarely saw his father, who was in the Navy. Edward was raised by three women. He felt this upbringing affected his leadership style, which he considered very caring and genuine as compared to a more masculine, assertive style. 
Edward expressed strong opinions concerning the influence of gender; however, late in the interview he acknowledged that he might be contradicting himself on his views of gender. For example, Edward bonded with an outspoken male student whom Edward knew did not like women. When asked if he felt misunderstood, Edward commented, "This is classic Edward. . .I like women; I respect women; I stand up for women."

When Edward recalled what first came to mind about his graduate studies, he discussed an introductory leadership course and frequent, intensive debates between two female students and the outspoken male student. He believed these debates were not within the spirit of class discussion, but represented an ongoing fight between the three parties. Edward spoke fondly of the outspoken male student, but was uncomplimentary of the two female students.

Edward's written answers to interview questions summarize his perceptions of classroom gender influences. For example, when discussing interactions with female students, Edward asserted these interactions "were tenacious - some of there [sic] ladies did not step back. Most [women] however, were moderate. I think women tend to be more supportive of each other." In describing whether men and women were treated differently, Edward wrote: "Not really, although I think one women [sic] (and maybe 2) experienced preferential treatment because of how they 'played the gender card.' [They were] wonderful actresses who successfully tugged @ heart strings of others." During the interview, Edward indicated this female student (one of the two female students who argued with the outspoken male) would break down and cry in class when describing personal hardships. After witnessing this behavior in several classes, Edward began to question the motive and validity of these emotions. 
Edward viewed himself as the defender of women in need; he mentioned the role on more than one occasion during the interview. However, the role could backfire and subject Edward to criticism. For example, his written response to question 9 (asking whether he felt misunderstood by some class event) included the statement, "Yes. I came to the aid of women, defended women; some women, however, took my words out of context and thought I was putting them [other women] down. Most women, however, understood me."

Edward viewed the classroom environment as gender neutral: "A vast majority of classmates understood it's about the character of the individual, not gender." Edward believed at least one female professor gave preferential treatment to women. When challenged by the interviewer, he also provided an example of a male professor who gave preferential treatment to men.

At the end of the formal interview questions, the interviewer asked Edward whether he believed USD's approach to gender issues was adequate. Edward replied, "Yes. EDLD 600 [an introductory leadership course] for me that really, really opened my eyes. So for me, I'm not saying I'm an expert [on gender issues], but it was definitely an ah-ha here."

Now in his mid-forties, Edward did not consider himself a minority in the classroom. His interview lasted 47 minutes and 17 seconds.

\section{James}

(May 15, 2005) For correspondence with the researcher, James preferred e-mails to "snail mail." He used e-mail to send his signed acceptance form and to review his completed transcripts. A superintendent in a Canadian school system, James frequently 
traveled and explained he could check e-mails in a hotel at "four in the morning." Now in his mid-forties, James used his studies to compare the Canadian and American school systems in terms of "general philosophy" and other areas. James enjoyed his doctoral studies: "I'd go back tomorrow for a post doctorate course."

James' International Studies Cohort started with four men, eight non-native American women, and three First Nation women, whom James referred to as "aboriginal." James felt the First Nation women contributed to cohort diversity and insight, asserting:

Three of our students in our class were aboriginal from Canada, and they were female aboriginal. And what they brought to that class, that adult development class, was the uniqueness of not only the culture of the Canadian aboriginal, also the status of gender, the place of gender in that culture.

When asked about interactions with women, James initially replied, "That's a tough question." After some thinking out loud, James commented:

I guess when I really look we just kind of treated each other as contemporaries. We just worked together and. . we are all in this together; and maybe that's the cohort idea in that gender has no basis within a cohort. James did not feel inhibited by being in the male minority in his cohort.

James perceived men and women were not treated differently in the classroom, although weaker students (male or female) may have been given "a bit more quarter" in the classroom and provided assistance to succeed.

James did not feel misunderstood by an individual or event in the classroom, but stated, "sometimes you get caught up in your, you know, your male ego; where females 
get caught in their female ego." As a result, James felt some heated discussion resulted from egos. He believed some gender-related discussion did occur, although "we knew where each person [was] coming from a different angle or perspective." When asked for an example, James replied:

I'm having difficulty just because, because bottom line is that, uh, is it gender. . . race or. . not understanding where the other person is coming from. For example, sometimes I don't think we fully understand, you know, the aboriginal custom. ... And, then offend and then it caused hard feelings; for example, you know, is that gender or is that race or is it because a female?

James perceived the classroom was a gender neutral environment. He qualified his response by noting the class norms would depend on the instructor. He demonstrated some honest self-reflection when asked how a woman would respond to his answers. James observed, "I would suspect that maybe you might find is that some of the female responses may be significantly different from mine. I would guess they probably thought there was more gender bias than I. . .see through my lenses." James' response was interesting because the term gender bias had not been used in the interview prior to this time.

James spoke highly of Dr. Hopper. He felt that an early course she taught "probably brought us together more as a group in terms of understanding one another." James' interview lasted 34 minutes and 21 seconds.

$$
\text { Joe }
$$

(May 16, 2005) A Canadian school superintendent in his fifties, Joe enjoyed his educational experience as a "nice break" from his superintendent duties, commenting, "I 
love learning." Joe's cohort was small-14 students ( 5 men and 9 women) who participated in the extended 8-month residency at USD. Joe described cohort interactions as equitable; students supported one another and Joe liked the "closeness" of the cohort.

When asked to recall an event involving gender, Joe described an exercise in a female professor's class. In this exercise, students were assigned various roles to playJoe was a "male dominant figure." Joe enjoyed the role, overacting the part. In his words, he "played it [male dominant role] to the hilt." However, at least one female student saw the exercise in a different light and, after class, confronted Joe, exclaiming "you son of a bitch, you're just like that aren't you."

Joe felt women and men were not treated differently because of gender. However, he believed that students may have been treated differently because of their career background or position, such as superintendent, school principal, or teacher.

Joe described the classroom environment as gender neutral. He had the impression (based on cohort discussions) that one or two professors "favored" one gender or the other. When asked what he meant by favored, Joe indicated that women or men might receive a preference in grades from the professor. Joe indicated that the professor who favored female students was a woman. Unfortunately, the interviewer did not ask the gender of the professor that favored males.

In class, Joe initiated discussions saying he "kept things going." Joe enjoyed his class with Dr. Buckley, describing him as "a riot." While Joe did enjoy Dr. Buckley, he observed that other students had "mixed feelings" and "thought he [Dr. Buckley] was a bit pompous."

Joe's interview lasted almost 18 minutes. 


\section{Lenny}

(May 23, 2005) A public sector professional in his late forties, Lenny felt his Hispanic ethnicity had limited influence on his graduate education experience (except no one else in the classroom looked like him). Lenny enjoyed the classroom diversity; the USD Ed.D. Program provided him an opportunity to interact with professionals from many fields. Lenny particularly enjoyed discussions with "older people" who had "more life experiences."

Lenny seemed to have few opinions on gender issues. To him, the classroom reflected a gender neutral environment, and women and men were treated equitably. During his studies, Lenny was not involved in any incidents of mistreatment because of gender and believed women would respond to interview questions "by saying the same thing" as he had said.

While Lenny's responses appear to provide limited insight concerning gender issues, when asked about classroom gender inequities, Lenny responded, "men have just as much an opportunity as women to make it [e.g., graduate]." This curious response appears to suggest that men were the subjugated group in the classroom, possibly because Lenny observed that a large percentage of students were women.

Lenny frequently discussed his application of academic leadership coursework to his professional work and used small group dynamics as an example. Lenny worked for 6 years to complete his doctoral studies; his interview lasted 18 minutes and 25 seconds.

\section{Lewis}

(May 12, 2005) A retired civil service manager from a Department of Defense support activity, Lewis began the discussion by advising that he might be hard pressed to 
remember gender issues. His interview was actually among the longest. In his late fifties, Lewis had recently moved from San Diego County to a mountain community near the Mohave Desert; his new home is within sight of the school where his wife now teaches (as compared to an extended commute for both of them in San Diego). Lewis attended the USD Ed.D. Program while still a civil service manager. He loved the program, and his reason for attending was "purely self development." Lewis found the disciplined course of study very useful - "I have a beginning and I have an end" to study efforts.

Lewis strongly believed there were no gender inequities at USD and, after formal interview questions, he challenged the researcher and asked what caused the researcher to think there were gender inequities at USD. After the researcher explained the background behind questions, Lewis confidently suggested:

If they [women] had an issue [about gender], I would have bet that they would have taken it on. ... They would not have let it lay, they would have, they would have been talking to somebody about it because they didn't appear to me to be women who were going to tolerate too much nonsense.

Lewis' response to question 8 (whether women and men were treated differently) also reflected his views of an equitable classroom environment. Lewis could not recall a single classroom incident based on gender and was not aware of any time that "you get a blurb that. . kind of goes through your psyche somehow that something is not quite right." He then recalled a classroom incident in which he challenged Dr. Buckley on an apparent conflict in the professor's theories. Lewis stated the class got silent for almost 4 minutes and Dr. Buckley became "red faced." Finally, Dr. Buckley looked at Lewis and asserted, "I don't have an explanation [for the conflict]." Lewis described Dr. Buckley as 
"garrulous" and close-minded with a rough demeanor. Lewis was not aware of female students who complained about Dr. Buckley, and he did not observe any inappropriate gender-related actions in Dr Buckley's class.

When asked whether he felt demeaned in class by some action, Lewis recalled a woman challenging him: "What would you know about it [a gender issue]?" Lewis felt the comment was harmless and not a reproach. He revealed that he had been a single parent for 8 years before remarrying, and was unaware of gender-related problems. He added, "now my wife sometimes says that I'm, you know, not observant, and that may be true; but all I can do is answer your [the interviewer's] questions."

When asked if he had ever demeaned a female student, Lewis replied, "No, if I demeaned anybody, I was equal opportunity to demean, I suppose." He continued the discussion, observing:

I always used to tell people. . .the real people of the world were out there working and they [USD faculty and students] were up there studying. . . . We were up there solving the world's problems; there were people out there picking strawberries for $\$ 3$ an hour.

Lewis' answers to questions 12 (asking how a woman might view his answers) and 13 (about classroom gender inequities) were similar. When asked if he believed there were gender inequities in the USD classroom, he responded:

No-there is no way I can answer yes because I don't have a single example in my mind of anything that happened. . despite my wife's warnings, I do think I, that I'm reasonably sensitive to that [gender inequities]. 
Lewis acknowledged that some women may feel they were treated unfairly; however, he observed:

I can only speak from my own perspective; but I don't, like I said, I don't know of any of the women that I spoke with or had in study groups, I don't remember anybody ever making a comment to my recollection that implied that they were somehow not being treated fairly either on the negative or positive side.

Lewis viewed the graduate classroom as gender equitable.

\section{Mario}

(May 3, 2005) Mario (as in Andretti) described himself as driven to finish the program before the Navy transferred him to another duty station. The third interviewee, Mario used a speakerphone throughout the interview while he sat at his desk and looked out the window at the Chesapeake Bay area countryside. Now in his forties, Mario began his doctoral studies as a member of the Navy Doctoral Cohort and, like the researcher, transferred to the on-campus program when that cohort disbanded. During the interview, Mario acknowledged that he felt fortunate to finish his studies on campus - there was more diversity among the doctoral students' backgrounds compared to those of the Navy Doctoral Cohort. Mario was able to meet more students compared to the smaller Navy Doctoral Cohort class sizes, and he enjoyed the "eyeball liberty." ${ }^{21}$ Mario is still in the Navy.

Mario fondly described his Ed.D. studies as a lot of work, adding, "I grew a lot as a result of it [doctoral studies], personally." When asked to describe an event involving gender in the classroom, Mario provided extensive details about a fellow "pro-female" student, who, when she began the doctoral program, was defensive around men. Mario

\footnotetext{
21 "Eyeball liberty" is Navy slang; it refers to an environment which has many attractive women to look at.
} 
referred to her as "safety wired;" "I am woman [referring to the popular 1972 Helen Reddy song];" and believing she was "not getting a fair shake." During a class session designed to evaluate the moment, eliminate distractions, and "trust in silence," the profemale student had "an epiphany" when she realized she was overreacting to men who she did not think appreciated her point of view. Mario commented that her perceptions had been driven by the "color of the glasses that she wore," but after the epiphany she realized that "people are people; they are who they are."

Mario "didn't notice any difference" between males and females; however, he remarked, "For a Catholic school. . .to be that open to people who were gay; I was OK with it, but I was surprised [by the relatively large gay population at USD]." Mario later admitted he was uncomfortable with gays at first, but his attitude gradually changed.

Mario's answers reflected his changing attitudes toward his perceived stereotypes. When asked if women and men were treated differently, Mario replied:

I don't feel that they were treated differently; but there were some students that I felt that had-that were favorites, a couple of them. But that was my first impression; but after reflecting on it, it wasn't that at all; it. . .appeared that there were a couple of them that were favorites, but that was only because they were very likeable. They were hard workers.

Mario concluded that he did not feel men and women were treated differently because of their gender.

Mario apparently did not perceive that gender influenced the graduate classroom. He could not recall any incidents involving student mistreatment, and he believed class "norms were neutral for the most part. . .I really didn't see anything that was gender 
related." His response to the interview question on how a woman might respond to his answers summarized his view of gender:

I would be inclined to think that the female gender, a couple of them, might disagree with my answers, they might-I wasn't as observant, I don't have an ax to grind when it comes to that subject; pretty much people are people.

Mario's interview lasted 30 minutes and 20 seconds.

\section{Milburn}

(June 4, 2005) Milburn's interview lasted almost 68 minutes and was the longest interview by about 20 minutes. Now in his early forties, Milburn was among the youngest interviewees. He was an elementary school teacher during his time as a doctoral student, but now works as a research analyst when he is not mobilized as a reservist in the military.

As "one of the few" young White males, Milburn felt he was a minority in the classroom. He compared his academic experience to having a "big heavy anvil on the top of my head," and described the doctoral program as a lot of work that limited his social life. He later admitted to fond memories of some aspects of the program.

Milburn routinely characterized the Ed.D. "Program [as] very much in crisis at the time" of his studies. Milburn discussed the departure of a female professor who left USD for a variety of reasons including, in Milburn's opinion, gender differences. He talked of issues involving a male professor whose 3-year contract was not renewed and felt the School of Education had problems finding the right professor to teach selected courses. Milburn believed this crisis, as well as gender issues and conflict among professors, "spilled over into the classroom and affected the students a great deal." 
When asked whether women and men were treated differently, Milburn discussed gender, cultural, and ethnic issues in the USD Ed.D. Program. He felt gender issues were slightly more prominent than the others. For example, his unsubstantiated belief was that First Nation women in the International Studies Cohort were "definitely given special treatment" and he was warned "don't even go there" when he raised the issue.

Milburn indicated that he was mistreated because of his gender. During a term project with a female student, Milburn felt the woman was not meeting the assignment's requirements. The woman disagreed and accused Milburn of treating her like a "stupid female." Later the woman visited the professor for clarification of the assignment and subsequently apologized to Milburn for her actions. Milburn told the woman she had ruined his semester. When asked if he believed the woman was being defensive, Milburn indicated she might have been defensive or she might have truly felt that Milburn's treatment was demeaning.

When asked if he had been demeaning toward a female student, Milburn's response indicated prior reflection on the question. He responded that he had "thought about that—I'm sure there was a time [he was demeaning], but I can't recall." Milburn indicated he tried to be politically correct and at times "I bit my lip;" no one ever criticized his behavior.

When asked how a woman might respond to his answers, Milburn felt a woman would consider him "gender inconsiderate"-a term he used four times. He equated gender inconsiderate to gender insensitive and provided examples such as making uncomfortable or inappropriate statements and committing actions that made women 
uncomfortable. When asked if he felt knowledgeable of gender issues, Milburn responded "probably not enough; probably not enough."

\section{Mitch}

(May 10, 2005) Mitch was working at home the day of the interview. A graduate program director at a university, frequent telephone calls from work interrupted the interview, but these calls were not the distraction that Mitch feared. Inquisitive and knowledgeable, Mitch's prior theology and philosophy degrees provided a contrasting perspective on the USD Ed.D. Program compared to other graduates with an educational background. In his fifties, Mitch did not consider himself a minority although his prior educational disciplines and non-Christian religious heritage did separate him from other students.

Mitch found the classroom studies a great challenge and enjoyed the excitement of engaging others in leadership discussions. Regarding his time as a teaching fellow at USD, he reflected that the "politics that continually occur within a small Catholic university were not pleasant," discussing the philosophical disagreements among faculty members. He suggested that politics led to his teaching contract not being renewed. Mitch discussed his views of both Drs. Buckley and Hopper. Dr. Buckley was Mitch's advisor and dissertation chairperson, and Mitch still routinely communicates with him on leadership topics and leadership theory models-Dr. Buckley telephoned during the interview. Mitch viewed Dr. Hopper as "very, very pro-feminist and antimale." When asked if women and men were treated differently, Mitch referred to Dr. Hopper, asserting, "She really would favor women and, I think, really did do that, and we all knew that." In a matter-of-fact fashion, he went on to observe "that's Dr. Hopper," 
referring to her preferential feminist teaching style. He also felt the classroom environment was gender neutral, except in Dr. Hopper's classes.

During a discussion in one of Dr. Hopper's classes, Mitch related an incident in which he disagreed with a book on caring, which he felt was inadequate. (Mitch described his perspective on class issues as "very Western, very male-dominated, linear perspective on ethics and philosophy.") Two women became angry at the criticism, arguing in favor of the book with other male and female students. A leader of the "opposition," Mitch felt this incident was important because Dr. Hopper sided with the two angry women, possibly disregarding a more neutral posture.

Mitch believed that gender issues were debated throughout his classes. He did not feel he was prejudiced by either gender or ethnic issues, asserting, "I count people as people, I guess."

Mitch did feel he was at time misunderstood by women in a class environment. He noted, "I can recall once or twice someone [later clarified to be women] saying, 'Well, you know, you're a man. No wonder you wouldn't understand that."' Mitch believed women would agree with most of his answers, depending on the woman, and he observed that agreement with him "depends on your perspective in the context from which one's life emerges. And that's, if you're going to quote, that's very important to quote it that way."

Mitch quickly answered the last question, stating, "No, absolutely not. Even with Dr. Hopper, I don't think there were inequities [in the USD classroom]." His interview lasted another 10 minutes after the last qualitative question and touched on leadership 
theory, Dr. Buckley and Dr. Hopper, and his dissertation topic. The second longest interview, Mitch's phone call lasted almost 48 minutes.

\section{Phil}

(May 8, 2005) Phil began the interview by asking if he could use a speakerphone: "that's kind of what I like to do." Now 60 years old, Phil works as a contracts manager for a defense contractor. As an older White male, Phil identified himself as a minority in the classroom but added, "I had a lot of company [other older White male students]." Phil enlisted in the Marine Corps after high school and returned to the classroom later in life; he had received both an MBA and Ed.D. within the past 10 years. He observed that, "with our age group, life gets in the way [of graduate studies]."

When asked about an event involving gender in the classroom, Phil responded "Dr. Hopper." He spoke highly of Dr. Hopper's classes: "I was very moved by the experience [of being introduced to female authors such as Gilligan (1982)].” $\mathrm{He}$ appreciated Dr. Hopper's efforts to bring the "female aspect" to studies and commented "it was an eye-opening experience for me." Phil felt he gained an understanding of women, although he acknowledged further shortcomings in that area.

When asked about interactions with female students, Phil replied, "I guess one word comes to mind-warm." He described the women in the program as warm people, observing that, because most female students were career teachers, he gained an appreciation for the teaching profession.

Phil paused a long time before revealing his perceptions about whether men and women were treated differently in the classroom. Again discussing one of Dr. Hopper's classes, Phil felt she structured the class to enhance the awareness of men toward 
women's issues. He did not believe Dr. Hopper was "pushing the feminist side at all," but instead observed that she brought awareness to male "blind spots when it comes to understanding what women are experiencing." He noted that Dr. Hopper treated women differently “in a non value-laden way-it didn't have a value on it, wasn't good or bad." Phil believed Dr. Hopper had observed that women needed a sense of connection, and she used her courses to provide that connection.

Phil felt he was put down in a class because of his gender. During a small group exercise, one young woman was hostile toward Phil and another older male, although Phil did not know the young woman. During the ensuing discussion, Phil concluded that he "reminded her of some male authority figure in her life that really hurt her. . II represented that memory to her" as she relived the experience.

Phil felt that class norms would "come down a little bit on the feminine side," primarily because most professors were women. When asked how women would respond to his answers, Phil said, "I think they would say 'Yeah, I think you've [Phil] answered these questions honestly based on your actual experience." He noted that classes were small and fellow students would respect "authentic" answers.

Phil did not believe inequities existed in the USD classroom, but felt there were differences between how men and women were supported. Phil believed women needed more support than men (although some men also needed support). As an example, he cited times when women got emotional and needed extra understanding.

Phil enjoyed his "stimulating" educational experience at USD. He said, "I miss it [the USD Ed.D. Program]," and then fondly recalled his study group—study group 
members still keep in touch with each other. Phil's interview lasted about 40 minutes and 30 seconds.

\section{Richard}

(May 2, 2005) The first interviewee, Richard is an organizational development professional in his mid forties. He enjoyed the active participation in class discussions and fondly recalled a class in which Carol Gilligan (Gilligan, 1982) was the guest speaker He declared, "It [Gilligan's book] was very profound."

Richard believed in a gender neutral attitude toward fellow students:

They [women] were human beings first and gender secondary; and gender was not a primary factor. . From my perception, that really influenced dialogue. . . .It [gender] was invisible. . . .From my perception. . I'm not thinking "Oh, this is a woman speaking," it's a person speaking.

Richard summarized his classroom approach to interactions as, "I guess I wasn't filtering on gender." His initial reaction to question 8 concerning whether women and men were treated differently was, "Gerald, the simple answer is no." After reflection, however, he recalled his statistics class in which he believed the female instructor was more sympathetic if females had trouble with study topics. Richard would ask many questions in the class and commented, "I just got the impression that I was being burdensome, but females asking. . .the same number of questions, they [female student questions] were more welcomed."

Richard believed that class norms were gender neutral because "the participation was usually equal or balanced among gender." He did not believe gender inequities existed in the classroom, although he recalled a heated faculty conflict between a male 
professor and a female professor based on philosophical differences and the male professor's perception of gender.

Richard's most interesting answer was when he discussed what a woman might say about his answers. He responded:

I think they [females] would probably say that they [my answers], uh, were sensitive and thoughtful. . .I think females are stronger with those areas [sensitivity and thoughtfulness] than men; and I think that it's a wiring thing [in women compared to men]. I think women tend to be just a combination being about biological and environment, nature and nurture. But I think women bring a [sic] equalities to the environment—-stronger; typically more strongly, than men do.

Richard's interview provides an interesting paradox: he treats people as human beings first but acknowledges feminine strengths such as sensitivity and thoughtfulness. Richard's interview lasted 18 minutes and 16 seconds.

\section{Ronald}

(May 24, 2005) Using a speakerphone, Ronald spoke with a slight Canadian accent. In his fifties and an educator and administrator, Ronald felt he was a minority in the classroom and explained, "gender-wise, yes [I was a minority], because-I should have researched this to get precise numbers-but approximately I was one of four [actually three] males in a class of about fourteen. So the males were in the minority."

Ronald's first memories of the program reflected his educational challenge as he acknowledged "realizing just how far out of my sort of comfort zone and my knowledge 
zone educational leadership could go. .. The emphasis of the program on feminism was a real stretch for me. . . It was clearly out of my comfort zone."

While Ronald perceived the program emphasized a "feminist nature," he did not appear to believe that men's efforts were marginalized, and he did not perceive the classes as inequitable for men. Ronald did observe that there were "real issues in our [Canadian] cohort between [the three female] First Nation [students] and non-First Nation [students]." He described these issues as philosophical, discussing differences in how First Nation students might deal with a leadership issue compared to non-First Nation students. Ultimately he concluded, "We just had to agree we were different." Ronald repeatedly characterized the doctoral program as feminine, but felt the environment was "wholesome" and that men never felt in the minority. For example, when asked to categorized class norms, Ronald asserted:

Overall, because there were more women and there was a strong feminist, I felt, feminist theme throughout the program, one might be likely to conclude there was . . .sort of a leaning toward the feminist side. If there was, I have to say I sort of fitted quite well into it.

Ronald did not believe that men and women were treated differently and did not perceive any inequities in the classroom, although he took the opportunity to reemphasize that the gender imbalance enriched the program. Ronald did feel he was criticized because of his gender. (Ronald was the oldest male in the cohort and believed at one time that he might have been viewed as a recalcitrant "old codger.") Ronald cited an incident in which he criticized affirmative action, and asserted it "guaranteed equal resistance" to equality. When he advocated good leadership instead of affirmative action, other students 
criticized his position. Ronald commented, "that was a case where maybe I was misunderstood, or maybe, maybe I was wrong. But I took a stance and took a little heat on it."

Ronald felt most women would agree with his answers and concluded the interview as follows: "I suspect that [for] most of the people in my cohort, that [USD Ed.D. Program] was the best experience of my [and their] life." Ronald's interview lasted 28 minutes and 13 seconds.

\section{Stennis}

(May 7, 2005) A retired Naval aviator, Stennis started the interview with "let me turn off the baseball game [on the television]"- the game was a "time killer." Stennis graduated from USD the same year that he retired from the Navy, and had been a college instructor since his graduation. Now in his sixties, Stennis enjoyed his class work as a student, which he felt emphasized teamwork and collaboration. He described the doctoral student population as a small group who knew each other well and would gather for a beer after class.

Stennis' Navy experience appeared to shape his attitudes toward gender as a graduate student. During Stennis' Navy career, the Navy engaged in widespread sexual harassment training, women became aviators, and women achieved the rank of admiral in the Navy line community. Early in the interview he introduced the term gender bias into the discussion and added that he was "conscious of not doing something [e.g., gender bias]." When asked about interactions with women, he could not recall any instances of students or professors "knowingly" committing gender bias. Stennis did observe (in a somewhat Navy fashion) that "we were sort of biased against assholes, you know. We 
were biased against people who talk too much or who didn't know what they were doing, or unprepared. But it was never a gender thing."

Stennis recognized that his recollection of classroom events was somewhat faded. He did not perceive that men and women were treated differently and perceived class norms as gender neutral. He commented, "I'm not sure how one would define masculine or feminine norms."

Stennis' responses to question 12 (how a woman might respond to his answers) and question 13 (were there gender inequities in the USD classroom) were particularly insightful. In preparing his response to question 12, Stennis had asked his wife (also a college instructor) for feedback:

Because I am a man, am I less inclined to see, uh, shall we say, masculine gender bias, just because I'm a man? If I'm White, am I going to miss racial bias? And she [his wife] said, "No, I don't think so. I think that you're smart enough to figure out when-you'll know it [gender bias] when you see it." And so, I think that most women, that I know anyway, would respect that answer.

Stennis' response about classroom gender inequities also provided a perceptive answer: "I'm, you know, a White Anglo-Saxon Protestant, and so maybe when one is in that position, one does not see bias as well as someone who might be considered sort of a minority."

Stennis concluded his interview by observing that he did not perceive that gender bias was directed at anybody at USD. Stennis spoke highly of both Drs. Hopper and Buckley. His interview lasted slightly more than 26 minutes. 


\section{Thomas}

(May 16, 2005) In his late fifties, Thomas is currently an educational administrator. He took 10 years to complete the USD Ed.D. Program; he took his time to complete his dissertation.

Thomas and his fellow students formed a "tight-knit group"- - a term he frequently used - and would not tolerate any form of discrimination (even by a professor) or non-support by a member of his pseudo-cohort. The group appeared self-governing, and Thomas believed demeaning actions or language would have been challenged. Thomas asserted that he and his fellow students depended on each other in a gender neutral environment.

In Thomas' view, there were no gender issues during his studies at USD. He described interactions with female students as supportive with an "intellectual spiritedness." He felt women were fairly treated and all students were "treated equally."

Thomas' interview lasted slightly less than 19 minutes.

\section{Wilfred}

(May 3, 2005) Wilfred was among the most aggressive, outspoken interviewees, at times taking over the interview. (However, the interview was very enjoyable.) A graduate of the International Studies Cohort, Wilfred had an outgoing sense of humor. Now in his early sixties, he retired in 2000 as the deputy superintendent of a Canadian school system. Wilfred identified himself as a minority in three areas: (a) his ageWilfred was the oldest member of his cohort; (b) his gender-women outnumbered men by 2:1 in his cohort; and (c) his marital status - Wilfred indicated that only two members 
of the cohort were happily married. (During the interview, Wilfred's wife could be heard in the background, frequently commenting on his answers.)

On several occasions, Wilfred expressed strong feelings that there were too many women in the international USD Ed.D. Program. When asked his first recollections of the program, his immediate response was, "the number of female in the program"-there were too many women (both female colleagues and female instructors). For example, he felt that he took too many classes from Dr. Hopper, describing her as a "lovely lady" and feminist, but "enough [classes from her] is enough." He described an incident in which he complained of repeated assignments (over several classes) from Gilligan's 1982 book In a Different Voice. Another female student (whom Wilfred described as "one of the brightest") took exception to his complaint. He believed there were gender inequities at USD, suggesting that the school needed more balance in the international studies program between the number of male and female instructors.

Wilfred described Dr. Buckley as a "grumpy old man," but liked and respected him. He noted that other students did not care for Dr. Buckley. From past experience, Wilfred had "no problem with him [Dr. Buckley];" "it was not like or dislike, I was there to get an education."

Wilfred characterized interactions with female students as "very good," scholarly, and congenial. He enjoyed their perspectives on studies; he observed women "read different detail than I would." He also commented that "I was looking for leadership; I didn't care if it was male or female."

When asked if women and men were treated differently, Wilfred quickly responded "Oh, yeah." He felt assignments and literature reviews overemphasized a 
female or feminist perspective. He recommended more "gender balance" and more male instructors, and justified his feelings of excessive female perspectives by joking, "My wife gets tired of me, too."

When asked if he had been put down in a class by a female, Wilfred replied, "I was never put down by any of the instructors nor my colleagues; not at all." He did comment that "nitpicking" among women was more common then men nitpicking men, and he never observed this behavior between a woman and a man.

Wilfred characterized class norms as feminine because class activities emphasized process and not product. In his words, "I am more product-oriented than I am processoriented." He recognized that the process is important, but indicated that "writing a journal - it's just not my world, not my quality world."

Wilfred provided insight when he described what women might say about his answers. He felt they would agree with his answers, saying "We [women] expect that from you [Wilfred]." He felt women "understood where I came from," and he never perceived what he viewed as negative feedback from women. Wilfred added that he felt "females do things more introspectively and males are more interested in productivity."

After the last interview question, Wilfred exclaimed "And you can quote me, 'gender becomes an interference - that means to put it [leadership] in male or female- - to the understanding of functional leadership." He asserted that one cannot worry about gender when making decisions, and discussed an incident in which he had hired a lessqualified female in an effort to be politically correct.

Wilfred's interview lasted about 25 minutes and 30 seconds. 
Appendix F

The Massive Matrix

To evaluate potential relationships among the interviewees' responses to multiple questions, the researcher created a 42 x 13-cell matrix (a Microsoft Word table) that was nicknamed "The Massive Matrix." The matrix included a row for each interviewee. The columns included the following interviewee information: pseudonym, responses to questions 5 through 13, age, year of graduation, gender, and minority status. Matrix data could be sorted by column, thereby supporting analyses of possible relationships among responses to questions and demographic data.

To enhance data reviews, the researcher used a blank cell to represent the most common answer to each question; notes at the end of the matrix defines blank cells. By using blank cells, the researcher could visually identify responses that represented the most common answers to questions-that section of the matrix would be sparsely populated with data. The researcher color-coded some responses in red to further emphasize related answers and also highlighted male entries to aid analyses.

For question 8, some responses are coded "Yes W." This code indicates an interviewee who felt that women and men were treated differently and named Dr. Buckley, Dr. Hopper, or both in his or her response. For questions 9 and 10 (which discuss demeaning class activity), the responses are coded by the interviewee's yes or no answer to question 9 , followed by the response to question 10 . Thus, "NY" means the interviewee answered no to question 9 and yes to question 10. The value in the Age column represents the interviewee's current age by decade. A " 50 " means that the interviewee was in his or her fifties at the time of the interview. 
The Massive Matrix in Table 19 is sorted by question 6, which asked interviewees to describe a classroom event involving gender. (The year of graduation has been blacked out to safeguard interviewees' identity.) For "No opinion" responses under the question 6 column, note the few entries for responses to questions 5 through 13 . This visual observation led the researcher to identify the 11 interviewees with limited opinions on gender influences in the graduate classroom. 
Table 19. The Massive Matrix — sorted by question 6

\begin{tabular}{|c|c|c|c|c|c|c|c|c|c|c|c|c|}
\hline $\begin{array}{c}\text { Pseudo } \\
\text { Name }\end{array}$ & 5 & 6 & 7 & 8 & $9 / 10$ & 11 & 12 & 13 & Age & $\mathbf{Y r}$ & Men & Comments \\
\hline James & & Non gender & ? & 8 & & Feminine & Disagree & & 40 & & $\mathrm{M}$ & \\
\hline Carol & & Non gender & & & & Feminine & & & 50 & & & First Nation Canadian \\
\hline Diana & ? Ability & Non gender & & Yes & $\mathrm{YN}$ & Masculine & Depends & Yes & 60 & & & Hispanic and female \\
\hline Goldie & & Non gender & & & & & & & 60 & & & \\
\hline Mary & & No opinion & & & & & & & & & & Engineering background \\
\hline Gina & & No opinion & & & NY & Undecided & & & 30 & & & \\
\hline Marie & & No opinion & & Undecided & & Feminine & $\begin{array}{l}\text { Don't } \\
\text { know }\end{array}$ & & 50 & & & \\
\hline Betsy & & No opinion & & & & Feminine & Depends & & 50 & & & Age \\
\hline Grace & & No opinion & & & & & & & 50 & & & \\
\hline $\mathrm{Al}$ & & No opinion & & & & & & & 50 & & $\mathrm{M}$ & \\
\hline Thomas & & No opinion & & & & & & & 50 & & $\mathrm{M}$ & \\
\hline Jane & Negative & No opinion & & & & & $\begin{array}{l}\text { Don't } \\
\text { know }\end{array}$ & & 60 & & & Scientific background \\
\hline David & & No opimion & & Yes W & & Feminine & & & 60 & & M & White male \\
\hline Stennis & & No opimion & & & & & & & 60 & & M & \\
\hline Buford & & No opinion & & Yes & & Undecided & $\begin{array}{l}\text { Don't } \\
\text { know }\end{array}$ & Yes & 70 & & $\mathrm{M}$ & $\begin{array}{l}\text { Everyone else was: age, } \\
\text { perspective, personality }\end{array}$ \\
\hline Gwen & & Event & & & & & Depends & & 30 & & & \\
\hline Don & Negative & Event & Negative & Yes W & & Masculine & Disagree & Yes & 40 & & $\mathrm{M}$ & Chicano/Latino \\
\hline Milburn & Critical & Event & & Yes & $\mathrm{YY}$ & & Disagree & Yes & 40 & & $\mathrm{M}$ & Young White male \\
\hline Edward & Gender & Event & & Yes & $\mathrm{YN}$ & & Depends & Yes & 40 & & $\mathrm{M}$ & \\
\hline Mario & & Event & & & & & Disagree & & 40 & & M & \\
\hline Danielle & & Event & & Yes & & Masculine & $\begin{array}{l}\text { Don't } \\
\text { know }\end{array}$ & & 50 & & & $\begin{array}{l}\text { Female, age, faculty } \\
\text { member, religion }\end{array}$ \\
\hline Rose & Gender & Event & & Yes & $\mathrm{YY}$ & & Depends & & 50 & & & \\
\hline Annie & & Event & & Yes & $\mathrm{YN}$ & & & & 50 & & & \\
\hline Thomasina & ? Ability & Event & & & & & & & 50 & & & \\
\hline
\end{tabular}




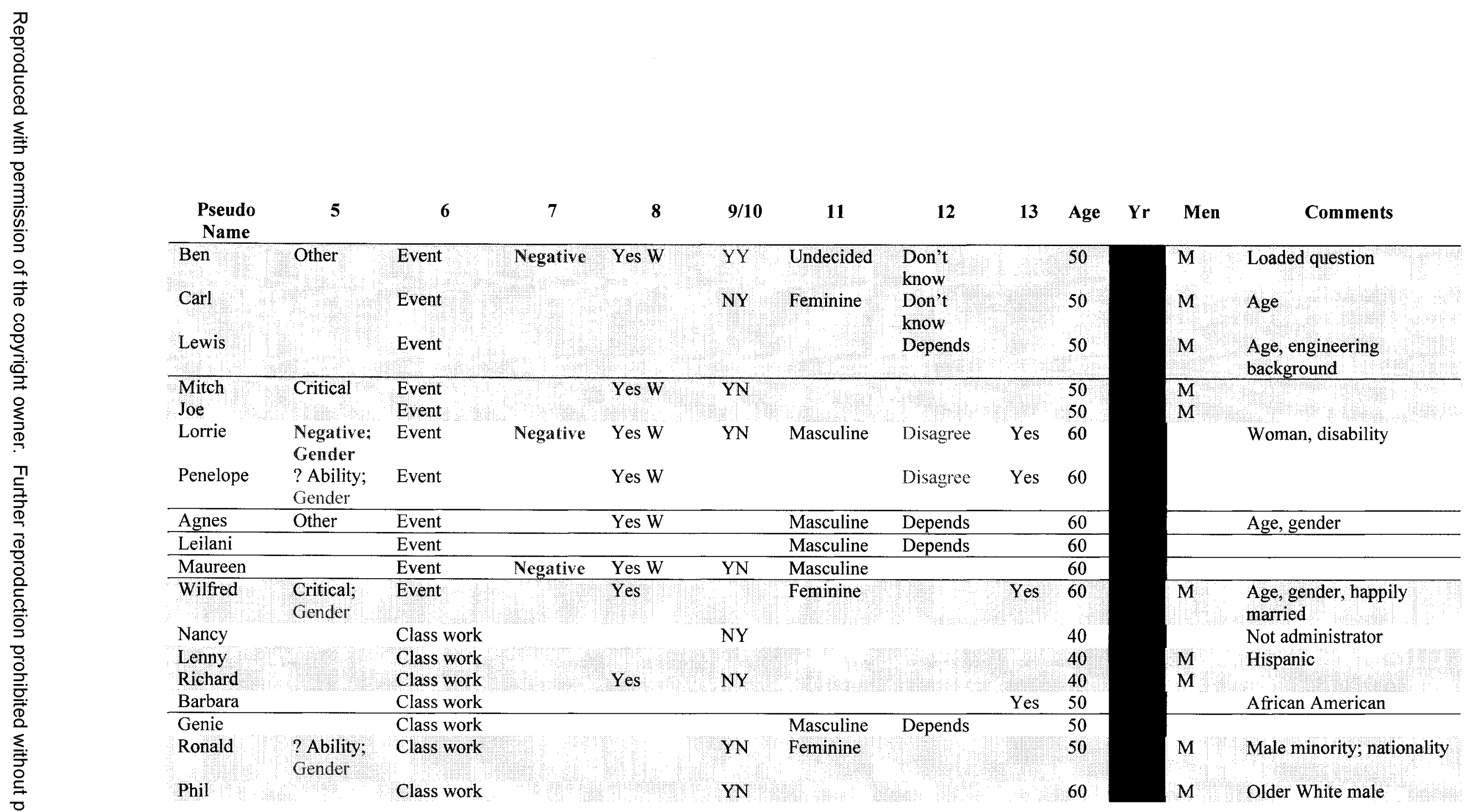


Definition of Blank Cells:

5-Positive experiences

7 - Positive comments about students of opposite gender

8 - No difference in treatment of women and men

$9 / 10-$ No demeaning experiences $(\mathrm{NN})$

11 - Gender neutral

12 - Opposite gender would agree with my answers

13 - No gender inequities 